FELIPE FARDIN GRILLO

ESTUDO DA SUBSTITUIÇÃO DA FLUORITA POR ALUMINA OU SODALITA E DE CAL POR RESÍDUO DE MÁRMORE EM ESCÓRIAS SINTÉTICAS DESSULFURANTES 
FELIPE FARDIN GRILLO

\section{ESTUDO DA SUBSTITUIÇÃO DA FLUORITA POR ALUMINA OU SODALITA E DE CAL POR RESÍDUO DE MÁRMORE EM ESCÓRIAS SINTÉTICAS DESSULFURANTES}

Tese apresentada à Escola Politécnica da Universidade de São Paulo para obtenção do título de Doutor em Engenharia.

Área de concentração:

Engenharia Metalúrgica e de Materiais

Orientador:

Prof. Dr. Denise Crocce Romano Espinosa

Coorientador:

Prof. Dr. Jorge Alberto Soares Tenório

São Paulo 
Este exemplar foi revisado e corrigido em relação à versão original, sob responsabilidade única do autor e com a anuência de seu orientador.

São Paulo,

de

stembor

de $20 / 5$

Assinatura do autor:

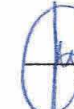

Assinatura do orientador:

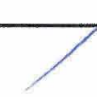

Catalogação-na-publicação

\section{Grillo, Felipe Fardin}

Estudo da substituição da fluorita por alumina ou sodalita e de cal por resíduo de mármore em escórias sintéticas dessulfurantes / F. F. Grillo versão corr. - São Paulo, 2015.

$156 \mathrm{p}$.

Tese (Doutorado) - Escola Politécnica dá Universidade de São Paulo. Departamento de Engenharia Metalúrgica e de Materiais.

1.Dessulfuração 2.Resíduo de mármore 3.Escórias sintéticas 1.Universidade de São Paulo. Escola Politécnica. Departamento de Engenharia Metalúrgica e de Materiais II.t. 


\section{AGRADECIMENTOS}

Agradeço a Deus por tudo.

Agradeço a minha família, meu pai João Pedro Grillo, Minha Mãe Rosa Amélia Fardin Grillo e meus irmãos Flávia e Fabrício, por todo apoio e incentivo em realizar mais um projeto na minha carreira.

À Prof. $\mathrm{Dr}_{\mathrm{a}}$. Denise Crocce Romano Espinosa, pela orientação neste trabalho.

Ao Prof. Dr. Jorge Alberto Soares Tenório, pela coorientação e ajuda durante a realização deste trabalho.

Ao Prof. Dr. José Roberto de Oliveira pela colaboração inestimável sempre que solicitado.

Ao Prof. Dr. Rudiger Deike pela coorientação na parte experimental realizada no Institut für Technologien der Metalle (ITM).

À Karla pelo carinho, paciência e compreensão.

Aos amigos da Escola Politécnica de São Paulo, em especial: Jorge Coleti, Eduardo Junca, Victor Bridi, Carlos, Marcos e André Melado.

Aos técnicos do PMT-USP, Danilo, Rubens, Vera, Patrícia, Suellen, Ivo, Lívio e Rafael pela sempre prontidão em ajudar.

Aos os amigos do Institut für Technologien der Metalle (ITM) da Alemanha pela paciência e aprendizado, destaco: Andrés, Aron, Gustavo, Manuel, Half e Genaro.

Ao CNPq pela bolsa concedida durante o período sanduíche. A Capes pela bolsa durante a realização desse trabalho no Brasil. A FAPESP pelo apoio financeiro para a realização deste trabalho pelo projeto 2012/50213-8.

A todos aqueles que de alguma forma colaboraram. Muito obrigado 


\section{RESUMO}

A siderurgia vem sofrendo transformações que buscam inovação e matérias-primas alternativas. Dentro deste contexto, o uso de resíduos industriais para a formação de escórias sintéticas é tido como alternativa na busca de novos materiais e rotas de reaproveitamento de resíduos. Portanto, este trabalho teve como objetivo estudar o uso de escórias sintéticas na etapa de dessulfuração do ferro-gusa, aço e ferro fundido. Assim como, propor a utilização da sodalita e da alumina em substituição à fluorita e o resíduo de mármore em substituição à cal convencional. Inicialmente, o resíduo foi caracterizado utilizando as seguintes técnicas: análise química, análise granulométrica, área de superfície específica, difração de raios- $X$, microscopia eletrônica de varredura (MEV) e análise de espectroscopia por energia dispersiva (EDS). Os resultados da caracterização mostraram que aproximadamente $90 \%$ das partículas do resíduo de mármore estão abaixo de $100 \mu \mathrm{m}$ e sua área superficial foi de $0,24 \mathrm{~m}^{2} / \mathrm{g}$. Através da difração de raios$X$ foi observado que o resíduo é composto por $\mathrm{CaCO}_{3}, \mathrm{MgCO}_{3}$ e $\mathrm{SiO}_{2} . \mathrm{Na}$ sequência, foram feitas simulações com o software Thermo-Calc para obter dados termodinâmicos das fases presentes nas misturas e compará-los com os resultados experimentais. Além disso, também foram calculados dados de capacidade de sulfeto $\left(C_{s}\right)$, partição de enxofre $\left(L_{s}\right)$ e basicidade ótica $(\Lambda)$ das misturas iniciais. Posteriormente, foram realizados os ensaios experimentais em escala laboratorial para ferro-gusa, ferro fundido e aço, respectivamente nas temperaturas de $1400^{\circ} \mathrm{C}$, $1550^{\circ} \mathrm{C}$ e $1600^{\circ} \mathrm{C}$. Nos ensaios de dessulfuração do aço e do ferro-gusa, utilizou-se um rotor de alumina com o objetivo de favorecer a agitação no metal e aumentar a remoção de enxofre. Na etapa de dessulfuração do ferro-gusa, constatou-se que a fase sólida de $\mathrm{CaO}$ é a responsável pela remoção de enxofre e que a presença das fases silicato tricálcio e aluminato tricálcio $\left(3 \mathrm{CaO} . \mathrm{SiO}_{2}\right.$ e $\left.3 \mathrm{CaO} . \mathrm{Al}_{2} \mathrm{O}_{3}\right)$ limitam a reação, sendo maiores suas concentrações nas escórias que utilizaram o resíduo de mármore e sodalita, devido a presença de $\mathrm{SiO}_{2}$ e $\mathrm{Al}_{2} \mathrm{O}_{3}$ nestas matérias-primas. Já para $\mathrm{O}$ aço e o ferro fundido, que foram estudados com escórias à base de $\mathrm{CaO} \mathrm{e}$ $\mathrm{Al}_{2} \mathrm{O}_{3}$, observou-se que 0 aumento da fase líquida favoreceu a dessulfuração. Verificou-se que a dessulfuração no ferro fundido foi por escória de topo e no aço por um processo misto, onde a fase líquida e fase sólida participaram da dessulfuração.

Palavras-chave: Dessulfuração, resíduo de mármore, fluorita. 


\begin{abstract}
The steel industry is going through transformations aiming at innovation and use of alternative raw materials. In this context, the use of industrial waste in the production of synthetic slag is considered an important option on the search for new materials and waste reuse. Therefore, the aim of this work was to study the use of synthetic slags at the desulfurization of hot metal, steel and cast iron. It was proposed the use sodalite and alumina instead of fluorite and the use of marble waste instead of lime. Marble waste was characterized by chemical analysis, particle size analysis, specific surface area, X-ray diffraction (XRD), scanning electron microscopy (SEM), analysis with energy dispersive spectroscopy (EDS). The characterization results showed that almost $90 \%$ of the particles are smaller than 100 $\mu \mathrm{m}$ and its specific surface area was $0.2406 \mathrm{~m}^{2} / \mathrm{g}$. The XRD has showed the presence of compounds such as $\mathrm{CaCO}_{3}$ and $\mathrm{MgCO}_{3}$ and $\mathrm{SiO}_{2}$. Further, simulations using Thermo-Calc were performed in order to obtain thermodynamic data of the present phases, and to compare with experimental data. Furthermore, sulfide capacity (Cs), sulfur partition (Ls) and optical basicity $(\Lambda)$ were determined. The experimental procedures were carried out at $1400^{\circ} \mathrm{C}, 1550^{\circ} \mathrm{C}$ and $1600^{\circ} \mathrm{C}$ for hot metal, cast iron and steel, respectively. In addition, steel and hot metal tests were performed using an alumina rotor to raise the desulphurization. In hot metal desulphurization, solid $\mathrm{CaO}$ phase was responsible for sulfur removal. Furthermore, $3 \mathrm{CaO} . \mathrm{SiO}_{2}$ and $3 \mathrm{CaO} . \mathrm{Al}_{2} \mathrm{O}_{3}$ phases limited the reaction, being their concentration higher in the slags with marble waste and sodalite, due to the presence of $\mathrm{SiO}_{2}$ and $\mathrm{Al}_{2} \mathrm{O}_{3}$ in these raw materials. Slags composed mainly of $\mathrm{CaO}$ and $\mathrm{Al}_{2} \mathrm{O}_{3}$ were used in steel and cast iron desulphurization. It was observed that when increasing liquid phase, the reaction of desulphurization was favored. Besides, it was found that cast iron desulfurization occurs by top slag mechanism and steel desulfurization by a mixed process where the liquid phase and solid phase have influence on the desulfurization.
\end{abstract}

Keyword: Desulfurization, marble waste, fluorspar 


\section{SUMÁRIO}

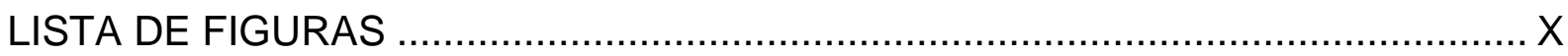

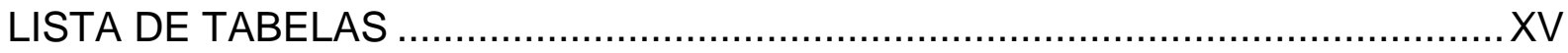

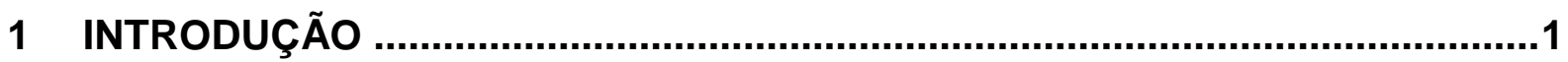

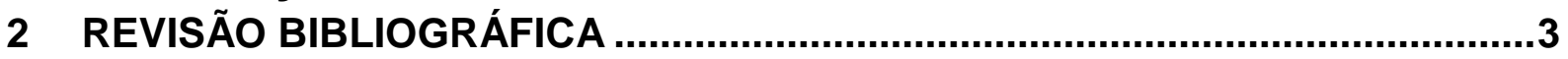

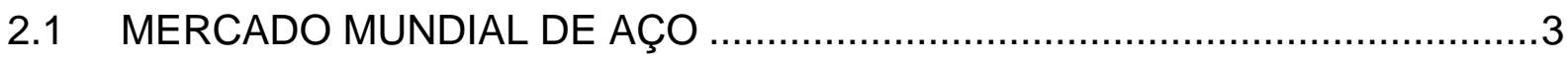

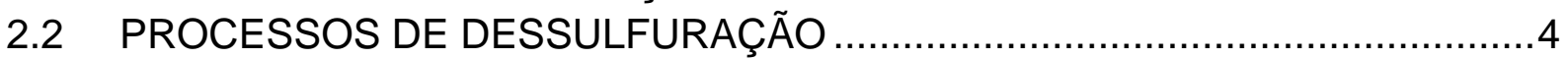

2.3 TERMODINÂMICA DA DESSULFURAÇÃO ……....................................

2.4 MODELOS EMPÍRICOS TERMODINÂMICOS PARA O PROCESSO DE

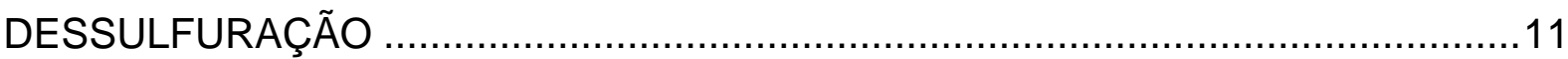

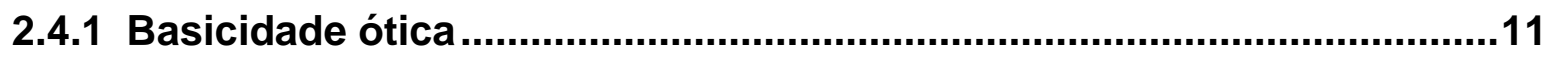

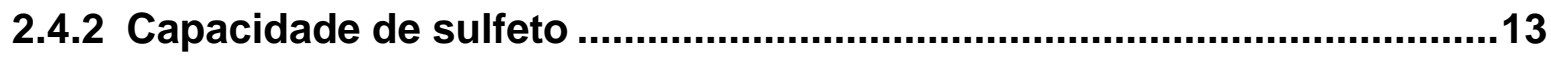

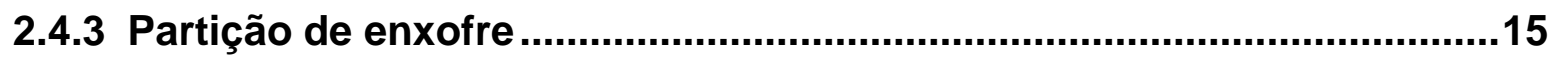

2.5 PARÂMETROS TERMODINÂMICOS E CINÉTICOS PARA O PROCESSO DE

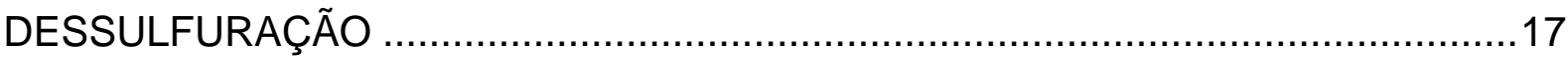

2.5.1 Importância da desoxidação para o processo de dessulfuração ...........17

2.5.2 Influência de fases líquidas e sólidas em escórias dessulfurantes de

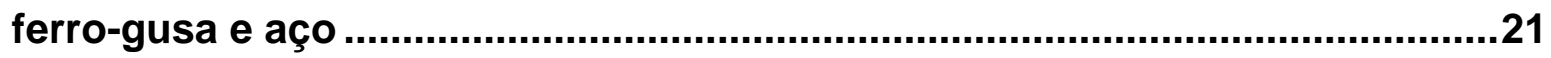

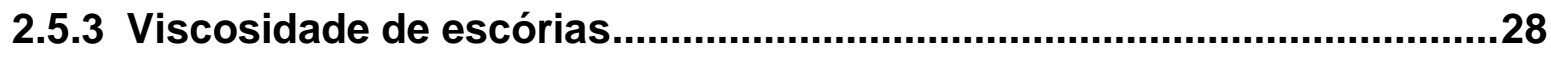

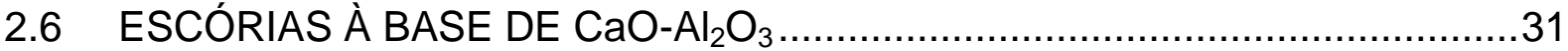

2.7 ESTUDOS SOBRE A SUBSTITUIÇÃO DA FLUORITA EM ESCÓRIAS

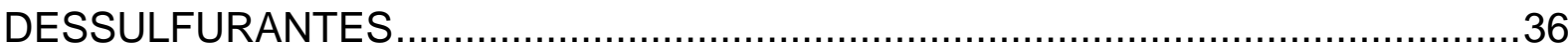

2.8 CINÉTICA DO PROCESSO DE DESSULFURAÇÃO ….............................38

2.9 USO DO RESÍDUO DE MÁRMORE EM ETAPAS DO PROCESSO DE

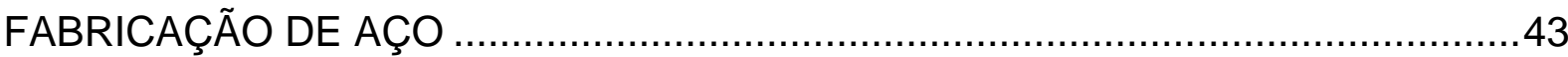

2.10 TERMODINÂMICA COMPUTACIONAL APLICADA AO PROCESSO DE

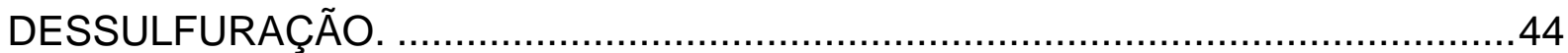

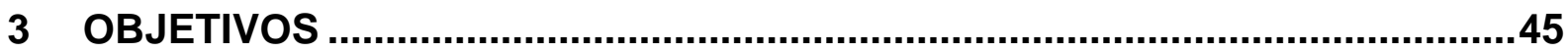

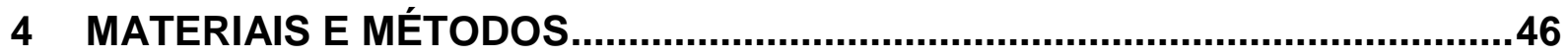

4.1 AQUISIÇÃO DOS MATERIAIS E EQUIPAMENTOS ….............................47

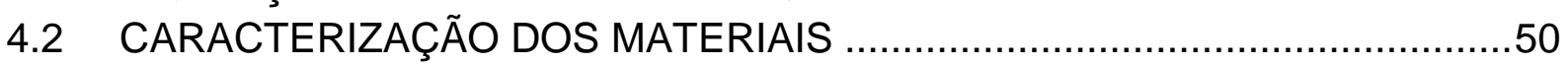

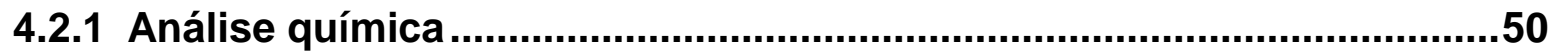

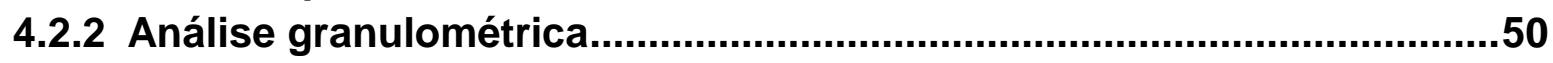

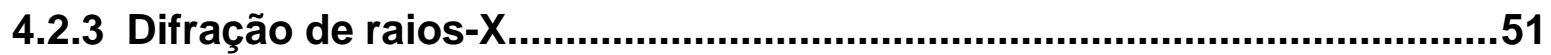

4.2.4 Microscopia eletrônica de varredura e EDS ...........................................51

4.2.5 Análise de superfície específica e de porosidade .................................51

4.3 PREPARAÇÃO DAS MISTURAS DESSULFURANTES ….........................52

4.3.1 Preparação de misturas dessulfurantes de aço ...................................52

4.3.2 Escórias sintéticas dessulfurantes de ferro-gusa.................................55

4.3.3 Escórias sintéticas dessulfurantes de ferro fundido .............................56

4.4 ETAPAS DO PROCEDIMENTO EXPERIMENTAL …................................58

4.4.1 Aparato experimental utilizado da dessulfuração de ferro-gusa e aço.59

4.4.2 Aparato experimental utilizado na dessulfuração de ferro fundido ......62 
4.5 CÁLCULOS TERMODINÂMICOS E CINÉTICOS ........................................65

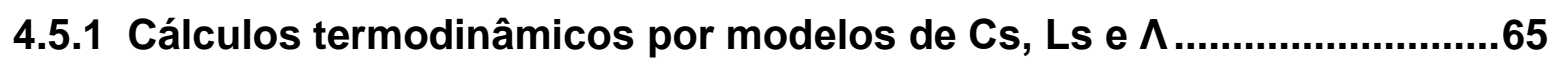

4.5.2 Simulações termodinâmicas computacionais..........................................66

4.5.3 Cálculo de eficiência dessulfurante ....................................................67

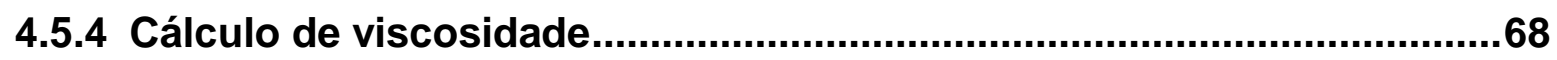

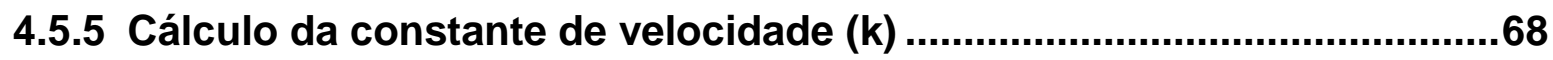

5 RESULTADOS E DISCUSSÃO …............................................................70

5.1 CARACTERIZAÇÃO DO RESÍDUO DE MÁRMORE, $\mathrm{CaO}, \mathrm{Al}_{2} \mathrm{O}_{3}, \mathrm{CaF}_{2} \mathrm{e}$

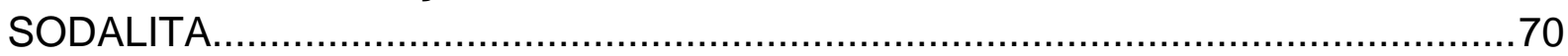

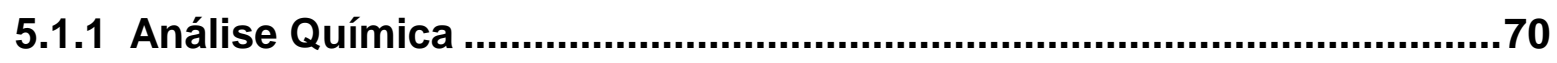

5.1.2 Análise Mineralógica por difratometria ..................................................71

5.1.3 Análise termogravimétrica do resíduo de mármore...............................72

5.1.4 Análise Granulométrica e Área Superficial Pelo Método de BET ..........72

5.1.5 Análise Microscópica Eletrônica de Varredura com EDS.......................74

5.2 ANÁLISES DOS RESULTADOS EXPERIMENTAIS ….................................75

5.2.1 Avaliação dos resultados encontrados para escórias dessulfurantes de

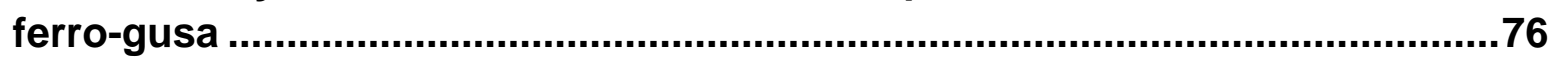

5.2.1.1 Análise dos resultados experimentais com o uso das misturas dessulfurantes de ferro-gusa ..................................................................... 76

5.2.1.2 Análise dos parâmetros termodinâmicos de basicidade ótica, capacidade e sulfeto e partição de enxofre ...................................................77

5.2.1.3 Análise dos testes experimentais através da termodinâmica

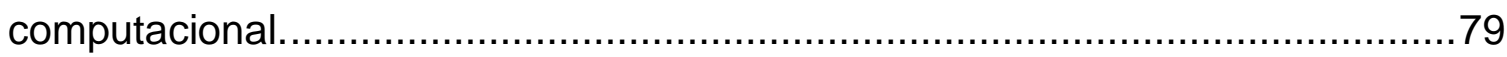

5.2.1.4 Efeito dos compostos sólidos $3 \mathrm{CaO} . \mathrm{SiO}_{2}$ e $3 \mathrm{CaO} . \mathrm{Al}_{2} \mathrm{O}_{3}$ na taxa de

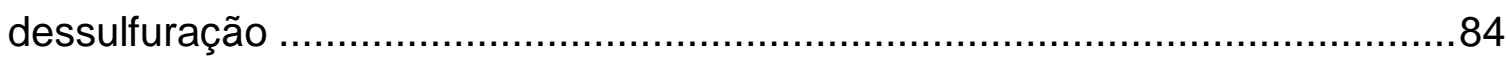

5.2.1.5 Efeito da viscosidade das misturas iniciais ........................................ 85

5.2.1.6 Efeito da fração de fase líquida e sólida em escórias dessulfurantes

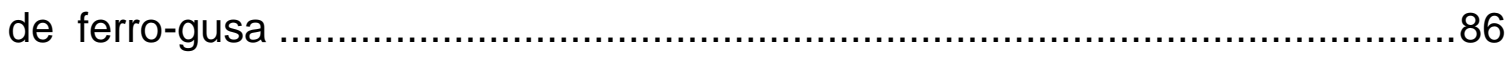

5.2.1.7 Metodologia de análise para prever a eficiência das misturas

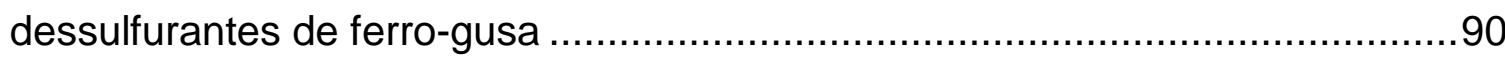

5.2.1.8 Cálculo da constante de velocidade $(\mathrm{k})$..........................................94

5.2.2 Avaliação dos resultados encontrados para as escórias dessulfurantes

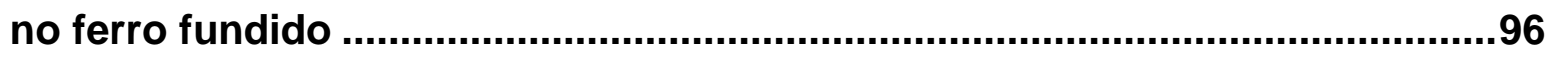

5.2.2.1 Análise dos resultados experimentais com o uso das misturas dessulfurantes de ferro fundido ...................................................................96

5.2.2.2 Resultados dos cálculos de Cs, Ls e $\wedge$ para as misturas dessulfurantes

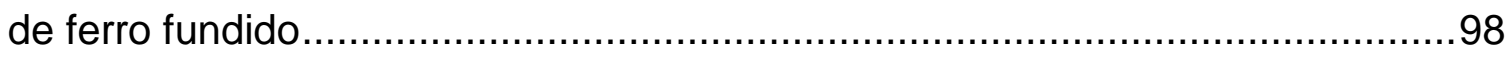

5.2.2.3 Utilização da termodinâmica computacional na análise dos resultados da dessulfuração de ferro fundido ..............................................................101

5.2.2.4 Efeito da fase líquida e da fase sólida na dessulfuração de ferro

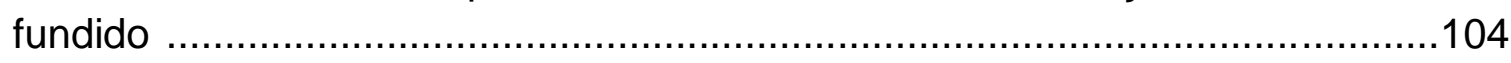

5.2.2.5 Análise comparativa da substituição da cal convencional por resíduo de

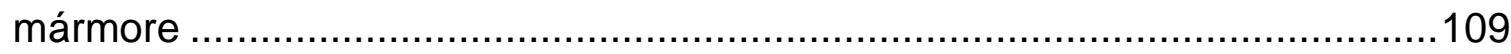

5.2.2.6 Análise comparativa da substituição da fluorita por $\mathrm{Al}_{2} \mathrm{O}_{3} \ldots \ldots \ldots \ldots \ldots \ldots . . . .111$ 
5.2.2.7 Efeito da viscosidade na dessulfuração de ferro fundido

5.2.2.8 Influência da granulometria no processo de dessulfuração no ferro fundido

5.2.2.9 Cálculo da constante de velocidade $(k)$ para escórias de ferro fundido.

5.2.3 Avaliação dos resultados encontrados para escórias dessulfurantes de aço.

5.2.3.1 Análise dos resultados experimentais para as misturas dessulfurantes de aço

5.2.3.2 Influência da decomposição dos carbonatos na dessulfuração de aço

5.2.3.3 Análise comparativa da substituição de resíduo de mármore por cal convencional e fluorita por $\mathrm{Al}_{2} \mathrm{O}_{3}$

5.2.3.4 Análise dos parâmetros termodinâmicos de basicidade ótica, capacidade de sulfeto e partição de enxofre

5.2.3.5 Utilização da termodinâmica computacional na análise dos resultados da dessulfuração do aço

5.2.3.6 Efeito da fração da fase líquida e sólida na dessulfuração 129

5.2.3.7 Efeito da viscosidade na dessulfuração de aço 135

5.2.3.8 Cálculo da constante de velocidade $(k)$ para escórias dessulfurantes de aço. 


\section{LISTA DE FIGURAS}

Figura 1. Produção brasileira de aço nos últimos 10 anos.......................................

Figura 2. Desenho esquemático mostrando a geometria do carro torpedo e o processo de injeção de agente dessulfurante. .................................................

Figura 3. Métodos industriais do processo de dessulfuração na panela. ...................6

Figura 4. Procedimento de adição de escória durante o vazamento para a panela de transferência no refino secundário. .............................................................

Figura 5. Influência no carbono e silício na atividade Henriana do enxofre. ................9

Figura 6. Correlação entre a basicidade óptica e a capacidade de sulfeto para escórias na temperatura de $1500^{\circ} \mathrm{C}$

Figura 7. Diagrama de equilíbrio entre o $\mathrm{Al}$ e o $\mathrm{O}$ no aço líquido com $0,45 \% \mathrm{C}$ a $1600^{\circ} \mathrm{C}$ via Thermo-Calc

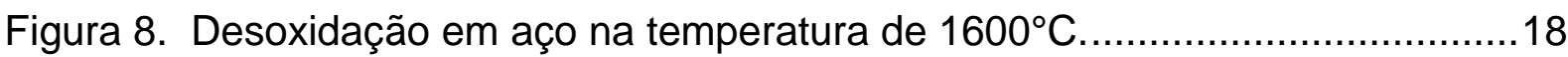

Figura 9. Valores de Oxigênio medidos por Kor e Glaws e calculados por

Turkdogan.

Figura 10. Relação entre a partição de enxofre com o alumínio dissolvido no metal em escórias do sistema $\mathrm{CaO}-\mathrm{Al}_{2} \mathrm{O}_{3}$

Figura 11. Seção isotérmica do sistema $\mathrm{CaO}-\mathrm{Al}_{2} \mathrm{O}_{3}-\mathrm{MgO}$ a $1600^{\circ} \mathrm{C}$......................21

Figura 12. Restrição do transporte de massa do enxofre até a partícula de $\mathrm{CaO}$ imposta pelo CaS formado

Figura 13. Variação do enxofre em função do tempo para diferentes porcentagens

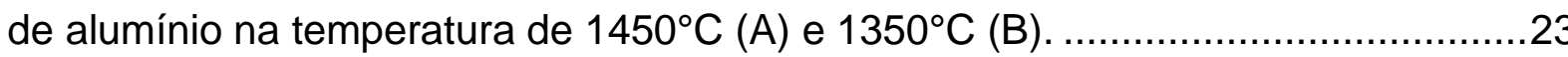

Figura 14. Relação entre o consumo de $\mathrm{CaO}$ e a taxa de dessulfuração. .................24

Figura 15. Representação do processo de dessulfuração em escórias não foi realizada o emprego do alumínio(a) e escórias com o uso do $\mathrm{Al}(\mathrm{b})$.

Figura 16. Foto tirada após 30 segundos de experimento, mostrando a formação de $\mathrm{CaS}$ ao redor da patícula de $\mathrm{CaO}$.

Figura 17. Formação de $\mathrm{CaS}$ ao redor da partícula de $\mathrm{CaC}_{2}$, mas sem a formação de $2 \mathrm{CaO} . \mathrm{SiO}_{2}$

Figura 18. Espessura da camada de CaS medido em função do tempo para os agentes dessulfurante flucal e $\mathrm{CaC}_{2}$.

Figura 19. Demonstração do processo de capilaridade em escórias com fase sólida $(\mathrm{CaO})$ e fase líquida.

Figura 20. Diagramas de isoviscosidade para o sistema $\mathrm{SiO}_{2}-\mathrm{CaO}-\mathrm{Al}_{2} \mathrm{O}_{3}$ a

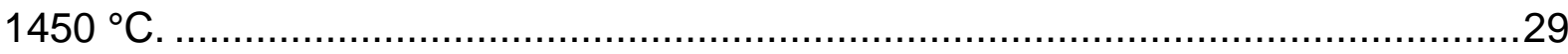

Figura 21. Ensaio de viscosidade utilizando o método do cilindro rotativo...............30

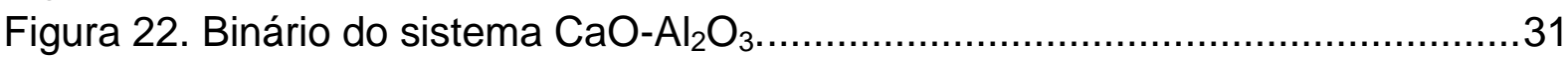

Figura 23. Relação entre a capacidade de sulfeto em função do teor de $\mathrm{Al}_{2} \mathrm{O}_{3}$ na escória e Temperatura. Os outros componentes da escória são constante a 8\% de $\mathrm{MgO}$ e $7 \%$ de $\mathrm{SiO}_{2}$ 
Figura 24. Relação entre a partição de enxofre em função da concentração de $\mathrm{Al}_{2} \mathrm{O}_{3}$ presente na escória. A temperatura é de $1550{ }^{\circ} \mathrm{C}$, o teor de alumínio no aço é $0,04 \%$ e os outros componentes da escória são constante a $8 \%$ de $\mathrm{MgO}$ e $7 \%$ de $\mathrm{SiO}_{2}$.

Figura 25. Coeficiente de partição de enxofre do equilibro entre metal e escória.

Teor de alumínio de $0,03 \%$; sistema $\mathrm{CaO}-\mathrm{Al}_{2} \mathrm{O}_{3}-\mathrm{SiO}_{2}(5 \%) \mathrm{MgO}$ a $1625^{\circ} \mathrm{C}$. 33

Figura 26. Relação entre a concentração de $\mathrm{Al}_{2} \mathrm{O}_{3}$ e $\mathrm{CaO}$ na taxa de dessulfuração de aço.

Figura 27. Efeito de escórias do sistema $\mathrm{CaO}-\mathrm{CaF}_{2}(\mathrm{~A})$ e $\mathrm{CaO}-\mathrm{Al}_{2} \mathrm{O}_{3}(\mathrm{~B})$ no processo de dessulfuração de aço na temperatura de $1600^{\circ} \mathrm{C}$.

Figura 28. Relação entre $\mathrm{CaF}_{2}$ e $\mathrm{Al}_{2} \mathrm{O}_{3}$ no coeficiente de transporte de massa global(A) e coeficiente de transporte de massa na escória(B). 36

Figura 29. Efeito da basicidade binária, (\%) $\mathrm{Al}_{2} \mathrm{O}_{3}$ e $\mathrm{TiO}_{2}$ na partição de enxofre e viscosidade de escória.

Figura 30. Comparação entre os teores de enxofre calculados pelo modelo proposto e os encontrados nos experimentos.

Figura 31. Comparação entre os teores de enxofre calculados e os encontrados experimentalmente.

Figura 32. Fluxograma simplificado das principais etapas desenvolvidas neste trabalho.

Figura 33. Sequência de procedimentos para a fabricação dos cadinhos de $\mathrm{MgO}-\mathrm{C}$.

Figura 34. Croqui dos cadinhos de $\mathrm{MgO}$ carbono (A) Vista lateral (B) Vista seção cortada.

Figura 35. Agitador mecânico, vista frontal e lateral.

Figura 36. Impeller de alumina de alta pureza e croqui.

Figura 37. Relação entre o $\mathrm{CaO}$ na escória e enxofre de equilíbrio no metal para escórias sintéticas dessulfurantes de aço.

Figura 38. Relação entre o teor de alumínio e porcentagem de oxigênio no metal.

Figura 39. Forno de resistência elétrica utilizado para os ensaios de dessulfuração $(A)$ e desenho esquemático do forno $(B)$.

Figura 40. Fluxograma detalhado da realização dos experimentos de ferro-gusa e aço.

Figura 41. Posicionamento descentralizado do agitador mecânico no metal líquido.

Figura 42. Retirada das amostras durante os experimentos de dessulfuração de aço e ferro-gusa.

Figura 43. Esquema do aparato experimental utilizado para realizar a etapa de dessulfuração de ferro fundido no Instituto de Tecnologia em Metalurgia (ITM) na Alemanha.

Figura 44. Momento de aferir a temperatura antes de realizar a adição da escória. 
Figura 45. Esquema de amostragem do metal com o auxílio de um tubo Venturi. ...64 Figura 46. Procedimento de adição de escória com auxílio de uma espátula de metal.

Figura 47. Materiais utilizados para realizar os ensaios: Amostrador, termopar,

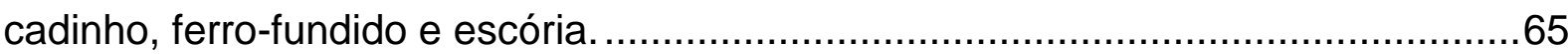

Figura 48 Tela inicial de entrada de dados no Thermo-Calc. .................................67

Figura 49. Análise difratométrica do resíduo de mármore.......................................71

Figura 50. Análise termogravimétrica do resíduo de mármore apresentando a variação de massa com a decomposição dos carbonatos. ......................................72

Figura 51. Distribuição granulométrica do resíduo de mármore...............................73

Figura 52. Distribuição granulométrica do óxido de cálcio. .....................................73

Figura 53. Imagem de elétrons retroespalhados obtida em microscópio eletrônico de varredura do resíduo de mármore e análise de microrregiões por dispersão de energia (EDS) da região em destaque.

Figura 54. Imagem de elétrons retroespalhados obtida em microscópio eletrônico de varredura da sodalita e análise de microrregiões por dispersão de energia

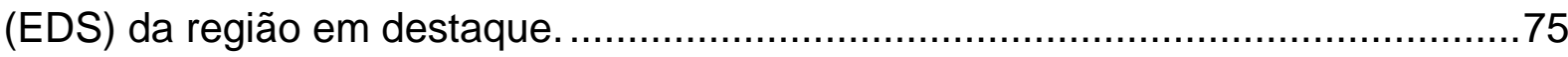

Figura 55. Variação do enxofre no ferro-gusa em função do tempo de experimento para as escórias com a cal convencional. .76

Figura 56. Variação do enxofre no ferro-gusa em função do tempo de experimento para escórias com o resíduo de mármore.

Figura 57. (A) Influência da (\%) de $\mathrm{CaO}$ na basicidade $(\Lambda)$ e (B) influência da basicidade $(\Lambda)$ na capacidade de Sulfeto $(C s)$.

Figura 58. Relação entre a basicidade ótica(A), partição de enxofre (B) e capacidade de sulfeto $(C)$ em função do teor de enxofre de equilíbrio para as misturas dessulfurantes de ferro-gusa.

Figura 59. Comparação entre a concentração de fase líquida com o uso da fluorita e sodalita na dessulfuração de ferro-gusa.

Figura 60. Influência da concentração de $\mathrm{SiO}_{2}$ e $\mathrm{Al}_{2} \mathrm{O}_{3}$ na formação do composto silicato tricálcio e aluminato tricálcio das escórias iniciais na temperatura de $1400^{\circ} \mathrm{C}$.

Figura 61. Fases presentes nas misturas iniciais de ferro-gusa com o aumento da temperatura.

Figura 62. Influência dos compostos $3 \mathrm{CaO} . \mathrm{SiO}_{2}$ e $3 \mathrm{CaO} \cdot \mathrm{Al}_{2} \mathrm{O}_{3}$ na eficiênciada dessulfuração das misturas dessulfurantes de ferro-gusa.

Figura 63. Efeito da viscosidade das misturas iniciais no comportamento da dessulfuração do ferro-gusa na temperatura de $1400^{\circ} \mathrm{C}$

Figura 64. Relação entre a eficiência dessulfurante em função da porcentagem

de fase líquida para as misturas dessulfurantes de ferro-gusa.

Figura 65. Relação entre o silicato tricálcio e fase líquida das escórias finais dos experimentos de dessulfuração de ferro-gusa

Figura 66. Relação entre o CaS e fase líquida das escórias finais dos experimentos de dessulfuração de ferro-gusa. 
Figura 67. Influência dos parâmetros (\%) $\mathrm{CaO}_{\mathrm{SD}} \mathrm{e}(\%) \mathrm{CaO}_{\text {TD }}$ em função da eficiência dessulfurante, (A) e (C) escórias com a cal convencional e (B) e (D) escórias com o resíduo de mármore.

Figura 68. Relação entre a constante de velocidade em função do trisilicato dicálcio, aluminato tricálcio e da eficiência dessulfurante para escórias dessulfurantes de ferro-gusa.

Figura 69. Relação entre a constante de velocidade e $\mathrm{CaO}$ sólido para escórias dessulfurantes de ferro-gusa.

Figura 70. Teor de enxofre no ferro fundido em função do tempo de experimento para as escórias com a cal convencional.

Figura 71. Teor de enxofre no ferro fundido em função do tempo de experimento para as escórias com resíduo de mármore.

Figura 72. Relação entre a partição de enxofre $(A)$, basicidade ótica(B), capacidade de sulfeto $(C)$, e função d eficiência $(\eta \%)$ obtida nos testes de dessulfuração.

Figura 73. Fases presentes nas misturas iniciais dessulfurantes utilizadas na dessulfuração de ferro fundido.

Figura 74. Relação entre a eficiência e a quantidade de fase líquida para escórias dessulfurantes à base de cal $(A)$ e resíduo de mármore $(B)$. 106

Figura 75. Relação entre a concentração de $\mathrm{CaO}$ na fase líquida em função da eficiência dessulfurante para escórias dessulfurantes à base de cal $(A)$ e resíduo de mármore (B).

Figura 76. Relação entre a concentração de $\mathrm{MgO}$ em função da fase líquida e eficiência dessulfurante para as escórias formuladas com resíduo de mármore. ...107 Figura 77. Porcentagem de dessulfuração dos experimentos de ferro fundido......110 Figura 78. Remoção do enxofre em função do tempo, utilizando as escórias CICAF11, CIRM8, CIRMF12 e CICA3.

Figura 79. Comparação entre a fração de fase líquida das misturas e a eficiência de dessulfuração dessulfurante para as misturas utilizadas no ferro fundido.

Figura 80. Relação entre a viscosidade em função da eficiência (\%) para escórias dessulfurantes de ferro fundido...................................................................113

Figura 81. Análise da influência da granulometria do $\mathrm{CaO}$ em função do teor de enxofre no metal.

Figura 82. Foto tirada aos 5 minutos de experimento com a Cal $<100 \mu \mathrm{m}$, apresentado a aglomeração das partículas.

Figura 83. Foto tirada aos 5 minutos de experimento com a Cal 0,5-1,0 mm, mostrando que não ocorreu o processo de aglomeração das partículas.

Figura 84. Efeito do tamanho de partícula na remoção do enxofre.

Figura 85. Relação entre constante de velocidade em função da (\%) de fase líquida.

Figura 86. Variação do enxofre e relação ao tempo de experimento para as misturas dessulfurantes com o uso de Cal e alumina (A) e resíduo de alumina $(B)$. 
Figura 87. Variação do enxofre em função do tempo de experimento das misturas dessulfurantes de aço com o uso de resíduo calcinado e não calcinado.

Figura 88. Análise comparativa entre o uso do resíduo de mármore e cal convencional com o uso de fluorita e $\mathrm{Al}_{2} \mathrm{O}_{3}$.

Figura 89. Relação entre a capacidade de sulfeto, partição e basicidade ótica em função do rendimento de misturas dessulfurantes de aço.

Figura 90. Curvas de equilíbrio das misturas iniciais a diferentes temperaturas para as escórias dessulfurantes de aço.

Figura 91. Influência da porcentagem $\mathrm{Al}_{2} \mathrm{O}_{3}$ e $\mathrm{SiO}_{2}$ na fração de fase líquida das escórias com resíduo e cal convencional.

Figura 92. Relação entre a fração de fase líquida em função da eficiência dessulfurante das misturas formuladas com cal convencional (A) e com resíduo de mármore (B).

Figura 93. Relação entre a (\%) de $\mathrm{CaO}$ na composição inicial e (\%) de $\mathrm{CaO}$ sólido calculado pelo Thermo-Calc em função da eficiência dessulfurante das escórias $(A)$ e (B) cal convencional e $(C)$ e (D) resíduo de mármore.

Figura 94. Relação entre a concentração de $\mathrm{CaO}$ sólido em função da eficiência dessulfurante e da atividade do $\mathrm{CaO}$ nas escórias finais produzidas com cal convencional (ACAD1 - ACAD6).

Figura 95. Relação entre a concentração de $\mathrm{CaO}$ sólido em função da eficiência dessulfurante e da atividade do $\mathrm{CaO}$ nas escórias finais produzidas com resíduo de mármore (ARMD7 - ARMD10).

Figura 96. Influência da basicidade sobre a fase líquida e viscosidade efetiva das misturas produzidas com resíduo de mármore (ARMD7 - ARMD10) e cal convencional (ACAF1 - ACAF6).

Figura 97. Viscosidade e eficiência das escórias com cal convencional em função da fase sólida de $\mathrm{CaO}$ presente.

Figura 98. Viscosidade e eficiência das escórias com resíduo de mármore em função da fase sólida de $\mathrm{CaO}$ presente.

Figura 99. Relação entre a constante de velocidade em função da eficiência das escórias dessulfurantes de aço. 


\section{LISTA DE TABELAS}

Tabela 1. Relação de consumo de aço por pessoa em alguns países 4

Tabela 2. Principais reações de dessulfuração do ferro-gusa e aço quando é utilizado $\mathrm{CaO}$.....

Tabela 3. Outros insumos dessulfurantes utilizados no processo de dessulfuração.

Tabela 4. Eletronegatividade, caráter do óxido e basicidade ótica de alguns

óxidos

Tabela 5. Modelos de capacidade de sulfeto para escórias à base de

$\mathrm{CaO}-\mathrm{MgO}-\mathrm{Al}_{2} \mathrm{O}_{3}-\mathrm{SiO}_{2}$

Tabela 6. Composição de escórias dessulfurantes.

Tabela 7. Composição das escórias sintéticas dessulfurantes utilizadas no aço......54

Tabela 8. Misturas dessulfurantes à base de cal convencional e $\mathrm{Al}_{2} \mathrm{O}_{3} \ldots \ldots \ldots \ldots \ldots \ldots . . .54$

Tabela 9. Misturas dessulfurantes à base de resíduo de mármore e $\mathrm{Al}_{2} \mathrm{O}_{3} \ldots \ldots \ldots . . .55$

Tabela 10. Misturas dessulfurantes produzidas com resíduo de mármore, cal convencional e fluorita.

Tabela 11. Composição química (\% massa) das escórias dessulfurantes,

massa em gramas de $\mathrm{CaO}$, massa total das misturas e de resíduo calcinado.

Tabela 12. Composição das escórias utilizadas para o processo de dessulfuração de ferro fundido.

Tabela 13. Composição das misturas produzidas com cal convencional, $\mathrm{Al}_{2} \mathrm{O}_{3} \mathrm{e}$ $\mathrm{Na}_{2} \mathrm{O}$.

Tabela 14. Composição das misturas dessulfurantes de ferro fundido formuladas com o resíduo de mármore.

Tabela 15. Composição das misturas com o uso de fluorita, resíduo de mármore, cal convencional e $\mathrm{Al}_{2} \mathrm{O}_{3}$.

Tabela 16. Variação da granulometria de $\mathrm{CaO}$ nas misturas utilizadas na etapa de dessulfuração do ferro fundido

Tabela 17. Composição química inicial do ferro-gusa e aço utilizada nos testes experimentais.

Tabela 18. Composição química inicial do ferro fundido

Tabela 19. Etapas desenvolvidas durante o procedimento experimental de dessulfuração de ferro fundido.

Tabela 20. Modelos termodinâmicos da literatura utilizados na avaliação das

misturas dessulfurantes 66

Tabela 21. Resultados das análises químicas das matérias-primas.

Tabela 22. Variação do enxofre no ferro-gusa durante o processo de dessulfuração.

Tabela 23. Valores da basicidade ótica $(\Lambda)$ e capacidade de sulfeto $(C s)$ das misturas dessulfurantes de ferro-gusa a $1400^{\circ} \mathrm{C}$.

Tabela 24. Concentração de equilíbrio do ferro-gusa a $1400^{\circ} \mathrm{C}$ 
Tabela 25 Fases formadas nas misturas dessulfurantes utilizando o Thermo-Calc na temperatura de $1400{ }^{\circ} \mathrm{C}$.

Tabela 26. Composição da fase líquida das escórias iniciais geradas no software Thermo-Calc e suas respectivas massas (gramas).

Tabela 27. Teor de enxofre inicial e composição de equilíbrio após o cálculo no

Thermo-Calc.

Tabela 28. Composição das fases formadas nas escórias finais dos experimentos de ferro-gusa.

Tabela 29. Resultados dos cálculos do $\mathrm{CaO}_{\mathrm{SD}}$ e $\mathrm{CaO}_{\text {TD }}$ para as escórias dessulfurantes.

Tabela 30. Constante de velocidade em função do tempo de cada experimento com escórias de ferro-gusa.

Tabela 31. Teor de enxofre dos experimentos de ferro fundido em função do tempo.

Tabela 32. Valores da basicidade ótica $(\Lambda)$ e capacidade de sulfeto $(\mathrm{Cs})$ das escórias dessulfurantes de ferro-gusa a $1400{ }^{\circ} \mathrm{C}$

Tabela 33. Teores de equilíbrio dos elementos presentes na composição química do ferro fundido.

Tabela 34. Resultados dos cálculos de equilíbrio das misturas iniciais dessulfurantes de ferro fundido, utilizando o software Thermo-Calc.

Tabela 35. Teor de enxofre inicial e final dos experimentos e composição de equilíbrio após o cálculo no Thermo-Calc.

Tabela 36. Fases formadas nas escórias finais após o balanço de massa e cálculo no Thermo-Calc.

Tabela 44. Cálculo da constante de velocidade (k) em diferentes tempos de retirada de amostras para cada experimento.

Tabela 45. Variação do enxofre no tempo de experimento e rendimento em ordem descrescente dos experimentos de dessulfuração do aço.

Tabela 46. Variação do enxofre para as misturas à base de cal convencional e resíduo de mármore com o uso do $\mathrm{Al}_{2} \mathrm{O}_{3}$.

Tabela 47. Variação do enxofre no tempo de experimento para misturas à base de resíduo de mármore e resíduo de mármore calcinado.

Tabela 41. Variação do enxofre no tempo de experimento para misturas com cal convencional e resíduo de mármore.

Tabela 49. Resultados dos cálculos termodinâmicos de basicidade ótica $(\Lambda)$, capacidade de sulfeto (Cs) e coeficiente de partição para misturas dessulfurantes de aço.

Tabela 50. Concentração de equilíbrio do aço na temperatura de $1400^{\circ} \mathrm{C}$............126

Tabela 51. Cálculos das fases presentes nas misturas dessulfurantes de aço. .....129

Tabela 52. Concentração de fase líquida e sólida das escórias finais atividade final e enicial do $\mathrm{CaO}$.

Tabela 53. Valores da constante de velocidade para as escórias de dessulfurantes de aço. 


\section{INTRODUÇÃO}

A crescente demanda de aços conhecidos como ultra baixo enxofre (Ultra-Low-Sulfur-ULS) ${ }^{(1)}$ e aços com maior grau de limpidez (aços ligados para forjamento e aços resistentes à fratura induzida pelo Hidrogênio-HIC), têm levado as siderúrgicas a adotarem um melhor controle do processo de produção, bem como a otimização do ajuste químico de escórias sintéticas. Estes fatores contribuem para o desenvolvimento de aços com teores de enxofre menores que 10ppm, possibilitando o desenvolvimento de aços, nesta linha de produtos, com melhores propriedades mecânicas $^{(2,3,4)}$.

O alto-forno é responsável por $97 \%$ da remoção do enxofre ${ }^{(5)}$ na redução de minérios de ferro. Contudo, esta remoção não é suficiente para os requisitos de aplicação exigidos pelo mercado. Além disso, devem ser consideradas as novas políticas das empresas em diminuir custos de produção nos altos-fornos ${ }^{(6)}$.

A dessulfuração em forno panela (aço) e em Reator Kambara (KR) são as mais utilizadas. Entretanto, algumas empresas não possuem o forno panela, sendo necessário, nestes casos, um controle das matérias-primas ou que seja efetuada a remoção do enxofre do aço durante o vazamento do conversor para a panela de transferência.

No caso do ferro fundido, o processo de dessulfuração é realizado em fornos de indução. O magnésio metálico é utilizado como agente dessulfurante. No entanto, a China responde por $75 \%$ de todo o magnésio metálico produzido no mundo. Com isso, empresas produtoras de ferro fundido ficam dependetes do preço chinês ${ }^{(7)}$. Dessa forma, esta pesquisa propõe a substituição do magnésio metálico por escória a base de $\mathrm{CaO}-\mathrm{Al}_{2} \mathrm{O}_{3}$.

Aliado ao processo de refino, é necessário que as indústrias siderúrgicas atendam as novas exigências ambientais. A gestão ambiental está ligada à gestão da qualidade, uma vez que todo desperdício (resíduo) é visto como custo do processo. Portanto, a reutilização de resíduos pode ser uma alternativa para diminuir os custos e os impactos ambientais.

Os principais agentes dessulfurantes utilizados nas escórias dessulfurantes são o óxido de cálcio ( $\mathrm{CaO}$ ), (carbureto de cálcio) $\mathrm{CaC}_{2}$ e magnésio $(\mathrm{Mg})$. Estes materiais podem ser utilizados individulamente ou por muitas vezes em adição 
conjunta com um fluidificante, como o fluoreto de cálcio $\left(\mathrm{CaF}_{2}\right)$ e óxido de sódio $\left(\mathrm{Na}_{2} \mathrm{O}\right)^{(8)}$. O fluoreto de cálcio é utilizado ainda com algum receio, tendo em vista a agressão que pode causar no revestimento refratário. Outra restrição a este material é o flúor disponível na escória, que agride o meio ambiente ${ }^{(9)}$.

A fluorita encontrada no Brasil, possui teores de sílica $\left(\mathrm{SiO}_{2}\right)$ acima de $20 \%$, o que prejudica o uso da fluorita em escórias dessulfurantes ${ }^{(10)}$. Além disso, as reservas de fluoreto de cálcio no Brasil correspondem apenas 0,4\% das reservas mundiais. Estima-se que as reservas mundias de fluoreto de cálcio cheguem a 230 milhões de toneladas. Os principais países com maiores percentuais das reservas são: África do Sul (17,1\%), México (13,3\%), China (8,8\%) e Mongólia (5,0\%) ${ }^{(10)}$.

Outra opção é a utilização de resíduos que possuam agentes dessulfurantes em sua composição. Neste quesito, o resíduo de mármore pode ser uma alternativa, visto que, o material é composto por: $\mathrm{CaO}, \mathrm{MgO}$ e $\mathrm{SiO}_{2}$. Estes óxidos são utilizados na fabricação de escórias sintéticas.

Desta forma, este trabalho busca realizar o ajuste de escórias sintéticas dessulfurantes para o processo de dessulfuração de ferro-gusa, aço e ferro fundido, visando a substituição da fluorita e cal convencional. Além disso, comparar os resultados obtidos por software termodinâmico computacional e por modelos da literatura $(\mathrm{Cs}$, Ls e $\Lambda$ ) com os resultados experimentais. 


\section{REVISÃO BIBLIOGRÁFICA}

Neste capítulo serão abordadas as principais propriedades das escórias sinéticas utilizadas no processo de dessulfuração. Além disso, serão apresentados e discutidos os fundamentos termodinâmicos e cinéticos relevantes na definição de uma escória ideal para a etapa de dessulfuração. Foram adicionados também, estudos que empregaram o uso de escórias do sistema $\mathrm{CaO}-\mathrm{Al}_{2} \mathrm{O}_{3}$ que despontam como alternativa para a substituição da fluorita. Por fim, foi incluída uma breve discussão sobre o uso do resíduo de mármore em processos de fabricação de aço.

\subsection{MERCADO MUNDIAL DE AÇO}

A produção mundial de aço bruto em janeiro de 2015 , caiu 2,9\% em relação ao ano de 2014. Já a produção brasileira foi de 33,9 milhões de toneladas em $2014^{(1)}, 0,75 \%$ menor que a produção de 2013. A produção brasileira de aço bruto dos últimos 10 anos é mostrada na Figura 1.

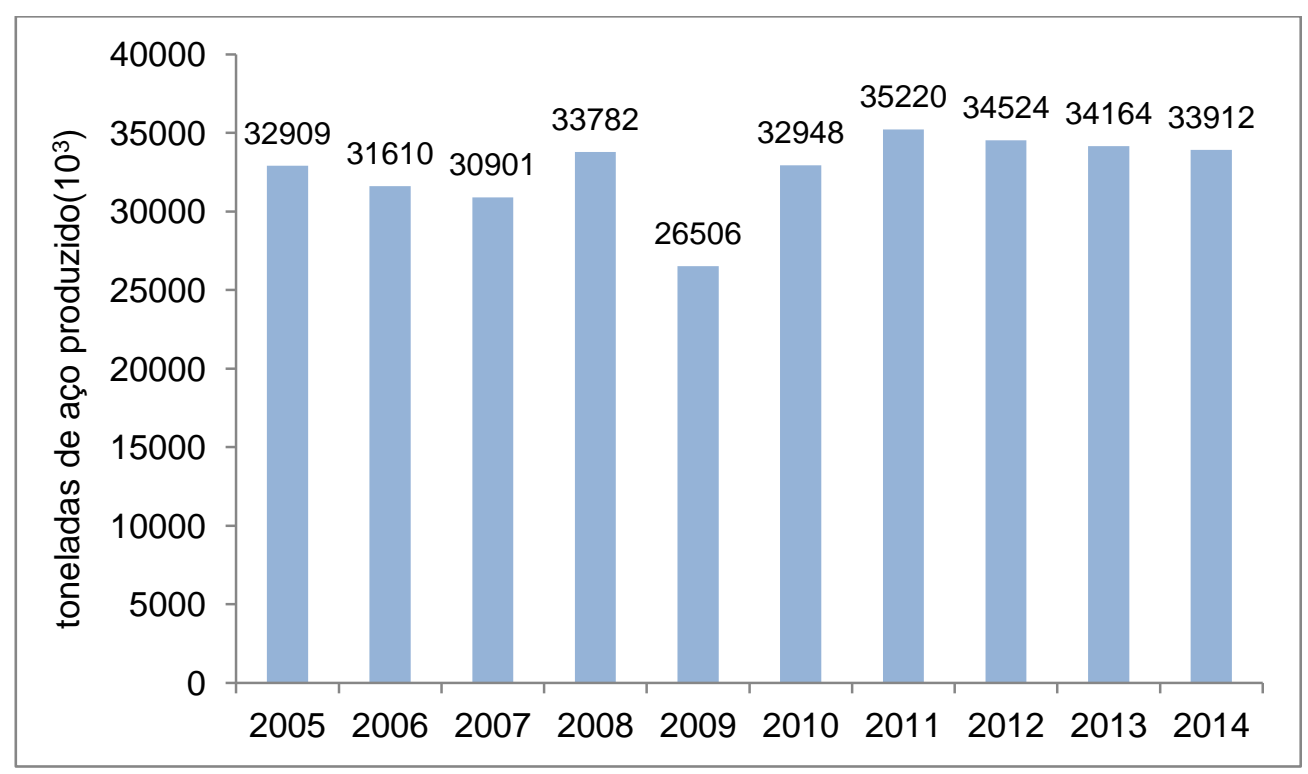

Figura 1. Produção brasileira de aço nos últimos $10 \operatorname{anos}^{(1)}$.

Analisando a Figura 1, observa-se que após a crise mundial de 2008 e 2009, o Brasil atingiu o recorde de produção de aço em 2011, mas nos anos seguintes a produção brasileira de aço decresceu. Entretanto, na contramão da produção 
mundial de aço, em janeiro de 2015, a produção brasileira de aço bruto somou 2,9 milhões de toneladas, o que corresponde a uma alta de $12,8 \%$ em relação ao volume fabricado em dezembro de 2014 (2,6 milhões de toneladas) e a uma expansão de 7,7\% ante a quantidade registrada em igual mês de 2014 (2,7 milhões de toneladas) ${ }^{(1)}$.

Atrelado ao baixo crescimento de produção de aço em 2014 está o baixo consumo de aço por habitante no Brasil. Em 2013, o consumo por pessoa foi de 146kg, valor menor em relação a média de alguns países também considerados emergentes, conforme apresentado na Tabela 1.

Tabela 1. Relação de consumo de aço por pessoa em alguns países ${ }^{(1)}$.

\begin{tabular}{cc}
\hline País & Per capta $(\mathrm{kg})$ \\
\hline México & 173 \\
Turquia & 382 \\
Brasil & 127 \\
Tailândia & 234 \\
China & 488 \\
Indonésia & 51 \\
Índia & 57 \\
Vietnã & 122 \\
\hline
\end{tabular}

Aliado a produção de aço, estima-se que o uso de escorificantes brutos para o ano 2013 foi de 13,8 milhões de toneladas, cujo crescimento ocorre proporcionalmente ao da produção de aço. Para o Brasil, mantendo-se as mesmas proporções, caso o consumo per capita passar para $240 \mathrm{~kg}$, em 2025, com uma população de 230 milhões, estima-se que o consumo interno de aço será de 55 milhões de toneladas ${ }^{(1)}$.

\subsection{PROCESSOS DE DESSULFURAÇÃO}

O enxofre presente no ferro-gusa é oriundo principalmente do coque, utilizado como combustível nos altos-fornos. Apesar de o alto-forno possuir um ambiente redutor e eliminar $97 \%$ do enxofre, os valores atingidos não atendem às exigências dos $\operatorname{aços}^{(11)}$.

O enxofre está presente no aço na forma de inclusões de sulfeto de manganês $(\mathrm{MnS})$ e sulfeto de ferro I e II (FeS, FeS ${ }_{2}$. Essas inclusões apresentam 
mais plasticidade que o aço e, durante um processo de deformação, agem como ponto de início de trinca ${ }^{(12,13)}$.

$O$ processo de dessulfuração pode ser realizado em diferentes etapas do processo de fabricação de aço. Um desses processos bastante difundido no Brasil é a dessulfuração em carro torpedo. Porém, devido à geometria do carro torpedo para preservar a temperatura, há dificuldades de homogeneização, o que torna o processo pouco eficaz. Através de uma lança é injetado material dessulfurante no seio do metal (Figura 2$)^{(13)}$.

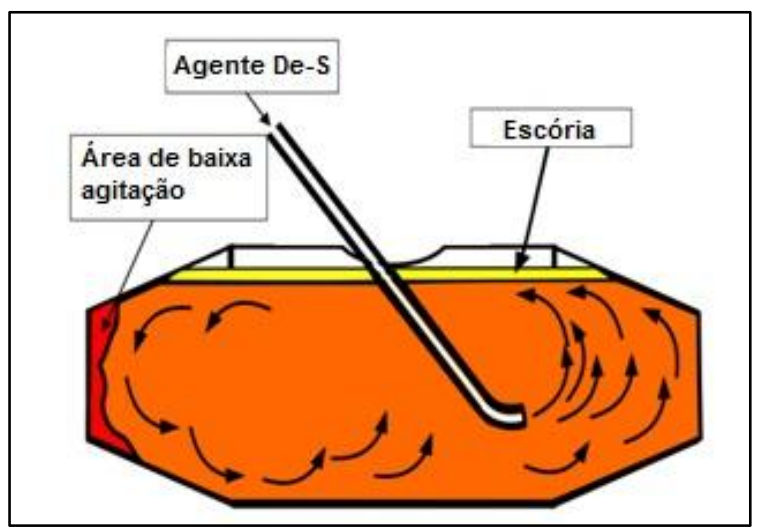

Figura 2. Desenho esquemático mostrando a geometria do carro torpedo e o processo de injeção de agente dessulfurante ${ }^{(13)}$.

Após o processo de dessulfuração no carro torpedo, o ferro-gusa pode ser direcionado para a aciaria a oxigênio. Dependendo do aço a ser fabricado e os teores de enxofre exigidos, o ferro-gusa pode ser submetido à etapa de dessulfuração na panela de gusa ${ }^{(13)}$. A Figura 3 apresenta três possíveis processos de dessulfuração do ferro-gusa na panela. 


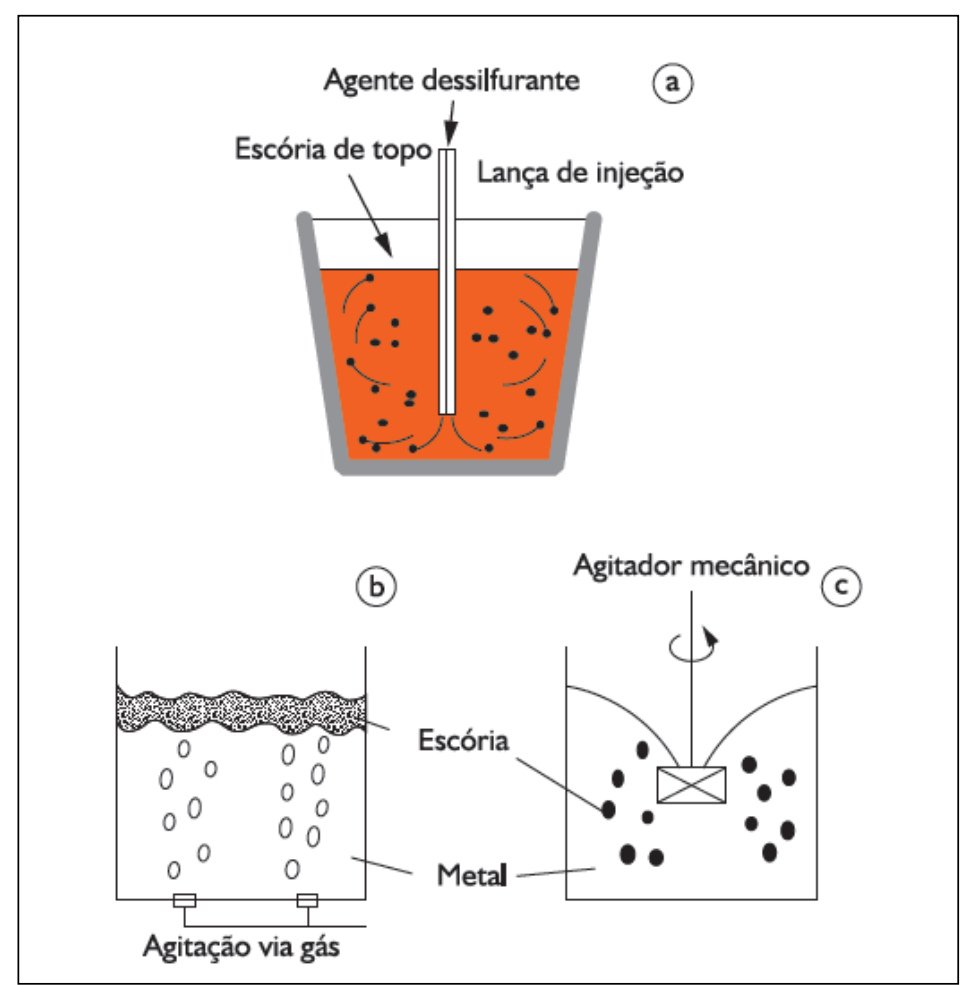

Figura 3. Métodos industriais do processo de dessulfuração na panela de ferro-gusa ${ }^{(14)}$.

Na Figura 3(a) pode-se observar o processo de injeção pneumaticamente de escória no seio do metal líquido, provocando agitação suficiente ao misturar o material. A Figura 3(b) apresenta o processo de injeção de gás pela parte inferior da panela, visando aumentar a agitação da interface metal/escória, e por fim, a Figura 3(c) mostra o processo de agitação com o uso de um agitador, processo conhecido como $\mathrm{KR}$ (kambara reator). Escórias à base de $\mathrm{CaO}_{-} \mathrm{CaF}_{2}$ são utilizadas neste processo. O processo KR é utilizado quando são exigidos aços de melhor qualidade, que possuem teores de enxofre menores do que 50 ppm (X70 e X80). Estes aços são geralmente aplicados na indústria petroquímica ${ }^{(14)}$.

Após o processo de dessulfuração, o ferro-gusa é direcionado para a aciaria a oxigênio. Nesta etapa é realizado o sopro de oxigênio para transformar o ferro-gusa em aço. Entretanto, devido à dificuldade em controlar matérias-primas com menores teores de enxofre, ocorre o aumento do enxofre no aço. Empresas que não possuem forno panela, têm aproveitado o vazamento do LD para a panela do refino secundário para promover a remoção do enxofre. A Figura 4 apresenta 0 procedimento de vazamento do aço na panela do refino secundário. 


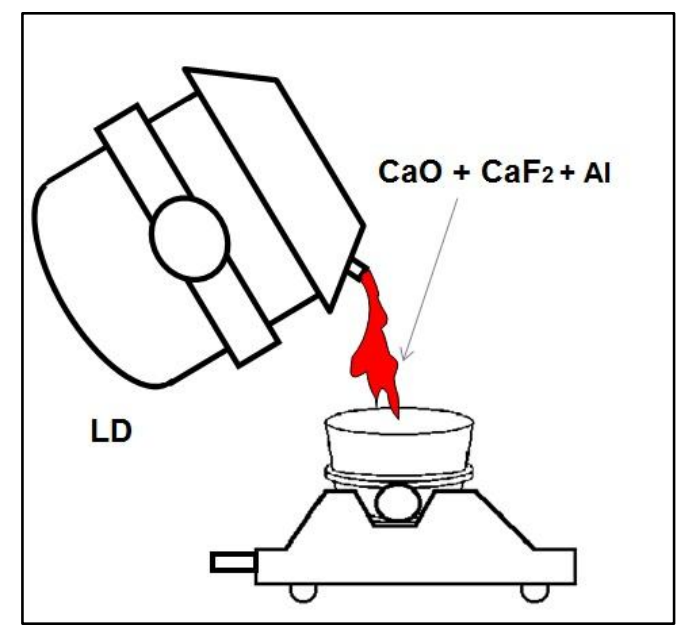

Figura 4. Procedimento de adição de agente dessulfurantes durante o vazamento para a panela de transferência no refino secundário ${ }^{(13)}$.

Durante o vazamento é adicionado alumínio, $\mathrm{CaO}$ e $\mathrm{CaF}_{2}$. $\mathrm{O}$ alumínio é utilizado para promover a desoxidação do metal. $\mathrm{O} \mathrm{Al}_{2} \mathrm{O}_{3}$ obtido após adição de $\mathrm{Al}$ e os demais óxidos que foram adicionados formam uma escória líquida à base de $\mathrm{CaO}-\mathrm{Al}_{2} \mathrm{O}_{3}-\mathrm{CaF}_{2}$.

\subsection{TERMODINÂMICA DA DESSULFURAÇÃO}

A equação geral de remoção do enxofre entre metal-escória (Equação 1) e gás-escória (Equação 2) são representadas pelas reações a seguir ${ }^{(11)}$.

$$
\begin{aligned}
& {[S]+\left(O^{2-}{ }_{\text {escoria }}\right)=\left(S^{2-}\right)+\left[O_{\text {aço }}\right]} \\
& 1 / 2 S_{\text {gás }}+\left(O^{2-}{ }_{\text {escória }}\right)=\left(S^{2-}\right)+1 / 2 O_{\text {gas }} \\
& \Delta G_{2}^{\circ}=118535-58,8157 \cdot T(\mathrm{~J} / \mathrm{mol})
\end{aligned}
$$

Onde, [ ] representa o elemento dissolvido no metal (diluição infinita no estado padrão) e () representa o elemento dissolvido na escória. Analisando a reação 1, observa-se que o oxigênio vai ser o doador de elétron, reduzindo o enxofre. Portanto, o processo de remoção do enxofre no metal é favorecido em ambientes redutores. 
A constante de equilíbrio da Equação 2 é expressa pela Equação 3:

$$
K_{2}=\frac{a_{s^{-2}}}{a_{O^{-2}}} \cdot \sqrt{\frac{P O_{2}}{P S_{2}}}=\frac{f_{S^{-2}} .(\% S)_{\text {escória }}}{a_{O^{-2}}} \cdot \sqrt{\frac{P O_{2}}{P S_{2}}}
$$

Onde: $a_{S^{-2}}$ e $a_{0^{-2}}$ são respectivamente as atividades do oxigênio e do enxofre na escória, $\mathrm{PO}_{2}$ e $\mathrm{PS}_{2}$ são as pressões parciais do enxofre e do oxigênio, $f_{S^{-2}}$ representa o coeficiente de atividade do enxofre na escória e por fim, $(\% S)_{\text {escória }}$ é a porcentagem de enxofre presente na escória. Com a Equação 3, Richardson e Fincham ${ }^{(15)}$, em 1954, desenvolveram o conceito de capacidade de sulfeto (Cs) que será descrito no capítulo 2.4.2.

Devido às dificuldades em descrever as atividades das espécies na forma iônica $\left(\mathrm{O}^{2-}\right.$ e $\left.\mathrm{S}^{2-}\right)$, a determinação é realizada através do equilíbrio escória-metal. Para que a dessulfuração ocorra de fato, é necessário a formação de um sulfeto estável. Quando é empregado $\mathrm{CaO}$ no processo de dessulfuração, a Equação 4 é válida:

$$
\begin{aligned}
& (\mathrm{CaO})_{(S)}+[S]=(\mathrm{CaS})_{(S)}+[\mathrm{O}] \\
& \Delta G_{4}^{\circ}=115358-38,66 . T(\mathrm{~J} / \mathrm{mol})
\end{aligned}
$$

Quando considerados os teores de carbono e silício contidos no ferro-gusa e ferro fundido, são válidas as reações das Equações 5 e $6^{(16,17)}$.

$$
\begin{aligned}
& (\mathrm{CaO})_{(S)}+[\mathrm{S}]+[\mathrm{C}]=(\mathrm{CaS})_{(S)}+\mathrm{CO}_{(g)} \\
& \Delta G_{5}^{\circ}=87550-68,50 \cdot T(\mathrm{~J} / \mathrm{mol}) \\
& (\mathrm{CaO})_{(S)}+[\mathrm{S}]+1 / 2[\mathrm{Si}]=(\mathrm{CaS})_{(S)}+1 / 2\left(\mathrm{SiO}_{2}\right)_{(S)} \\
& \Delta G_{6}^{\circ}=1280543-32,4 \cdot T(\mathrm{~J} / \mathrm{mol})
\end{aligned}
$$

A Figura 5 apresenta a influência do carbono e do silício sobre a atividade henriana do enxofre $\left[f_{s}\right]$. 


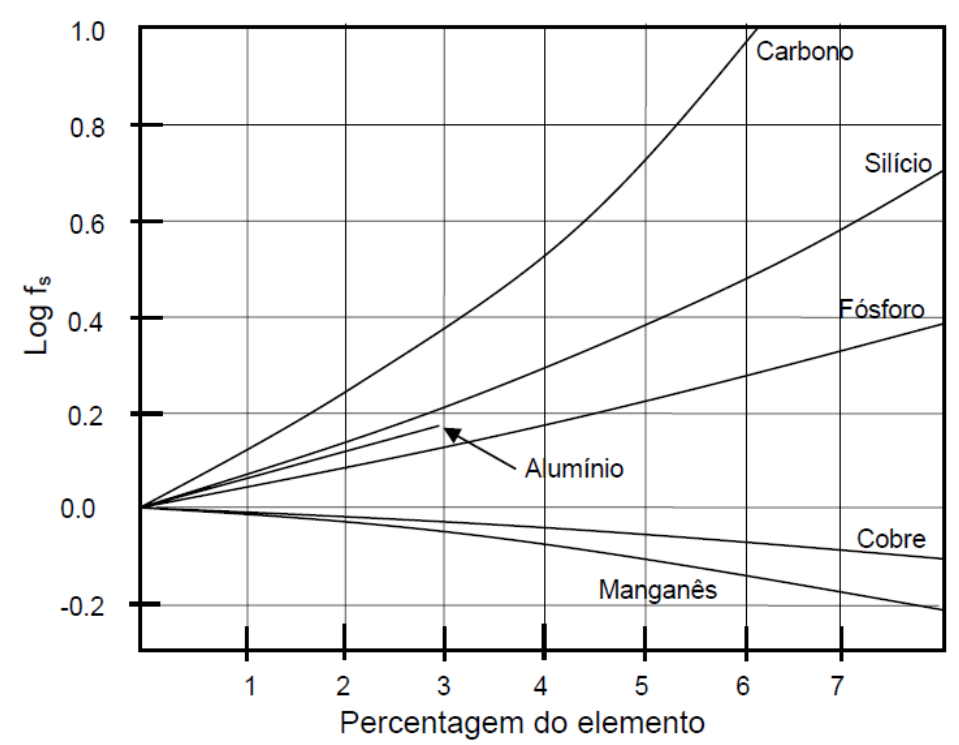

Figura 5. Influência no carbono e silício na atividade Henriana do enxofre.

Analisando a Figura 5, nota-se que o carbono e o silício aumentam o coeficiente de atividade do enxofre. Tal fato evidencia a superioridade do processo de dessulfuração no ferro-gusa sobre o processo de dessulfuração no aço. Quando se considera a dessulfuração em aço acalmado ao $\mathrm{Al}^{(11)}$, a Equação 7 é válida:

$3(\mathrm{CaO})+2[\mathrm{Al}]+3[\mathrm{~S}]=3(\mathrm{CaS})_{(s)}+\mathrm{Al}_{2} \mathrm{O}_{3(s)}$

(Equação 7)

$\Delta G_{7}^{0}=-319,343+111,3 T(\mathrm{~J} / \mathrm{mol})$

A Equação 7 pode ser reescrita na forma iônica, de acordo com a Equação 8.

$2 / 3 \underline{A l}+\underline{S}+\left(O^{2-}\right)=\left(S^{2-}\right)+1 / 3\left(A l_{2} O_{3}\right)$

(Equação 8)

$\Delta G_{8}^{0}=-319343+111,3 T(\mathrm{~J} / \mathrm{mol})$

A reação tem o equilíbrio químico afetado no sentido de formação dos produtos pela redução no teor de oxigênio, que é possibilitada pela presença de alumínio metálico. Com base nessas equações, é possível perceber que o oxigênio proveniente do convertedor LD prejudicará o processo de dessulfuração.

Em resumo, na Tabela 2 constam as principais reações envolvidas na dessulfuração do aço e ferro-gusa quando é utilizado $\mathrm{CaO}$. 
Tabela 2. Principais reações de dessulfuração do ferro-gusa e aço quando é utilizado $\mathrm{CaO}^{(18,19)}$.

\begin{tabular}{|c|c|c|}
\hline $\mathbf{N}^{\circ}$ & Reações & Delta G (J) \\
\hline 1 & $1 / 2\left\{\mathrm{O}_{2}\right\}=[\mathrm{O}\}_{1 \%}$ & $\Delta \mathrm{G}^{0}{ }_{1}=-114361-5,57 \mathrm{~T}$ \\
\hline 2 & $1 / 2\left\{S_{2}\right\}=[S]_{1 \%}$ & $\Delta \mathrm{G}^{0}{ }_{2}=-131880+22,05 \mathrm{~T}$ \\
\hline 3 & $\langle\mathrm{CaS}\rangle+1 / 2\left\{\mathrm{O}_{2}\right\}=\langle\mathrm{CaO}\rangle+1 / 2\left\{\mathrm{~S}_{2}\right\}$ & $\Delta \mathrm{G}^{\mathrm{u}}=-92000+2,55 \mathrm{~T}$ \\
\hline 4 & $2[\mathrm{~A} \mid\}+3[\mathrm{O}]=\left\langle\mathrm{Al}_{2} \mathrm{O}_{3}\right\rangle$ & $\Delta \mathrm{G}^{\mathrm{U}}{ }_{4}=-1287760+429,25 \mathrm{~T}$ \\
\hline 5 & {$[\mathrm{~S}]+1 / 2\left\{\mathrm{O}_{2}\right\}=[\mathrm{O}]+1 / 2\left\{\mathrm{~S}_{2}\right\}$} & $\Delta G^{u^{4}}=\Delta G^{0}{ }_{1}-\Delta G^{0}{ }_{2}=17519-27,62 T$ \\
\hline 6 & $\langle\mathrm{CaS}\rangle+[\mathrm{O}]=\langle\mathrm{CaO}\rangle+[\mathrm{S}]$ & $\Delta G^{0}{ }_{6}=-\Delta G^{0}{ }_{1}+\Delta G^{0}{ }_{2}+\Delta G^{0}{ }_{3}=-109519+30,17 T$ \\
\hline 7 & $\left.\langle\mathrm{CaO}\rangle+2 / 3[\mathrm{Al}]+[\mathrm{S}]=\langle\mathrm{CaS}\rangle+1 / 3<\mathrm{Al}_{2} \mathrm{O}_{3}\right\rangle$ & $\Delta G^{0}=1 / 3 \Delta G_{4}^{0}-\Delta G_{6}^{0}=-319734+11,91 T$ \\
\hline
\end{tabular}

De acordo com Shevchenko et al ${ }^{(20),}$ além do uso de $\mathrm{CaO}$ como principal agente dessulfurante, outros insumos são utilizados para remover o enxofre, conforme apresentado na Tabela 3.

Tabela 3. Outros insumos dessulfurantes utilizados no processo de dessulfuração ${ }^{(21)}$.

\begin{tabular}{cc}
\hline Elementos & Reação \\
\hline Carbureto de Cálcio & $\mathrm{CaC}_{2}+[\mathrm{S}]=\mathrm{CaS}+2 \mathrm{C}$ \\
Barrilha & $\mathrm{CaC}_{2}+[\mathrm{FeS}]=(\mathrm{CaS})+[\mathrm{Fe}]+2[\mathrm{C}]$ \\
& $\mathrm{Na}_{2} \mathrm{CO}_{3(\mathrm{~s})}+[\mathrm{S}]+[\mathrm{C}]=\mathrm{Na}_{2} \mathrm{~S}_{(\mathrm{l})}+\mathrm{CO}_{2(\mathrm{~g})}+\mathrm{CO}_{(\mathrm{g})}$ \\
$\mathrm{Na}_{2} \mathrm{CO}_{3(\mathrm{~s})}+[\mathrm{S}]+[\mathrm{Si}]=\mathrm{Na}_{2} \mathrm{~S}_{(\mathrm{l})}+\mathrm{CO}_{(\mathrm{g})}+\left(\mathrm{SiO}_{2}\right)$ \\
$\mathrm{Magnésio}$ & $\mathrm{Mg}_{(\mathrm{g})}+\mathrm{CaO}_{(\mathrm{s})}+[\mathrm{S}]=\mathrm{CaS}_{(\mathrm{s})}+\mathrm{MgO}_{(\mathrm{s})}$ \\
& $\mathrm{Mg}(\mathrm{g})+[\mathrm{S}]=\mathrm{MgS}_{(\mathrm{s})}$ \\
\hline
\end{tabular}

Em outra pesquisa, Kumar e $\mathrm{Liu}^{(22)}$ apresentaram a possibilidade de usar $\mathrm{ZnO}$ para a dessulfuração de ferro-gusa, de acordo com a Equação 9:

$$
\begin{aligned}
& \mathrm{ZnO}+[\mathrm{S}]=3 \mathrm{ZnS}_{(g)}+[\mathrm{O}] \\
& \Delta G_{9}^{0}=-368987-173,61(\mathrm{~J} / \mathrm{mol})
\end{aligned}
$$

Entretanto, este trabalho sofreu críticas de David et $a l^{(23)}$. Segundo os autores, o zinco em nada interfere na dessulfuração. $O$ estudo de David et $a^{(24)}$ indica que os dados iniciais (energia de Gibbs e oxigênio de equilíbrio) utilizados por Kumar e $\mathrm{Liu}^{(22)}$ não representam a realidade dos experimentos. Os autores realizaram um novo cálculo utilizando os dados corretos e verificaram que o zinco em nada remove o enxofre do metal ${ }^{(24)}$.

Por fim, independentes do agente dessulfurante utilizado, existem fatores termodinâmicos e cinéticos que devem ser considerados para máxima remoção do enxofre do metal. Estes fatores foram abordados por Silva ${ }^{(25)}$ e Takano ${ }^{(26)}$, são eles:

- Escórias básicas e saturadas com $\mathrm{CaO}$; 
- Escórias com baixo potencial de oxigênio;

- Escórias fluidas (com adições de fluorita que fluidifica a escória sem alterar muito seu potencial dessulfurante);

- Composição de escória que favorece as capacidades de sulfeto ou de enxofre;

- Composição do metal que conduz o aumento do coeficiente de atividade de enxofre e a diminuição da atividade de oxigênio (desoxidação com Si ou Al);

- Mecanismos que auxiliam o transporte de enxofre do metal até a interface metal-escória.

\subsection{MODELOS EMPÍRICOS TERMODINÂMICOS PARA O PROCESSO DE DESSULFURAÇÃO}

Com a necessidade de obtenção de aços com teores de enxofre e fósforo cada vez menores, surgem novas escórias com multicomponentes. Para uma compreensão melhor das propriedades dessas escórias, alguns modelos empíricos são utilizados, tais como: capacidade de sulfeto $\left(C_{s}\right)$, basicidade ótica $(\Lambda)$ e o coeficiente de partição do enxofre $\left(L_{S}\right)$. Portanto, neste capítulo serão descritos modelos empíricos para verificar o potencial dessulfurante das escórias.

\subsubsection{Basicidade ótica}

O conceito de basicidade ótica foi desenvolvido por Duffy e $\operatorname{Ingram}^{(27,28)} \mathrm{em}$ 1970. Este conceito é caracterizado por utilizar uma escala de acidez relacionada com o $\mathrm{O}^{2-}$. Duffy ${ }^{(28)}$ notou que um íon traçador introduzido na estrutura do óxido, produz um desvio na frequência da banda de absorção ultravioleta durante a transição entre os subníveis $6 \mathrm{~s}$ e $6 \mathrm{p}$. Essas mudanças podem ser relacionadas à basicidade de um vidro ou escória ${ }^{(29)}$.

A basicidade ótica de um determinado óxido puro é função da eletronegatividade de Pauling $(\xi)$. Conforme apresentado na Equação 10. 
$\Lambda_{\text {Oxido }}=\frac{0,74}{\xi-0,26}$

(Equação 10)

A Tabela 4 mostra a eletronegatividade, o caráter do óxido e a basicidade ótica de alguns óxidos:

Tabela 4. Eletronegatividade, caráter do óxido e basicidade ótica de alguns óxidos ${ }^{(30)}$.

\begin{tabular}{cccc}
\hline Caráter do Óxido & Óxido & $\begin{array}{c}\text { Eletronegatividade do } \\
\text { Cátion }(\xi)\end{array}$ & Basicidade ótica $(\Lambda)$ \\
\hline \multirow{3}{*}{ Básico } & $\mathrm{K}_{2} \mathrm{O}$ & 0,8 & 1,37 \\
& $\mathrm{Na}$ & 0,9 & 1,16 \\
& $\mathrm{BaO}$ & 0,9 & 1,16 \\
& $\mathrm{CaO}$ & 1,0 & 1,00 \\
& $\mathrm{MnO}$ & 1,4 & 0,65 \\
\multirow{4}{*}{ Intermediário } & $\mathrm{FeO}$ & 1,7 & 0,51 \\
& $\mathrm{MgO}$ & 1,2 & 0,79 \\
& $\mathrm{Fe}_{2} \mathrm{O}_{3}$ & 1,8 & 0,48 \\
& $\mathrm{Al}_{2} \mathrm{O}_{3}$ & 1,5 & 0,60 \\
& $\mathrm{TiO}_{2}$ & 1,6 & 0,55 \\
& $\mathrm{SiO}_{2}$ & 1,8 & 0,48 \\
& $\mathrm{~B}_{2} \mathrm{O}_{3}$ & - & 0,43 \\
& $\mathrm{P}_{2} \mathrm{O}_{5}$ & 2,1 & 0,40 \\
\hline
\end{tabular}

Para escórias que contenham fluorita em sua composição química, o valor da basicidade ótica $(\Lambda)$ é 0,67 . Com os dados fornecidos na Tabela 4 é possível determinar a basicidade de escórias a partir da Equação 11 e 12:

$$
\Lambda_{\text {Escória }}=X_{1} \cdot \Lambda_{1}+X_{2} \cdot \Lambda_{2}+\ldots
$$

Onde:

$$
X_{i}=\frac{n_{\text {AtomosOxigênio }}^{\circ} \cdot A_{i}}{\sum n_{\text {AtomosOxigênio }}^{\circ} \cdot A_{i}}
$$

Onde: $X_{i}$ é um parâmetro relacionado ao número de átomos de oxigênio e fração molar do óxido na escória;

$A_{i}$ : Fração molar do óxido na escória.

Segundo Ghosh et $a^{(31)}$, a viscosidade do sistema de escória é reduzida com o aumento da basicidade ótica. 


\subsubsection{Capacidade de sulfeto}

O conceito de capacidade de sulfeto $\left(C_{s}\right)$ foi desenvolvido na década de 1950 , por Richardson e Fincham ${ }^{(15)}$, e representa a capacidade de uma escória remover enxofre do aço.

A capacidade de sulfeto de uma escória $\left(\mathrm{C}_{\mathrm{s}}\right)$ é o termo utilizado para descrever a capacidade de uma escória remover o enxofre do metal ${ }^{(32)}$.

Fincham e Richardson ${ }^{(15)}$ definiram a capacidade de sulfeto $\left(\mathrm{C}_{\mathrm{s}}\right)$ como o potencial de uma escória fixar o enxofre como sulfeto, e pode ser descrita de acordo com a reação de equilíbrio gás-escória mostrada na Equação 13.

$$
1 / 2 S_{2(g)}+\left(O^{-2}\right)=1 / 2 O_{2(g)}+\left(S^{-2}\right)
$$

A capacidade de sulfeto proposta por Fincham e Richardson ${ }^{(15)}$ baseada na reação gás-escória é mostrada na Equação 14.

$$
C_{S}=\left(\% S^{-2} \text { na escória }\right) \times\left(\frac{p_{O_{2}}}{p_{S_{2}}}\right)^{1 / 2}
$$

Observa-se que a capacidade de sulfeto é proposta com base no equilíbrio das fases do sistema gás/escória. Entretanto, industrialmente as escórias siderúrgicas são muito mais complexas. Portanto, é necessário calcular a capacidade de sulfeto através de equações que considerem essas escórias. Por isso, diversas pesquisas ${ }^{(33,34,35,36,37)}$ desenvolveram relações para obter a capacidade de sulfeto a partir da temperatura do processo e da composição química da escória dessulfurante.

Neste contexto, Sosinsky e Sommerville ${ }^{(38)}$ descrevem que as escórias dessulfurantes possuem uma relação mútua com a temperatura e composição química. Com isso, os autores visaram obter uma correlação para a capacidade de sulfeto de escórias em função da composição química, da temperatura do processo, da fácil aplicação e que possa ser usada, desde o pré-tratamento de ferro-gusa até o refino secundário, esta relação é apresentada na Equação 15: 
$\log C_{S}=\left(\frac{22690-54640 . \Lambda}{T}\right)+43,6 . \Lambda-25,2$

(Equação 15)

Estimulada por uma relação empírica entre capacidade de sulfeto, temperatura, basicidade óptica e interação entre os elementos da escória, muitos modelos de predição da capacidade de sulfeto têm sido desenvolvidos ${ }^{(39,40)}$.

Nessas circunstâncias, Shankar et $a^{(34)}$ e Taniguchi et a/(35) propuseram recentemente dois modelos para prever com precisão a capacidade de sulfeto para escórias à base de $\mathrm{CaO}-\mathrm{SiO}_{2}-\mathrm{MgO}-\mathrm{Al}_{2} \mathrm{O}_{3}$. Estes e outros modelos de capacidade de sulfeto podem ser vistos na Tabela 5.

Tabela 5. Modelos de capacidade de sulfeto para escórias à base de $\mathrm{CaO}-\mathrm{MgO}-\mathrm{Al}_{2} \mathrm{O}_{3}-\mathrm{SiO}_{2}{ }^{(41)}$.

\begin{tabular}{|c|c|}
\hline Autor & Modelo \\
\hline $\begin{array}{l}\text { Young }^{(33)}(\wedge \\
\quad<0,8)\end{array}$ & $\begin{array}{l}\log C_{S}=-13,913+42,84 \Lambda-23,82 \Lambda^{2}-\frac{11710}{T}-0,02223 . \% \mathrm{SiO}_{2} \\
-0,02275 . \% \mathrm{Al}_{2} \mathrm{O}_{3}\end{array}$ \\
\hline $\begin{array}{l}\text { Young }^{(33)} \\
(\wedge \geq 0,8)\end{array}$ & $\begin{array}{l}C_{S}=-0,6261+0,4808 \Lambda+0,7917 \Lambda^{2}+\frac{1697}{T}-\frac{2587 \Lambda}{T} \\
+0,0005144 . \% \mathrm{FeO}\end{array}$ \\
\hline Shankar ${ }^{(34)}$ & $\begin{array}{l}C_{S}=9,852 \times 10^{-6}\left(\% \mathrm{Al}_{2} \mathrm{O}_{3}\right)+0,010574 \Lambda-(16,2933 / \mathrm{T})+0,002401 \\
\quad-\log C_{S}=7,350+94,89 \log \wedge-(10051+\wedge(-388(\% \mathrm{MgO})+\end{array}$ \\
\hline Tanigushi ${ }^{(35)}$ & $\begin{array}{l}0,0841(\% \mathrm{MnO})) / \mathrm{T})+0,2284\left(\% \mathrm{SiO}_{2}\right)+0.1379\left(\mathrm{AL}_{2} \mathrm{O}_{3}\right)- \\
0,0587(\% \mathrm{MgO})+0,0841(\% \mathrm{MnO})\end{array}$ \\
\hline $\begin{array}{l}\text { Modelo } \\
\mathrm{KTH}^{(36,37)}\end{array}$ & 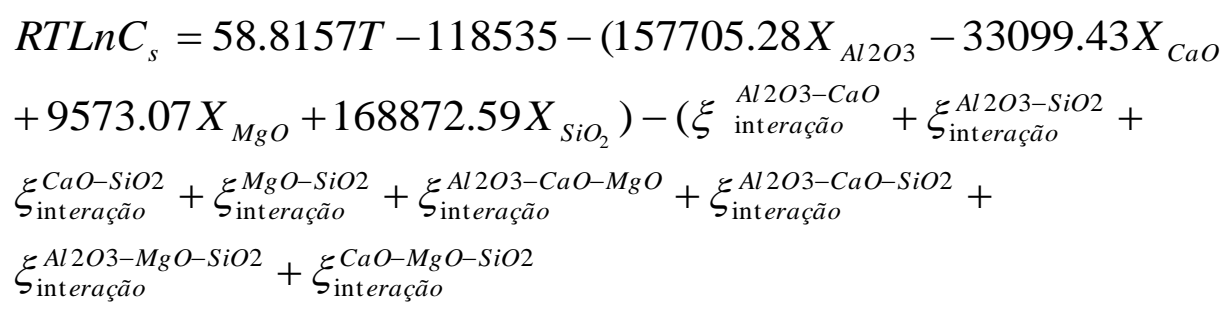 \\
\hline $\begin{array}{l}\text { Modelo } \\
\text { IMCT }^{(41)}\end{array}$ & $\begin{array}{l}\log C_{S, \mathrm{CaO}}=\lg \left(16 k_{\mathrm{CaS}} N_{\mathrm{CaO}} \sum n_{i}\right)+\frac{935}{T}-1,375 \\
\log C_{S, \mathrm{MgO}}=\lg \left(16 k_{\mathrm{MgS}} N_{\mathrm{MaO}} \sum n_{i}\right)+\frac{935}{T}-1,375 \\
\log C_{S}=\left[\lg \left(16 k_{\mathrm{CaS}} N_{\mathrm{CaO}}+k_{\mathrm{MgS}} N_{\mathrm{MaO}}\right) \sum n_{i}\right]+\frac{935}{T}-1,375\end{array}$ \\
\hline
\end{tabular}

Em um esforço para melhorar a precisão das correlações com basicidade óptica em regimes específicos de composição das escórias, foram propostos vários 
ajustes ou correções. A aplicabilidade destas equações provavelmente está limitada a composições das escórias próximas das composições originais utilizadas para obter estas correlações. A correlação entre basicidade e capacidade de sulfeto pode ser observada na Figura 6.

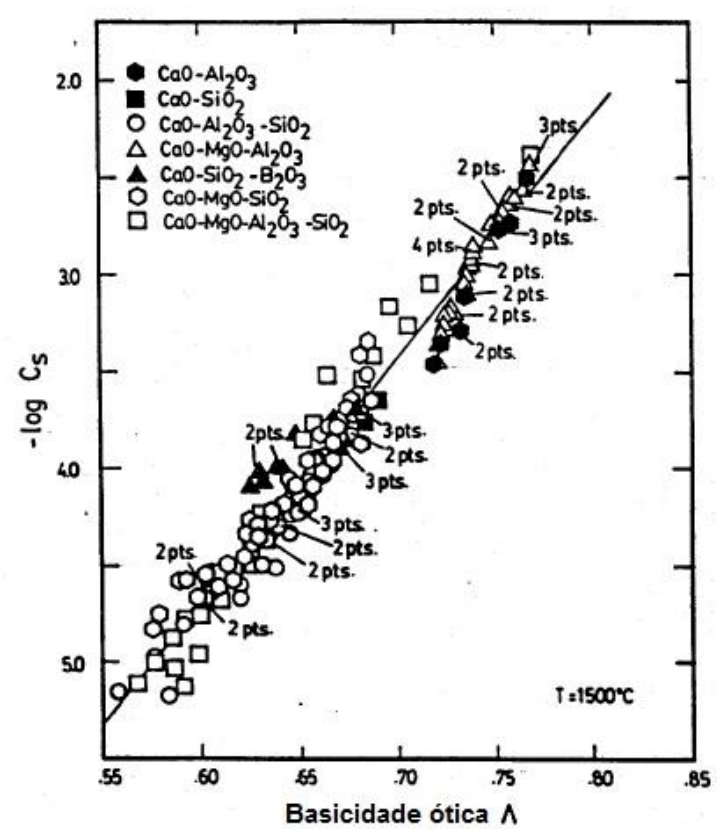

Figura 6. Correlação entre a basicidade óptica e a capacidade de sulfeto para escórias na temperatura de $1500^{\circ} \mathrm{C}$.

\subsubsection{Partição de enxofre}

O coeficiente de partição do enxofre expressa à relação de equilíbrio entre a concentração de enxofre na escória e a concentração de enxofre no metal. Tal relação é mostrada na Equação 16.

$$
L_{S}=\frac{\left(\% S_{e q}\right)}{\left[\% S_{e q}\right]}
$$

O conceito de partição de enxofre foi determinado e explanado de acordo com equação gás-metal e gás-escória (Equações 1 e 2$)^{(41)}$. Quando se realiza a combinação entre as duas equações, temos a Equação 17: 
$[S]+\frac{1}{2} O_{2(g)}=\frac{1}{2} S_{2(g)}+[O]$

(Equação 17)

$\Delta G_{17}^{0}=17907,96-26,3355(\mathrm{~J} / \mathrm{mol})$

A constante $\mathrm{K}$ de equilíbrio da Equação 17 pode ser expressa de acordo com a Equação $18^{(42)}$ :

$\lg K=\lg \left(\frac{a_{O}}{a_{S}} \cdot \sqrt{\frac{P_{S_{2}}}{P_{O_{2}}}}\right)=\lg \left(\frac{a_{O}}{[\% S] \cdot f_{s}} \cdot \sqrt{\frac{P_{S_{2}}}{P_{O_{2}}}}\right)=-\frac{935}{T}+1,375$

Derivando a Equação e inserindo a capacidade de sulfeto, chega-se na Equação $19^{(34)}$.

$\log L_{S}=\log C_{S}-\frac{935}{T}+1,375+\log f_{S}-\log h_{O}$

O termo $\log f_{S}$ é obtido mediante a Equação 20:

$\log f_{S}=\% S . e_{S}^{S}+\% C . e_{S}^{C}+\% S i . e_{S}^{S i}+\% M n . e_{S}^{M n}+\% P . e_{S}^{P}+\% O . e_{S}^{O}$

(Equação 20)

Onde:

$e_{i}^{j}$ : Coeficiente de interação do elemento $j$ sobre o elemento $i$, ambos dissolvidos no metal. Observa-se que a diminuição na atividade de oxigênio no metal contribui para o aumento do coeficiente de partição do enxofre. O termo $h_{0}$ pode ser obtido da seguinte maneira: $h_{O}=\% O \cdot f_{O}$.

Em outro estudo, Inoue e Suito ${ }^{(43)}$ estimaram uma relação para prever o coeficiente de partição do enxofre como função da capacidade de sulfeto, temperatura e coeficiente de atividade do enxofre no metal $\left(f_{S}\right)$, conforme apresentado na Equação 21: 
$\log L_{S}=\log C_{S}-\frac{1053}{T}+5,73+\log f_{S}$

(Equação 21)

Por fim, Mitsutaka ${ }^{(44)}$ estudou a capacidade de sulfeto para escórias do sistema $\mathrm{CaO}-\mathrm{Al}_{2} \mathrm{O}_{3}-\mathrm{MgO}$ e $\mathrm{CaO}-\mathrm{Al}_{2} \mathrm{O}_{3}-\mathrm{SiO}_{2}$ na faixa de temperatura de $1550^{\circ} \mathrm{C}$ a $1650^{\circ} \mathrm{C}$ para aplicação no refino secundário do aço. Segundo o autor, com a desoxidação do aço no refino secundário, e adição de escórias à base de $\mathrm{CaO}$, surgem escórias do sistema $\mathrm{CaO}-\mathrm{Al}_{2} \mathrm{O}_{3}$. Portanto, após este estudo foi proposto o modelo de partição apresentado na Equação 22:

$\log L_{S}=\log C_{S}-(1 / 3) \log a_{\mathrm{Al}_{2} \mathrm{O}_{3}}+(2 / 3) \log [\%$ massaAl $]+(21168 / T)-5,703 \quad$ (Equação 22)

Em escórias $\mathrm{CaO}-\mathrm{Al}_{2} \mathrm{O}_{3}$, quando ocorre o aumento do $\mathrm{MgO}$ na escória, provavelmente proveniente do desgaste refratário do reator, ocorre o aumento da partição de enxofre. Por outro lado, o aumento do $\mathrm{SiO}_{2}$ oriundo de etapas anteriores diminuiu a partição de enxofre.

\subsection{PARÂMETROS TERMODINÂMICOS E CINÉTICOS PARA O PROCESSO DE DESSULFURAÇÃO}

\subsubsection{Importância da desoxidação para o processo de dessulfuração}

O oxigênio e o enxofre são elementos químicos da mesma família na tabela periódica, por isso, apresentam semelhança em seu comportamento físico-químico e competem entre si por ligantes disponíveis no aço líquido, onde o oxigênio predomina sobre o enxofre.

$O$ processo de dessulfuração é dependente da atividade do oxigênio no banho metálico. A quantidade de Al necessário é dependente do teor de oxigênio inicial no aço e do oxigênio visado no final da desoxidação. A Figura 7 ilustra a desoxidação pela adição de $\mathrm{Al}$ no aço com $0,45 \%$ de $\mathrm{C}$ a $1600^{\circ} \mathrm{C}$, onde $\circ \mathrm{Al}$ consumido forma o óxido, cuja quantidade pode ser calculada com base na estequiometria da reação. 


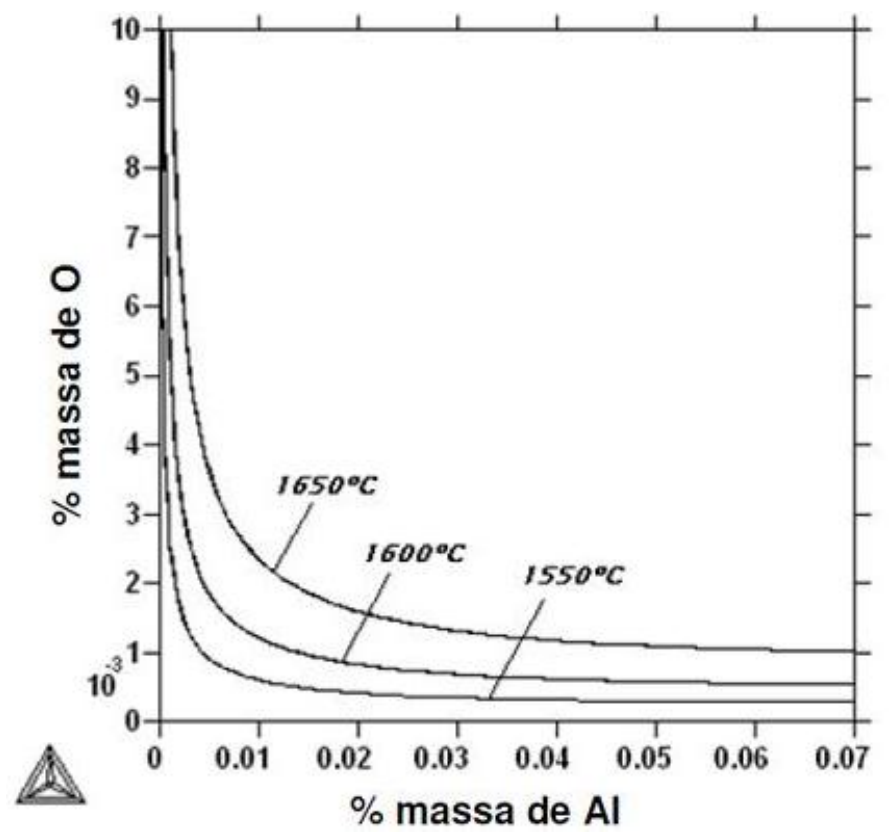

Figura 7. Diagrama de equilíbrio entre o $\mathrm{Al}$ e o $\mathrm{O}$ no aço líquido com $0,45 \% \mathrm{C}$ a $1600^{\circ} \mathrm{C}$ via ThermoCalc $^{(45)}$.

Observa-se na Figura 7 que $0,01 \%$ de Al reduz o teor de oxigênio para valores próximos de $10 \mathrm{ppm}^{(5)}$.

Por outro lado, Turkdogan ${ }^{(46)}$ apresenta um limite no teor de alumínio, onde após certo teor, o oxigênio aumenta com o aumento do Al, conforme apresentado na Figura 8.

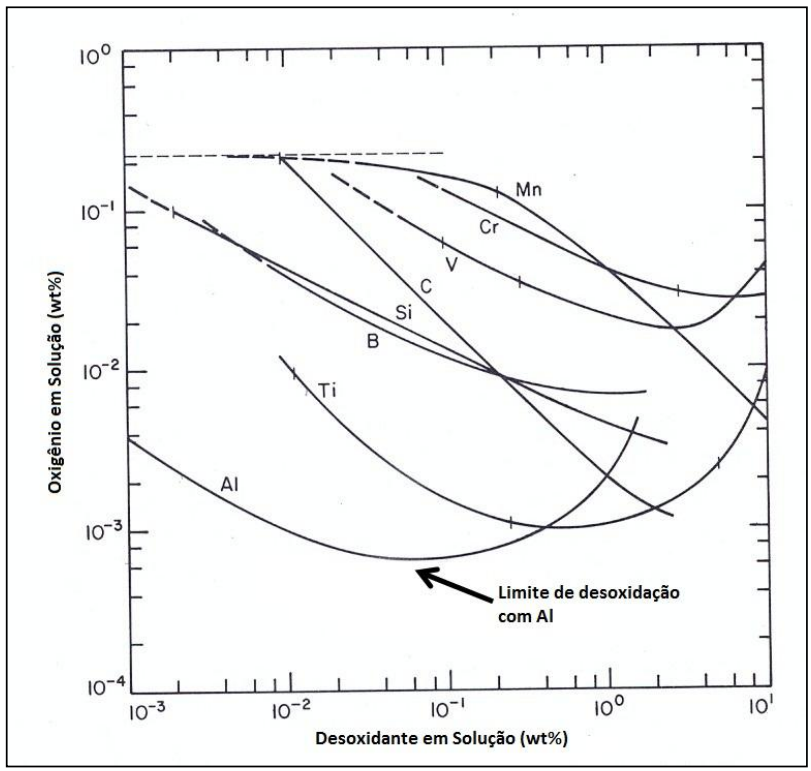

Figura 8. Desoxidação em aço na temperatura de $1600^{\circ} \mathrm{C}$. 
Comparando os elementos, observa-se que o $\mathrm{Mn}$ é um desoxidante mais fraco e o Al e o Ti são fortes desoxidantes, sendo o silício de eficiência intermediária. O titânio é um elemento de liga, devido ao maior custo, não é empregado como desoxidante na etapa de metalurgia da panela ou mesmo no refino secundário. Pode-se observar ainda que, a desoxidação do aço líquido com o Al é mais eficiente em termos de reduzir o teor de oxigênio em solução do que a desoxidação com Si e Mn. Pode-se atingir teores de oxigênio dissolvido na faixa de 2 a 3 ppm com $\mathrm{Al}^{(46)}$.

A Figura 9 apresenta os teores de oxigênio dissolvidos no equilíbrio para diferentes teores de alumínio, valores calculados por Turkdogan ${ }^{(12)}$ e medidos experimentalmente por Kor e Glaws ${ }^{(47)}$.

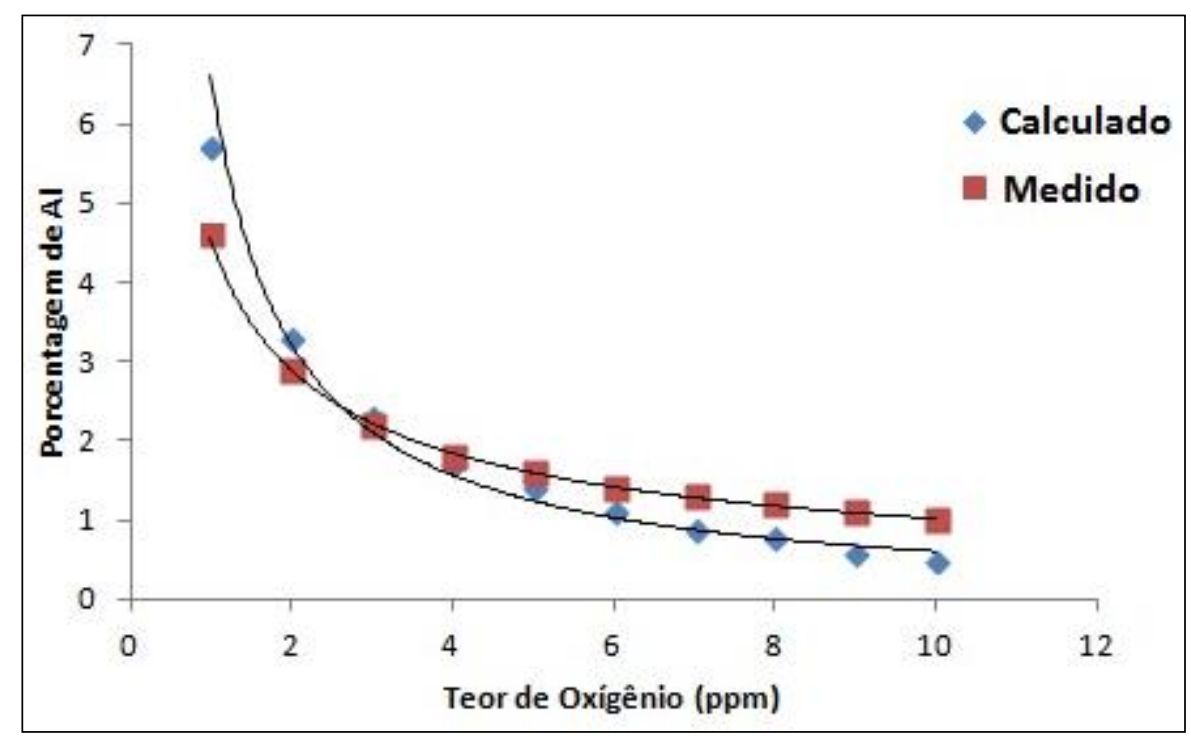

Figura 9. Valores de Oxigênio medidos por Kor e Glaws ${ }^{(47)}$ e calculados por Turkdogan ${ }^{(12)}$.

Observa-se na Figura 9, que a atividade do alumínio tem impacto sobre a magnitude do oxigênio no banho. Quanto maior o teor de desoxidante no metal, menor será a atividade do oxigênio. Por outro lado, quanto menor for a atividade do oxigênio no metal, maior a partição de enxofre $\left(L_{s}\right)$, como consequência, melhor dessulfuração. Esta relação pode ser expressa pela Equação 19, que descreve a partição de enxofre $\left(L_{s}\right)$ :

$\log L_{S}=\log C_{S}-\frac{935}{T}+1,375+\log f_{S}-\log h_{O}$ 
Nota-se que a partição de enxofre é dependente da atividade do oxigênio, de modo que sua variação altera a partição de enxofre. A Figura 10 apresenta a relação entre a partição de enxofre com o alumínio dissolvido no metal em escórias $\mathrm{CaO}$ $\mathrm{Al}_{2} \mathrm{O}_{3}$.

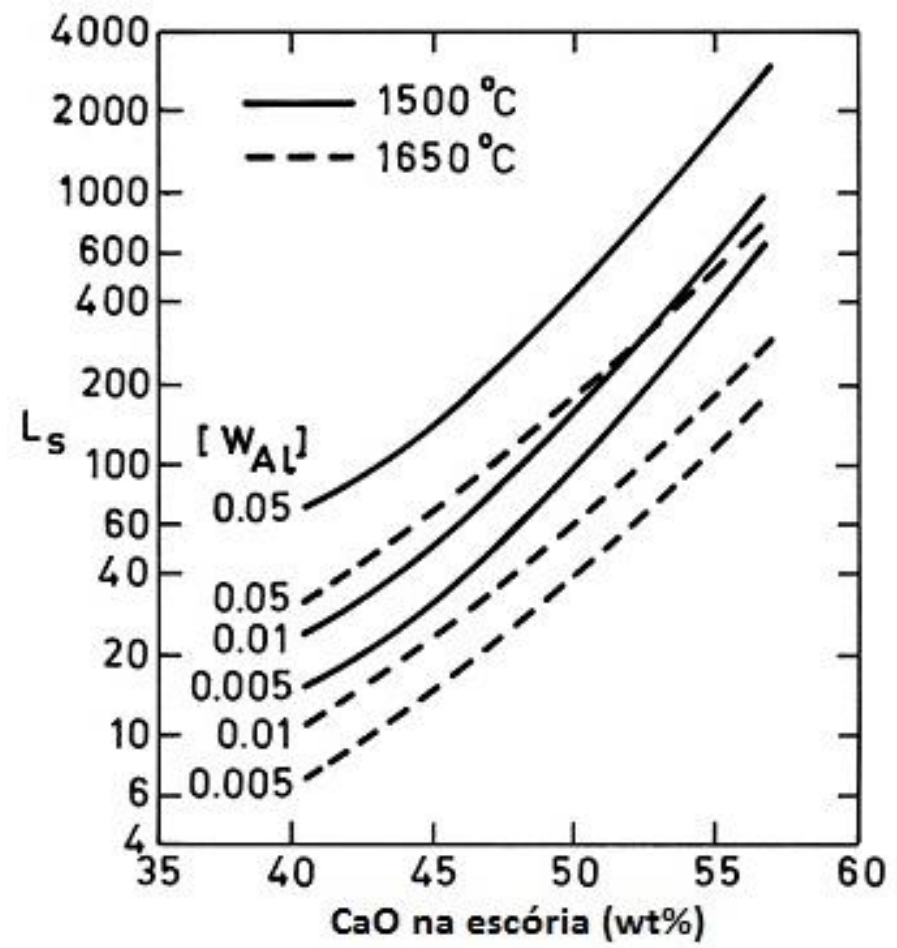

Figura 10. Relação entre a partição de enxofre com o alumínio dissolvido no metal em escórias do sistema $\mathrm{CaO}-\mathrm{Al}_{2} \mathrm{O}_{3}{ }^{(11)}$.

Observa-se na Figura 10, que o aumento da massa de Al, promove um aumento na partição, como consequência uma maior dessulfuração do aço.

Fruehan $^{(48)}$ realizou um estudo sobre os mecanismos de dessulfuração com $\mathrm{CaO}$ em ligas Fe-Al e Fe-Si. Segundo o autor, em ligas Fe-Al a dessulfuração é muito rápida, enquanto para ligas de $\mathrm{Fe}-\mathrm{Si}$ é mais lenta. A diferença básica é que as ligas $\mathrm{Fe}-\mathrm{Al}$ geram como produto um óxido simples $\left(\mathrm{Al}_{2} \mathrm{O}_{3}\right)$, enquanto que para as ligas $\mathrm{Fe}$-Si é necessária a formação de $\mathrm{Ca}_{2} \mathrm{SiO}_{4}$, onde a sua formação é complexa e lenta. Além disso, a taxa de dessulfuração de ligas de Fe-Si é controlada pela formação dos intermediários gasosos, por outro lado, a taxa de dessulfuração de ligas Fe-Al é aparentemente controlada pela difusão do enxofre até a interface metal escória.

Outros estudos ${ }^{(49,50)}$ têm sido realizados com o intuito de elucidar fenômenos mal compreendidos na desoxidação para o processo de dessulfuração. 


\subsubsection{Influência de fases líquidas e sólidas em escórias dessulfurantes de ferro-gusa e aço}

Um dos aspectos mais importantes, que é frequentemente negligenciado quando se avalia a capacidade de uma escória dessulfurante é a fração da fase líquida e sólida. A fluidez de escórias básicas é controlada por essas duas frações. Quanto maior for o teor de fração sólida, menor é a fluidez da escória. Por outro lado, a escória completamente líquida possui fluidez máxima(51). A Tabela 6 apresenta a composição de duas escórias.

Tabela 6. Composição de escórias dessulfurantes.

\begin{tabular}{ccc}
\hline Compostos & Escória O(\% massa) & Escória K (\% massa) \\
\hline $\mathrm{SiO}_{2}$ & 38 & 35 \\
$\mathrm{CaO}$ & 45 & 50 \\
$\mathrm{MgO}$ & 17 & 15 \\
$\%$ Fases & \multirow{2}{*}{$100 \%$ líquido } & $56 \%$ líquido, \\
& & $39 \% \mathrm{Ca}_{2} \mathrm{SiO}_{4}, 5 \% \mathrm{MgO}$ \\
\hline
\end{tabular}

A fração de líquido na escória $(\mathrm{O})$ tem composição idêntica à escória $(K)$, ou seja, a adição de cal, apenas resultou em um decréscimo na quantidade de líquido disponível para realizar a dessulfuração. Este comportamento pode ser visualizado na Figura 11.

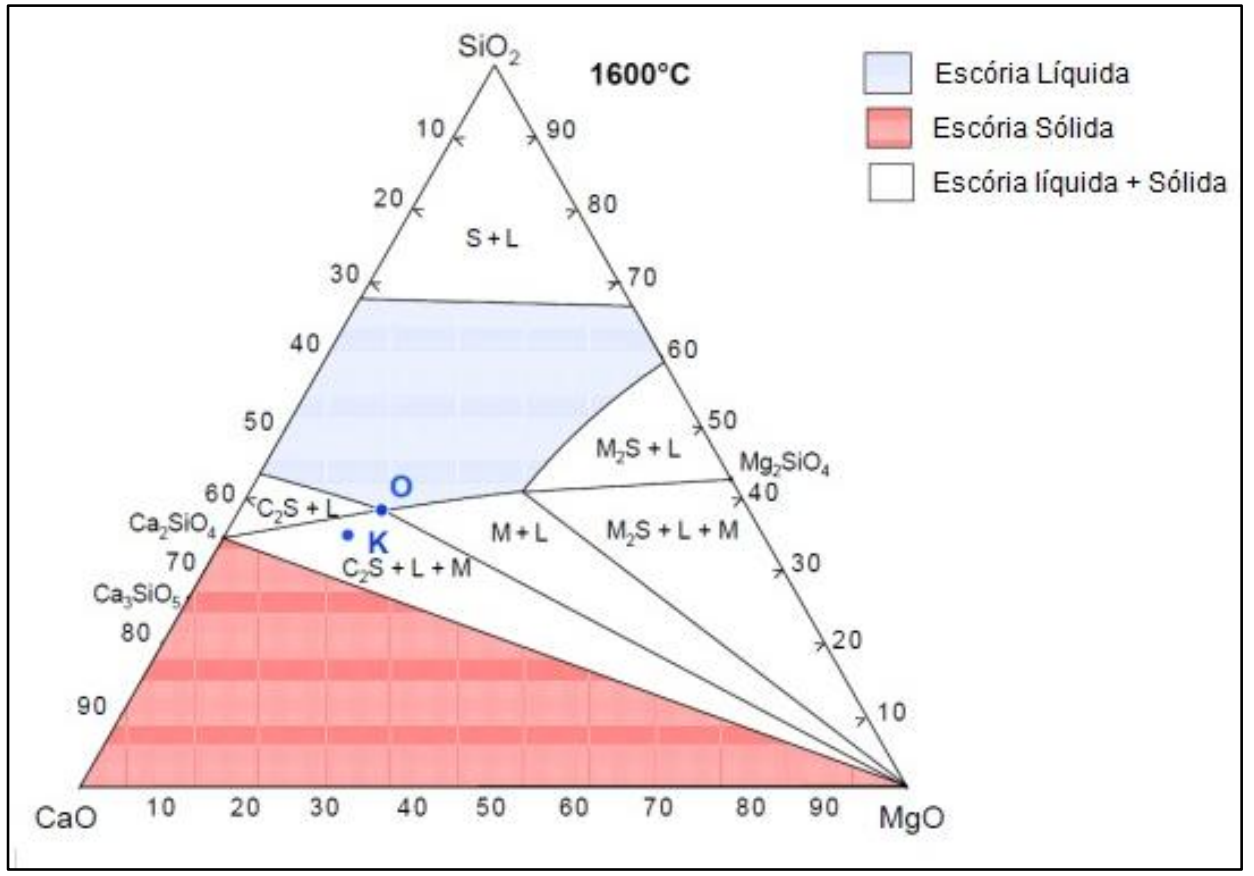

Figura 11. Seção isotérmica do sistema $\mathrm{CaO}-\mathrm{Al}_{2} \mathrm{O}_{3}-\mathrm{MgO}$ a $1600^{\circ} \mathrm{C}^{(102)}$. 
Este aumento do $\mathrm{CaO}$, que teoricamente melhoraria a dessulfuração, deslocou a escória para uma região com a presença de fase sólida e líquida, prejudicando o processo de dessulfuração, visto que, a fase responsável pelo processo de dessulfuração no aço é a fase líquida. Além disso, esse aumento de cal contribui para a formação dos compostos $2 \mathrm{CaO} . \mathrm{SiO}_{2}, 3 \mathrm{CaO} . \mathrm{SiO}_{2}$ e CaS. Estes compostos possuem pontos de fusão em torno de $1480^{\circ} \mathrm{C}$ e se formam ao redor da partícula de $\mathrm{CaO}$, impedindo a transferência dos íons de $\mathrm{S}^{2-}$ e limitando a reação de dessulfuração. Conforme apresentado na Figura 12.

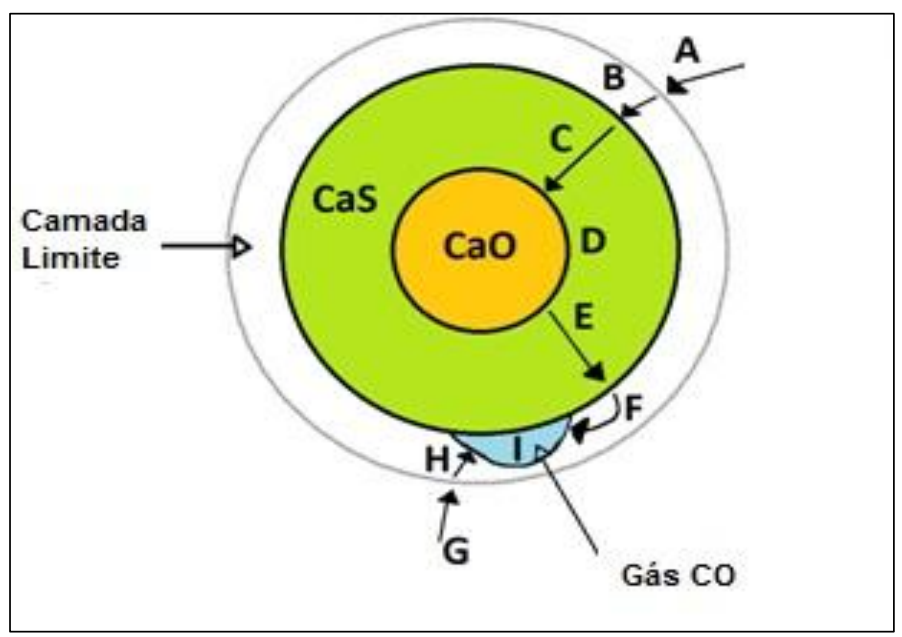

Figura 12. Restrição do transporte de massa do enxofre até a partícula de $\mathrm{CaO}$ imposta pelo $\mathrm{CaS}$ formado ${ }^{(52)}$.

Niedringhaus e Fruehan ${ }^{(53)}$ estudaram o efeito do Al na dessulfuração de ferro-gusa. As experiências foram realizadas para determinar se o aumento da dessulfuração pelo Al é devido a redução do potencial de oxigênio ou a formação de uma fase líquida que aumenta a transferência de enxofre na interface de reação. $O$ efeito do $\mathrm{Al}$ na dessulfuração por $\mathrm{CaO}$ pode ser visualizado na Figura 13. 

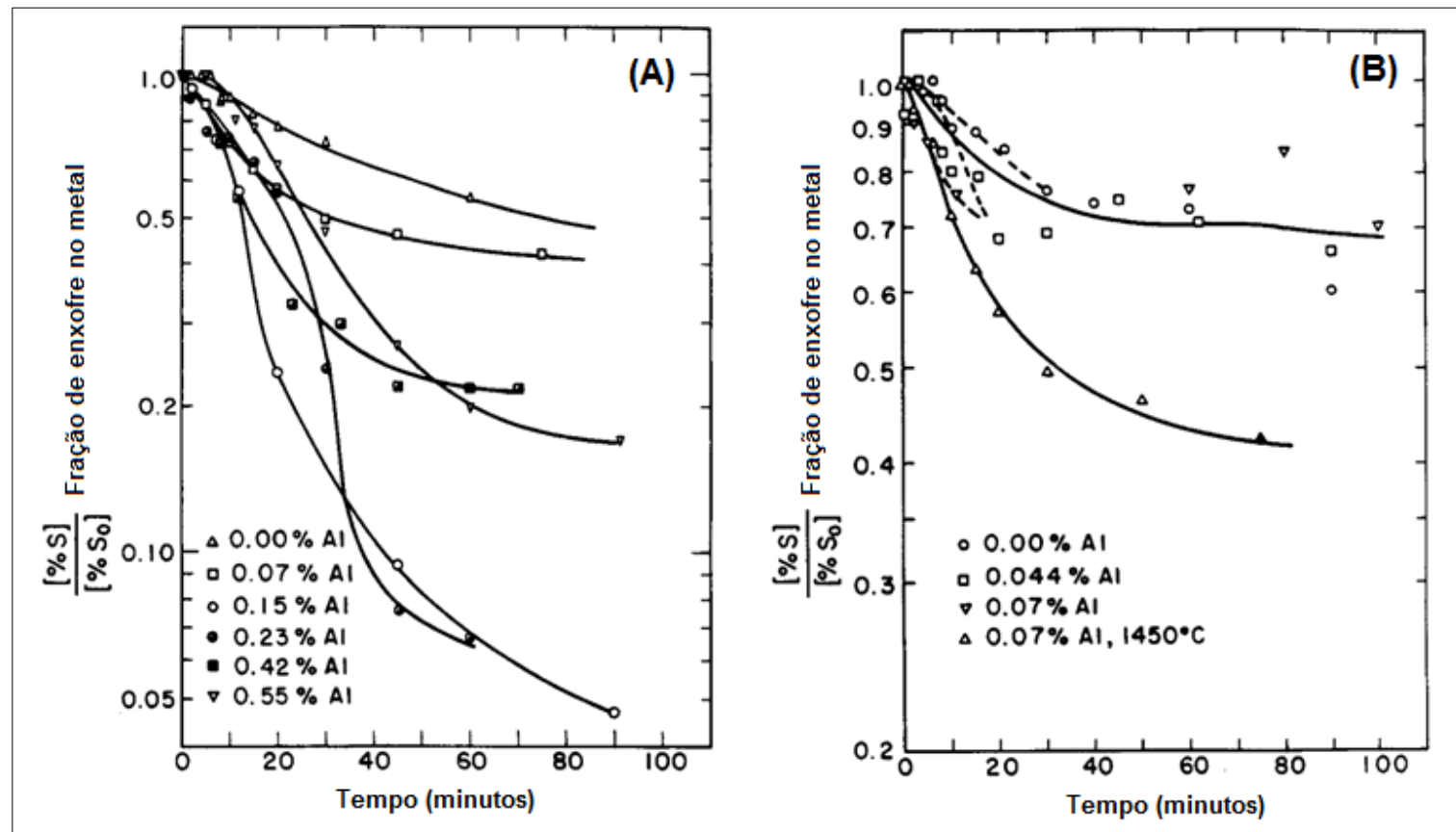

Figura 13. Variação do enxofre em função do tempo para diferentes porcentagens de alumínio na temperatura de $1450^{\circ} \mathrm{C}(\mathrm{A})$ e $1350^{\circ} \mathrm{C}(\mathrm{B})$.

Verifica-se que o aumento do alumínio favorece a dessulfuração na temperatura de $1450^{\circ} \mathrm{C}$. Por outro lado, este comportamento não é observado na temperatura de $1350^{\circ} \mathrm{C}$, uma vez que, o Al forma um produto líquido (aluminato de cálcio) na temperatura de $1450^{\circ} \mathrm{C}$ e um produto sólido a $1350^{\circ} \mathrm{C}$.

A dessulfuração diminui com o aumento do alumínio acima de 0,23\%. De acordo com Niedringhaus e Fruehan ${ }^{(53)}$, pode ter ocorrido a formação de aluminatos de cálcio sólido rico em alumina, tais como: $\mathrm{CaAl}_{2} \mathrm{O}_{4}$ e $\left(\mathrm{CaO} \cdot \mathrm{Al}_{2} \mathrm{O}_{3}\right)$. Com a formação desses sólidos, diminui a concentração de $\mathrm{CaO}$ sólido disponível para reagir com o enxofre.

Em outra pesquisa, Shoji et a/ ${ }^{(54)}$ avaliou a adição de Al para o processo de dessulfuração de ferro-gusa. Os resultados mostraram que a taxa de dessulfuração foi aumentada, mantendo a concentração de alumínio superior a 0,005\% no metal. Os resultados comparativos dos ensaios com e sem a adição de Al podem ser visualizados na Figura 14. 


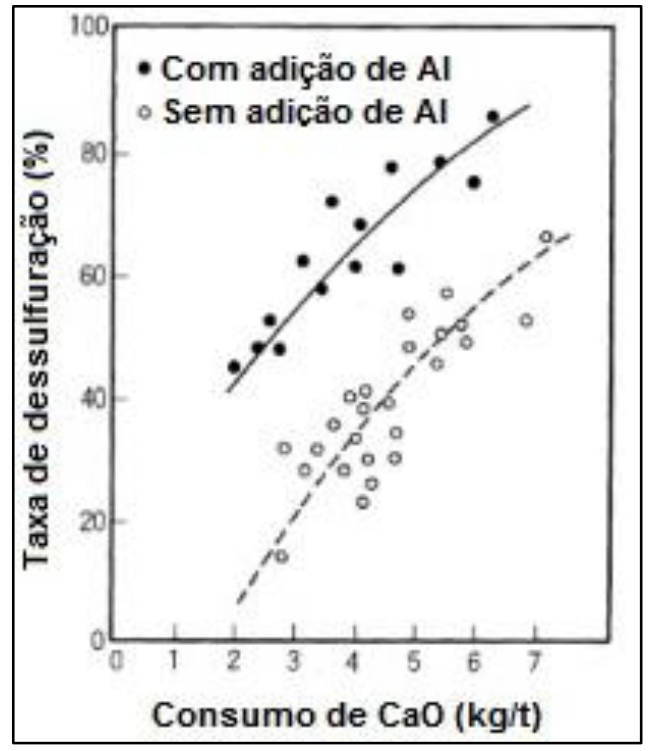

Figura 14. Relação entre o consumo de $\mathrm{CaO}$ e a taxa de dessulfuração.

De acordo com os autores, foi observado que quando não houve adição de alumínio no metal, formou-se uma camada de silicato de cálcio de alto ponto de fusão e baixa solubilidade na superfície da partícula de cal, retardando a transferência de $\mathrm{S}^{2-}$. Por outro lado, quando alumínio é adicionado, é formado uma camada de escória do sistema $\mathrm{CaO}-\mathrm{Al}_{2} \mathrm{O}_{3}-\mathrm{FeO}$. Esta camada de escória possui menor ponto de fusão, facilitando o transporte de massa dos íons de enxofre. A Figura 15 representa o processo descrito neste parágrafo.

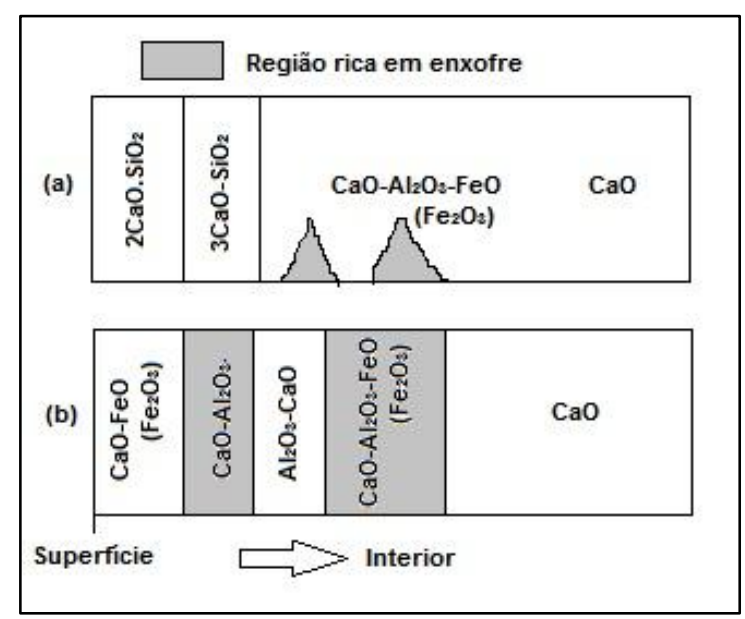

Figura 15. Representação do processo de dessulfuração em escórias sem a utilização do alumínio(a) e escórias com o uso do $\mathrm{Al}(\mathrm{b})$. 
Lindstrom e Sichen ${ }^{(55)}$ realizaram um estudo cinético sobre a dessulfuração de ferro-gusa utilizando $\mathrm{CaO}$ e $\mathrm{CaC}_{2}$. A fusão do ferro-gusa foi realizada em um cadinho de grafite. Para isso, um forno com atmosfera controlada foi utilizado e a agitação do metal e da escória promovida por um rotor. Foram utilizados dois agentes dessulfurantes. O primeiro é identificado por flucal, composto basicamente por $\mathrm{CaO}, 0,5 \%$ de $\mathrm{SiO}_{2}$ e traços de $\mathrm{CaF}_{2}$. O segundo agente dessulfurante é o carboneto de cálcio (95\% em massa de $\mathrm{CaC}_{2}$ ).

Os resultados mostraram que as partículas de $\mathrm{CaO}(<50 \mu \mathrm{m})$ foram completamente transformadas em CaS, favorecendo o processo de dessulfuração. Por outro lado, em partículas maiores de $\mathrm{CaO}$, houve a formação de uma camada de CaS com maior espessura e formação da fase $2 \mathrm{CaO} \mathrm{SiO}_{2}$, dificultando 0 processo. A Figura 16 apresenta a formação do CaS ao redor da partícula de $\mathrm{CaO}$.

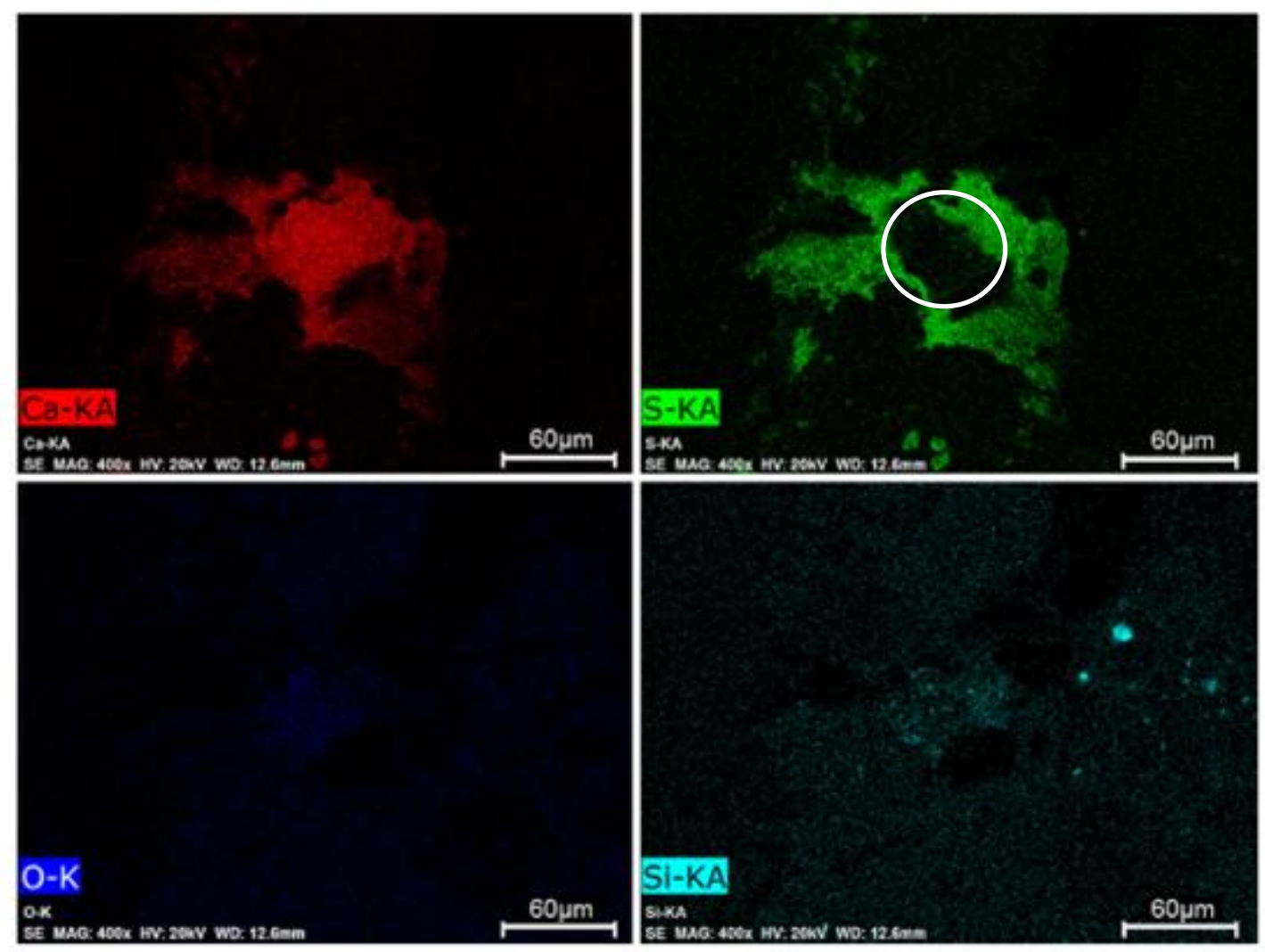

Figura 16. Foto tirada após 30 segundos de experimento, mostrando a formação de CaS ao redor da patícula de $\mathrm{CaO}^{(55)}$.

Os autores notaram que a formação de $2 \mathrm{CaO} \cdot \mathrm{SiO}_{2}$ foi favorecido por um elevado potencial de oxigênio e a concentração local de oxigênio em torno de maiores partículas de $\mathrm{CaO}(>50 \mu \mathrm{m})$ foi maior do que em torno de partículas 
menores. Quando foi utilizado $\mathrm{CaC}_{2}$ como agente dessulfurante não foi observada a formação de fase $2 \mathrm{CaO} . \mathrm{SiO}_{2}$ conforme mostrado na Figura 17.

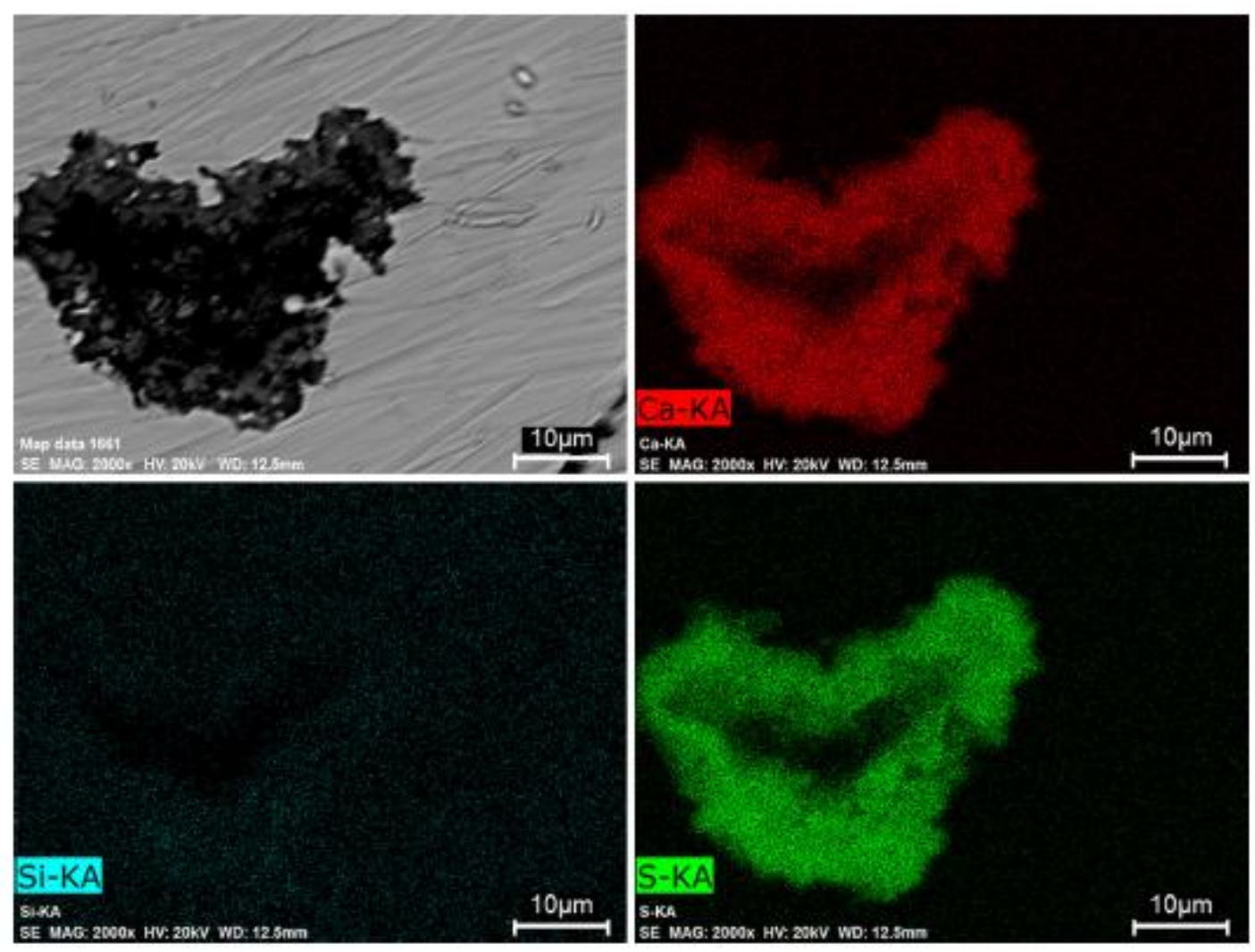

Figura 17. Formação de $\mathrm{CaS}$ ao redor da partícula de $\mathrm{CaC}_{2}$, mas sem a formação de $2 \mathrm{CaO} \mathrm{SiO}_{2}{ }^{(55)}$

Lindstrom e Sichen ${ }^{(55)}$ também mediram a espessura da camada de CaS formada ao redor da partícula em função do tempo. O comportamento da espessura de CaS pode ser visualizado na Figura 18. 


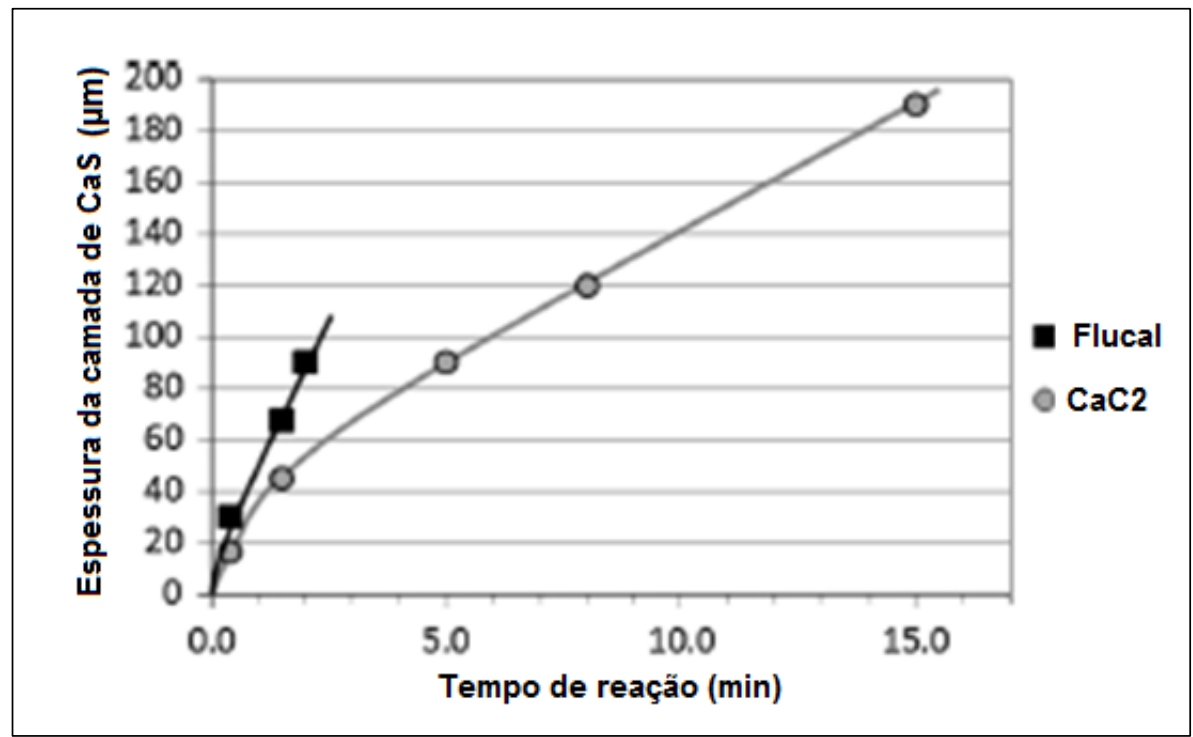

Figura 18. Espessura da camada de CaS medido em função do tempo para os agentes dessulfurante flucal e $\mathrm{CaC}_{2}$.

Verifica-se que quando foi utilizado Flucal, a espessura da camada de CaS cresce até 3 minutos de experimentos e depois não é observada alteração. Por outro lado, quando se utilizou $\mathrm{CaC}_{2}$ a espessura de $\mathrm{CaS}$ se manteve crescente com o decorrer dos experimentos. Segundo os autores, a flucal teve melhor desempenho na dessulfuração do que o $\mathrm{CaC}_{2}$. Isto se deve ao fato da menor granulometria das partículas de $\mathrm{CaO}$, o que facilitou a interação da reação com o enxofre.

Kawai et $a{ }^{(56)}$ realizaram ensaios para verificar a influência da fase sólida, principalmente a fase sólida $\mathrm{CaO}$ em escórias dessulfurantes. Segundo estes autores, a velocidade de reação é controlada pela transferência de massa de enxofre pela camada de CaS sólido formado sobre a superfície de CaO. Além disso, eles mostraram que a taxa de dessulfuração diminuiu com o aumento de Si do metal, devido ao aumento da formação de fase $\mathrm{Ca}_{2} \mathrm{SiO}_{4}$ na superfície da partícula de $\mathrm{CaO}$. Notou-se que a dessulfuração foi influenciada pelas características geométricas da partícula de $\mathrm{CaO}$, sendo que a presença de poros (maior que $20 \mu \mathrm{m}$ ) melhoraram a cinética da dessulfuração.

Tanaka et $a{ }^{(57)}$ também estudaram o efeito da fase sólida $(\mathrm{CaO})$ no processo de dessulfuração em escórias do sistema $\mathrm{CaO}-\mathrm{Al}_{2} \mathrm{O}_{3}$ e $\mathrm{CaO}-\mathrm{SiO}_{2}-\mathrm{MgO}_{-}-\mathrm{Al}_{2} \mathrm{O}_{3}$. Segundo os autores, as partículas de $\mathrm{CaO}$, em sua grande maioria, não são fundidas nas escórias e incorporadas na fase líquida para realizar o processo de refino. No entanto, as partículas de $\mathrm{CaO}$ sólido presente nas escórias, possuem 
tubos de capilares de sua superfície para o interior. Quando a fase líquida da escória entra em contato com as partículas de $\mathrm{CaO}$ sólido, as impurezas de $\mathrm{CaS}$ ou $\mathrm{P}_{2} \mathrm{O}_{5}$ são removidos pela força capilar. A Figura 19 exemplifica este conceito.

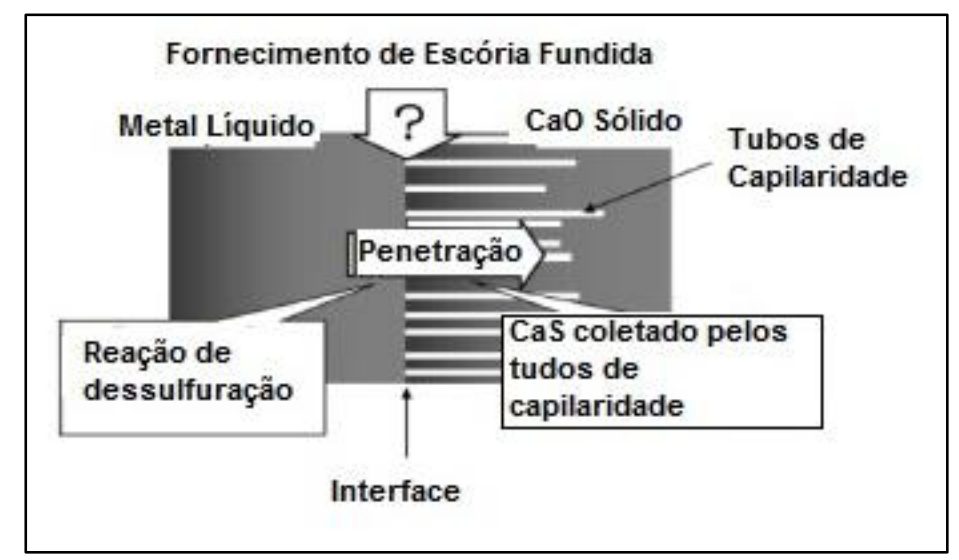

Figura 19. Demonstração do processo de capilaridade em escórias com fase sólida $(\mathrm{CaO})$ e fase líquida.

Em um trabalho mais recente, Takahashi et a/ ${ }^{(58)}$ analisaram não somente 0 efeito da fase sólida na escória, mas a influência da fase líquida, visto que, essas duas fases coexistem em escórias dessulfurantes de ferro-gusa.

Os autores concluíram, que a taxa de dessulfuração é lenta quando cal sólida é utilizada, uma vez que, ocorre a formação de uma camada interfacial que inibe a transferência de massa de enxofre. Além disso, não foi encontrado enxofre no $\mathrm{CaO}$ sólido presente na escória, o que levou a concluir que a transferência de massa de enxofre a partir da escória líquida para o $\mathrm{CaO}$ sólido é lenta.

Por fim, os autores concordaram com o que foi apresentado por Tanaka et $a{ }^{(57)}$. Quando forma-se silicato de cálcio na interface, a dessulfuração diminui. Por outro lado, quando é formado aluminato de cálcio, a dessulfuração aumenta, visto que, esta camada não impede a transferência de massa.

\subsubsection{Viscosidade de escórias}

A viscosidade é a medida da habilidade de movimentação de uma camada de moléculas sobre uma camada adjacente de moléculas. É medida em poise (SI), 
segundo a lei da viscosidade Newton ${ }^{(59)}$. É uma propriedade física que caracteriza a resistência ao escoamento simples e pode ser representada pela Equação 23.

$$
\mu=-\tau\left(\frac{d V}{d y}\right)^{-1}
$$

Onde:

$\tau=\left[\right.$ dina $\left./ \mathrm{cm}^{2}\right] ; \mathrm{V}=[\mathrm{cm} / \mathrm{s}] ; \mathrm{y}=[\mathrm{cm}]$ e $\mu=[$ poise $]$.

A título de exemplo, em escórias metalúrgicas líquidas a viscosidade varia em torno de 50 a 1500 centipoise [cp].

Campos $^{(59)}$ afirma que a viscosidade influi no processamento do aço por meio da velocidade de reação através do transporte de massa metal/escória, assim como, na velocidade de escoamento, por exemplo, no alto-forno, em que se deseja separar rapidamente a escória do metal e ainda na velocidade de decantação das fases, atuando na eliminação de inclusões do aço.

Rosenqvist ${ }^{(60)}$ afirma, que para uma temperatura constante, a viscosidade decresce com o aumento da concentração de $\mathrm{CaO}$ e adição de $\mathrm{SiO}_{2}$ e $\mathrm{Al}_{2} \mathrm{O}_{3}$. $\mathrm{A}$ Figura 20 ilustra curvas de isoviscosidade para o sistema $\mathrm{SiO}_{2}-\mathrm{CaO}-\mathrm{Al}_{2} \mathrm{O}_{3}$ à $1450^{\circ} \mathrm{C}$.

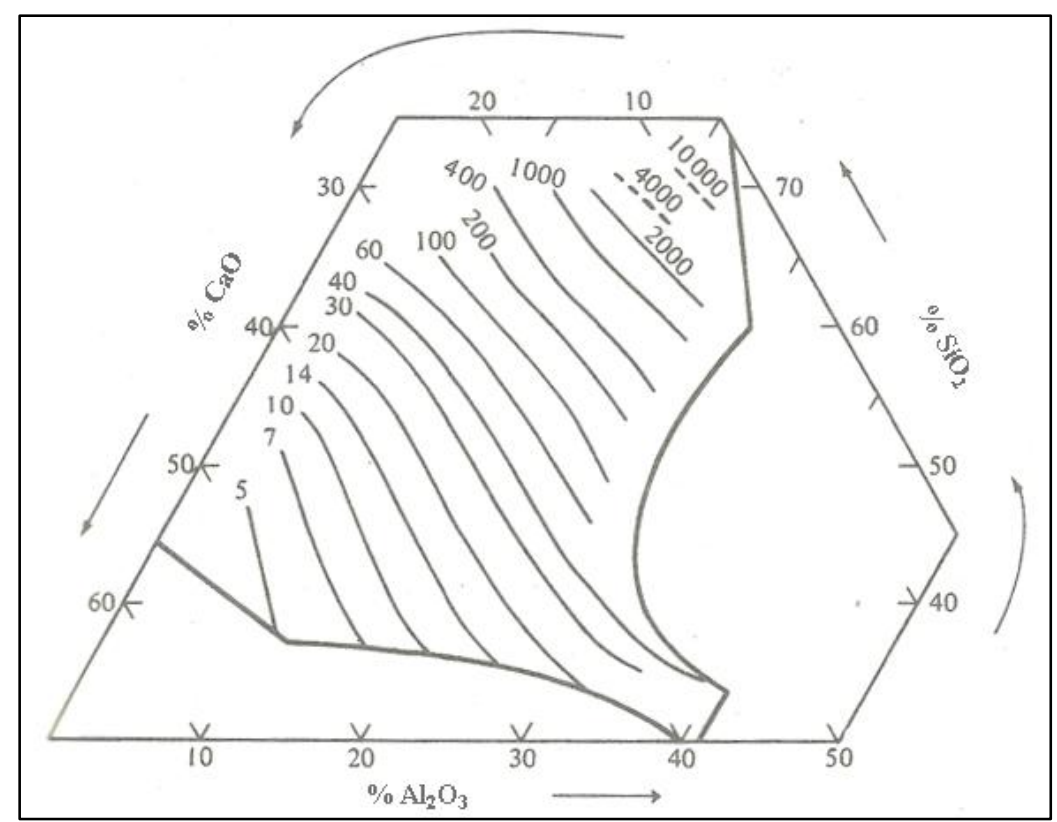

Figura 20. Diagramas de isoviscosidade para o sistema $\mathrm{SiO}_{2}-\mathrm{CaO}-\mathrm{Al}_{2} \mathrm{O}_{3}$ a $1450{ }^{\circ} \mathrm{C}$. 
Shahbazian, Sichen e Seetharaman ${ }^{(61)}$ estudaram a viscosidade de escórias do sistema $\mathrm{CaO}-\mathrm{FeO}-\mathrm{SiO}_{2}-\mathrm{CaF}_{2}$ com adições de alumina na temperatura de $1500^{\circ} \mathrm{C}$. Nesta temperatura as escórias apresentaram somente fase líquida. Segundo os autores, as viscosidades das escórias sempre aumentaram com o aumento da alumina. Outros estudos ${ }^{(62,63,64,65)}$ também encontraram esses resultados.

Mills et $a^{(66)}$ propuseram um modelo para cálculo da viscosidade por meio de basicidades óticas, que tem a vantagem de ser aplicado a qualquer tipo de escória e não apenas às composições estudadas. Já Shankar et al(67) estudaram experimentalmente a viscosidade de escórias dos sistemas $\mathrm{CaO}-\mathrm{SiO}_{2}-\mathrm{MgO}_{-}-\mathrm{Al}_{2} \mathrm{O}_{3} \mathrm{e}$ $\mathrm{CaO}-\mathrm{SiO}_{2}-\mathrm{MgO}-\mathrm{Al}_{2} \mathrm{O}_{3}-\mathrm{TiO}_{2}$ utilizando o método do cilindro rotativo, como ilustrado na Figura 21. Foi demonstrado que a viscosidade decresce com o aumento da basicidade de 0,46 para 0,8. Nas escórias estudadas com basicidade de 0,8, a viscosidade diminui mesmo com uma mínima quantidade de $\mathrm{TiO}_{2}(2 \%)$ na composição. Além disso, ilustram também, que um aumento na atividade da sílica de 0,1 para 0,4 a viscosidade também se eleva.

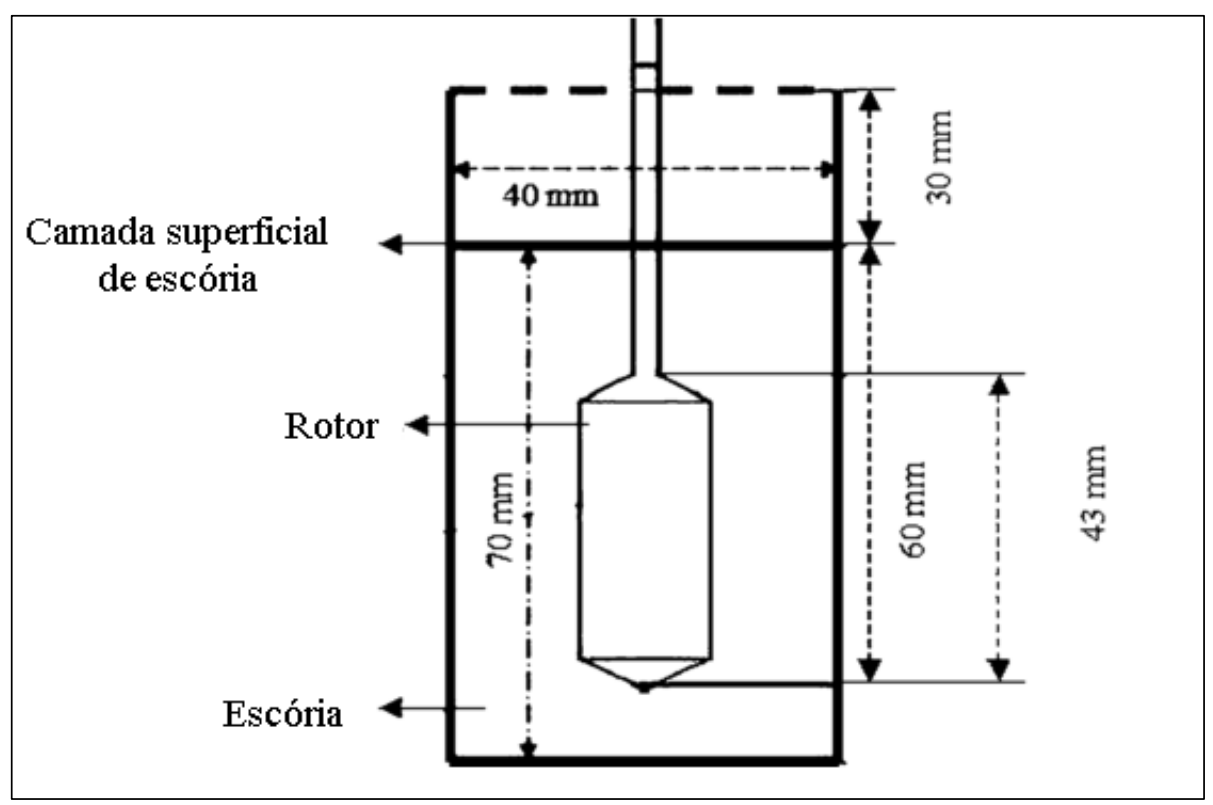

Figura 21. Ensaio de viscosidade utilizando o método do cilindro rotativo.

Song et $a^{(68)}$ utilizaram o mesmo método com o cilindro rotativo para calcular viscosidades do sistema $\mathrm{Al}_{2} \mathrm{O}_{3}-\mathrm{CaO}-\mathrm{MgO}-\mathrm{SiO}_{2}$ e também mostram que a viscosidade decresce com o aumento da temperatura e com a diminuição da 
porcentagem de sílica na composição da escória. Propuseram também, um novo modelo para cálculo das viscosidades através de um banco de dados, e este, se mostrou uma ótima ferramenta para a análise da viscosidade. Os autores mostraram ainda, que $\circ \mathrm{Al}_{2} \mathrm{O}_{3}$ tem efeito muito similar ao $\mathrm{SiO}_{2}$, e age como formador de rede no sistema $\mathrm{Al}_{2} \mathrm{O}_{3}-\mathrm{CaO}-\mathrm{MgO}-\mathrm{SiO}_{2}$.

\subsection{ESCÓRIAS À BASE DE CaO- $\mathrm{Al}_{2} \mathrm{O}_{3}$}

O volume de escória gerada e os impactos ambientais estão sendo cada vez mais mitigados no setor siderúrgico. Portanto, o uso da fluorita está sendo evitado. Deste modo, as escórias do sistema $\mathrm{CaO}-\mathrm{Al}_{2} \mathrm{O}_{3}$ têm sido apontadas como alternativa. Na Figura 22 observa-se um diagrama binário de $\mathrm{CaO}-\mathrm{Al}_{2} \mathrm{O}_{3}$.

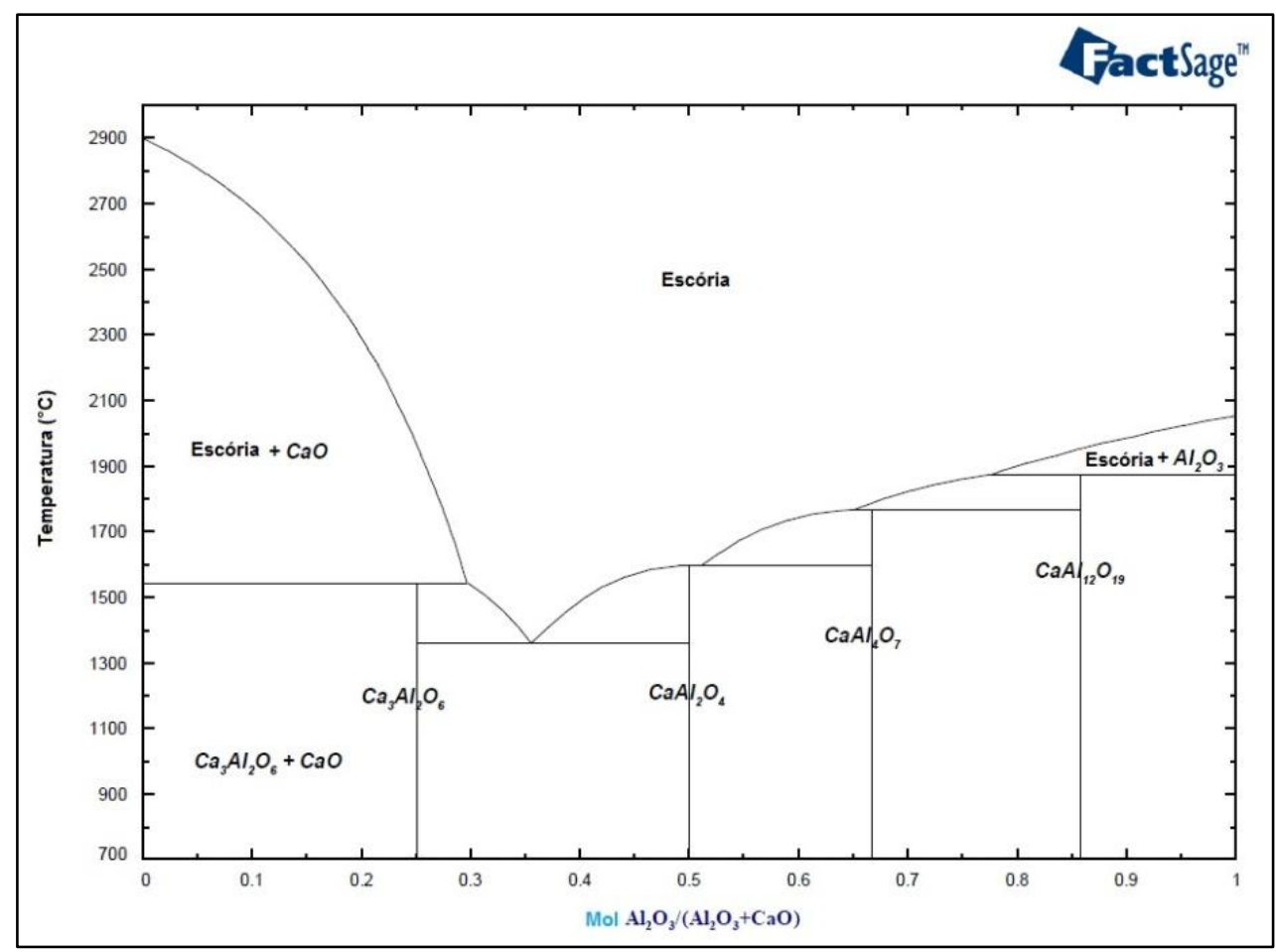

Figura 22. Binário do sistema $\mathrm{CaO}-\mathrm{Al}_{2} \mathrm{O}_{3}$.

Analisando a Figura 22, observa-se que 0 aumento de $\mathrm{Al}_{2} \mathrm{O}_{3}$ favorece a diminuição da temperatura de fusão da escória dessulfurates de aço, em uma faixa de composição, assim como os dados encontrados por Gaye et $a^{(69)}$. 
Andersson et al(70) estudaram a variação da composição química e temperatura na capacidade de sulfeto de escórias do sistema $\mathrm{CaO}-\mathrm{Al}_{2} \mathrm{O}_{3}$. Os resultados podem ser visualizados nas Figuras 23 e 24.

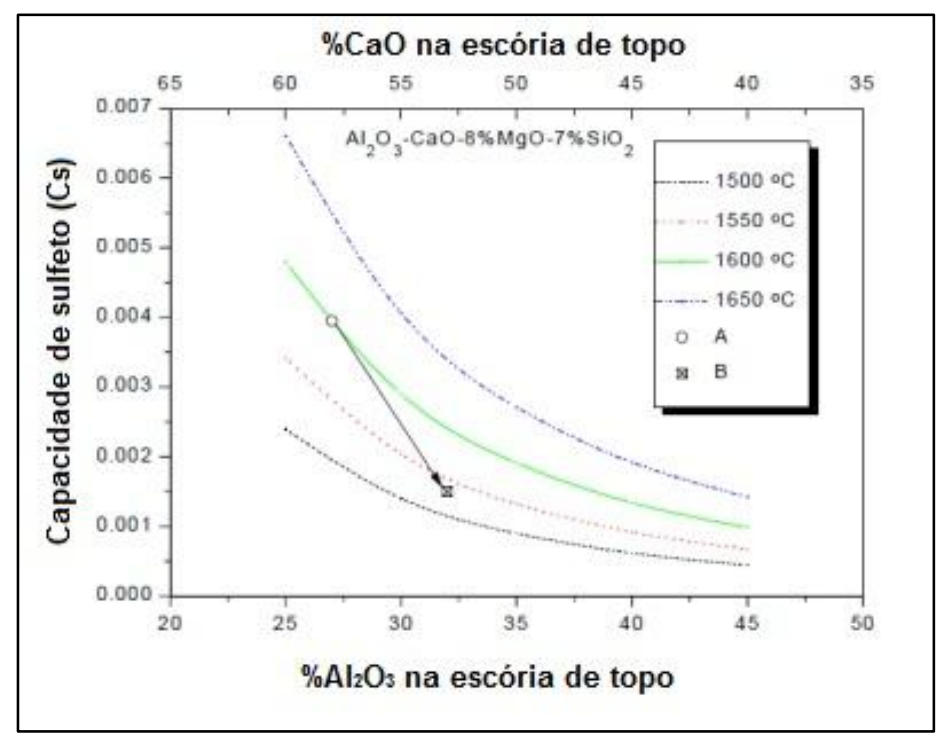

Figura 23. Relação entre a capacidade de sulfeto em função do teor de $\mathrm{Al}_{2} \mathrm{O}_{3}$ na escória e temperatura ${ }^{(70)}$. Os outros componentes da escória são constantes a $8 \%$ de $\mathrm{MgO}$ e $7 \%$ de $\mathrm{SiO}_{2}$.

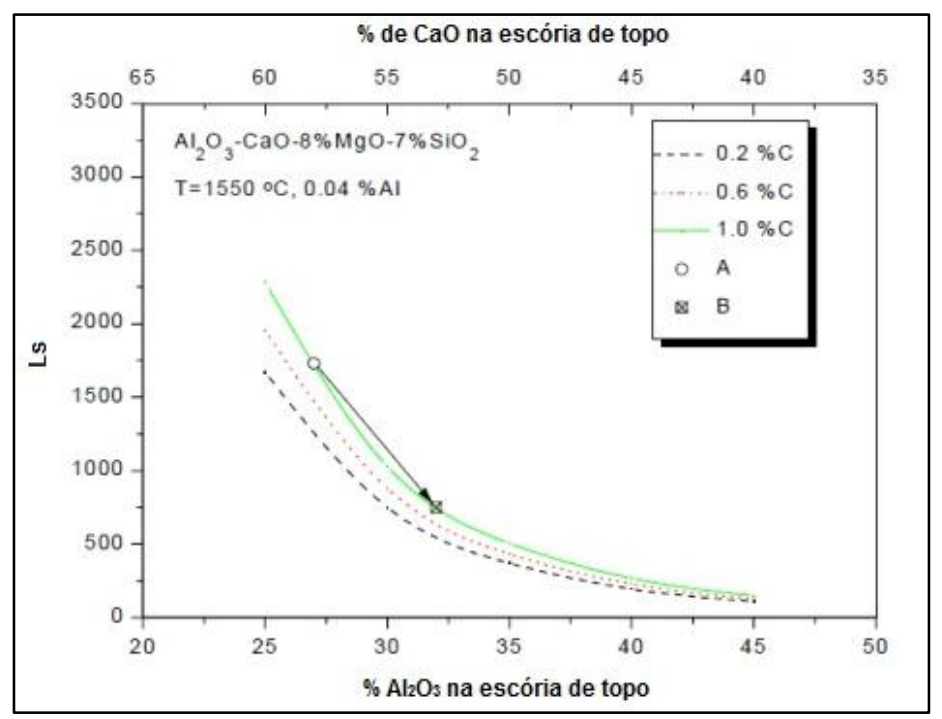

Figura 24. Relação entre a partição de enxofre em função da concentração de $\mathrm{Al}_{2} \mathrm{O}_{3}$ presente na escória. A temperatura é de $1550^{\circ} \mathrm{C}$, o teor de alumínio no aço é $0,04 \%$ e os outros componentes da escória são constante a $8 \%$ de $\mathrm{MgO}$ e $7 \%$ de $\mathrm{SiO}_{2}$.

Observa-se na Figura 23, que com a diminuição da temperatura de $1600^{\circ} \mathrm{C}$ (ponto A) para 1535으 (ponto B), concomitante com o aumento da porcentagem de $\mathrm{Al}_{2} \mathrm{O}_{3}$ de 27 para $32 \%$, ocorre a diminuição da capacidade de sulfeto. Na Figura 24 
pode ser visualizado, que o aumento na proporção de $\mathrm{Al}_{2} \mathrm{O}_{3}$ provoca a diminuição da partição de enxofre. Segundo os autores, a diminuição da capacidade de sulfeto afeta negativamente a partição de enxofre. Além disso, o aumento da atividade de $\mathrm{Al}_{2} \mathrm{O}_{3}$ aumenta a atividade do oxigênio em equilíbrio no metal, favorece a diminuição da partição de enxofre.

Concomitante a estes resultados, Gaye et $a^{(69)}$ também verificaram que o aumento de $\mathrm{Al}_{2} \mathrm{O}_{3}$ em escórias do sistema $\mathrm{CaO}-\mathrm{SiO}_{2}-\mathrm{Al}_{2} \mathrm{O}_{3}$ prejudica o coeficiente de partição de enxofre, conforme mostra a Figura 25.

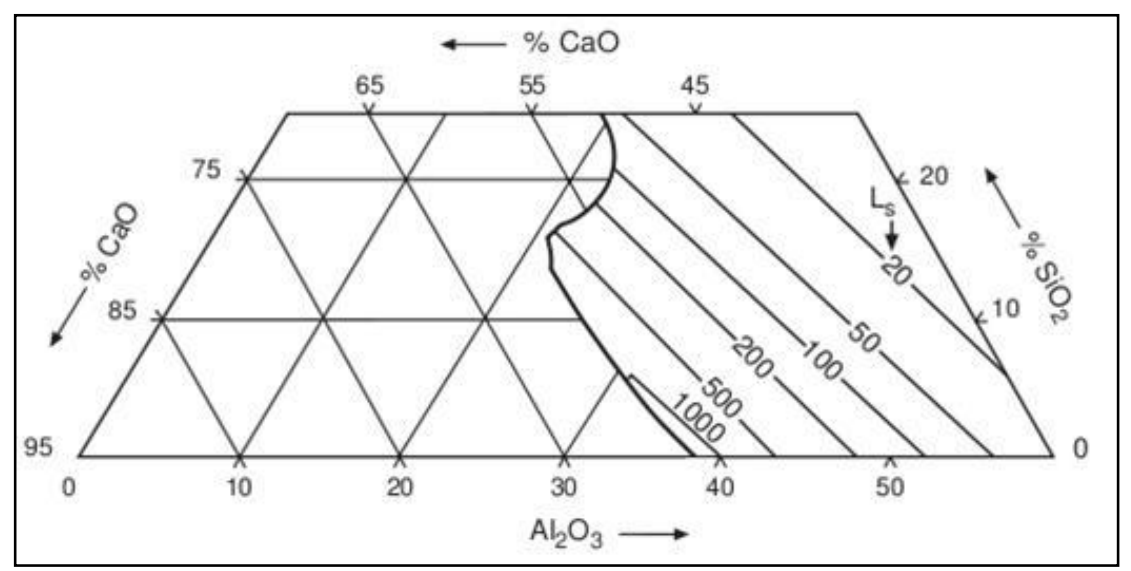

Figura 25. Coeficiente de partição de enxofre do equilibro entre metal e escória. Teor de alumínio de 0,03\%; sistema $\mathrm{CaO}-\mathrm{Al}_{2} \mathrm{O}_{3}-\mathrm{SiO}_{2}(5 \%) \mathrm{MgO}$ a $1625^{\circ} \mathrm{C}$.

Segundo Iwase et $\mathrm{al}^{(71)}$ as escórias do sistema $\mathrm{SiO}_{2}-\mathrm{CaO}-\mathrm{MgO}-\mathrm{Al}_{2} \mathrm{O}_{3}$, com $35 \%$ de $\mathrm{Al}_{2} \mathrm{O}_{3}$, sempre vão coexistir com uma fase sólida de $\mathrm{CaO}$ na temperatura de $1400-1450^{\circ} \mathrm{C}$.

Basicamente, a escória consiste em duas frações: uma fração de líquido e outra fração de sólido. A viscosidade de escórias básicas é controlada por essas duas frações. Quanto maior for o teor da fração sólida, maior é a viscosidade da escória. Por outro lado, a escória completamente líquida possui menor viscosidade $^{(72)}$.

A Figura 26 apresenta a relação entre $\mathrm{Al}_{2} \mathrm{O}_{3} / \mathrm{CaO}$ e a eficiência dessulfurante desenvolvida por Pretorius ${ }^{(51)}$. 


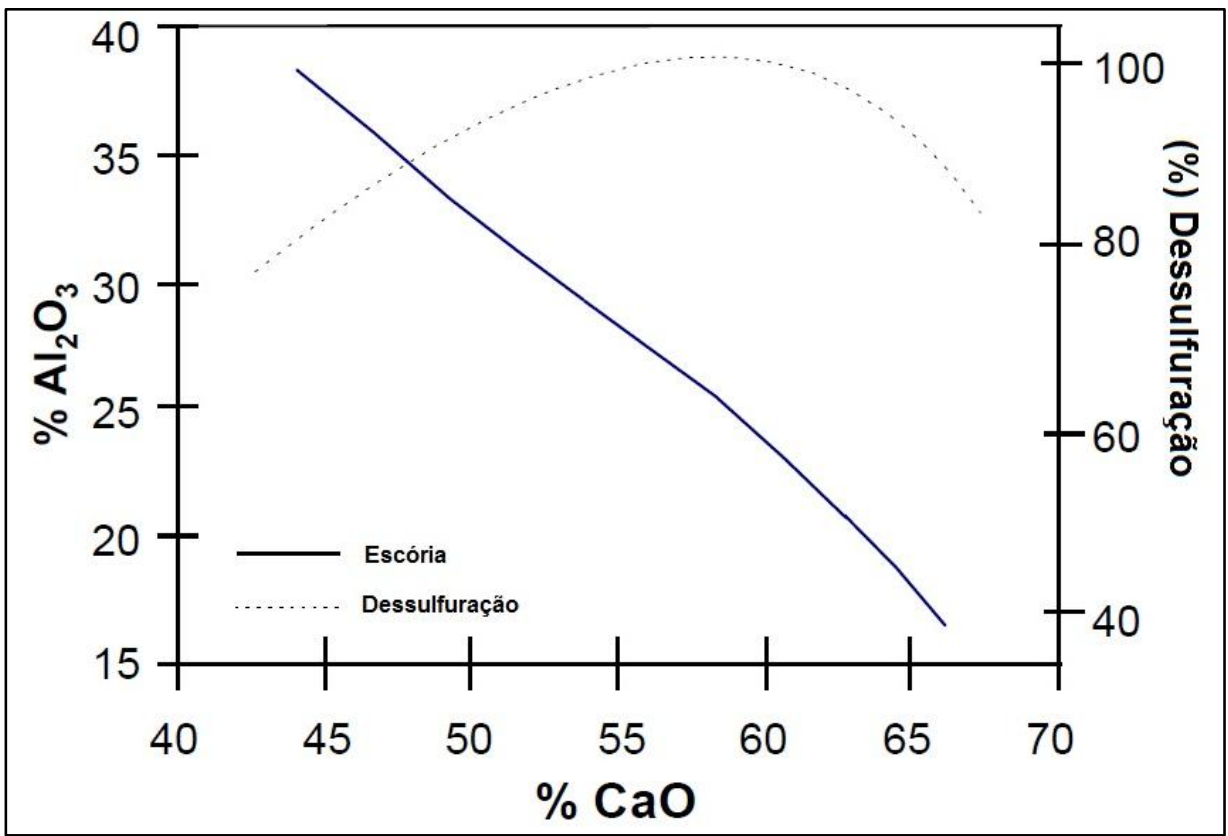

Figura 26. Relação entre a concentração de $\mathrm{Al}_{2} \mathrm{O}_{3}$ e $\mathrm{CaO}$ na taxa de dessulfuração de aço ${ }^{(51)}$.

Observa-se que escórias com concentração de $\mathrm{CaO}$ acima de $60 \%$, tendem a não ser completamente líquidas, o que limita o processo de remoção de enxofre do metal, conforme mostra a Figura 26. Além disso, o aumento da concentração de $\mathrm{Al}_{2} \mathrm{O}_{3}$ diminui a capacidade de sulfeto das escórias ${ }^{(42)}$.

Carlsson et $a{ }^{(73)}$, por sua vez, realizaram um estudo sobre dessulfuração do aço em uma panela de 6 toneladas. Segundo os autores, os melhores resultados de dessulfuração foram atingidos com composição inicial saturada em $\mathrm{CaO}$. Com isso, o $\mathrm{Al}_{2} \mathrm{O}_{3}$ proveniente da desoxidação do aço pode incorporar na escória e promover o aumento da fase líquida. Além disso, melhores condições termodinâmicas foram obtidas com adição de fluoreto de cálcio, uma vez que, houve aumento dos íons $\mathrm{Ca}^{2+}$ na escória.

Matsuzawa e $\operatorname{Harada}^{(74)}$ realizaram experimentos em um forno de resistência, visando comparar escórias do sistema $\mathrm{CaO}-\mathrm{CaF}_{2}$ e $\mathrm{CaO}-\mathrm{Al}_{2} \mathrm{O}_{3}$ no processo de dessulfuração. O comportamento da dessulfuração com as escórias pode ser observado na Figura 27. 


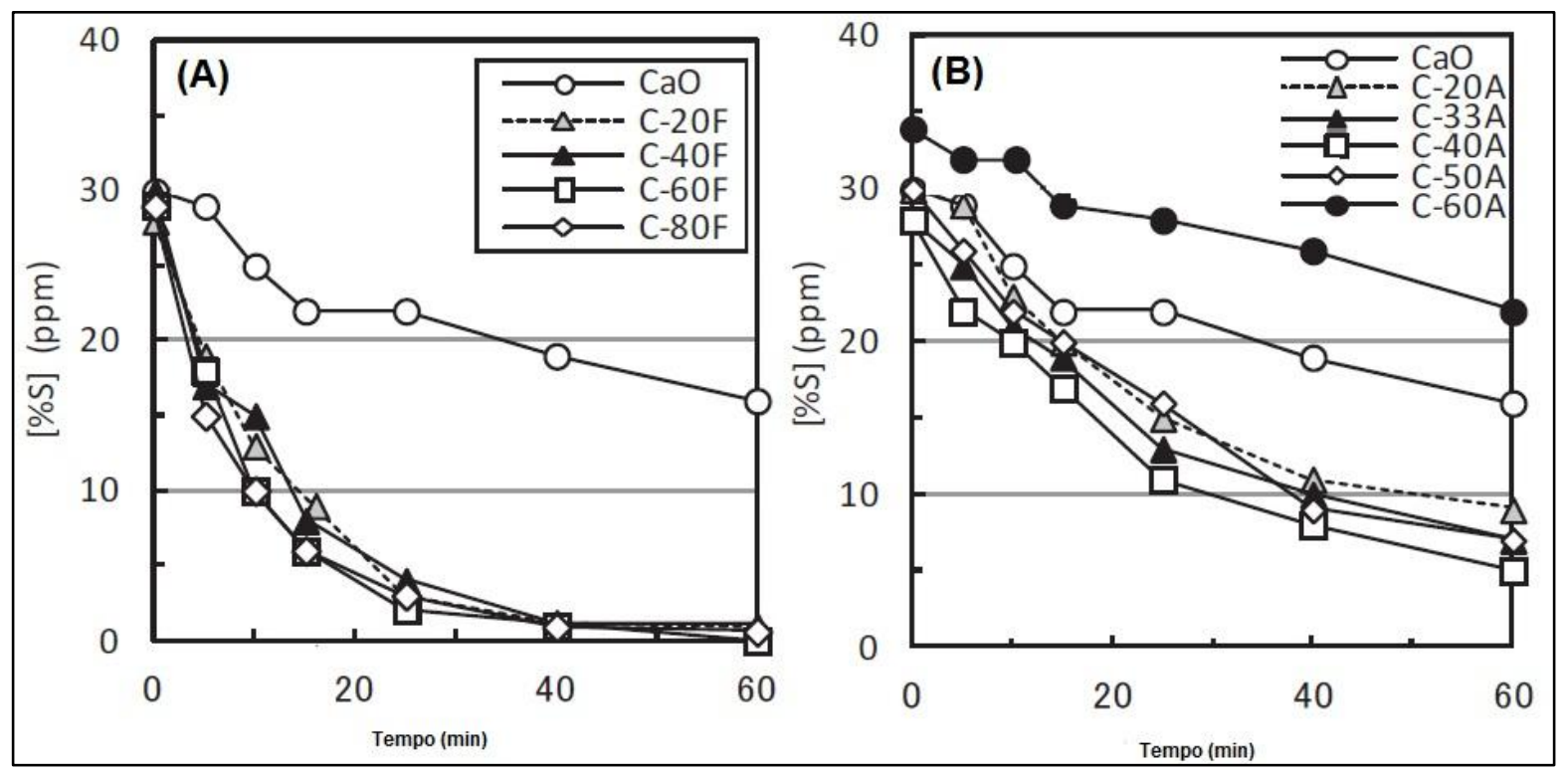

Figura 27. Efeito de escórias do sistema $\mathrm{CaO}-\mathrm{CaF}_{2}(\mathrm{~A})$ e $\mathrm{CaO}-\mathrm{Al}_{2} \mathrm{O}_{3}(\mathrm{~B})$ no processo de dessulfuração de aço na temperatura de $1600^{\circ} \mathrm{C}$.

Analisando a Figura 27 e comparando os resultados obtidos nas escórias com fluorita e com $\mathrm{Al}_{2} \mathrm{O}_{3}$, nota-se que dessulfuração com $\mathrm{Al}_{2} \mathrm{O}_{3}$ é mais lenta do que $\mathrm{CaF}_{2}$. Além disso, escórias com $40 \%$ de $\mathrm{Al}_{2} \mathrm{O}_{3}$ (C-40A) apresentaram os melhores resultados. Valores acima de $40 \%$ de $\mathrm{Al}_{2} \mathrm{O}_{3}$ a dessulfuração foi mais lenta ${ }^{(74)}$.

Neste mesmo trabalho, foi analisado o coeficiente de transporte de massa e a partição de enxofre para as escórias do sistema $\mathrm{CaO}-\mathrm{CaF}_{2}$ e $\mathrm{CaO}-\mathrm{Al}_{2} \mathrm{O}_{3}$. Os resultados podem ser analisados na Figura 28. 


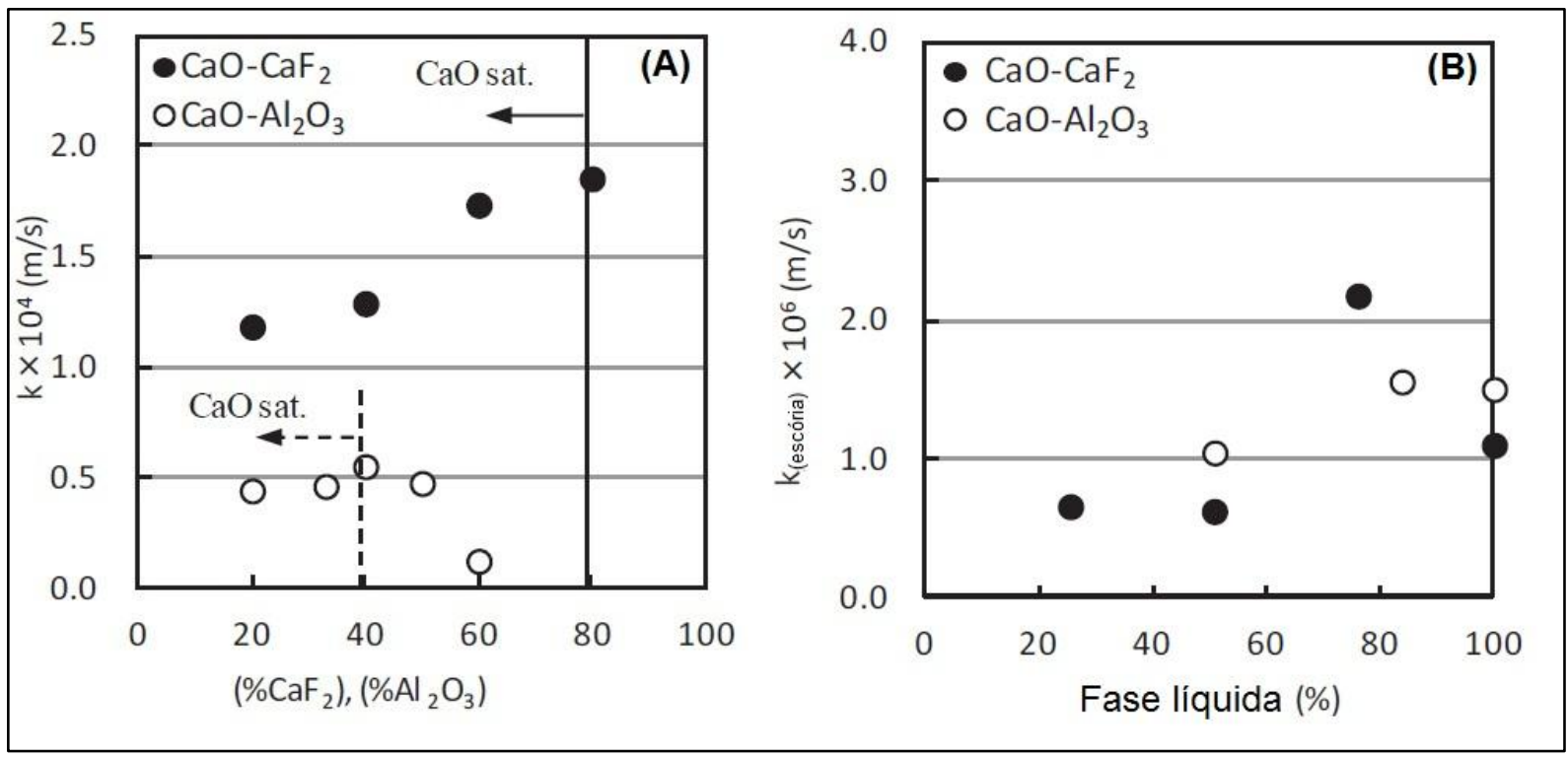

Figura 28. Relação entre $\mathrm{CaF}_{2}$ e $\mathrm{Al}_{2} \mathrm{O}_{3}$ no coeficiente de transporte de massa global(A) e coeficiente de transporte de massa na escória(B).

Observa-se que o valor máximo encontrado do coeficiente de transporte de massa global foi sempre próximo a composição de saturação de $\mathrm{CaO}$ em ambas as escórias $\left(\mathrm{CaF}_{2}\right.$ e $\left.\mathrm{Al}_{2} \mathrm{O}_{3}\right)$. Além disso, é possível observar que o coeficiente de transporte de massa na escória, aumenta com o aumento da fase líquida, em ambas escórias de $\mathrm{CaO}-\mathrm{Al}_{2} \mathrm{O}_{3}$ e $\mathrm{CaO}-\mathrm{CaF}_{2}$. Este resultado sugere que o $\mathrm{CaO}$ sólido afeta negativamente a transferência de enxofre para escória ${ }^{(75,76)}$.

\subsection{ESTUDOS SOBRE A SUBSTITUIÇÃO DA FLUORITA EM ESCÓRIAS DESSULFURANTES}

Como descrito no capítulo 2.6, escórias do sistema $\mathrm{CaO}-\mathrm{Al}_{2} \mathrm{O}_{3}$ despontam como principal alternativa para a substituição da fluortia. Entretanto, alternativas foram propostas em estudos que serão destacados a seguir.

Tribe et $a^{(77)}$ desenvolveu uma série de ensaios em laboratórios, através dos quais propôs a substituição parcial ou total da fluorita por sienito nefelínico (feldspato alcalino, nefelina e clinopiroxênio), comumente conhecido por sodalita. Verificou-se que o comportamento reológico da escória foi semelhante ao de escórias com fluorita. 
Segundo Maclean et a ${ }^{(78)}$, a sodalita tem como principal função a redução da viscosidade da escória. Em outro estudo, Volkmann ${ }^{(79)}$ aplicou a sodalita no convertedor e na panela de refino secundário. Em ambos os casos, não houve nenhuma alteração dos resultados nas reações de refino. Segundo o autor, o teor de sílica presente na sodalita impede a utilização em excesso nas escórias, para não prejudicar a capacidade dessulfurante das escórias.

Segundo Silva ${ }^{(80)}$, a sodalita é, essencialmente, um sílico-aluminato enriquecido em álcalis $\left(\mathrm{Na}_{2} \mathrm{O}\right.$ e $\left.\mathrm{K}_{2} \mathrm{O}\right)$. Apresenta teores em torno de $50 \%$ de $\mathrm{SiO}_{2}$, $23 \%$ de $\mathrm{Al}_{2} \mathrm{O}_{3}, 12 \%$ de $\mathrm{Na}_{2} \mathrm{O}, 5 \%$ de $\mathrm{K}_{2} \mathrm{O}$ e teores residuais de $\mathrm{Fe}_{2} \mathrm{O}_{3}, \mathrm{MgO}, \mathrm{CaO}$ e $\mathrm{TiO}_{2}$. Silva ${ }^{(80)}$ também realizou ensaios em uma estação de tratamento de uma usina semi-integrada. Os resultados indicaram que a substituição de fluorita por sodalita apresentou vantagem econômica, devido à diferença de preço entre os dois materiais (sodalita custa em média $60 \%$ do valor da fluorita). Além disso, a escória gerada no tratamento de dessulfuração está livre de flúor, o que se trata de uma vantagem no aspecto ambiental.

Singh et $a^{(81)}$ realizaram ensaios industriais para mostrar o efeito do uso do ilmenite (mineral de ferro-titânio $\mathrm{FeTiO}_{3}$ ) no processo de dessulfuração. Segundo os autores, $\mathrm{F} \mathrm{FeTiO}_{3}$ pode ser utilizado como substituto da fluorita. Poggi e Lee ${ }^{(82)}$ também constataram que a fluorita e $\mathrm{FeTiO}_{3}$ tem ponto de fusão próximos (1360 e $1365^{\circ} \mathrm{C}$, respectivamente), além de garantir fluidez da escória com a alteração da temperatura.

Amini et a ${ }^{(83)}$ compararam o uso de sodalita, fluorita e ilmenite na dissolução do $\mathrm{CaO}$ em escória do sistema $\mathrm{CaO}-\mathrm{Al}_{2} \mathrm{O}_{3}-\mathrm{SiO}_{2}$. As escórias foram analisadas por Microssonda Eletrônica (EPMA). Segundo os autores, a ilmenite é mais eficaz que a sodalita. Além disso, na temperatura de $1500^{\circ} \mathrm{C}$ uma camada de trissilicato dicálcio sólida é observada na interface $\mathrm{CaO} / \mathrm{escó}$ ria, fato este não encontrado na temperatura de $1600^{\circ} \mathrm{C}$. Por fim, os autores concluem que tanto a ilmenite quanto a sodalita podem ser utilizados no aumento da dissolução do $\mathrm{CaO}$.

Em outro estudo, Dong et $a^{(84)}$ realizaram ensaios com escórias do sistema CaO- $-\mathrm{Al}_{2} \mathrm{O}_{3}-\mathrm{SiO}_{2}-\mathrm{TiO}_{2}$, visando aproveitar resíduos à base de óxidos de titânio. $\mathrm{A}$ influência encontrada da basicidade, concentração de $\mathrm{Al}_{2} \mathrm{O}_{3}$ e $\mathrm{TiO}_{2}$ na partição e viscosidade é mostrada na Figura 29. 


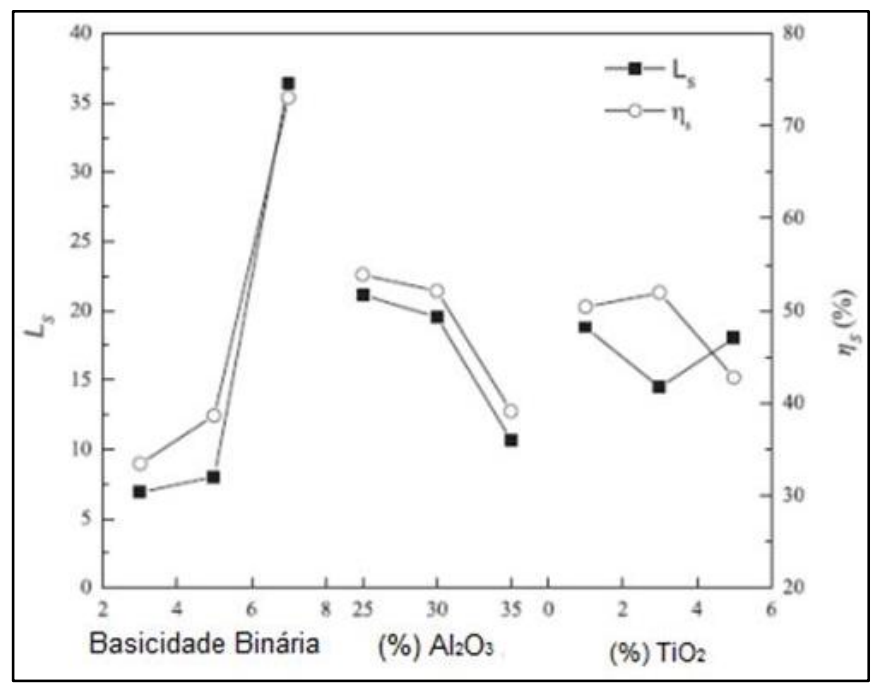

Figura 29. Efeito da basicidade binária, (\%) $\mathrm{Al}_{2} \mathrm{O}_{3}$ e $\mathrm{TiO}_{2}$ na partição de enxofre e viscosidade de escória.

Segundo os autores, à medida que ocorre o aumento de óxido básico ( $\mathrm{CaO})$, ocorre à divisão das redes de $\mathrm{SiO}_{2}$ em grupos de ânions menores e a proporção de íons de oxigênio aumenta $\left(\mathrm{O}^{2-}\right)$, tendo como efeito o aumento da viscosidade e partição. Também foi observado que o aumento da quantidade de alumina diminui a partição de enxofre. Por fim, verificou-se que não ocorre nenhuma mudança substancial na partição e na viscosidade com o aumento do óxido de titânio. Por outro lado, este mesmo óxido, em maiores basicidades tende a existir na forma de $\mathrm{TiO}_{6}^{8-}$. Portanto, $\mathrm{O} \mathrm{TiO}_{2}$ em escórias forma os ânions que fazem os íons de $\mathrm{O}^{2-}$ diminuirem, atuando como óxido ácido em escórias básicas, ou seja, diminuindo a atividade do $\mathrm{CaO}$ e prejudicando o processo de dessulfuração. Resultado também compartilhado por Sommerville e Bell ${ }^{(85,86)}$.

\subsection{CINÉTICA DO PROCESSO DE DESSULFURAÇÃO}

A velocidade em que o enxofre é removido do metal até atingir o equilíbrio, é função da diferença entre a concentração instantânea de enxofre, teor de enxofre final e de equilíbrio de acordo com a Equação $24^{(87)}$.

$$
\frac{d \underline{S}}{d t}=K\left(\underline{S}-\underline{S}_{e q}\right)
$$


Onde: $\underline{S}=$ Concentração ou porcentagem de enxofre no aço, no tempo t;

$\underline{S}_{\text {eq }}=$ Concentração ou porcentagem de enxofre, no aço no equilíbrio;

$\mathrm{k}=$ constante cinética

A partir da integração da Equação 25 , é possível obter a relação para 0 cálculo do coeficiente de transporte de massa global do enxofre $(k)$, conforme mostrado a Equação 25.

$$
\ln \left(\frac{\left[\% S_{0}\right]-\left[\% S_{e q}\right]}{\left[\% S_{t}\right]-\left[\% S_{e q}\right]}\right)=k . t
$$

Onde,

\% $\mathrm{S}_{0}$ : Concentração de enxofre inicial no metal;

\%S eq: Concentração de enxofre de equilíbrio no metal;

\%ST: Concentração de enxofre no tempo "t" no metal.

Derivando a Equação 25 é possível determinar a porcentagem de enxofre (Equação 26).

$\% S_{t}=\% S_{e q}+\left(\% S_{0}-\% S_{e q}\right) \cdot e^{-k t}$

Com isso, a constante cinética $(\mathrm{k})$ pode ser determinada experimentalmente para um determinado processo e temperatura. A mesma terá influência no grau de oxidação do metal. Quanto maior o teor de oxigênio, menor será a velocidade da reação. Por outro lado, quanto mais rápida a reação, maior o valor da constante (k).

Choi et $a^{(88)}$ avaliaram o transporte de massa do enxofre desde o seio do banho metálico até a interface metal-escória usando escórias do sistema $\mathrm{CaO}-\mathrm{SiO}_{2}$ $\mathrm{Al}_{2} \mathrm{O}_{3}-\mathrm{Na}_{2} \mathrm{O}$ e propuseram o seguinte modelo, conforme Equação 27:

$$
-\frac{d[\% S]}{d t}=\left(k_{m}+k_{s} \cdot L_{s}+k_{f}\right) \cdot\left(\frac{A}{V_{m}}\right) \cdot\left\{[\% S]-[\% S]_{e q}\right\}
$$

Onde:

$k$ : Coeficiente de transferência de massa do enxofre $(\mathrm{m} / \mathrm{s})$. 
$m, s, f$ : Denotam a fase metal, a fase escória e a interface metal-escória, respectivamente.

$A$ : Área Interfacial $\left(\mathrm{m}^{2}\right)$.

$V_{m}=$ Volume de metal $\left(\mathrm{m}^{3}\right)$.

De acordo com os autores ${ }^{(88)}$, o coeficiente global de transferência de massa $\left(k^{\prime}\right)$ o qual é representado pelo termo $\left(k_{m}+k_{s} \cdot L_{s}+k_{f}\right)$, é dependente da temperatura e composição química da escória. Os valores de $k^{\prime}$ encontrados pelos autores variaram de $0,5 \cdot 10^{-5}$ a $5 \cdot 10^{-5} \mathrm{~m} / \mathrm{s}$, na temperatura dos testes realizados $\left(1350{ }^{\circ} \mathrm{C}\right)$. A Figura 30 mostra uma comparação entre os valores calculados pelo modelo (Equação 28) e medidos experimentalmente.

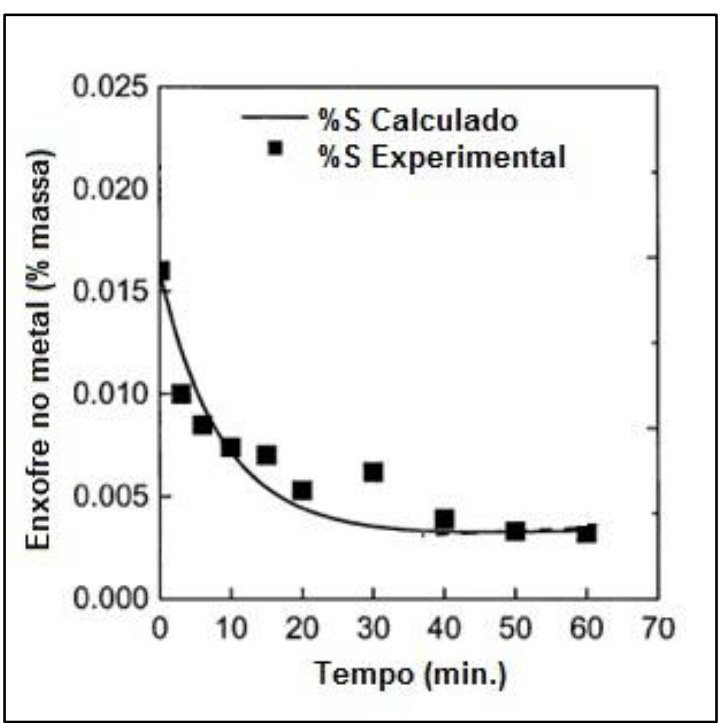

Figura 30. Comparação entre os teores de enxofre calculados pelo modelo proposto e os encontrados nos experimentos ${ }^{(88)}$.

Os dados de Choi et a/ ${ }^{(88)}$ mostram que os resultados da taxa de dessulfuração calculados pelo modelo matemático estão próximos dos resultados obtidos pelos experimentos práticos.

Seshadri et al ${ }^{(89)}$ aplicaram um modelo cinético ao processo de dessulfuração de ferro-gusa através da injeção de mistura contendo $\mathrm{CaO}$ pulverizada. De acordo com os autores, a dessulfuração é melhorada com o aumento da temperatura, do volume de escória de topo, da área interfacial metal-escória, da profundidade de injeção da mistura e diminuição do tamanho da partícula. 
Em estudo mais recente, Muhmood et $a l^{(90)}$ analisaram a difusividade do enxofre na escória do sistema $\mathrm{CaO}-\mathrm{Al}_{2} \mathrm{O} 3-\mathrm{SiO}_{2}$. Para o desenvolvimento do modelo foram utilizados parâmetros como: coeficiente de difusão, capacidade de sulfeto, partição de enxofre e densidade de escória. Os resultados levaram a concluir que o decréscimo do $\mathrm{SiO}_{2}$ na escória, aumentou o coeficiente de difusão do enxofre e proporcionou o aumento da taxa de dessulfuração.

Yan et $a^{(91)}$ desenvolveram um modelo cinético para prever a evolução do teor de enxofre em função do tempo no aço. Segundo os autores, os valores encontrados pelo modelo apresentaram concordância com os valores experimentais. O modelo simplificado proposto é apresentado na Equação 28:

$\ln =\left\{\left(L s+\frac{W_{m}}{W_{s}}\right)[S]^{t}-\frac{W_{m}}{W_{S}}[S]^{0}\right\}=-\frac{A \cdot p_{s} \cdot k_{s}}{W_{m}}\left(L s+\frac{W_{m}}{W_{s}}\right) t+\ln \left\{L s \cdot[S]^{0}\right\}$

Onde:

Ls : partição de enxofre;

$A$ : Área de contato entre metal e escória $\left(\mathrm{m}^{2}\right)$;

$W_{m} ; W_{s}$ : massa de metal e escórias, respectivamente $(\mathrm{kg})$;

$\mathrm{p}_{\mathrm{s}}$ : Densidade da escória $\left(\mathrm{kg} / \mathrm{m}^{3}\right)$;

$\mathrm{t}:$ Tempo (s);

$\mathrm{k}_{\mathrm{s}}$ : Coeficiente de transporte de massa $(\mathrm{m} / \mathrm{s})$;

$\mathrm{O} \mathrm{k}_{\mathrm{S}}$ pode ser calculado utilizando as seguintes reações (Equações 29 e 30):

$k_{s}=\frac{S h \cdot D_{S}}{L}$

e

$$
D_{s}=\frac{k_{B} T}{\mu \lambda}
$$

Onde:

Sh: número de Sherwood; 
$D_{s}$ : Coeficiente de difusão de enxofre na escória $\left(\mathrm{m}^{2} / \mathrm{s}\right)$;

$L$ : Comprimento característico $(\mathrm{m})$;

$k_{B}$ : Constante de Boltzmann $(\mathrm{J} / \mathrm{K})$;

$\mu$ : Viscosidade da escória $(\mathrm{Pa} / \mathrm{s})$;

$\lambda$ : Distancia interatômica $(m)$.

Os resultados da aplicação do modelo em comparação com os dados experimentais podem ser visualizados na Figura 31.

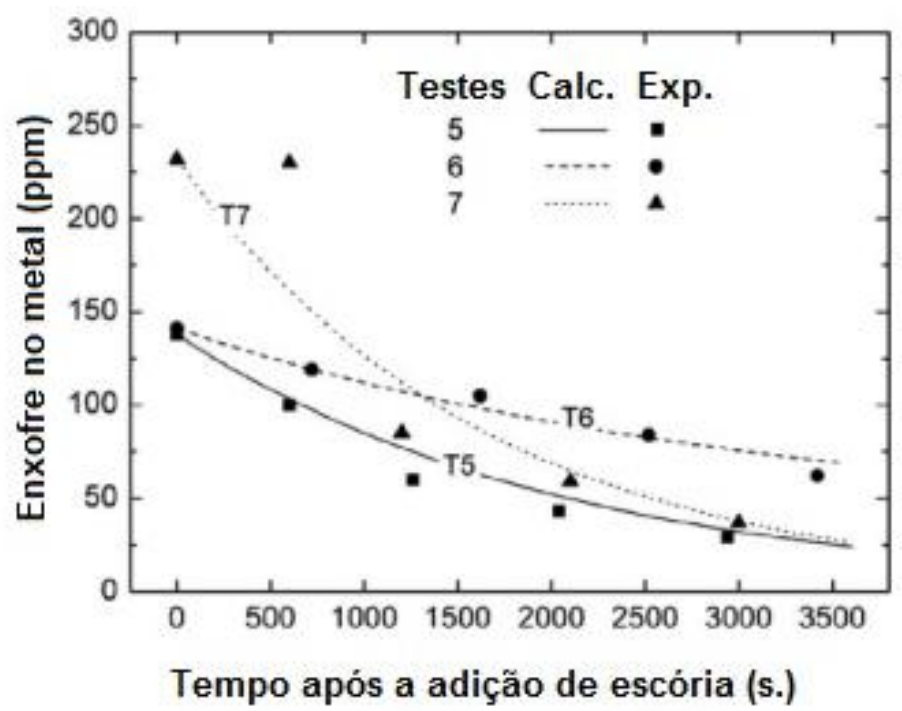

Figura 31. Comparação entre os teores de enxofre calculados e os encontrados experimentalmente.

Observa-se que os resultados calculados estão próximos aos encontrados nos experimentos, mostrando a possibilidade de aplicar este modelo ao processo de dessulfuração de aço na panela.

Por fim, Xu et a $a^{(92)}$ estudaram a taxa de dessulfuração de escórias à base de $\mathrm{CaO}-\mathrm{CaF}_{2}$. Verificaram que o aumento da fluorita até $10 \%$, proporcionou o aumento da taxa de remoção do enxofre no ferro-gusa. 


\subsection{USO DO RESÍDUO DE MÁRMORE EM ETAPAS DO PROCESSO DE FABRICAÇÃO DE AÇO}

O resíduo de mármore é gerado durante o processo de beneficiamento do mármore nas serrarias. É composto basicamente de carbonatos de cálcio e magnésio. Devido aos seus teores de $\mathrm{CaO}$ e $\mathrm{MgO}$ presentes e sua baixa granulometria, o resíduo de mármore apresenta características que permitem sua utilização em substituição a cal convencional e cal dolomítica.

Aguiar $^{(93)}$ aplicou o resíduo de mármore em escórias dessulfurantes de ferro-gusa. Em misturas de resíduo de mármore com barrilha e fluorita, a eficiência dessulfurante foi de 48,2 e 54\%, respectivamente. Segundo o autor, essas escórias com resíduo reúnem características termodinâmicas para serem utilizadas no processo de dessulfuração de ferro-gusa durante o pré-tratamento.

Aguiar ${ }^{(93)}$, em seu estudo, apresenta que uma possível restrição do uso do resíduo seria a decomposição dos carbonatos de cálcio $\left(\mathrm{CaCO}_{3}\right)$ e de magnésio $\left(\mathrm{MgCO}_{3}\right)$. Isto porque, esta decomposição é endotérmica e afetaria a temperatura do metal, retardando a reação. As reações de decomposição dos carbonatos são apresentadas nas Equações 31 e 32.

$$
\begin{aligned}
& \mathrm{CaCO}_{3(S)}=(\mathrm{CaO})+\mathrm{CO}_{2(g)} \\
& \Delta G_{31}^{0}=41769-36,19 T(\mathrm{cal}) \\
& \mathrm{MgCO}_{3(S)}=(\mathrm{MgO})+\mathrm{CO}_{2(\mathrm{~g})} \\
& \Delta G_{32}^{0}=27237-39,72 T(\mathrm{cal})
\end{aligned}
$$

Entretanto, foi observado que a decomposição dos carbonatos aumenta a agitação do sistema metal/escória, favorecendo o transporte de massa, o que pode compensar a redução da taxa de transporte de massa causada pela queda da temperatura. Além disso, a presença do $\mathrm{MgO}$ no resíduo de mármore também é um ponto favorável à sua utilização em escórias, pois este diminui o desgaste de refratários durante o processo de desfosforação, que também são à base de MgO. 


\subsection{TERMODINÂMICA COMPUTACIONAL APLICADA AO PROCESSO DE DESSULFURAÇÃO.}

Bielefeld ${ }^{(94)}$ aborda que nos últimos anos ocorreu o aumento do uso dos softwares termodinâmicos. Entretanto, em muitos casos não é realizada uma formulação correta do problema que se deseja analisar. Parte dos problemas é decorrente da falta de conhecimentos termodinâmicos para analisar os resultados fornecidos.

Oertel e Silva ${ }^{(95)}$ indicam que o equilíbrio entre metal/escória ou gás/escória é um cálculo que apresenta certa complexidade. Sendo assim, os softwares de termodinâmica computacional atuam de forma a facilitar as análises do equilíbrio, bem como identificar as fases presentes no metal e na escória.

Moraes et $a^{(96)}$ destacam que softwares de termodinâmica computacional tem sido empregados na avaliação de fenômenos que ocorrem nas interfaces metal líquido-escória, metal líquido-inclusões e escória-inclusões no processo de refino do aço.

Grillo et $a l^{(97,98)}$ realizaram uma análise termodinâmica de misturas dessulfurantes à base de cal convencional através do uso da termodinâmica computacional. Os resultados mostraram que a utilização apenas de parâmetros termodinâmicos clássicos $\left(C_{s}, L_{s}\right.$ e $\left.\Lambda\right)$, em algumas situações, pode levar à conclusões precipitadas sobre a eficiência dessulfurante de diferentes misturas. Além disso, os modelos de $C_{s}$, $L_{s}$ e basicidade ótica ficam restritos a composição e temperatura em que foram criados, limitando sua aplicação.

Sampaio ${ }^{(99)}$ realizou análise comparativa entre os resultados obtidos pelos softwares de termodinâmica computacional (Thermo-Calc e Factsage) e os modelos termodinâmicos presentes na literatura $\left(C_{s}, L_{s}\right.$ e $\left.\Lambda\right)$ nas etapas de dessiliciação, dessulfuração e desfosforação no pré-tratamento do ferro-gusa. Segundo o autor, os softwares de termodinâmica computacional mostraram-se úteis na avaliação da etapa de dessiliciação, dessulfuração e desfosforação de ferro-gusa, uma vez que, na ausência de parâmetros termodinâmicos que visam a análise deste processo, tais softwares auxiliam tanto na avaliação termodinâmica quanto na identificação de variáveis cinéticas (fase líquida e sólida, viscosidade) que podem vir a limitar a reação de dessiliciação. 


\section{OBJETIVOS}

Este trabalho tem por objetivo propor escórias sintéticas para o processo de dessulfuração de ferro-gusa, aço e ferro fundido, visando a substituição da fluorita por $\mathrm{Al}_{2} \mathrm{O}_{3}$ ou sodalita e o resíduo de mármore em substituição a cal convencional. Além disso, comparar os resultados obtidos por software termodinâmico computacional e por modelos da literatura $\left(C_{s}, L_{s}\right.$ e $\left.\Lambda\right)$ com os dados experimentais. 


\section{MATERIAIS E MÉTODOS}

Neste capítulo serão descritos os procedimentos e as condições adotadas para a obtenção dos resultados. Inicialmente, é apresentada a metodologia experimental para a caracterização das matérias-primas que compõem as escórias. Em seguida, descritas as escórias desenvolvidas neste trabalho. Por fim, o aparato experimental e as condições adotadas serão detalhados. Na Figura 32 pode ser visualizada as principais etapas da metodologia deste trabalho.

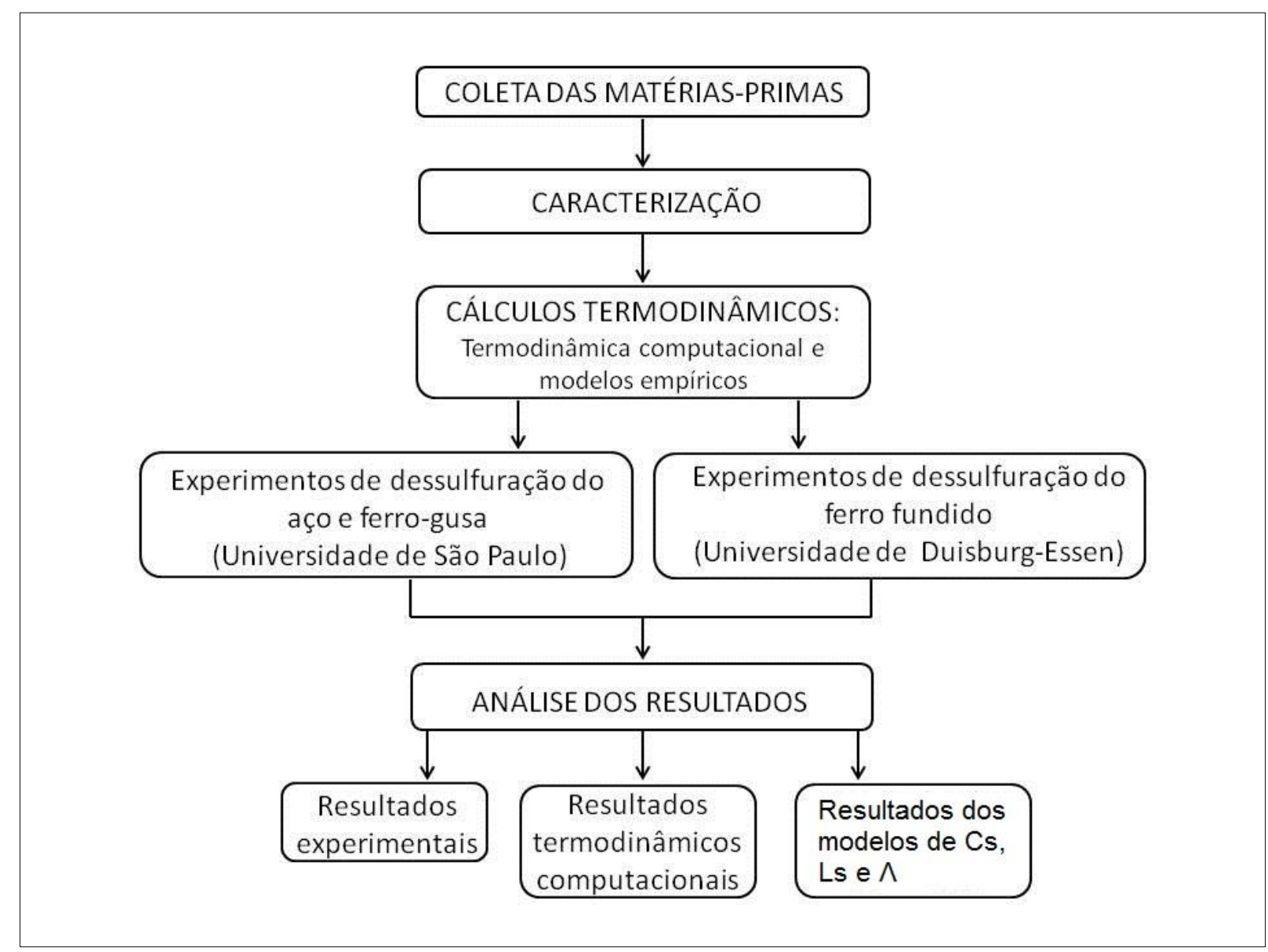

Figura 32. Fluxograma simplificado das principais etapas desenvolvidas neste trabalho.

Cada etapa descrita no fluxograma da Figura 32 será detalhada nos próximos itens. 


\subsection{AQUISIÇÃO DOS MATERIAIS E EQUIPAMENTOS}

Neste estudo, foram utilizados tijolos de magnésio carbono ( $\mathrm{MgO}-\mathrm{C}$ ) normalmente usados em linha de escória de conversores LD, fornecidos pela empresa ArcellorMittal Tubarão. Com esses tijolos foram fabricados os cadinhos utilizados na fusão do aço e ferro-gusa. Para isso, foram efetuados furos nos tijolos de magnésio carbono ( $\mathrm{MgO}-\mathrm{C}$ ) com broca do tipo serra copo. Na Figura 33 pode-se observar, sequencialmente, as etapas de fabricação dos cadinhos.
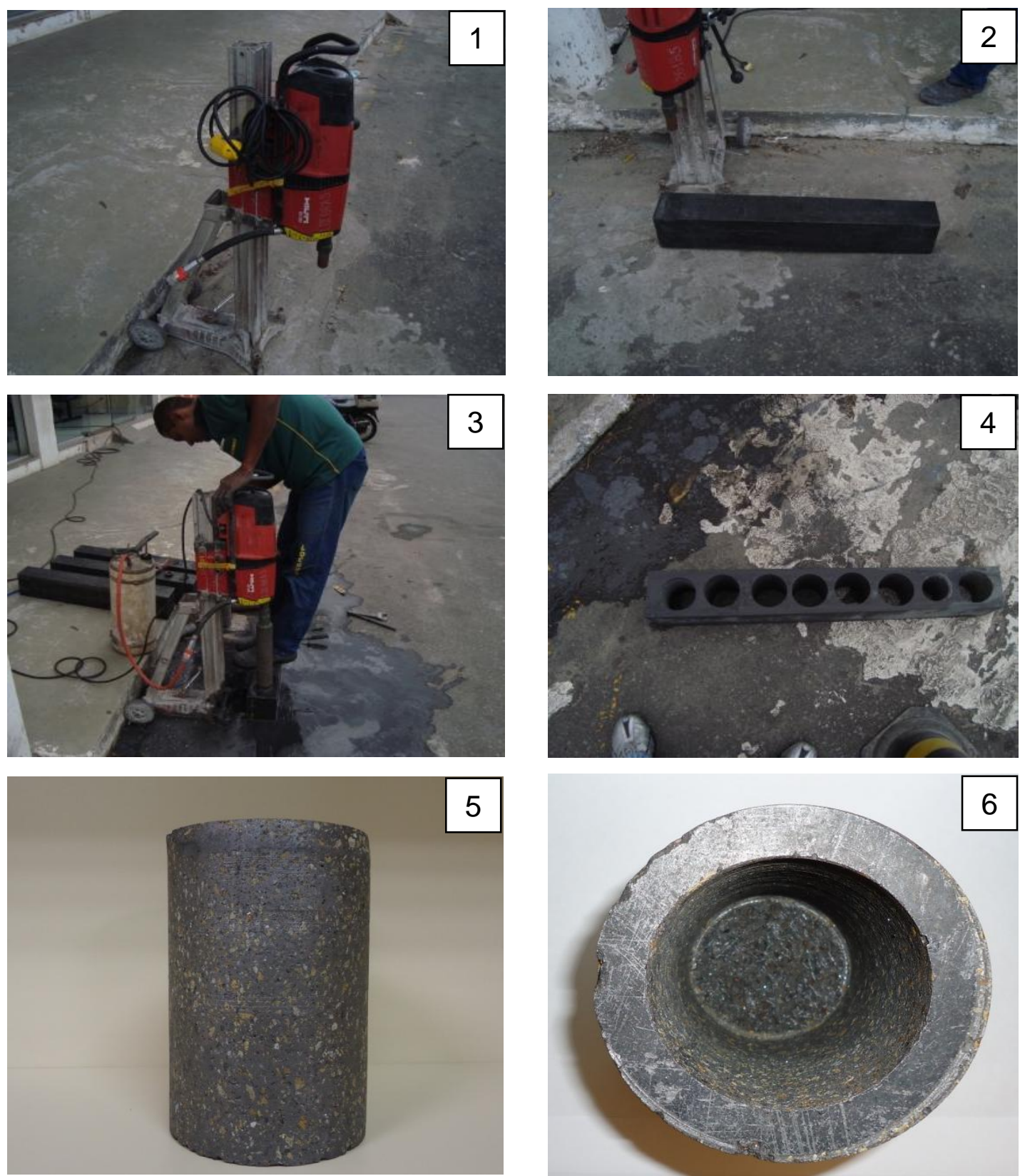

Figura 33. Sequência de procedimentos para a fabricação dos cadinhos de MgO-C. 
Os cadinhos foram produzidos com dimensões de $70 \mathrm{~mm}$ de diâmetro interno, $90 \mathrm{~mm}$ de diâmetro externo e $110 \mathrm{~mm}$ de altura. Um croqui dos cadinhos pode ser visto na Figura 34.

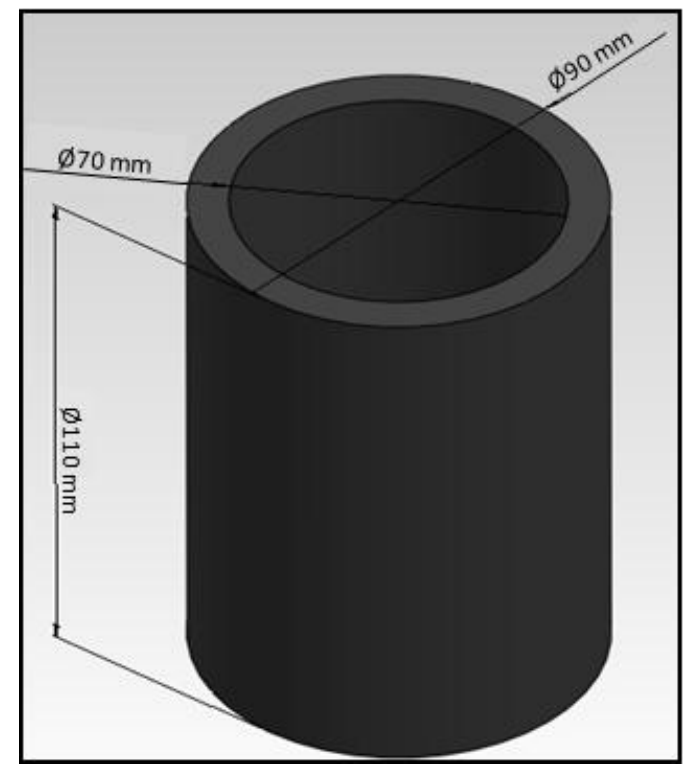

Figura 34. Croqui dos cadinhos de $\mathrm{MgO}$ carbono.

O resíduo de mármore foi fornecido pela empresa Mineração Capixaba, sendo o mesmo coletado em um tanque de decantação. Após a coleta, o resíduo foi seco em temperatura ambiente e, em seguida, homogeneizado e quarteado.

A fluorita, $\mathrm{Al}_{2} \mathrm{O}_{3}$ e $\mathrm{MgO}$ foram fornecidos pela ArcelorMittal Tubarão.

A sodalita e a cal convencional foram fornecidas pela empresa Tecnosulfur.

Para promover a agitação mecânica do banho metálico, foi adquirido um agitador mecânico, conforme mostrado na Figura 35. 

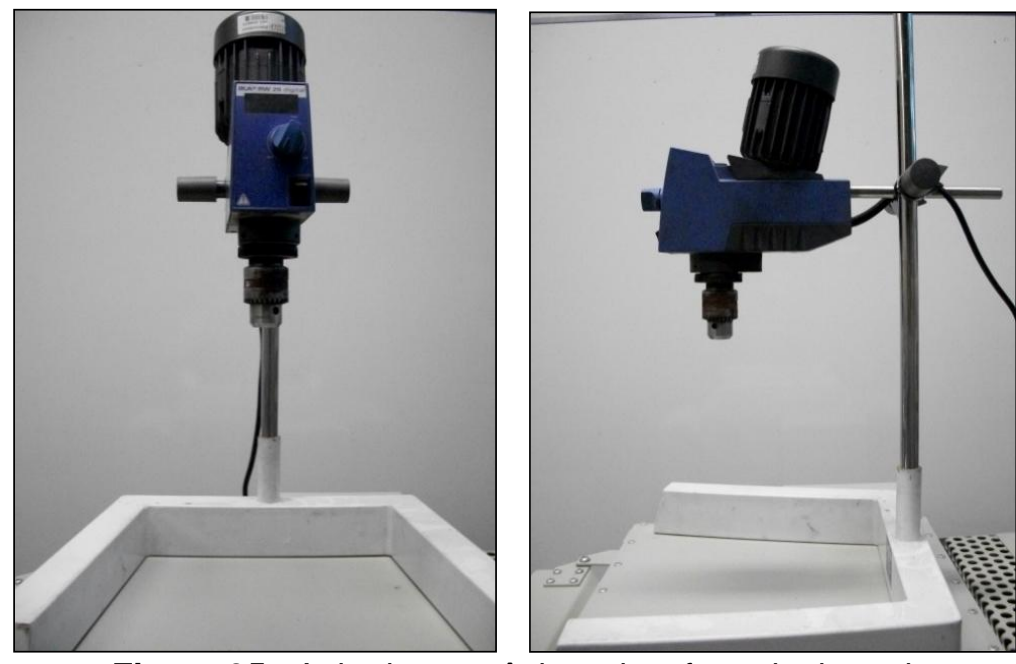

Figura 35. Agitador mecânico, vista frontal e lateral.

Utilizou-se um rotor de alumina $\left(\mathrm{Al}_{2} \mathrm{O}_{3}\right)$ por experimento, com dimensões apresentadas na Figura 36. O rotor foi dimensionado de forma que fosse possível promover uma melhor agitação do metal líquido.
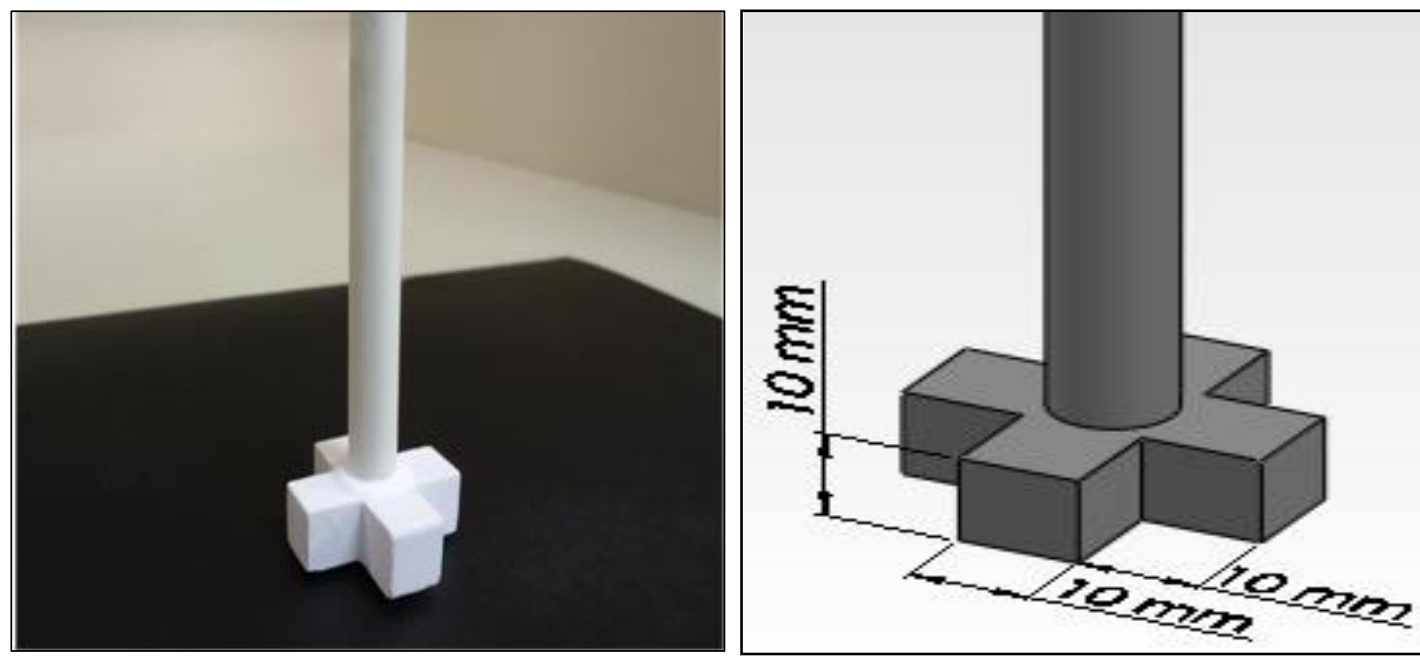

Figura 36. Rotor de alumina de alta pureza e croqui.

Outros materiais também foram utilizados no desenvolvimento da etapa experimental, a saber:

$>$ Tubos de Alumina para injeção de argônio sobre a superfície do banho;

> Funil de aço inoxidável: para adicionar as escórias sintéticas;

> Tenaz: para fazer a movimentação do cadinho de MgO-C no forno. 


\subsection{CARACTERIZAÇÃO DOS MATERIAIS}

Os insumos utilizados na fabricação das escórias sintéticas foram submetidos a seguintes técnicas de caracterização:

1) Análise química;

2) Análise granulométrica;

3) Difração de raios- $X$;

4) Microscopia eletrônica de varredura (MEV);

5) Análise por dispersão de energia (EDS); e

6) Análise de superfície específica e porosidade (ASAP).

Nenhum dos materiais que compõem as misturas sofreu qualquer tipo de pré-tratamento (físico, químico ou mecânico), com exceção da retirada da umidade. Todos os resíduos foram secos em estufa a $100^{\circ} \mathrm{C}$, durante três horas, para a eliminação da umidade.

\subsubsection{Análise química}

A análise química foi realizada para confirmar os teores dos elementos presentes no resíduo de mármore e nos demais materiais (Sodalita, $\mathrm{CaO}, \mathrm{Al}_{2} \mathrm{O}_{3}$, $\mathrm{SiO}_{2}$ e $\mathrm{MgO}$ ). O equipamento utilizado foi o espectrômetro de fluorescência de raios-X por energia dispersiva (EDXRF), da marca PANalytical, modelo Epsilon 3-XL anodo de Ag. Utilizou-se o método semi-quantitativo utilizando o software Omnian $^{(100)}$. Os resultados destas análises foram comparados com os dados sobre a composição química dos materiais fornecidos pelas empresas que cederam as amostras.

\subsubsection{Análise granulométrica}

A análise granulométrica dos materiais utilizados neste trabalho foi necessária para avaliar a distribuição dos tamanhos das partículas, assim como o diâmetro médio destas. $\mathrm{O}$ equipamento empregado consistiu em um analisador de tamanho 
de partículas (MALVERN Mastersizer 2000), que utiliza difração de raio "laser" para medir o diâmetro das partículas. A amostra foi exposta ao ultrassom durante cinco minutos, sendo a água o meio de dispersão utilizado.

\subsubsection{Difração de raios-X}

Utilizou-se a difração de raios- $X$ para a determinação dos compostos presentes no resíduo de mármore usadas na fabricação das misturas. Para a análise mineralógica difratométrica, foi utilizado um difratômetro X'PERT da marca PHILLIPS com radiação cobre Ka.

\subsubsection{Microscopia eletrônica de varredura e EDS}

Para este tipo de análise foi utilizado o Microscópio Eletrônico de Varredura modelo XL - 30 Philips, que possui acoplado um detector de microssonda para análise de energia dispersiva de fluorescência de raios- $X$. Através deste equipamento, foi possível observar a morfologia das partículas e o aspecto topográfico dos materiais. Amostras de resíduo de mármore e sodalita foram colocadas numa fita dupla face e em seguida inseridas no porta amostra.

\subsubsection{Análise de superfície específica e de porosidade}

Os materiais utilizados na formulação das escórias sintéticas foram submetidos à análise de superfície específica e porosidade. $O$ equipamento utilizado foi o Micrometics ASAP 2020. 


\subsection{PREPARAÇÃO DAS MISTURAS DESSULFURANTES}

Neste tópico serão detalhadas as etapas desenvolvidas para formular as misturas dessulfurantes.

\subsubsection{Preparação de misturas dessulfurantes de aço}

Inicialmente, foram realizadas simulações no software termodinâmico Thermo-Calc, visando obter misturas dessulfurantes com potencial termodinâmico para diminuir o teor de enxofre no aço entre 1 a 10 ppm. Para isso, a curva apresentada na Figura 37 foi gerada pelo Thermo-Calc e utilizada para dimensionar as escórias sintéticas.

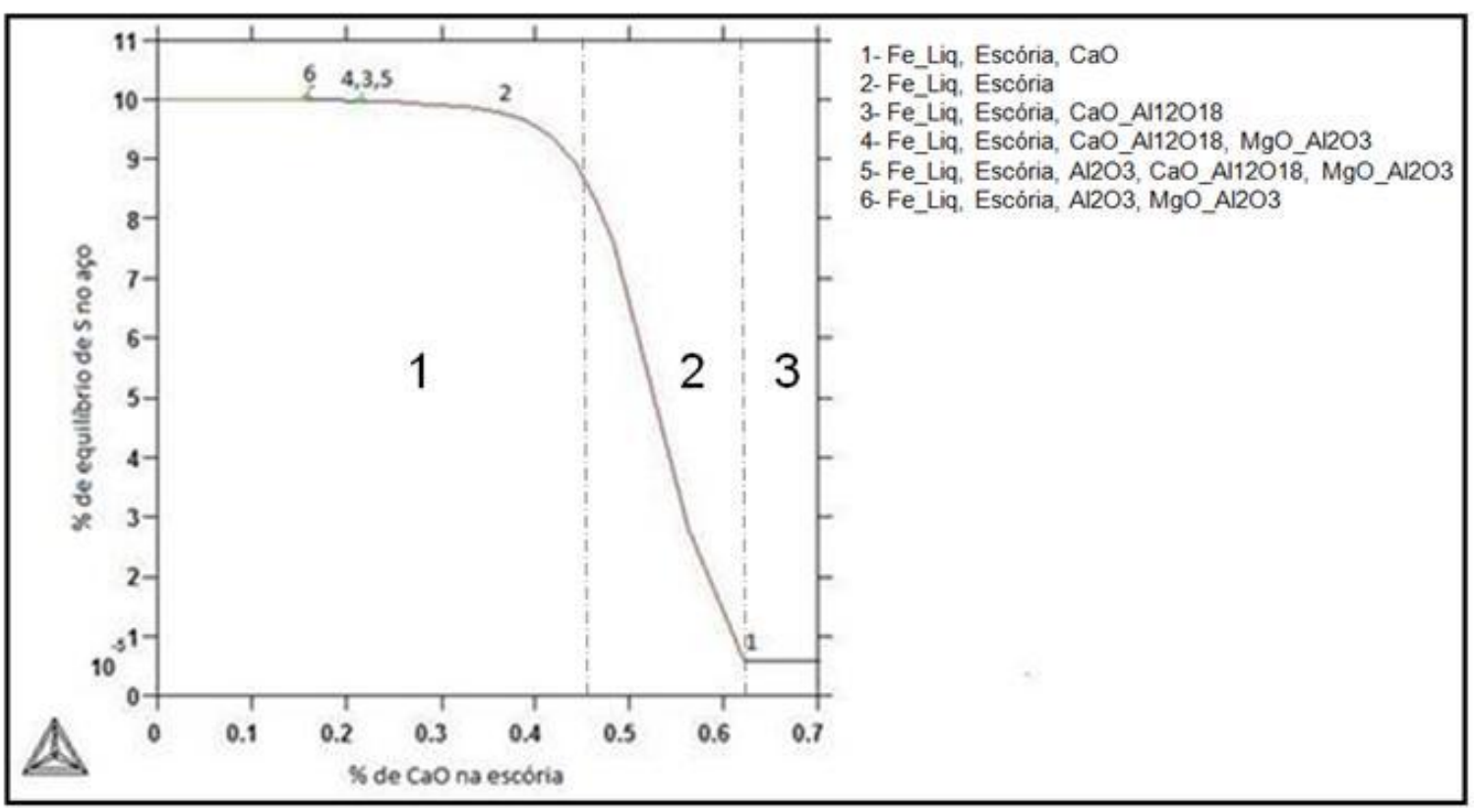

Figura 37. Relação entre o $\mathrm{CaO}$ na escória e enxofre de equilíbrio no metal para escórias sintéticas dessulfurantes de aço.

Nota-se na Figura 37, a presença de 3 fases. Na região 1, a variação da porcentagem de $\mathrm{CaO}$ de 0 a $45 \%$ pouco interfere no teor enxofre de equilíbrio. $\mathrm{Na}$ região 2, verifica-se que o aumento da porcentagem de $\mathrm{CaO}$ de 45 até $60 \%$ interfere significativamente na diminuição do teor de enxofre de equilíbrio. Por fim, na região 3, acima dos $60 \%$ de $\mathrm{CaO}$, observa-se que o aumento da quantidade de $\mathrm{CaO}$ 
mantém constante o enxofre de equilíbrio, mantendo o $\mathrm{CaO}$ em excesso na composição da escória. Dessa forma, para os experimentos físicos de aço, foram formuladas escórias dentro das regiões 2 e 3.

Para o estudo de dessulfuração do aço, é importante conhecer o teor de equilíbrio de oxigênio no metal, sendo este um dos principais empecilhos para a obtenção de menores valores de enxofre na composição do metal. Portanto, com o uso do Thermo-Calc, foi gerada a curva da porcentagem de oxigênio em função da porcentagem de alumínio no metal (Figura 38).

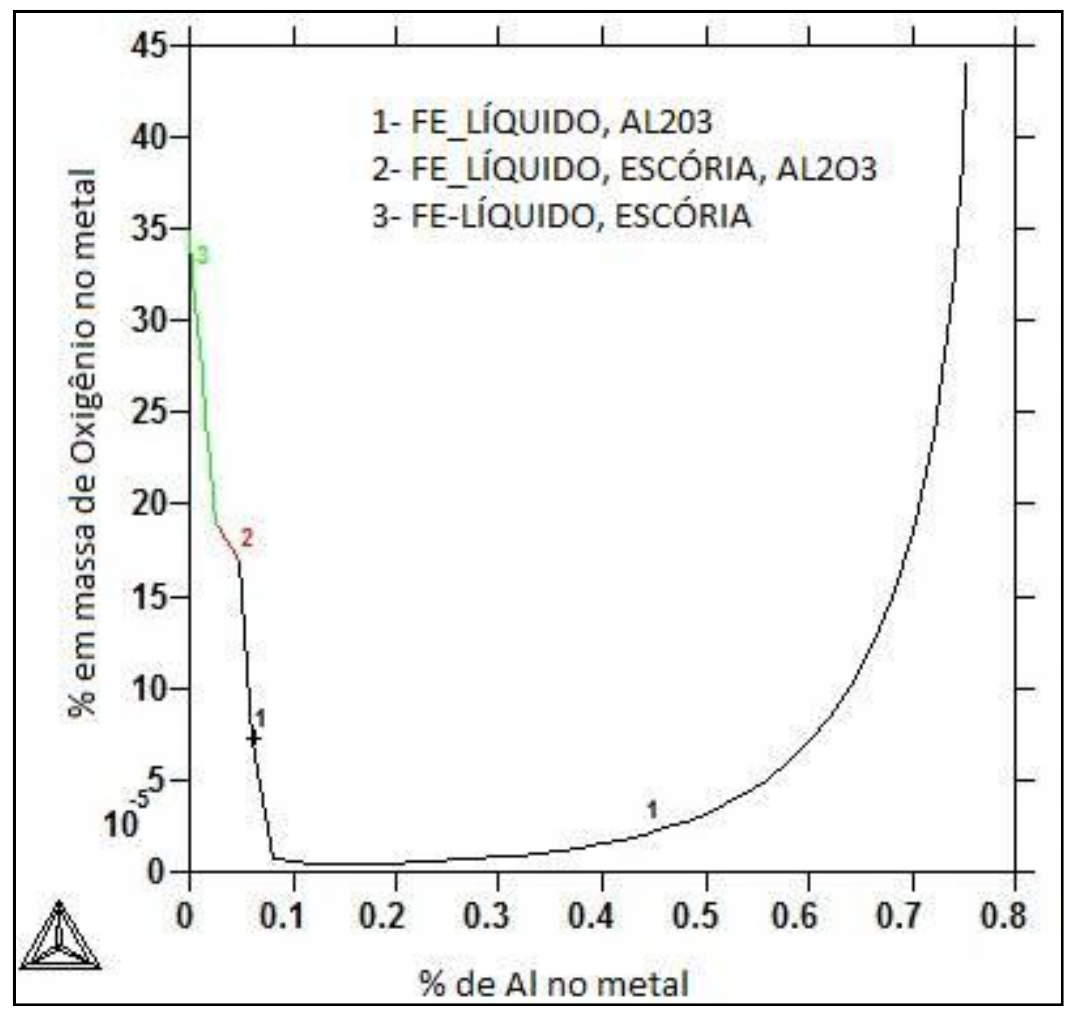

Figura 38. Relação entre o teor de alumínio e porcentagem de oxigênio no metal.

Observa-se na Figura 38, que para a máxima desoxidação do metal, o teor de alumínio deve estar entre 0,1 e 0,2 (\% em massa) no metal. Desta forma, foi realizado o ajuste da concentração de alumínio na composição do aço, visando uma máxima desoxidação.

Para todas as escórias dessulfurantes de aço apresentadas neste estudo, é válida a seguinte identificação: $A$ primeira letra $(A)$ representa que a escória foi utilizada na dessulfuração de aço. As duas próximas letras (CA ou RM) representam que foi utilizada cal convencional $(\mathrm{CA})$ ou resíduo de mármore $(\mathrm{RM})$. A quarta letra 
identifica a utilização de fluorita $(\mathrm{F})$ e $\mathrm{Al}_{2} \mathrm{O}_{3}(\mathrm{D})$. A letra $(\mathrm{C})$ foi utilizada para identificar misturas com resíduo de mármore calcinado. Os números inseridos após as letras representam a sequência de experimento.

$\mathrm{Na}$ Tabela 7, pode ser visualizada a composição química, quantidade em gramas de $\mathrm{CaO}$ e $\mathrm{Al}_{2} \mathrm{O}_{3}$ e a massa total das misturas utilizadas no processo de dessulfuração de aço.

Tabela 7. Composição das escórias sintéticas dessulfurantes utilizadas no aço.

\begin{tabular}{ccccccccccc}
\hline \multirow{2}{*}{ Misturas } & \multicolumn{3}{c}{ Composição dos compostos (\% em massa) } & \multicolumn{3}{c}{ Massa (g) } \\
\cline { 2 - 11 } & $\mathrm{Al}_{2} \mathrm{O}_{3}$ & $\mathrm{CaO}$ & $\mathrm{Fe}_{2} \mathrm{O}_{3}$ & $\mathrm{MgO}$ & $\mathrm{MnO}$ & $\mathrm{SiO}_{2}$ & $\mathrm{CaF}_{2}$ & $\mathrm{CaO}$ & $\mathrm{Al}_{2} \mathrm{O}_{3}$ & Total \\
\hline ACAD1 & 20,1 & 72,3 & 0,38 & 6,04 & 0,07 & 1,24 & - & 7,9 & 2,14 & 10,95 \\
ACAD2 & 23,1 & 69,1 & 0,37 & 6,00 & 0,07 & 1,20 & - & 7,5 & 2,54 & 10,95 \\
ACAD3 & 26,8 & 65,5 & 0,37 & 5,96 & 0,07 & 1,16 & - & 7,2 & 2,93 & 10,95 \\
ACAD4 & 29,5 & 62,9 & 0,36 & 5,94 & 0,07 & 1,11 & - & 6,8 & 3,2 & 10,95 \\
ACAD5 & 33,2 & 59,3 & 0,35 & 5,9 & 0,07 & 1,05 & - & 6,5 & 3,63 & 10,95 \\
ACAD6 & 36,8 & 55,8 & 0,34 & 5,9 & 0,07 & 0,9 & - & 6,1 & 4,0 & 10,95 \\
ARMD7 & 21,8 & 54,1 & - & 19,6 & - & 4,5 & - & 7,2 & 2,9 & 21,0 \\
ARMD8 & 24,4 & 52,3 & - & 18,9 & - & 4,4 & - & 6,8 & 3,20 & 20,4 \\
ARMD9 & 27,6 & 50,1 & - & 18,1 & - & 4,2 & - & 6,5 & 3,6 & 20,0 \\
ARMD10 & 28,9 & 49,2 & - & 17,8 & - & 4,1 & - & 6,1 & 4,0 & 19,4 \\
ARMF11 & 20,27 & 50,31 & & 18,24 & - & 4,20 & 7,0 & 7,2 & 2,9 & 22,0 \\
ACAF12 & 19,54 & 65,58 & 0,37 & 5,96 & 0,07 & 1,15 & 7,0 & 7,2 & 2,23 & 10,95 \\
ARMDC13 & 21,78 & 54,15 & & 19,43 & & 4,51 & - & 7,2 & 2,9 & 13,31 \\
ARMFC14 & 20,26 & 50,37 & & 18,17 & - & 4,2 & 7,0 & 7,2 & 2,9 & 14,31 \\
\hline
\end{tabular}

Para melhor compreensão dos ensaios dessulfurantes de aço, a Tabela 7 foi dividida e organizada em baterias de experimentos. A primeira bateria de ensaios realizados para aço é mostrada na Tabela 8.

Tabela 8. Misturas dessulfurantes à base de cal convencional e $\mathrm{Al}_{2} \mathrm{O}_{3}$.

\begin{tabular}{|c|c|c|c|c|c|c|c|c|c|}
\hline \multirow{2}{*}{ Misturas } & \multicolumn{6}{|c|}{ Composição dos compostos (\% em massa) } & \multicolumn{3}{|c|}{ Massa $(\mathrm{g})$} \\
\hline & $\mathrm{Al}_{2} \mathrm{O}_{3}$ & $\mathrm{CaO}$ & $\mathrm{Fe}_{2} \mathrm{O}_{3}$ & $\mathrm{MgO}$ & $\mathrm{MnO}$ & $\mathrm{SiO}_{2}$ & $\mathrm{CaO}$ & $\mathrm{Al}_{2} \mathrm{O}_{3}$ & Total \\
\hline ACAD1 & 20,1 & 72,3 & 0,38 & 6,04 & 0,07 & 1,24 & 7,9 & 2,14 & 10,95 \\
\hline ACAD2 & 23,1 & 69,1 & 0,37 & 6,00 & 0,07 & 1,20 & 7,5 & 2,54 & 10,95 \\
\hline ACAD3 & 26,8 & 65,5 & 0,37 & 5,96 & 0,07 & 1,16 & 7,2 & 2,93 & 10,95 \\
\hline ACAD4 & 29,5 & 62,9 & 0,36 & 5,94 & 0,07 & 1,11 & 6,8 & 3,2 & 10,95 \\
\hline ACAD5 & 33,2 & 59,3 & 0,35 & 5,9 & 0,07 & 1,05 & 6,5 & 3,63 & 10,95 \\
\hline ACAD6 & 36,8 & 55,8 & 0,34 & 5,9 & 0,07 & 0,9 & 6,1 & 4,0 & 10,95 \\
\hline
\end{tabular}

As misturas apresentadas na Tabela 8, foram construídas visando encontrar a melhor mistura dessulfurante à base de cal e alumina. Essas misturas foram definidas após simulações no Thermo-Calc. Com os dados gerados no software, foram formuladas misturas com fração de fase líquida na faixa de 58\% (ACAD1) até 100\% (ACAD6) e atividade inicial do $\mathrm{CaO}$ menor ou igual a 1. A massa de escória foi 
mantida constante, enquanto que, a massa de $\mathrm{CaO}$ e $\mathrm{Al}_{2} \mathrm{O}_{3}$ sofreram alterações. $\mathrm{Na}$ Tabela 9 pode ser visualizada a segunda bateria de ensaios para aço.

Tabela 9. Misturas dessulfurantes à base de resíduo de mármore e $\mathrm{Al}_{2} \mathrm{O}_{3}$.

\begin{tabular}{|c|c|c|c|c|c|c|c|c|c|}
\hline \multirow{2}{*}{ Misturas } & \multicolumn{6}{|c|}{ Composição dos compostos (\% em massa) } & \multicolumn{3}{|c|}{ Massa $(\mathrm{g})$} \\
\hline & $\mathrm{Al}_{2} \mathrm{O}_{3}$ & $\mathrm{CaO}$ & $\mathrm{Fe}_{2} \mathrm{O}_{3}$ & $\mathrm{MgO}$ & $\mathrm{MnO}$ & $\mathrm{SiO}_{2}$ & $\mathrm{CaO}$ & $\mathrm{Al}_{2} \mathrm{O}_{3}$ & Total \\
\hline ARMD7 & 21,8 & 54,1 & - & 19,6 & - & 4,5 & 7,2 & 2,9 & 21 \\
\hline ARMD8 & 24,4 & 52,3 & - & 18,9 & - & 4,4 & 6,8 & 3,20 & 20,4 \\
\hline ARMD9 & 27,6 & 50,1 & - & 18,1 & - & 4,2 & 6,5 & 3,6 & 20 \\
\hline ARMD10 & 28,9 & 49,2 & - & 17,8 & - & 4,1 & 6,1 & 4,0 & 19,4 \\
\hline ARMDC13 & 21,78 & 54,15 & - & 19,43 & - & 4,51 & 7,2 & 2,9 & 13,31 \\
\hline
\end{tabular}

Este conjunto de ensaios foi desenvolvido para comparar a substituição da cal convencional por resíduo de mármore. Deste modo, manteve-se as massas de CaO das novas misturas iguais às formuladas com cal convencional (ACAD3 - ACAD6). Para isso, variou a massa de resíduo e consequentemente a massa da mistura. $A$ mistura ARMDC13 foi realizada com o resíduo de mármore previamente calcinado. Esta mistura pode ser comparada com a ARMD7 e verificada a influência da decomposição dos carbonatos na dessulfuração de aço. A Tabela 10 mostra a terceira bateria de experimentos para misturas dessulfurantes de aço.

Tabela 10. Misturas dessulfurantes produzidas com resíduo de mármore, cal convencional e fluorita.

\begin{tabular}{ccccccccccc}
\hline \multirow{2}{*}{ Misturas } & \multicolumn{4}{c}{ Composição dos compostos (\% em massa) } & \multicolumn{3}{c}{ Massa (g) } \\
\cline { 2 - 11 } & $\mathrm{Al}_{2} \mathrm{O}_{3}$ & $\mathrm{CaO}$ & $\mathrm{Fe}_{2} \mathrm{O}_{3}$ & $\mathrm{MgO}$ & $\mathrm{MnO}$ & $\mathrm{SiO}_{2}$ & $\mathrm{CaF}_{2}$ & $\mathrm{CaO}$ & $\mathrm{Al}_{2} \mathrm{O}_{3}$ & Total \\
\hline ARMF11 & 20,27 & 50,31 & & 18,24 & - & 4,20 & 7,0 & 7,2 & 2,9 & 22 \\
ACAF12 & 19,54 & 65,58 & 0,37 & 5,96 & 0,07 & 1,15 & 7,0 & 7,2 & 2,23 & 10,95 \\
ARMFC14 & 20,26 & 50,37 & & 18,17 & - & 4,2 & 7,0 & 7,2 & 2,9 & 14,31 \\
\hline
\end{tabular}

Essas misturas foram formuladas para analisar o uso de fluorita com resíduo de mármore, resíduo de mármore calcinado e cal convencional. Além disso, essas misturas possuem a mesma massa de $\mathrm{CaO}$ que as formuladas com alumina (ACAD3, ARMD7 e ARMDC13). Desta forma, foi possível realizar uma análise comparativa sobre a substituição da fluorita por $\mathrm{Al}_{2} \mathrm{O}_{3}$.

\subsubsection{Escórias sintéticas dessulfurantes de ferro-gusa}

Foi realizado um estudo sobre o uso de um agente fluidificante alternativo, sodalita, em substituição a fluorita. Assim como, o uso de resíduo de mármore em 
substituição a cal convencional para utilização em escórias sintéticas dessulfurantes de ferro-gusa. Com base na composição química das matérias-primas, as seguintes misturas foram propostas.

Tabela 11. Composição química (\% massa) das escórias dessulfurantes, massa total das misturas e de resíduo calcinado.

\begin{tabular}{|c|c|c|c|c|c|c|c|c|c|c|}
\hline \multirow[b]{2}{*}{ Misturas } & \multicolumn{6}{|c|}{ Composição Química (\% em massa) } & \multirow[b]{2}{*}{$\mathrm{Fe}_{2} \mathrm{O}_{3}$} & \multicolumn{3}{|c|}{ Massa $(\mathrm{g})$} \\
\hline & $\mathrm{CaO}$ & $\mathrm{Na}_{2} \mathrm{O}$ & $\mathrm{CaF}_{2}$ & $\mathrm{Al}_{2} \mathrm{O}_{3}$ & $\mathrm{MgO}$ & $\mathrm{SiO}_{2}$ & & $\mathrm{CaO}$ & $\begin{array}{c}\text { Total } \\
\text { mistura }\end{array}$ & $\begin{array}{l}\text { Resíduo } \\
\text { calcinado }\end{array}$ \\
\hline CAF5 & 92,2 & 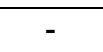 & 4,65 & 0,42 & 0,50 & 1,8 & 0,4 & 9,22 & 10 & 0 \\
\hline CAF10 & 87,4 & - & 9,29 & 0,4 & 0,51 & 1,99 & 0,35 & 8,74 & 10 & 0 \\
\hline CAS5 & 92,2 & 0,7 & - & 1,63 & 0,53 & 4,4 & 0,53 & 9,22 & 10 & 0 \\
\hline CAS10 & 87,4 & 1,39 & - & 2,82 & 0,50 & 7,19 & 0,7 & 8,73 & 10 & 0 \\
\hline RMF5 & 66,8 & - & 3,36 & - & 24,07 & 5,75 & 0 & 9,22 & 23,55 & 13,3 \\
\hline RMF10 & 64,3 & - & 6,83 & - & 23,14 & 5,73 & 0 & 8,74 & 22,90 & 12,6 \\
\hline RMS5 & 66,7 & 0,50 & - & 0,87 & 24,07 & 7,64 & 0,12 & 9,22 & 23,55 & 13,3 \\
\hline RMS10 & 64,2 & 1,02 & - & 1,78 & 23,8 & 9,56 & 0,24 & 8,74 & 22,90 & 12,6 \\
\hline
\end{tabular}

Com relação à primeira coluna da Tabela 11, as duas primeiras letras (CA e $\mathrm{RM}$ ) representam o material utilizado, sendo $(\mathrm{CA})$ cal convencional e $(\mathrm{RM})$ resíduo de mármore. A terceira letra seguida de um número identifica o fluidificante usado, sendo (F) fluorita e (S) sodalita e suas respectivas porcentagens (5\% e $10 \%$ da massa total para escória com cal convencional). Para as escórias com resíduo de mármore, manteve-se a mesma massa $(\mathrm{g})$ de $\mathrm{CaF}_{2}$ e Sodalita que foi utilizado nas misturas com cal convencional.

Os objetivos destes ensaios consistiram em comparar o uso da sodalita em substituição à fluorita e comparar a substituição da cal convencional por resíduo de mármore.

\subsubsection{Escórias sintéticas dessulfurantes de ferro fundido}

A Tabela 12 apresenta os ensaios de dessulfuração de ferro fundido realizados no laboratório de Tecnologia em Metalurgia da Universidade de Duisburg-Essen, Alemanha.

Nesta bateria de ensaios é válida a seguinte nomenclatura: As duas primeiras letras $(\mathrm{Cl})$ representam escórias dessulfurantes de ferro fundido. As duas próximas letras (CA ou $\mathrm{RM}$ ) representam a utilização de cal convencional (CA) ou resíduo de 
mármore $(\mathrm{RM})$. A quinta letra $(\mathrm{F})$ indica que foi utilizado fluorita. Por fim, os números apresentam a sequência de realização dos experimentos.

Tabela 12. Composição das escórias utilizadas para o processo de dessulfuração de ferro fundido.

\begin{tabular}{|c|c|c|c|c|c|c|c|c|c|c|}
\hline \multirow[b]{2}{*}{ Misturas } & \multicolumn{6}{|c|}{ Composição dos compostos (\%) } & \multicolumn{4}{|c|}{ Massa (g) } \\
\hline & $\mathrm{Al}_{2} \mathrm{O}_{3}$ & $\mathrm{CaO}$ & $\mathrm{MgO}$ & $\mathrm{SiO}_{2}$ & $\mathrm{Na}_{2} \mathrm{O}$ & $\mathrm{CaF}_{2}$ & $\mathrm{CaO}$ & $\mathrm{Al}_{2} \mathrm{O}_{3}$ & Total & $\begin{array}{l}\text { Resíduo } \\
\text { Calcinado }\end{array}$ \\
\hline CICA1 & 20,0 & 65,0 & 0,00 & 0,00 & 15,0 & 0,00 & 27,3 & 8,4 & 42 & 0 \\
\hline CICA2 & 25,0 & 65,0 & 0,00 & 0,00 & 10,0 & 0,00 & 27,3 & 10,5 & 42 & 0 \\
\hline CICA3 & 30,0 & 60,0 & 0,00 & 0,00 & 10,0 & 0,00 & 25,2 & 12,6 & 42 & 0 \\
\hline CICA4 & 25,0 & 60,0 & 0,00 & 0,00 & 15,0 & 0,00 & 25,2 & 10,5 & 42 & 0 \\
\hline CICA5 & 15,0 & 75,0 & 0,00 & 0,00 & 10,0 & 0,00 & 31,5 & 6,3 & 42 & 0 \\
\hline CIRM6 & 15,49 & 50,47 & 18,21 & 4,21 & 11,62 & 0,00 & 27,3 & 8,4 & 83,2 & 39,5 \\
\hline CIRM7 & 19,37 & 50,47 & 18,21 & 4,21 & 7,74 & 0,00 & 27,2 & 10,5 & 83,2 & 39,5 \\
\hline CIRM8 & 23,54 & 47,46 & 17,13 & 3,96 & 7,91 & 0,00 & 25,2 & 12,6 & 80,0 & 36,5 \\
\hline CIRM9 & 19,74 & 47,38 & 17,08 & 3,96 & 11,84 & 0,00 & 25,2 & 10,5 & 80,0 & 36,5 \\
\hline CIRM10 & 11,25 & 56,26 & 20,29 & 4,69 & 7,50 & 0,00 & 31,5 & 6,3 & 89,4 & 45,6 \\
\hline CICAF11 & 30,0 & 60,0 & 0,00 & 0,00 & 0,00 & 10,0 & 25,2 & 12,6 & 42 & 0 \\
\hline CIRMF12 & 23,68 & 47,37 & 17,08 & 3,95 & 0,00 & 7,89 & 25,2 & 12,6 & 80,0 & 36,5 \\
\hline
\end{tabular}

Para melhor compreensão dos ensaios dessulfurantes de ferro fundido, a Tabela 12 foi dividida e organizada em baterias de experimentos. A primeira bateria é representada por misturas de cal convencional e $\mathrm{Al}_{2} \mathrm{O}_{3}$ e consta na Tabela 13.

Tabela 13. Composição das misturas produzidas com cal convencional, $\mathrm{Al}_{2} \mathrm{O}_{3}$ e $\mathrm{Na}_{2} \mathrm{O}$.

\begin{tabular}{|c|c|c|c|c|c|c|c|c|c|}
\hline Misturas & \multicolumn{6}{|c|}{ Composição dos compostos (\%) } & \multicolumn{2}{|c|}{ Massa (g) } & \multirow[b]{2}{*}{ Total } \\
\hline & $\mathrm{Al}_{2} \mathrm{O}_{3}$ & $\mathrm{CaO}$ & $\mathrm{MgO}$ & $\mathrm{SiO}_{2}$ & $\mathrm{Na}_{2} \mathrm{O}$ & $\mathrm{CaF}_{2}$ & $\mathrm{CaO}$ & $\mathrm{Al}_{2} \mathrm{O}_{3}$ & \\
\hline CICA1 & 20,0 & 65,0 & 0,00 & 0,00 & 15,0 & 0,00 & 27,3 & 8,4 & 42 \\
\hline CICA2 & 25,0 & 65,0 & 0,00 & 0,00 & 10,0 & 0,00 & 27,3 & 10,5 & 42 \\
\hline CICA3 & 30,0 & 60,0 & 0,00 & 0,00 & 10,0 & 0,00 & 25,2 & 12,6 & 42 \\
\hline CICA4 & 25,0 & 60,0 & 0,00 & 0,00 & 15,0 & 0,00 & 25,2 & 10,5 & 42 \\
\hline CICA5 & 15,0 & 75,0 & 0,00 & 0,00 & 10,0 & 0,00 & 31,5 & 6,3 & 42 \\
\hline
\end{tabular}

Esta bateria de experimentos foi realizada com o objetivo de obter a eficiência dessulfurante com as misturas à base de cal convencional e $\mathrm{Al}_{2} \mathrm{O}_{3}$. A segunda bateria de experimentos é mostrada na Tabela 14.

Tabela 14. Composição das misturas dessulfurantes de ferro fundido formuladas com o resíduo de mármore.

\begin{tabular}{|c|c|c|c|c|c|c|c|c|c|c|}
\hline \multirow[b]{2}{*}{ Misturas } & \multicolumn{6}{|c|}{ Composição dos compostos (\%) } & \multicolumn{4}{|c|}{ Massa $(\mathrm{g})$} \\
\hline & $\mathrm{Al}_{2} \mathrm{O}_{3}$ & $\mathrm{CaO}$ & $\mathrm{MgO}$ & $\mathrm{SiO}_{2}$ & $\mathrm{Na}_{2} \mathrm{O}$ & $\mathrm{CaF}_{2}$ & $\mathrm{CaO}$ & $\mathrm{Al}_{2} \mathrm{O}_{3}$ & Total & $\begin{array}{l}\text { Resíduo } \\
\text { Calcinado }\end{array}$ \\
\hline $\mathrm{Cl}$ & 154 & 50,47 & & 4,2 & $116 ?$ & $\overline{0,0}$ & 27,3 & 8, & 83,2 & 39,5 \\
\hline CIRM7 & 9,3 & 50,47 & 18,21 & 4,21 & 7, & 0,0 & 27,2 & 10,5 & 83,2 & 39,5 \\
\hline CIRM8 & 23,54 & 47,46 & 17,13 & 3,96 & 7,91 & 0,00 & 25,2 & 12,6 & 80,0 & 36, \\
\hline & 4 & & & 3 & 11,84 & 0,00 & 25,2 & 10,5 & 80,0 & 36,5 \\
\hline CIRM10 & 11,25 & 56,26 & 20,29 & 4,69 & 7,50 & 0,00 & 31,5 & 6,3 & 89,4 & 45,6 \\
\hline
\end{tabular}


Esta bateria de experimentos foi formulada mantendo a mesma massa de $\mathrm{CaO}$ utilizada nas misturas com cal convencional, visando realizar uma análise comparativa dos resultados de misturas com cal convencional e com o resíduo de mármore. Na Tabela 15, consta a terceira bateria de experimento para ferro fundido.

Tabela 15. Composição das misturas com o uso de fluorita, resíduo de mármore, cal convencional e $\mathrm{Al}_{2} \mathrm{O}_{3}$.

\begin{tabular}{|c|c|c|c|c|c|c|c|c|c|c|}
\hline \multirow[b]{2}{*}{ Misturas } & \multicolumn{6}{|c|}{ Composição dos elementos(\%) } & \multicolumn{4}{|c|}{ Massa (g) } \\
\hline & $\mathrm{Al}_{2} \mathrm{O}_{3}$ & $\mathrm{CaO}$ & $\mathrm{MgO}$ & $\mathrm{SiO}_{2}$ & $\mathrm{Na}_{2} \mathrm{O}$ & $\mathrm{CaF}_{2}$ & $\mathrm{CaO}$ & $\mathrm{Al}_{2} \mathrm{O}_{3}$ & Total & $\begin{array}{l}\text { Resíduo } \\
\text { Calcinado }\end{array}$ \\
\hline CICA3 & 30,0 & 60,0 & 0,00 & 0,00 & 10,0 & 0,00 & 25,2 & 12,6 & 42 & 0 \\
\hline CIRM8 & 23,54 & 47,46 & 17,13 & 3,96 & 7,91 & 0,00 & 25,2 & 12,6 & 80.0 & 36.5 \\
\hline CICAF11 & 30,0 & 60,0 & 0,00 & 0,00 & 0,00 & 10,0 & 25,2 & 12,6 & 42 & 0 \\
\hline CIRMF12 & 23,68 & 47,37 & 17,08 & 3,95 & 0,00 & 7,89 & 25,2 & 12,6 & 80,0 & 36,5 \\
\hline
\end{tabular}

Esta bateria foi formulada para comparar a substituição do resíduo de mármore por cal convencional e a substituição da fluorita por $\mathrm{Al}_{2} \mathrm{O}_{3}$. Para isso, manteve-se a mesma massa de $\mathrm{CaO}$ para as misturas.

A quarta e última bateria de ensaios foi concentrada para verificar a influência da granulometria da cal no processo de dessulfuração de ferro fundido. A Tabela 16 mostra os ensaios realizados nesta etapa.

Tabela 16. Variação da granulometria de $\mathrm{CaO}$ nas misturas utilizadas na etapa de dessulfuração do ferro fundido.

\begin{tabular}{cc}
\hline Ensaios & Granulometria \\
\hline $\mathrm{CaO}-1$ & $0,5-1,0 \mathrm{~mm}$ \\
$\mathrm{CaO}-2$ & $100 \mu \mathrm{m}$ \\
$\mathrm{CaO}-3$ & $20 \mu \mathrm{m}$ \\
\hline
\end{tabular}

Nesta bateria, utilizou-se $\mathrm{CaO}$ com diferentes tamanhos de partículas. Desta forma, foi possível analisar a influência da granulometria na etapa de dessulfuração por escória de topo.

\subsection{ETAPAS DO PROCEDIMENTO EXPERIMENTAL}

Este trabalho é composto por dois arranjos experimentais. O primeiro arranjo foi construído na Universidade de São Paulo, onde realizaram-se as etapas de dessulfuração em ferro-gusa e aço. O segundo aparato experimental foi montado no 
Instituto de Tecnologia em Metalurgia da Universidade de Duisburg-Essen, na Alemanha. Este último foi utilizado para realizar a dessulfuração em ferro fundido.

\subsubsection{Aparato experimental utilizado da dessulfuração de ferro-gusa e aço}

Inicialmente, o ferro-gusa e aço foram cortados e pesados em amostras de 1000 gramas/experimento. As amostras foram colocadas dentro do cadinho de MgO-C para fusão. A composição química do ferro-gusa e aço pode ser visualizada na Tabela 17.

Tabela 17. Composição química inicial do ferro-gusa e aço utilizada nos testes experimentais.

\begin{tabular}{cccccccc}
\hline \multirow{2}{*}{ Identificação } & \multicolumn{6}{c}{ Composição Química Inicial (\%) } & \multirow{2}{*}{ Massa (kg) } \\
\cline { 2 - 6 } & $\mathrm{C}$ & $\mathrm{Mn}$ & $\mathrm{Si}$ & $\mathrm{P}$ & $\mathrm{S}$ & $\mathrm{Al}$ & \multirow{2}{*}{ (k } \\
\hline Ferro-gusa & 4,5 & 0,21 & 0,5 & 0,13 & 0,030 & 0 & \multirow{2}{*}{1} \\
Aço & 0,2 & 0,7 & 0,25 & 0,02 & 0,008 & 0,2 & \\
\hline
\end{tabular}

Este cadinho foi levado até um forno vertical. Em seguida, injetou-se argônio na câmara de aquecimento para evitar a oxidação do ferro-gusa ou do aço. $\mathrm{Na}$ Figura 39 pode-se observar o forno utilizado nos experimentos.
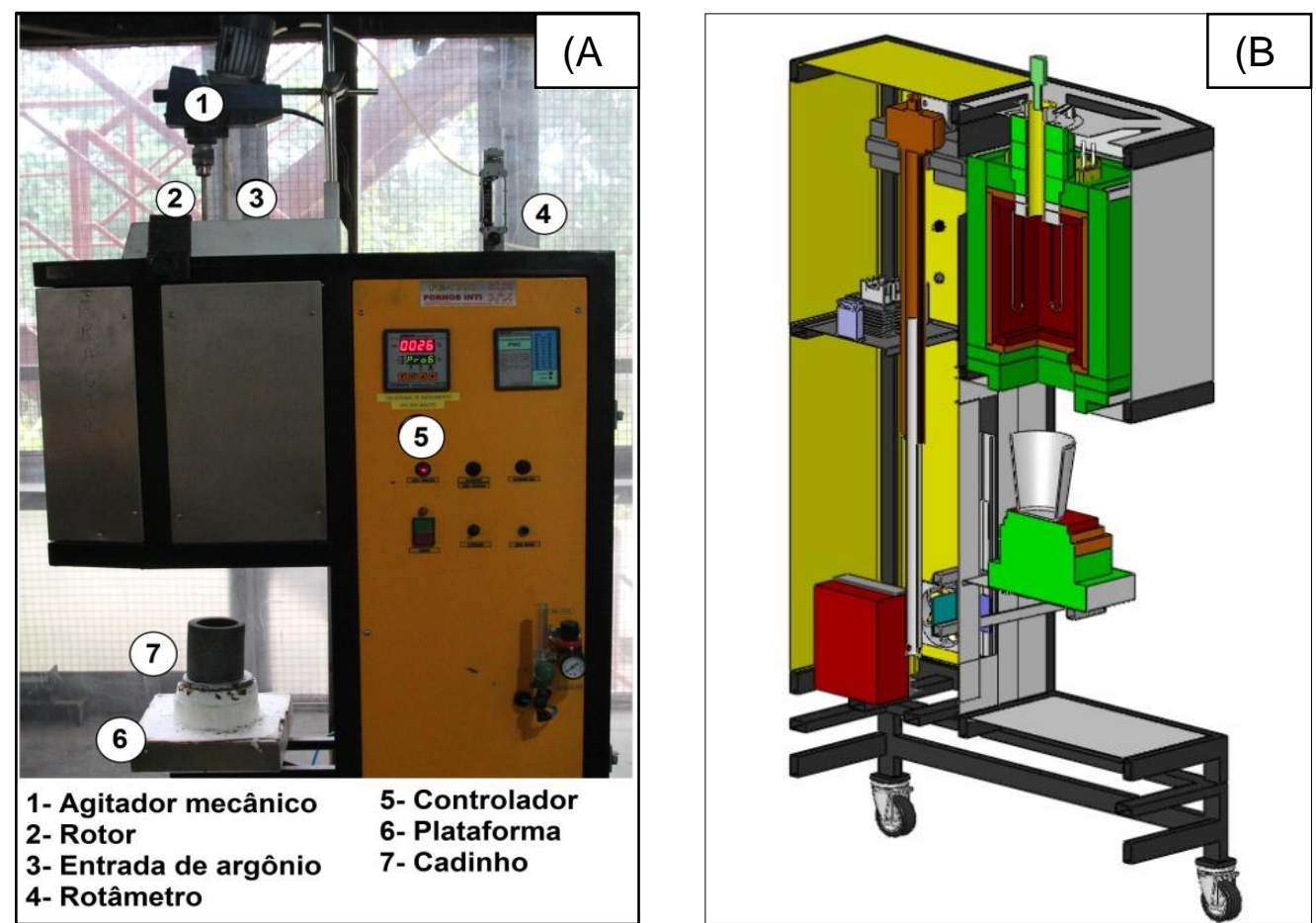

Figura 39. Forno de resistência elétrica utilizado para os ensaios de dessulfuração $(A)$ e desenho esquemático do forno (B). 
O forno de resistência elétrica modelo FE50RP, possui uma potência de $5500 W$, voltagem de 220 VOLTS, entrada de termopar tipo "S" e temperatura máxima alcançável de $1700^{\circ} \mathrm{C}$.

O forno é dotado de uma plataforma que se movimenta verticalmente para abrir e fechar o mesmo. O forno possui um tubo de material refratário que isola a câmara de reação e garante um ambiente inerte. Quando a temperatura do banho atingiu a temperatura de trabalho, de $1400^{\circ} \mathrm{C}$ para ferro-gusa e $1600^{\circ} \mathrm{C}$ para aço, a tampa superior do forno foi removida e as misturas foram adicionadas. Na Figura 40 pode-se observar os passos adotados na realização dos experimentos de dessulfuração de aço e ferro-gusa.

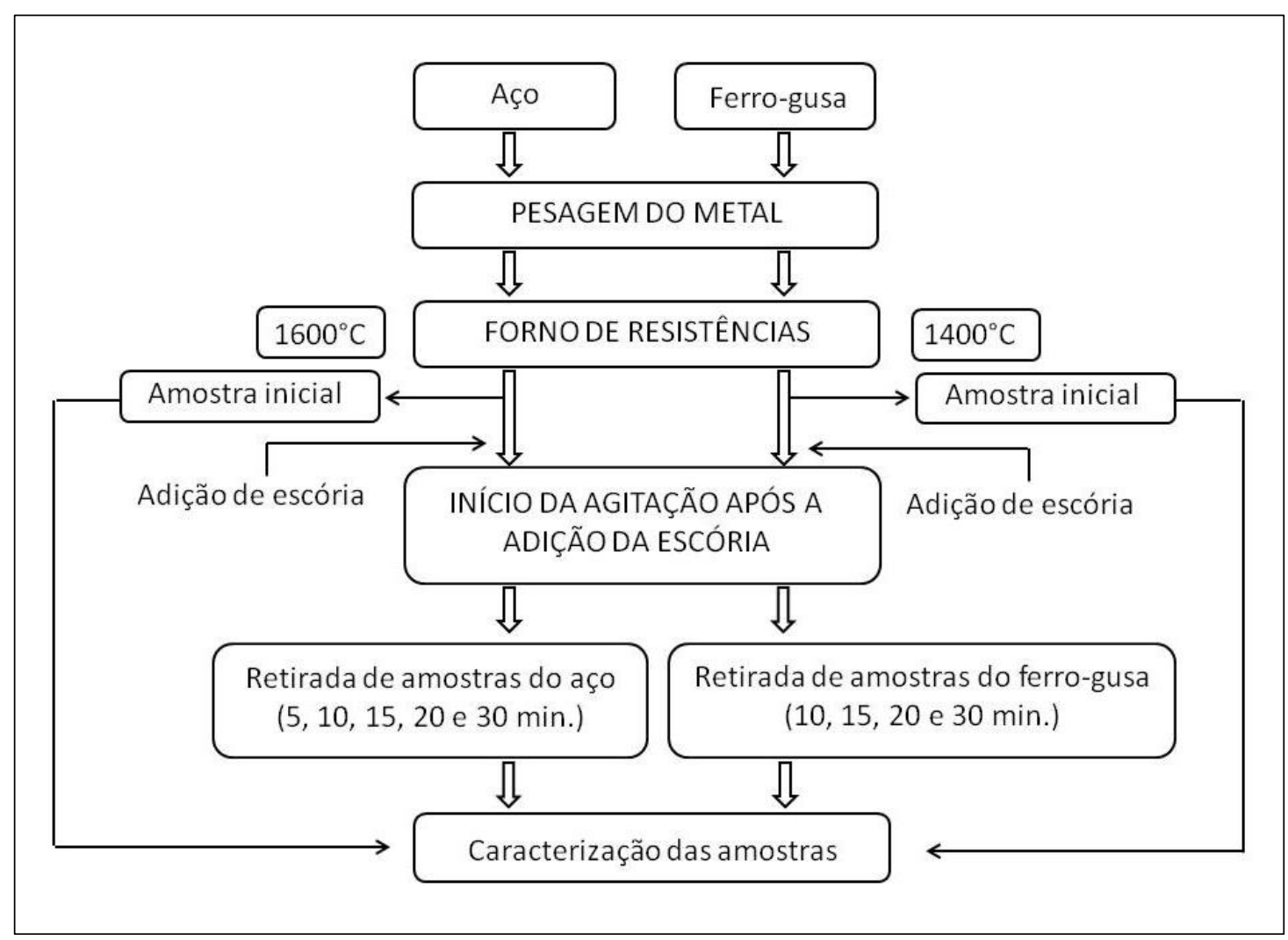

Figura 40. Fluxograma detalhado da realização dos experimentos de ferro-gusa e aço.

Cada experimento de dessulfuração envolveu os seguintes passos:

1- Posicionamento do cadinho de $\mathrm{MgO}-\mathrm{C}$ sobre a plataforma refratária móvel do forno;

2- Posicionamento do agitador mecânico sobre o forno; 
3- Posicionamento do rotor dentro do cadinho, permanecendo constante sua posição de agitação e de profundidade dentro do metal líquido. Todos os experimentos foram realizados mantendo os mesmos parâmetros;

4- Abertura do rotâmetro para entrada de gás argônio na câmara do forno, na vazão de $1 \mathrm{NL} /$ minuto;

5- Atingida a temperatura de trabalho e verificada a completa fusão do metal, realizou-se as adições das escórias sintéticas dessulfurantes. $O$ tempo de reação passou a ser contado imediatamente após o carregamento;

6- $\quad$ Após a adição das escórias, o agitador mecânico foi ligado com uma rotação de 200rpm para aço e 400rpm para ferro-gusa.

A velocidade de rotação do rotor foi determinada após a realização de ensaios em água. $\mathrm{Na}$ velocidade de rotação de 400rpm, não foi observada a projeção de água para fora do cadinho. Verificou-se também, que quando o agitador foi posicionado descentralizado, um vortex foi produzido e como consequência, houve aumento da turbulência e agitação do banho. Com isso, esta posição foi utilizada. Por outro lado, durante os ensaios com aço no forno a $1600^{\circ} \mathrm{C}$, notou-se que o rotor não suportava rotação de 400rpm, predeterminada em água, sofrendo uma ruptura e comprometendo os ensaios. Portanto, optou-se em fixar a rotação do rotor em 200rpm para experimentos no aço e 400rpm para o ferro-gusa. Após estas constatações, o agitador foi posicionado descentralizado conforme Figura 41. O rotor foi posicionado na metade do raio interno do cadinho.

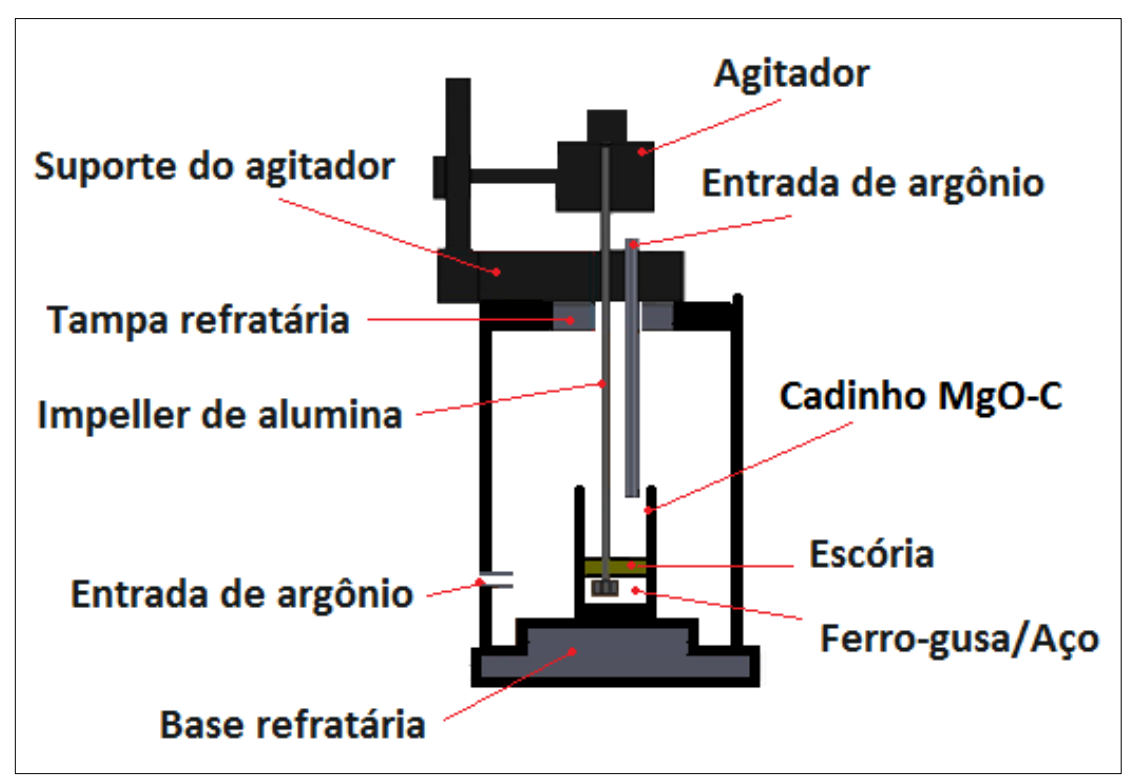

Figura 41. Posicionamento descentralizado do agitador mecânico no metal líquido. 
Para a amostragem do metal, um amostrador a vácuo foi encaixado em um tubo de aço inoxidável, permitindo que o amostrador fosse imerso no metal líquido, conforme apresentado na Figura 42.

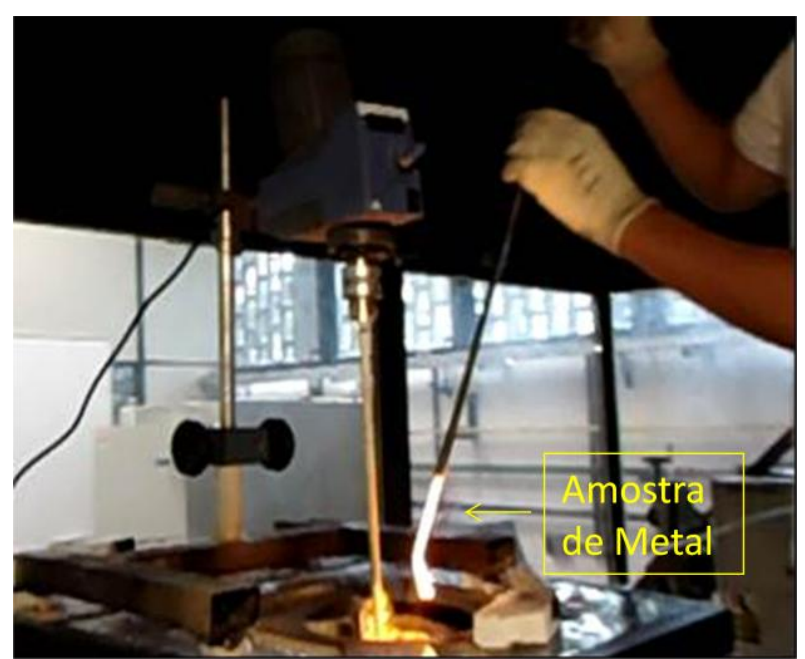

Figura 42. Retirada das amostras durante os experimentos de dessulfuração de aço e ferro-gusa.

Após o final de cada experimento, o cadinho foi retirado do forno e um novo cadinho foi inserido na câmara de reação.

\subsubsection{Aparato experimental utilizado na dessulfuração de ferro fundido}

Os experimentos de dessulfuração em ferro-fundido foram realizados no laboratório de Tecnologia em Metalurgia da Universidade de Duisburg-Essen, na Alemanha. A Figura 43, apresenta o aparato experimental utilizado para realizar os experimentos. 


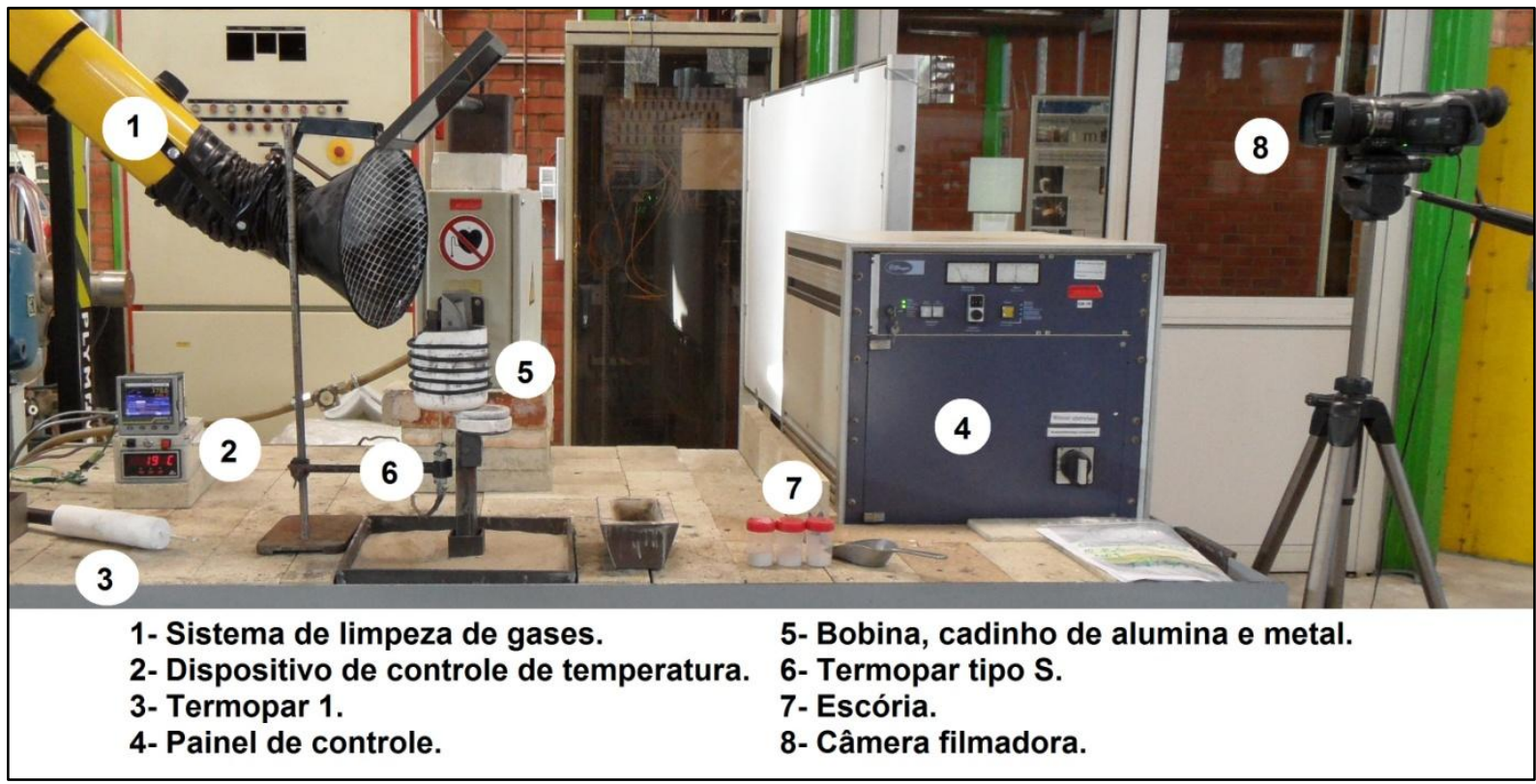

Figura 43. Esquema do aparato experimental utilizado para realizar a etapa de dessulfuração de ferro fundido no Instituto de Tecnologia em Metalurgia (ITM) na Alemanha.

Inicialmente, $1,4 \mathrm{~kg}$ de ferro fundido foram colocados em um cadinho de grafita e inserido no cadinho suceptor de alumina. A composição inicial do ferro fundido é apresentada na Tabela 18.

Tabela 18. Composição química inicial do ferro fundido.

\begin{tabular}{cccccc}
\hline \multirow{2}{*}{ Misturas } & \multicolumn{4}{c}{ Composição Quimica (\%) } & \multirow{2}{*}{ Massa $(\mathrm{kg})$} \\
\cline { 2 - 4 } & $\mathrm{C}$ & $\mathrm{Si}$ & $\mathrm{P}$ & $\mathrm{S}$ & \\
\hline CICA1 & 3,26 & 1,64 & 0,054 & 0,103 & \\
CICA2 & 3,18 & 1,64 & 0,054 & 0,084 & \\
CICA3 & 3,20 & 1,61 & 0,050 & 0,090 & \\
CICA4 & 3,28 & 1,68 & 0,056 & 0,103 & \\
CICA5 & 3,22 & 1,68 & 0,056 & 0,096 & \\
CIRM6 & 3,20 & 1,72 & 0,057 & 0,084 & 1,4 \\
CIRM7 & 3,16 & 1,72 & 0,053 & 0,084 & \\
CIRM8 & 3,24 & 1,69 & 0,052 & 0,082 & \\
CIRM9 & 3,32 & 1,73 & 0,057 & 0,087 & \\
CIRM10 & 3,37 & 1,7 & 0,064 & 0,091 & \\
CICAF11 & 3,25 & 1,71 & 0,064 & 0,101 & \\
CIRMF12 & 3,28 & 1,73 & 0,059 & 0,091 & \\
\hline
\end{tabular}

Para evitar a perda de calor, uma manta cerâmica de carbono foi inserida entre o cadinho de grafita e alumina. O processo de agitação foi promovido pela indução do forno. Portanto, não foi utilizado um rotor de alumina para promover a agitação do metal/escória. Após atingir a temperatura de experimento $\left(1550^{\circ} \mathrm{C}\right)$ e aferida a temperatura (Termopar 1), retirou-se uma amostra inicial de metal a fim de analisar a 
composição química. A cada 5 minutos de experimento, uma amostra de metal foi coletada e o tempo total de cada experimento correspondeu a 45 minutos. $\mathrm{Na}$ Tabela 19, podem ser vistas as etapas desenvolvidas durante os experimentos.

Tabela 19. Etapas desenvolvidas durante o procedimento experimental de dessulfuração de ferro fundido.

\begin{tabular}{cc}
\hline Tempo $(\mathrm{min})$ & Procedimentos experimentais \\
\hline- & Aferição da temperatura \\
- & Amostragem inicial \\
0 & Adição da primeira batelada de mistura \\
5 & Amostra 2 \\
10 & Amostra 3 \\
15 & Amostra 4 \\
15 & Adição da segunda batelada de mistura \\
20 & Amostra 5 \\
25 & Amostra 6 \\
30 & Amostra 7 \\
30 & Adição da terceira batelada de mistura \\
35 & Amostra 8 \\
40 & Amostra 9 \\
45 & Amostra 10 \\
45 & Término do experimento \\
\hline
\end{tabular}

As amostras foram retiradas com o auxílio de um amostrador acoplado em um tubo venturi. A Figura 44 e a Figura 45 mostram o momento da aferição da temperatura e amostragem do ferro fundido, respectivamente.

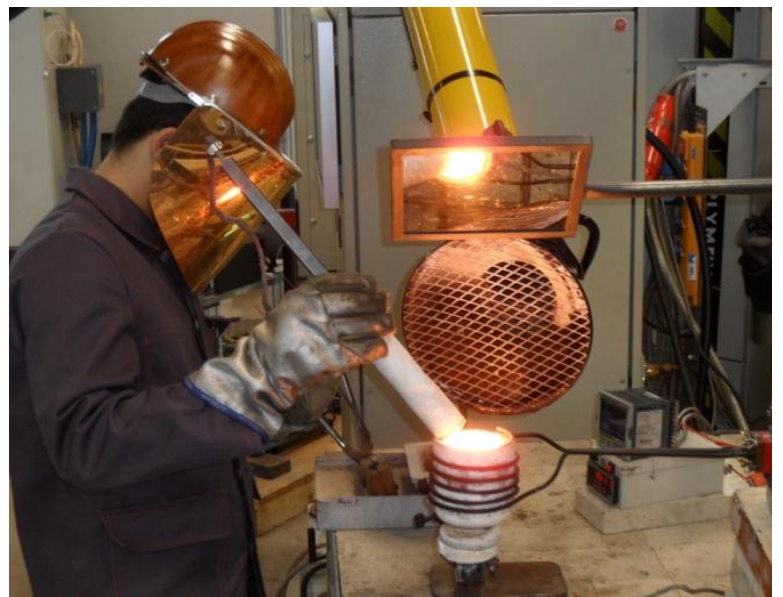

Figura 44. Momento de aferir a temperatura antes de realizar a adição da escória.

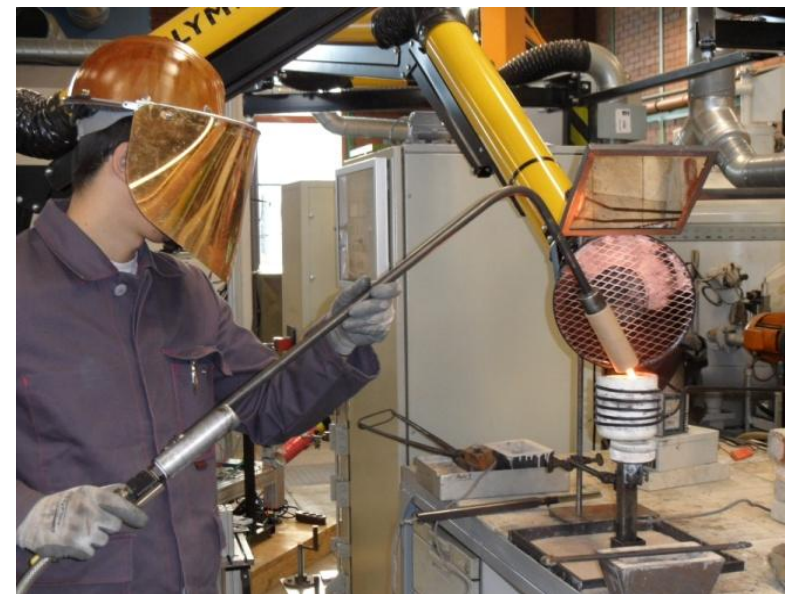

Figura 45. Esquema de amostragem do metal com o auxílio de um tubo venturi.

A adição da escória foi realizada em 3 momentos distintos (0, 15 e $30 \mathrm{~min}$ ), sendo a mesma realizada com auxílio de uma espátula de metal, conforme a 
Figura 46. A Figura 47 apresenta os materiais utilizados nesta etapa (escória, amostrador, metal, termopar e cadinho).

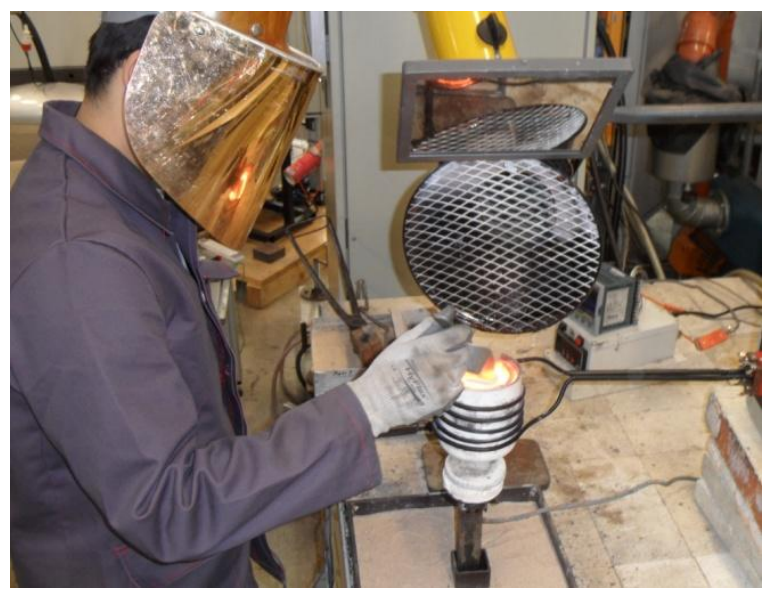

Figura 46. Procedimento de adição de escória com auxílio de uma espátula de metal.

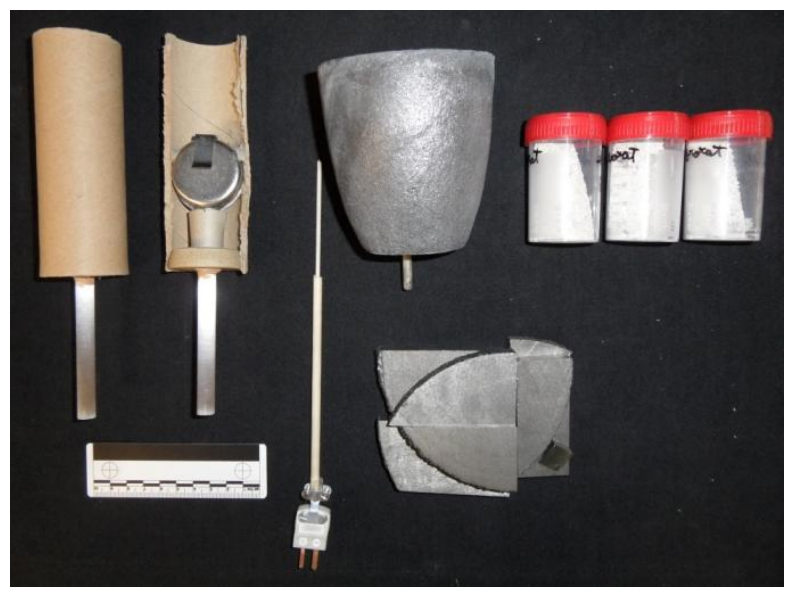

Figura 47. Materiais utilizados para realizar os ensaios: Amostrador, termopar, cadinho, ferrofundido e escória.

Ao término dos experimentos, as amostras de metal foram analisadas por espectrometria ótica de massa.

\subsection{CÁLCULOS TERMODINÂMICOS E CINÉTICOS}

\subsubsection{Cálculos termodinâmicos por modelos de Cs, Ls e $\wedge$}

Os cálculos termodinâmicos por modelos de Cs, Ls e $\Lambda$ foram utilizando a composição química das misturas e temperatura inicial. Os modelos de capacidade de sulfeto e partição de enxofre utilizado constam na Tabela 20. 
Tabela 20. Modelos termodinâmicos de Ls e Cs utilizados na avaliação das misturas dessulfurantes.

\begin{tabular}{|c|c|}
\hline Autor & Modelo \\
\hline $\begin{array}{l}\text { Young }^{(33)} \\
(\Lambda<0,8)\end{array}$ & $\begin{array}{l}\log C_{S}=-13,913+42,84 \Lambda-23,82 \Lambda^{2}-\frac{11710}{T}-0,02223 . \% \mathrm{SiO}_{2} \\
-0,02275 . \% \mathrm{Al}_{2} \mathrm{O}_{3}\end{array}$ \\
\hline $\begin{array}{l}\text { Young }^{(33)} \\
(\Lambda \geq 0,8)\end{array}$ & $\begin{array}{l}\log C_{S}=-0,6261+0,4808 \Lambda+0,7917 \Lambda^{2}+\frac{1697}{T}-\frac{2587 \Lambda}{T} \\
+0,0005144 . \% \mathrm{FeO}\end{array}$ \\
\hline Shankar ${ }^{(34)}$ & $C_{S}=9,852 \times 10^{-6}\left(\% \mathrm{Al}_{2} \mathrm{O}_{3}\right)+0,010574 \Lambda-(16,2933 / T)+0,002401$ \\
\hline Tanigushi $^{(35)}$ & $\begin{array}{l}-\log C_{S}=7,350+94,89 \log \Lambda-(10051+\Lambda(-388(\% M g O)+ \\
0,0841(\% \mathrm{MnO})) / \mathrm{T})+0,2284\left(\% \mathrm{SiO}_{2}\right)+0.1379\left(\mathrm{AL}_{2} \mathrm{O}_{3}\right)- \\
0,0587(\% \mathrm{MgO})+0,0841(\% \mathrm{MnO})\end{array}$ \\
\hline $\begin{array}{l}\text { Sosinsky e } \\
\text { Sommerville }\end{array}$ & $\log C_{S}=\left(\frac{22690-54640 . \Lambda}{T}\right)+43,6 . \Lambda-25,2$ \\
\hline Shankar ${ }^{(34)}$ & $\log L_{S}=\log C_{S}-\frac{935}{T}+1,375+\log f_{S}-\log h_{O}$ \\
\hline Inoue e Suito ${ }^{(43)}$ & $\log L_{S}=\log C_{S}-\frac{1053}{T}+5,73+\log f_{S}$ \\
\hline Mitsutaka $^{(44)}$ & $\log L_{S}=\log C_{S}-(1 / 3) \log a_{\mathrm{Al}_{2} \mathrm{O}_{3}}+(2 / 3) \log [\%$ massaAl $]+(21168 / T)-5,703$ \\
\hline
\end{tabular}

\subsubsection{Simulações termodinâmicas computacionais}

Para a determinação das fases formadas, fração de fase líquida e sólida, teor de enxofre de equilíbrio e atividade do $\mathrm{CaO}$, foi utilizado o software Thermo-Calc. $\mathrm{O}$ banco de dados utilizado para os cálculos foi o SLAG3 Database.

Inicialmente, foram efetuados os cálculos das fases presentes nas misturas iniciais em diferentes temperaturas, a fim de determinar a fração de fase sólida e líquida formada nas misturas. Para calcular os teores de enxofre de equilíbrio, foi necessário realizar um balanço de massa, para que fosse inserida a composição do sistema metal/escória. A tela inicial do programa Thermo-Calc pode ser visualizada na Figura 48. 


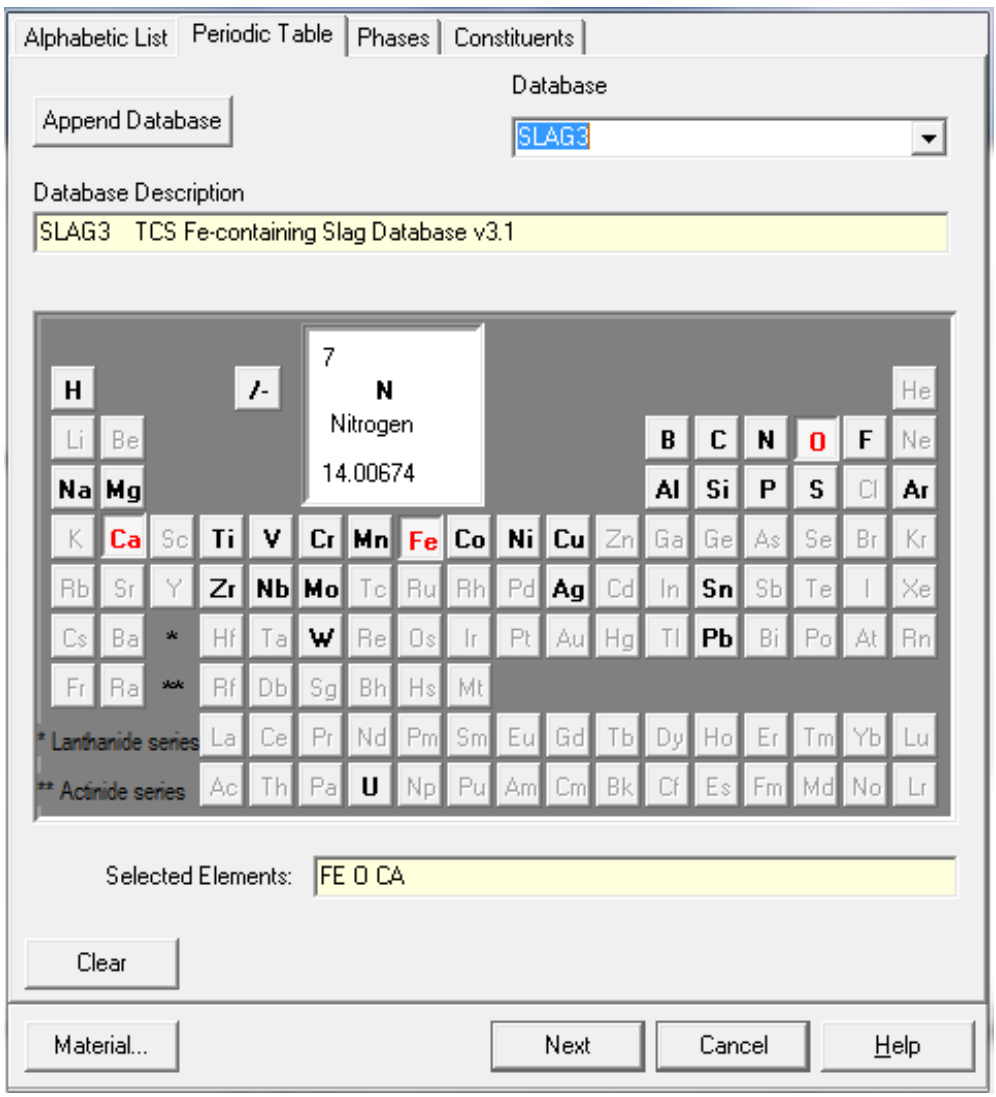

Figura 48 Tela inicial de entrada de dados no Thermo-Calc.

Verifica-se que na tela inicial é possível escolher o banco de dados e os elementos que estão presentes no sistema metal/escória. Após a identificação das fases formadas nas escórias dessulfurantes, foi realizado o cálculo de equilíbrio entre metal/escória.

O software FactSage 6.3 foi utilizado para o cálculo da viscosidade de todas as escórias. O banco de dados utilizado nesta análise foi o melts database.

\subsubsection{Cálculo de eficiência dessulfurante}

Para o cálculo da eficiência de dessulfuração, foi considerada a Equação 33. 
$\operatorname{Eficiência~}(\%)=\frac{\left(\left[\% S_{i}\right]-\left\lfloor \% S_{f}\right\rfloor\right)}{\left[\% S_{i}\right]} \times 100$

Onde:

Eficiência será abreviada em $\eta(\%)$;

[\% $\left.\mathrm{S}_{\mathrm{i}}\right]$ é a concentração de enxofre inicial; e

$\left[\% S_{f}\right]$ é a concentração final de enxofre.

\subsubsection{Cálculo de viscosidade}

O modelo de viscosidade do FactSage 6.3, calcula apenas a viscosidade da fase líquida ${ }^{(101)}$. No entanto, com a fração de fase sólida da escória e com os dados da viscosidade da fase líquida, pode ser calculada a viscosidade efetiva da escória de acordo com a equação desenvolvida por Pretorius e Carlisle ${ }^{(102)}$, como mostra a Equação 34.

$\eta_{e}=\eta^{*}\left(1-1.35^{*} X \text { sol }\right)^{-\frac{5}{2}}$

Onde:

$\eta_{\mathrm{e}}=$ Viscosidade efetiva da escória;

$\eta$ = Viscosidade da escória líquida; e

Xsol = Fração da fase sólida.

Este modelo foi utilizado para calcular a viscosidade efetiva de todas as escórias produzidas neste trabalho.

\subsubsection{Cálculo da constante de velocidade (k)}

A constante de velocidade $(k)$ foi calculada de acordo com Equação 35. 
$k=\ln \left(\frac{\left[\% S_{0}\right]-\left[\% S_{e q}\right]}{\left[\% S_{t}\right]-\left[\% S_{e q}\right]}\right) /(t)$

Onde,

\%S: Concentração de enxofre inicial no metal;

\% $\mathrm{S}_{\text {eq }}$ : Concentração de enxofre de equilíbrio no metal;

\% $\mathrm{S}_{\mathrm{t}}$ : Concentração de enxofre no tempo "t" no metal.

Substituindo os valores de enxofre inicial, de equilíbrio e com o enxofre obtido nos experimentos, foram determinados os valores da constante de velocidade $(k)$. 


\section{RESULTADOS E DISCUSSÃO}

Este tópico foi dividido em duas partes: Na primeira, foram discutidos os resultados de caracterização química, física e mineralógica das matérias-primas que compõem as escórias. $\mathrm{Na}$ segunda etapa, foram apresentados os resultados experimentais do (ferro-gusa, ferro fundido e aço) e comparados com dados termodinâmicos.

\subsection{CARACTERIZAÇÃO DO RESÍDUO DE MÁRMORE, $\mathrm{CaO}, \mathrm{Al}_{2} \mathrm{O}_{3}, \mathrm{CaF}_{2} \mathrm{e}$ SODALITA.}

\subsubsection{Análise Química}

$\mathrm{Na}$ Tabela 21 pode ser visualizada a composição química da cal convencional, sodalita, fluorita, $\mathrm{Al}_{2} \mathrm{O}_{3}, \mathrm{MgO}$ e do resíduo de mármore. Estes materiais foram utilizados na formulação das misturas dessulfurantes.

Tabela 21. Resultados das análises químicas das matérias-primas (\% massa).

\begin{tabular}{|c|c|c|c|c|c|c|c|c|c|}
\hline Elementos & $\begin{array}{c}\text { Cal } \\
\text { Calcítica }\end{array}$ & Sodalita & $\begin{array}{l}\text { Resíduo } \\
\text { mármore }\end{array}$ & $\begin{array}{l}\text { Resíduo } \\
\text { calcinado }\end{array}$ & $\mathrm{Al}_{2} \mathrm{O}_{3}$ & $\mathrm{MgO}$ & Fluorita* & Fluorita** & $\mathrm{CaO}$ \\
\hline $\mathrm{SiO}_{2}$ & 1,56 & 51,73 & 3,33 & 5,75 & - & 1 & - & 6,89 & - \\
\hline $\mathrm{Fe}_{2} \mathrm{O}_{3}$ & 0,37 & 3,05 & - & - & - & 2 & - & - & - \\
\hline $\mathrm{Al}_{2} \mathrm{O}_{3}$ & 0,43 & 21,87 & - & - & 98,4 & 1 & - & - & - \\
\hline $\mathrm{MnO}$ & - & & - & - & - & 1,2 & - & - & - \\
\hline $\mathrm{K}_{2} \mathrm{O}$ & - & 4,76 & - & - & - & - & - & - & - \\
\hline $\mathrm{Na}_{2} \mathrm{O}$ & - & 12,61 & - & - & - & - & - & - & - \\
\hline $\mathrm{CaF}_{2}$ & - & 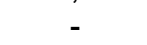 & - & - & - & - & 98,6 & 88,6 & - \\
\hline PF & 4,23 & 4,33 & 42,08 & - & - & - & - & 2,6 & - \\
\hline $\mathrm{CaO}$ & 92,87 & 0,98 & 39,80 & 68,72 & - & 0,8 & - & 1,85 & 99,9 \\
\hline $\mathrm{MgO}$ & 0,54 & - & 14,40 & 24,86 & - & 94 & - & - & - \\
\hline Outros & - & - & 0,39 & 0,67 & 1,6 & - & 1,4 & - & - \\
\hline
\end{tabular}

Verifica-se que a cal convencional possui $92,9 \%$ de $\mathrm{CaO}$. A sodalita é composta basicamente por $\mathrm{SiO}_{2}, \mathrm{Al}_{2} \mathrm{O}_{3}$ e $\mathrm{Na}_{2} \mathrm{O}$. Estes óxidos também foram encontrados por Silva ${ }^{(80)}$ na composição da sodalita.

Nota-se que o resíduo de mármore possui $39,8 \%$ de $\mathrm{CaO}$ e 14,4\% de $\mathrm{MgO}$. Esse teor de $\mathrm{CaO}(39,8 \%)$ foi considerado nos cálculos das misturas dessulfurantes. 
Com a adição das misturas com resíduo de mármore no metal, ocorre a decomposição dos carbonatos, liberando $42,08 \%$ da massa total na forma de $\mathrm{CO}_{2}$. Por fim, considerando apenas a massa de resíduo que chega ao metal e fazendo a normalização para $100 \%$, o resíduo possui $68,7 \%$ de $\mathrm{CaO}$. A composição química do resíduo de mármore está de acordo com os teores encontrados por Cocchi ${ }^{(103)}$.

Para as escórias de ferro fundido foi utilizada $\mathrm{CaO}$ analítico com 99,9\% em massa de $\mathrm{CaO}$.

\subsubsection{Análise Mineralógica por difratometria}

Na Figura 49 consta a análise difratométrica do resíduo de mármore.

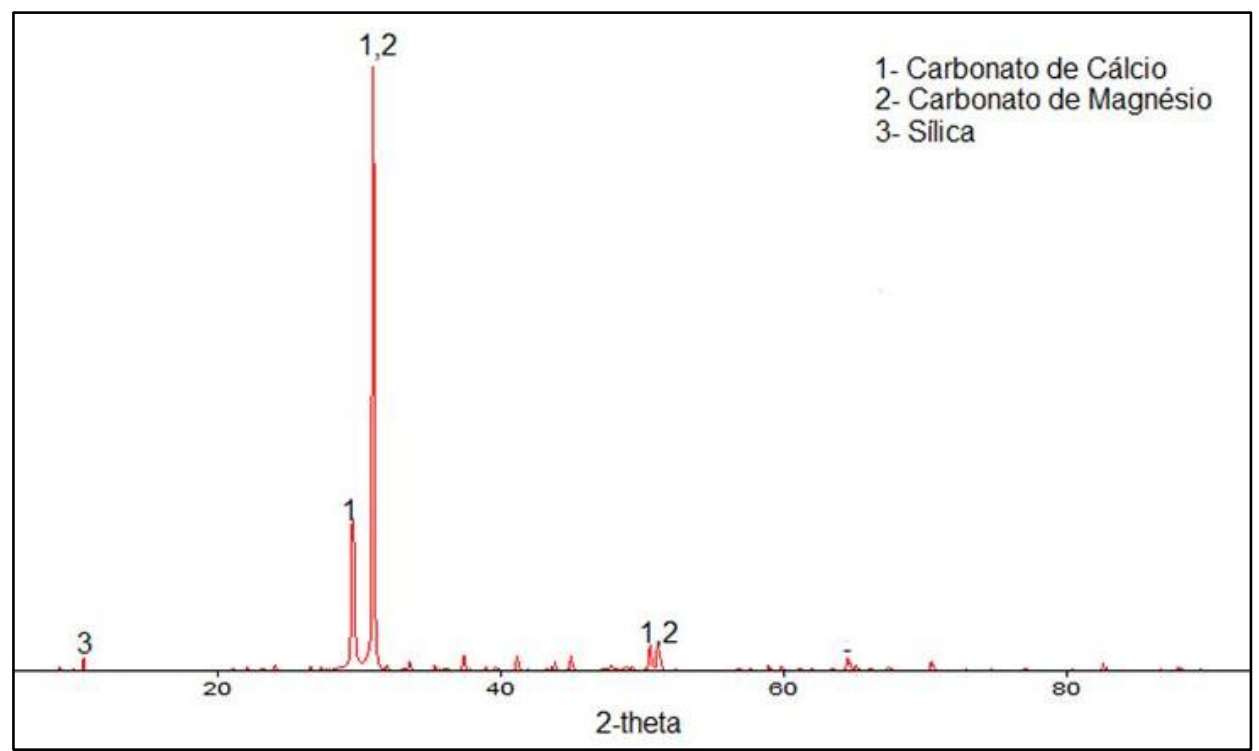

Figura 49. Análise difratométrica do resíduo de mármore.

Os resultados mostraram que o resíduo é composto de carbonato de cálcio, carbonato de magnésio e sílica (Quartzo). Os carbonatos, quando adicionados ao banho metálico, se decompõem em $\mathrm{CaO}, \mathrm{MgO}$ e $\mathrm{CO}_{2}$. Esta decomposição pode favorecer o transporte de massa do enxofre na escória. Por outro lado, a reação de decomposição dos carbonatos é endotérmica, o que pode diminuir a temperatura do metal, desfavorecendo a dessulfuração. 


\subsubsection{Análise termogravimétrica do resíduo de mármore}

Na Figura 50 pode ser visualizada a curva de perda de massa em função do tempo para o resíduo de mármore.

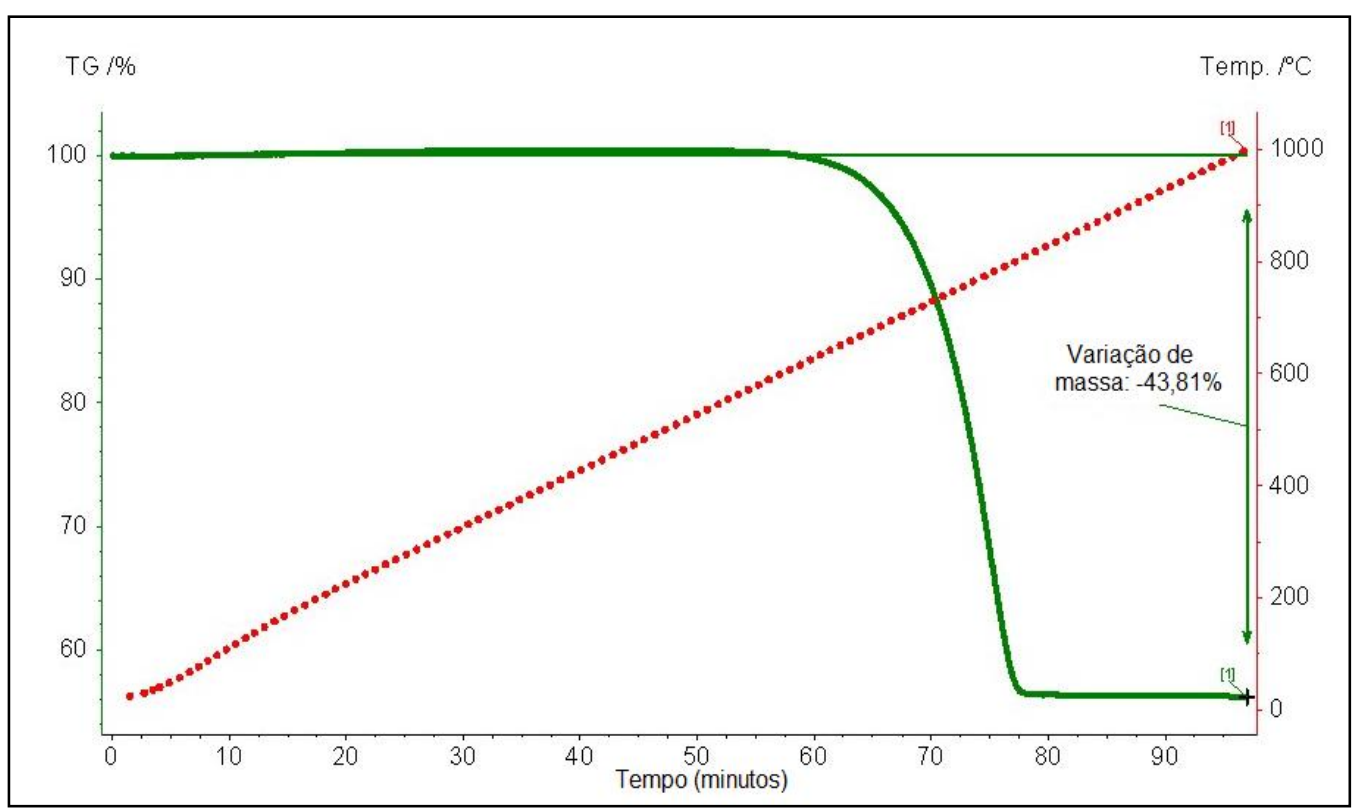

Figura 50. Análise termogravimétrica do resíduo de mármore apresentando a variação de massa com a decomposição dos carbonatos.

Nota-se que aproximadamente $100 \%$ da perda de massa do resíduo de mármore, ocorreu em temperaturas entre $700^{\circ} \mathrm{C}$ a $820^{\circ} \mathrm{C}$, intervalo em que ocorre a decomposição dos carbonatos de cálcio e magnésio. Não foi observada perda de massa por umidade no resíduo, uma vez que, não houve variação de massa em temperaturas de até $100^{\circ} \mathrm{C}$. Aguiar ${ }^{(93)}$ realizou o DTA do resíduo de mármore e observou um pico endotérmico entre as temperaturas de $750^{\circ} \mathrm{C}$ e $870^{\circ} \mathrm{C}$, faixa de decomposição dos carbonatos, similar ao encontrado neste trabalho.

\subsubsection{Análise Granulométrica e Área Superficial Pelo Método de BET}

A Figura 51 apresenta a curva de distribuição granulométrica do resíduo de mármore obtida através do equipamento Malvern - Mastersizer 2000. 


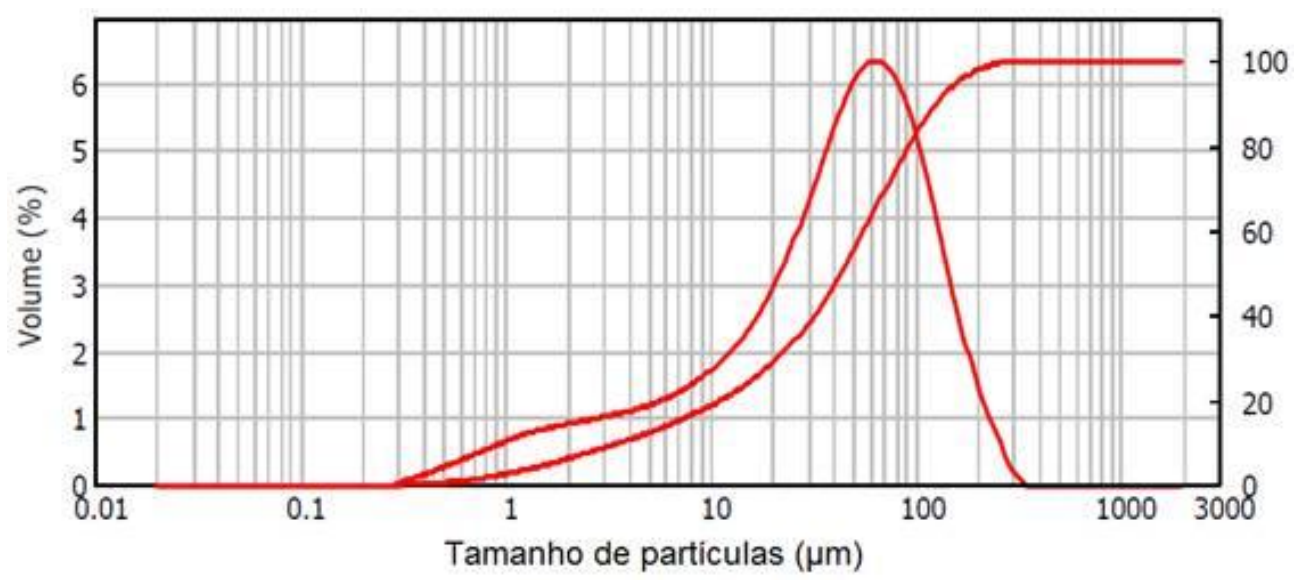

Figura 51. Distribuição granulométrica do resíduo de mármore.

Analisando a Figura 51, verifica-se que aproximadamente $90 \%$ das partículas estão abaixo de $100 \mu \mathrm{m}$. A Figura 52 apresenta a distribuição granulométrica das partículas de cal utilizada nos experimentos.

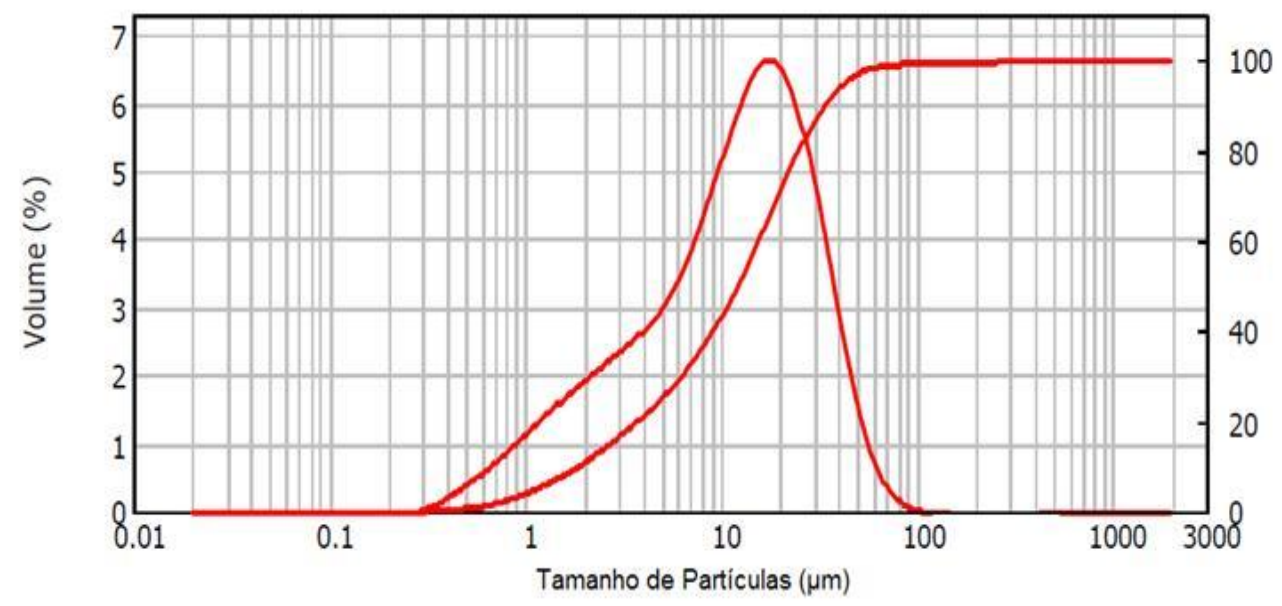

Figura 52. Distribuição granulométrica do óxido de cálcio.

Nota-se que aproximadamente $100 \%$ das partículas do $\mathrm{CaO}$ possuem diâmetro menor que $100 \mu \mathrm{m}$. Quando comparada com o resíduo de mármore, a cal apresenta menor diâmetro de partícula.

Fazendo uma correlação entre o diâmetro das partículas e a área superficial, o resíduo de mármore apresentou $0,24 \mathrm{~m}^{2} / \mathrm{g}$ de área superficial, enquanto que, o $\mathrm{CaO}$ apresentou $1,52 \mathrm{~m}^{2} / \mathrm{g}$ de área superficial. Estes resultados estão coerentes com as análises granulométricas, ou seja, maior o diâmetro das partículas, menor a área superficial. 
O MgO possui $95 \%$ das partículas com tamanho inferior a $105 \mu \mathrm{m}$. Por fim, a análise granulométrica da alumina mostrou que $100 \%$ do diâmetro de partículas estão na faixa de $34 \mu \mathrm{m}$ a $205 \mu \mathrm{m}$.

\subsubsection{Análise Microscópica Eletrônica de Varredura com EDS.}

Na Figura 53 podem ser visualizados os resultados da análise de MEV e EDS do resíduo de mármore utilizado para formular as misturas dessulfurantes.

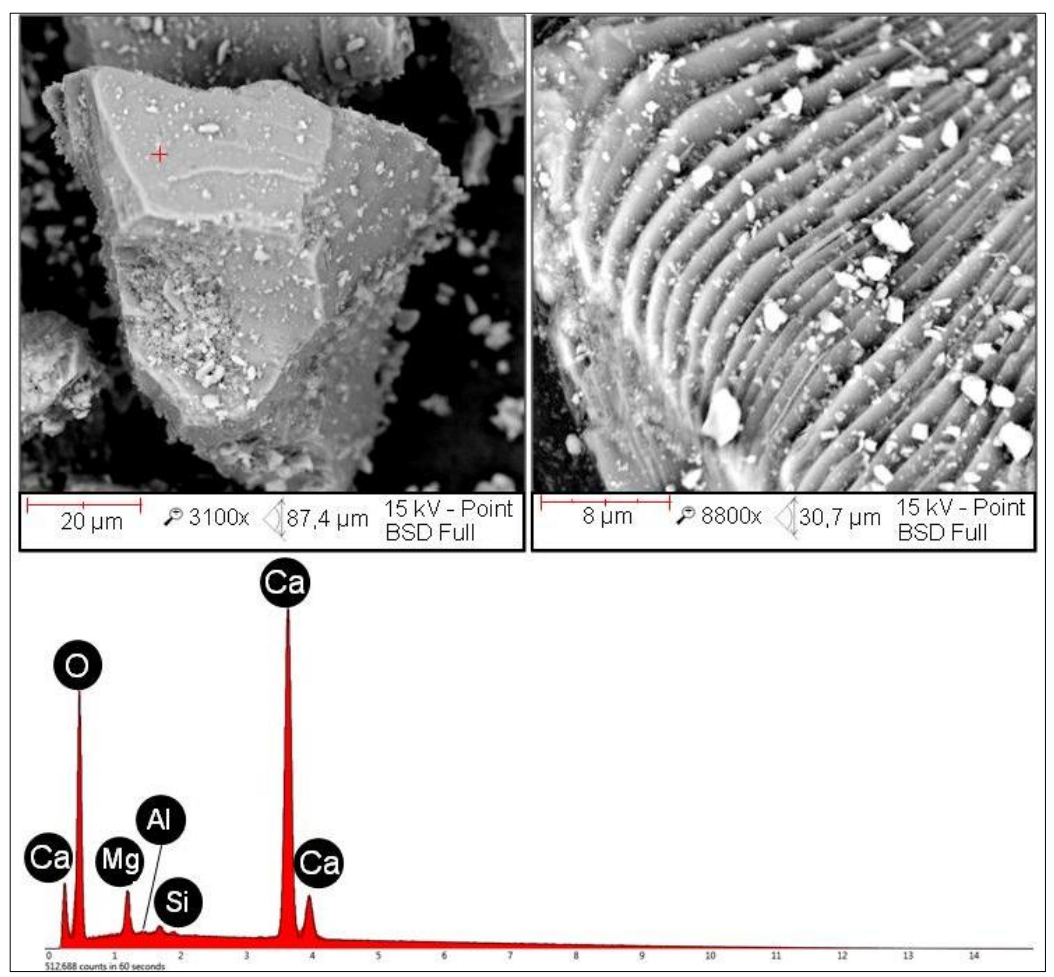

Figura 53. Imagem de elétrons retroespalhados obtida em microscópio eletrônico de varredura do resíduo de mármore e análise de microrregiões por dispersão de energia (EDS) da região em destaque.

Nota-se que o resíduo de mármore possui uma morfologia angular e textura rugosa, além de linhas de clivagem. Essas características também foram encontradas na caracterização do resíduo de mármore realizada por Alyamaç et $a{ }^{(104)}$. Mansur ${ }^{(105)}$ por sua vez, realizou a caracterização de amostras de calcário. Os resultados indicaram formas angulares com uma textura rugosa. 
$\mathrm{O}$ espectro revelou que os principais picos encontrados foram o $\mathrm{Ca}, \mathrm{Mg}, \mathrm{O}$ e Si. Estes resultados mostram que o cálcio está presente em maior proporção do que os demais constituintes.

Na Figura 54 podem ser visualizados os resultados da análise de MEV e EDS da sodalita.

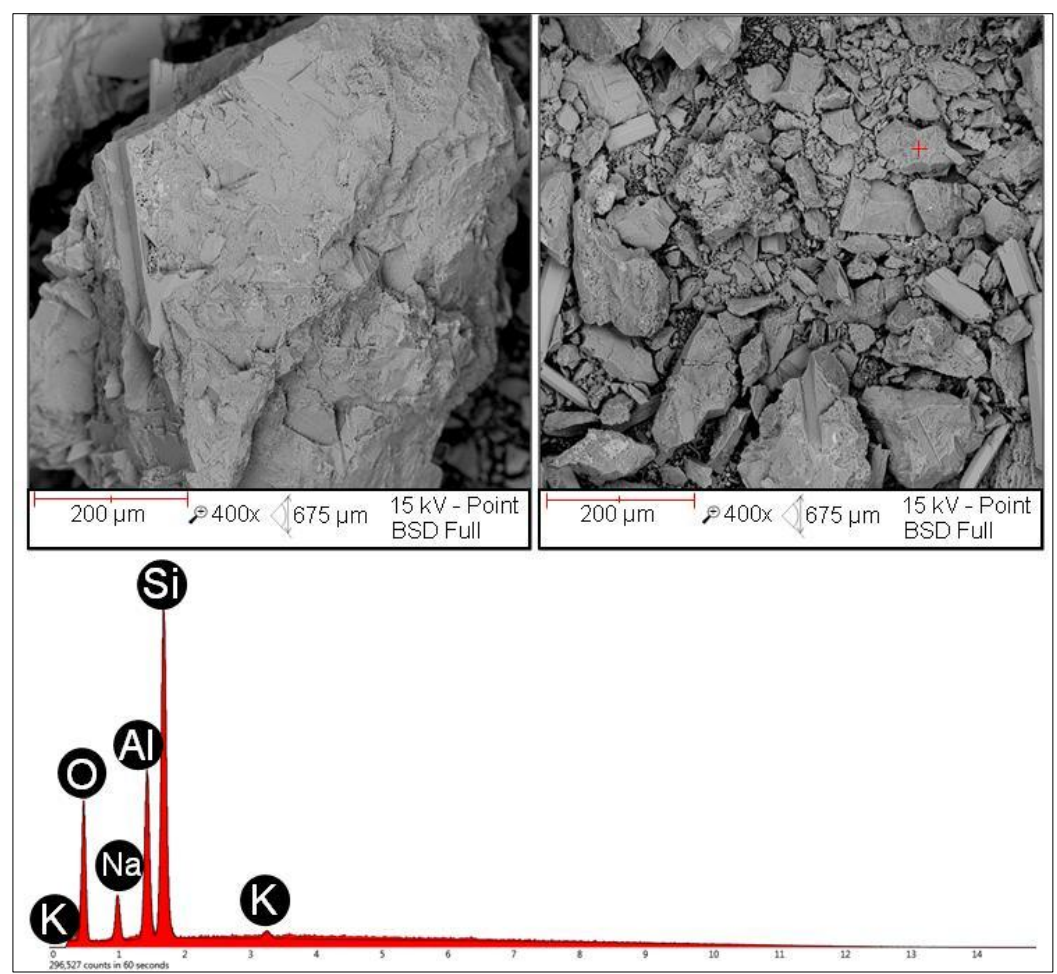

Figura 54. Imagem de elétrons retroespalhados obtida em microscópio eletrônico de varredura da sodalita e análise de microrregiões por dispersão de energia (EDS) da região em destaque.

Verifica-se que a miscrocopia eletrônica da sodalita mostrou que o material possui partículas angulosas e irregulares. É possível observar também, baseado no EDS, que em sua composição estão presentes silício, alumínio, sódio e potássio.

\subsection{ANÁLISES DOS RESULTADOS EXPERIMENTAIS}

Esta seção foi dedicada para descrever os resultados obtidos nos experimentos e compará-los com os dados termodinâmicos. Inicialmente, serão apresentados os dados encontrados para o ferro-gusa, em seguida os de ferro fundido e, por fim, de aço. 


\subsubsection{Avaliação dos resultados encontrados para escórias dessulfurantes de ferro-gusa}

5.2.1.1 Análise dos resultados experimentais com o uso das misturas dessulfurantes de ferro-gusa

A Tabela 22 mostra a variação da concentração do enxofre em função do tempo e da eficiência de dessulfuração para cada experimento. Todos os resultados foram organizados em ordem decrescente de eficiência dessulfurante.

Tabela 22. Variação do enxofre no ferro-gusa durante o processo de dessulfuração.

\begin{tabular}{ccccccc}
\hline \multirow{2}{*}{ Misturas } & \multicolumn{5}{c}{ Tempo (min) } & \multirow{2}{*}{$\eta(\%)$} \\
\cline { 2 - 5 } & Inicial & 10 & 15 & 20 & 30 & 97,1 \\
CAF10 & 0,0318 & 0,0132 & 0,0094 & 0,0031 & 0,0009 & 96,5 \\
CAF5 & 0,0286 & 0,0122 & 0,0092 & 0,0045 & 0,0010 & 90,2 \\
RMF10 & 0,0303 & 0,0177 & 0,0116 & 0,0067 & 0,0029 & 86,1 \\
RMF5 & 0,0291 & 0,0203 & 0,0142 & 0,0092 & 0,0040 & 85,9 \\
CAS5 & 0,0360 & 0,0198 & 0,0105 & 0,0068 & 0,0050 & 81,4 \\
RMS5 & 0,0287 & 0,0189 & 0,0103 & 0,0077 & 0,0053 & 78,6 \\
RMS10 & 0,0305 & 0,0217 & 0,0158 & 0,0111 & 0,0065 & 74,5 \\
CAS10 & 0,0282 & 0,0207 & 0,0157 & 0,0111 & 0,0071 & \\
\hline
\end{tabular}

Com o intuito de melhor avaliar o comportamento dos ensaios, foram construídas curvas de variação do enxofre em função do tempo de experimento nas Figuras 55 e 56.

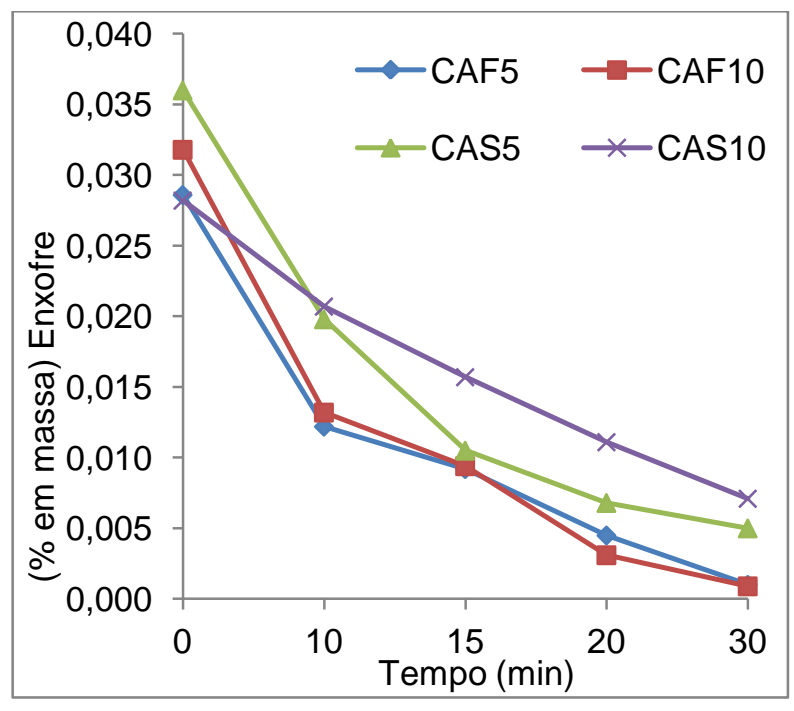

Figura 55. Variação do teor de enxofre no ferro-gusa em função do tempo de experimento para as escórias com a cal convencional.

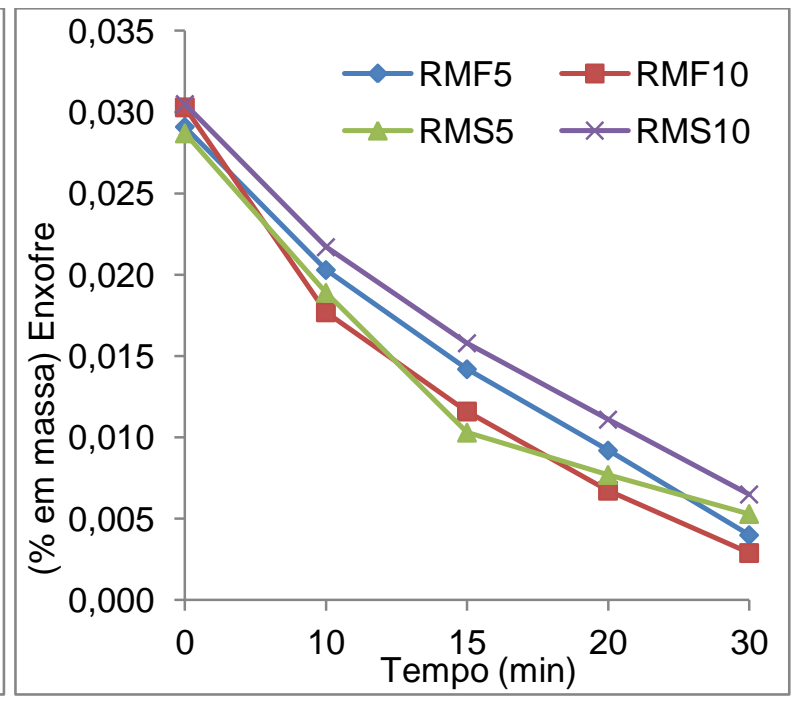

Figura 56. Variação do teor de enxofre no ferro-gusa em função do tempo de experimento para escórias com o resíduo de mármore. 
Nota-se na Figura 55, que as escórias formuladas com cal convencional e com o uso da fluorita (CAF5 e CAF10), obtiveram melhores rendimentos de dessulfuração. Além disso, a adição do dobro de quantidade de fluorita na mistura CAF10 não apresentou influência significativa sobre a eficiência, tendo um aumento de somente $0,6 \%$ no mesmo. Verifica-se ainda que as escórias com sodalita e cal convencional (CAS5 e CAS10) apresentaram menores rendimentos, com 85,9\% e $75,5 \%$, respectivamente.

$\mathrm{Na}$ Figura 56, em que a cal convencional é substituída pelo resíduo de mármore, também é possível observar que as escórias formuladas com a adição de fluorita (RMF5 e RMF10), obtiveram os melhores resultados de remoção do enxofre, com $86,1 \%$ e $90,2 \%$, respectivamente.

O efeito negativo na dessulfuração com o aumento da sodalita de $5 \%$ para $10 \%$, pode ocorrer devido a formação dos compostos $\left(3 \mathrm{CaO} . \mathrm{SiO}_{2}\right)$ e $\left(3 \mathrm{CaO} \cdot \mathrm{Al}_{2} \mathrm{O}_{3}\right)$, que segundo Mitsuo ${ }^{(54)}$ possuem baixa solubilidade de enxofre, o qual obstrui a transferência dos íons $\mathrm{S}^{2+}$ e retardam a dessulfuração.

5.2.1.2 Análise dos parâmetros termodinâmicos de basicidade ótica, capacidade e sulfeto e partição de enxofre

A Tabela 23 mostra os valores da basicidade ótica, capacidade de sulfeto e partição de enxofre das escórias sintéticas dessulfurantes de ferro-gusa. Para estes resultados, foram considerados os modelos de capacidade de sulfeto de Sosinky e Sommerville ${ }^{(32)}$ e Young ${ }^{(112)}$, que estão dentro da faixa de composição e temperatura para essas escórias. 
Tabela 23. Valores da basicidade ótica $(\Lambda)$, capacidade de sulfeto (Cs) e partição de enxofre (Ls) das misturas dessulfurantes de ferro-gusa a $1400^{\circ} \mathrm{C}$.

\begin{tabular}{|c|c|c|c|c|c|c|}
\hline \multirow[b]{2}{*}{ Misturas } & \multirow[b]{2}{*}{$\Lambda$} & \multicolumn{2}{|c|}{ Capacidade de sulfeto (Cs) } & \multicolumn{2}{|c|}{ Partição de enxofre (Ls) } & \multirow[b]{2}{*}{$\eta(\%)$} \\
\hline & & $\begin{array}{l}\text { Sosinsky e } \\
\text { Sommerville } \\
\text { (Log Cs) }\end{array}$ & $\begin{array}{l}\text { Young }{ }^{(112)} \\
\text { (Log Cs) }\end{array}$ & $\begin{array}{l}\text { Inoue e } \\
\text { Suito }{ }^{(49)} \\
\text { (Log Ls) }\end{array}$ & $\begin{array}{c}\text { Shankar }^{(34)} \\
\text { (Log Ls) }\end{array}$ & \\
\hline CAF10 & 0,97 & 0,0131 & 1,19183 & 5,515 & 1,644 & 97,1 \\
\hline CAF5 & 0,97 & 0,0150 & 1,19838 & 5,518 & 1,655 & 96,5 \\
\hline RMF10 & 0,89 & 0,0021 & 1,11858 & 5,476 & 1,447 & 90,2 \\
\hline RMF5 & 0,88 & 0,0022 & 1,11908 & 5,476 & 1,449 & 86,1 \\
\hline CAS5 & 0,95 & 0,0083 & 1,17017 & 5,505 & 1,604 & 85,9 \\
\hline RMS5 & 0,88 & 0,0018 & 1,11384 & 5,472 & 1,426 & 81,4 \\
\hline RMS10 & 0,87 & 0,0022 & 1,11971 & 5,467 & 1,397 & 78,5 \\
\hline CAS10 & 0,92 & 0,0044 & 1,14388 & 5,492 & 1,542 & 74,5 \\
\hline
\end{tabular}

Analisando na Tabela 23, observa-se que as misturas com maior basicidade ótica foram aquelas com maior capacidade de sulfeto. De acordo com Ban-Ya et $a{ }^{(106)}$, o aumento da porcentagem de $\mathrm{CaO}$, contribui com o aumento da basicidade ótica e consequentemente com o aumento da capacidade de sulfeto. Este comportamento pode ser visualizado na Figura 57.

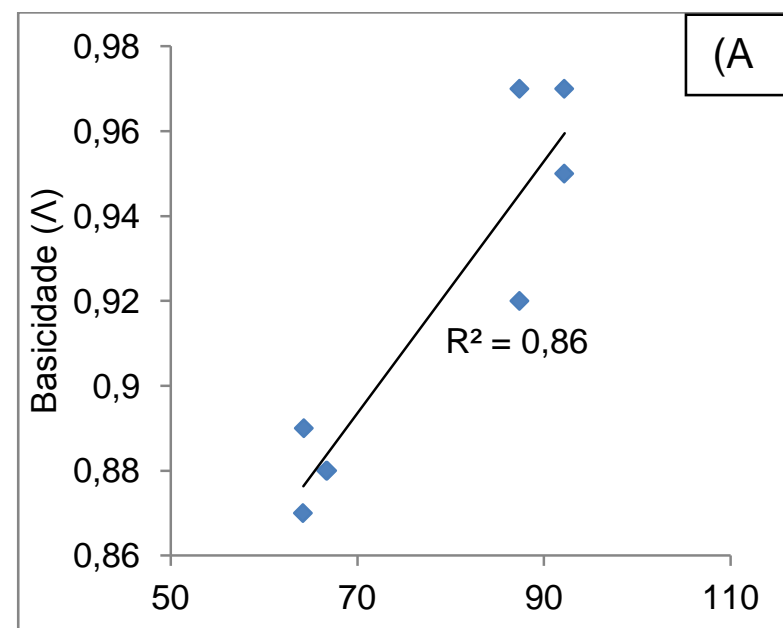

(\%) $\mathrm{CaO}$

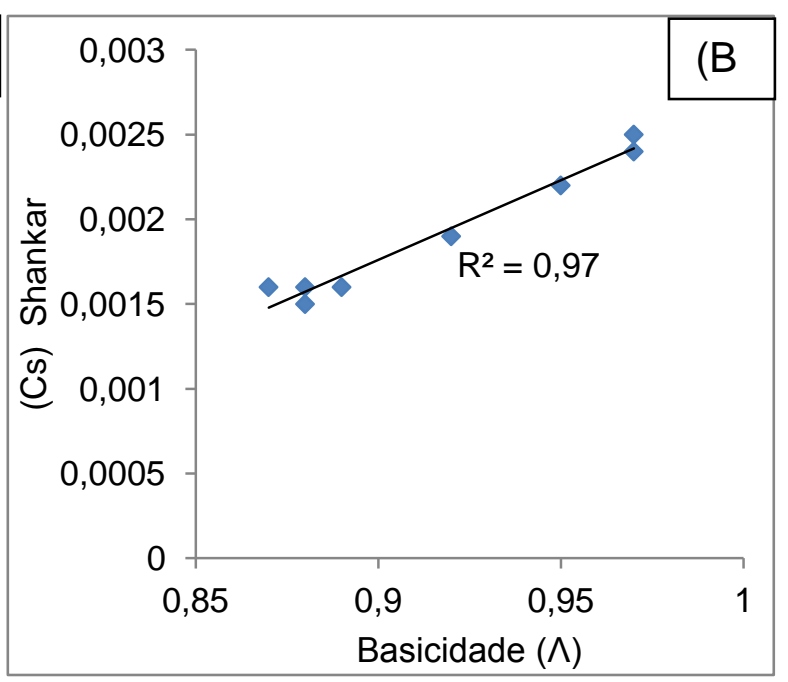

Figura 57. (A) Influência da $(\%)$ de $\mathrm{CaO}$ na basicidade $(\Lambda)$ e $(B)$ influência da basicidade $(\Lambda)$ na capacidade de Sulfeto (Cs).

A Figura 58 apresenta a relação entre a capacidade de sulfeto, partição de enxofre e basicidade ótica em função da eficiência dessulfurante obtida nos experimentos. 


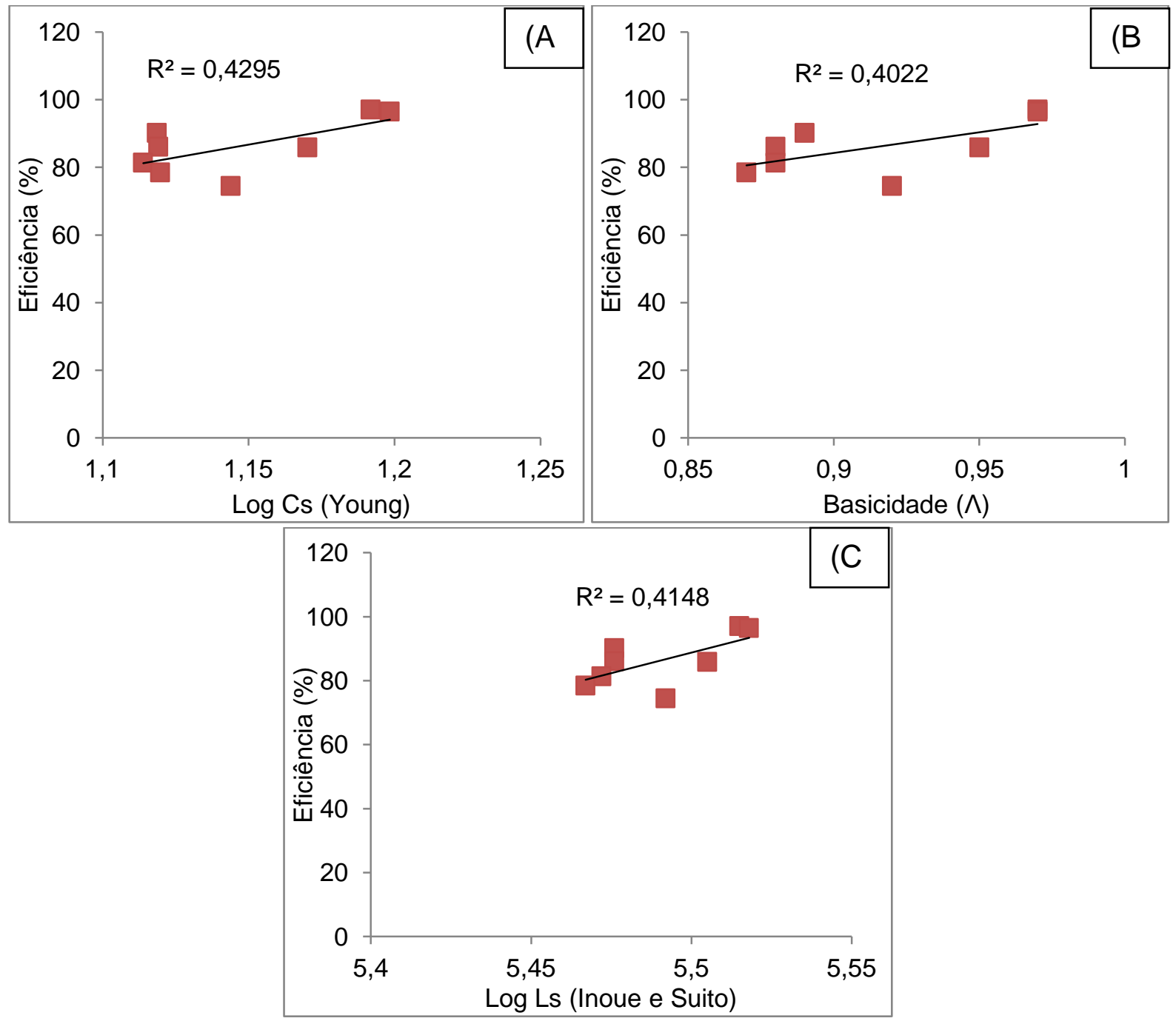

Figura 58. Relação entre a capacidade de sulfeto $(A)$, basicidade ótica $(B)$ e partição de enxofre $(C)$ em função da eficiência dessulfurante para as misturas dessulfurantes de ferro-gusa.

Analisando a Figura 58, observa-se que os parâmetros (Cs, Ls e $\Lambda$ ) não correlacionam com a eficiência dessulfurante. Além disso, nota-se que para o caso de escórias com a mesma basicidade ótica, Cs e Ls, foram obtidos valores de eficiência diferentes. Este comportamento pode dificultar na escolha da melhor escória dessulfurante de ferro-gusa.

5.2.1.3 Análise dos testes experimentais através da termodinâmica computacional.

$\mathrm{Na}$ Tabela 24 pode ser visualizada a concentração de equilíbrio do enxofre, silício, carbono e manganês no ferro-gusa. 
Tabela 24. Concentração de equilíbrio do ferro-gusa a $1400^{\circ} \mathrm{C}$.

\begin{tabular}{cccccc}
\hline Escória & {$\left[\% \mathrm{~S}_{\text {eq }}\right]$} & {$[\% \mathrm{Si}]$} & {$[\% \mathrm{C}]$} & {$[\% \mathrm{Mn}]$} & $\eta(\%)$ \\
\hline CAF10 & $1,60 \mathrm{E}-05$ & 0,46 & 4,47 & 0,18 & 97,1 \\
CAF5 & $1,53 \mathrm{E}-05$ & 0,48 & 4,50 & 0,21 & 96,5 \\
RMF10 & $1,57 \mathrm{E}-05$ & 0,47 & 4,47 & 0,18 & 90,2 \\
RMF5 & $1,46 \mathrm{E}-05$ & 0,52 & 4,50 & 0,21 & 86,1 \\
CAS5 & $1,67 \mathrm{E}-05$ & 0,44 & 4,44 & 0,19 & 85,9 \\
RMS5 & $1,47 \mathrm{E}-05$ & 0,51 & 4,50 & 0,22 & 81,4 \\
RMS10 & $1,65 \mathrm{E}-05$ & 0,45 & 4,42 & 0,19 & 78,5 \\
CAS10 & $1,53 \mathrm{E}-05$ & 0,48 & 4,52 & 0,19 & 74,5 \\
\hline
\end{tabular}

Note-se que as misturas possuem valores próximos de enxofre de equilíbrio, o que indica que ambas as escórias possuem o mesmo potencial termodinâmico para remover o enxofre. Sendo assim, fatores cinéticos podem ser preponderantes para descrever qual será a melhor escória sintética dessulfurante. Dessa forma, foram calculadas as fases presentes nas misturas iniciais com o Thermo-Calc. Com isso, foi identificada a fração de fase líquida e sólida, além dos compostos sólidos das misturas. A Tabela 25 apresenta os resultados.

Tabela 25. Fases formadas nas misturas dessulfurantes utilizando o Thermo-Calc na temperatura de $1400^{\circ} \mathrm{C}$.

\begin{tabular}{|c|c|c|c|c|c|c|c|}
\hline \multirow[b]{2}{*}{ Misturas } & \multirow[b]{2}{*}{ (\%) Líquido } & \multirow[b]{2}{*}{ (\%) Sólido } & \multicolumn{4}{|c|}{ Fases formadas na fase sólida (\%) } & \multirow[b]{2}{*}{$\eta(\%)$} \\
\hline & & & $\mathrm{CaO}$ & $3 \mathrm{CaO} .\left(\mathrm{SiO}_{2}\right)$ & $3 \mathrm{CaO} \cdot\left(\mathrm{Al}_{2} \mathrm{O}_{3}\right)$ & $\mathrm{MgO}$ & \\
\hline CAF10 & 16,82 & 83,18 & 79,61 & 3,57 & - & - & 97,1 \\
\hline CAF5 & 9,04 & 90,96 & 85,43 & 5,53 & - & - & 96,5 \\
\hline RMF10 & 7,41 & 92,59 & 50,58 & 18,21 & - & 23,79 & 90,2 \\
\hline RMF5 & 3,58 & 96,42 & 51,85 & 20,17 & - & 24,40 & 86,1 \\
\hline CAS5 & 2,56 & 97,44 & 77,24 & 16,77 & 3,42 & - & 85,9 \\
\hline RMS5 & 2,31 & 97,69 & 48,54 & 24,42 & 0,29 & 24,44 & 81,4 \\
\hline RMS10 & 4,78 & 95,22 & 43,84 & 27,00 & 0,72 & 23,67 & 78,5 \\
\hline CAS10 & 4,76 & 95,24 & 63,67 & 25,18 & 6,39 & - & 74,5 \\
\hline
\end{tabular}

$\mathrm{Na}$ análise dos dados da Tabela 25, nota-se que as escórias com o uso da cal convencional (CF5, CF10, CAS5, CAS10), apresentaram maiores porcentagens de fase líquida a $1400^{\circ} \mathrm{C}$, quando comparadas com as escórias em que o resíduo de mármore foi empregado (RMF5, RMF10, RMS5, RMS10), conforme observado na Figura 59. 


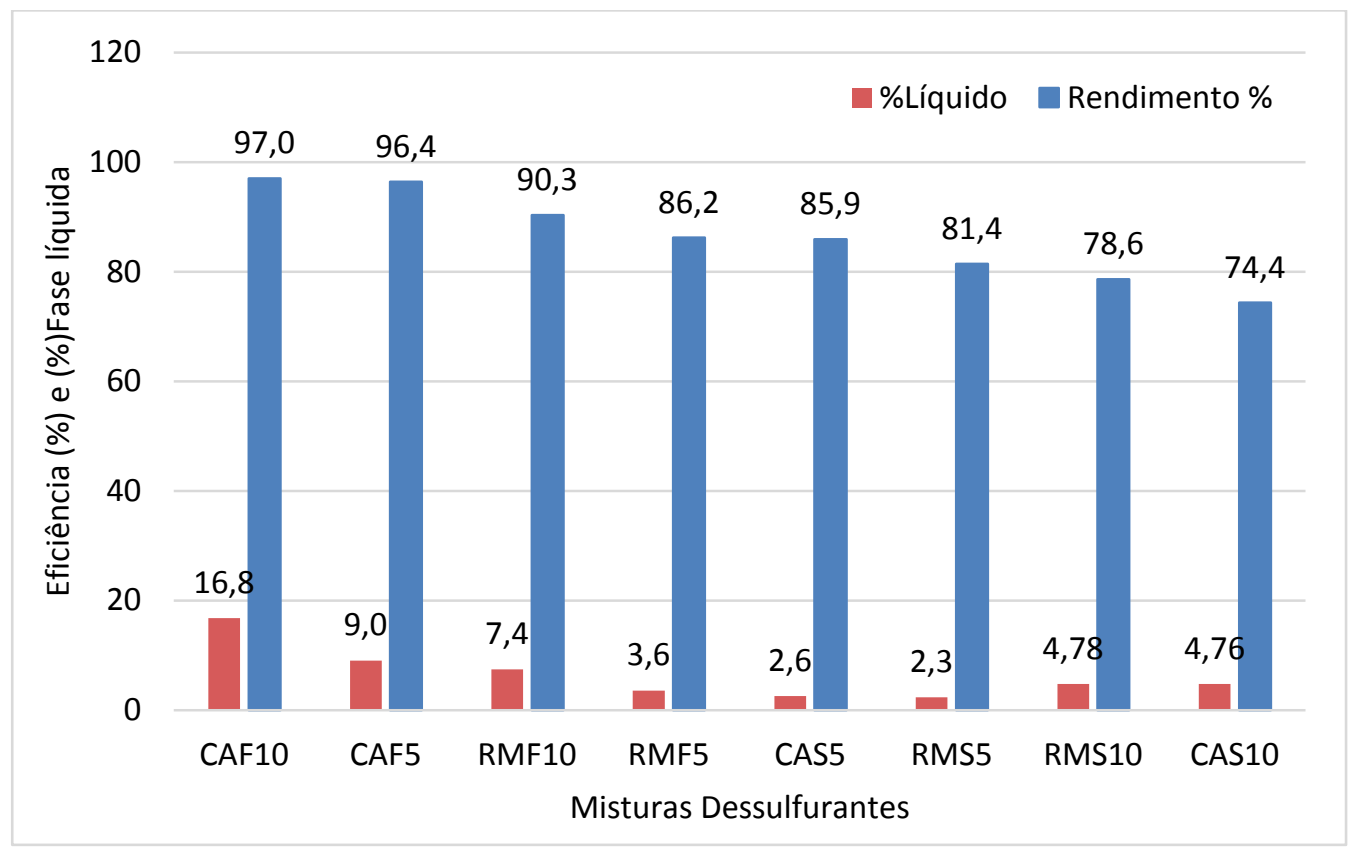

Figura 59. Comparação entre a concentração de fase líquida com o uso da fluorita e sodalita na dessulfuração de ferro-gusa.

Observa-se que as escórias que tiveram o uso de fluorita, apresentaram maior concentração de fase líquida, quando comparadas com as escórias em que se fez o uso da sodalita. Este comportamento é devido à formação de compostos sólidos com o uso da sodalita, conforme mostra a Figura 60.

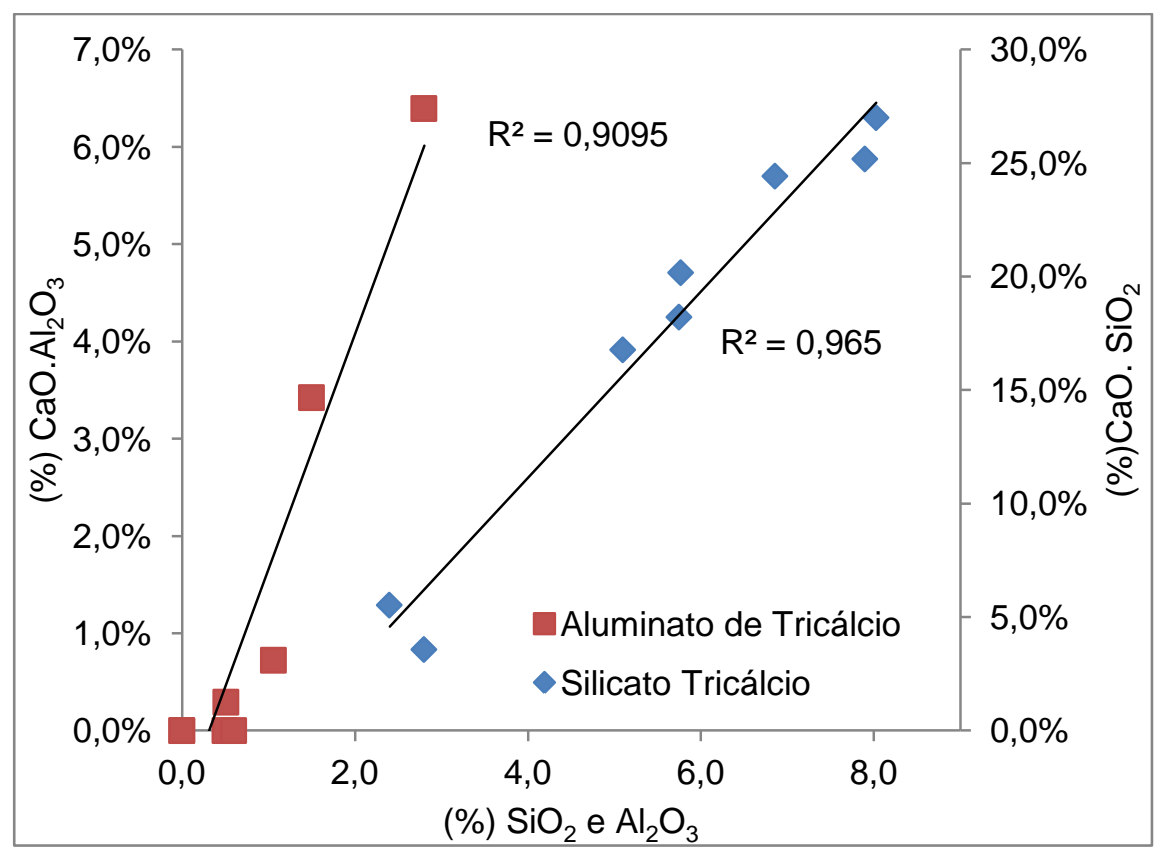

Figura 60. Influência da concentração de $\mathrm{SiO}_{2}$ e $\mathrm{Al}_{2} \mathrm{O}_{3}$ na formação do composto silicato tricálcio e aluminato tricálcio das escórias iniciais na temperatura de $1400^{\circ} \mathrm{C}$. 
Verifica-se que o aumento da concentração de $\mathrm{SiO}_{2}$ e $\mathrm{Al}_{2} \mathrm{O}_{3}$, favoreceu a formação dos compostos sólidos de silicato tricálcio $\left(3 \mathrm{CaO} . \mathrm{SiO}_{2}\right)$ e aluminato tricálcio $\left(3 \mathrm{CaO} \cdot \mathrm{Al}_{2} \mathrm{O}_{3}\right)$.

De acordo com Niedringhaus e Fruehan ${ }^{(53)}$, Ohya ${ }^{(107)}$ e Seok et a/ ${ }^{(108)}$, que estudaram a influência da camada sólida no processo de dessulfuração de ferro-gusa, o aumento da quantidade dos compostos $\left(3 \mathrm{CaO} . \mathrm{SiO}_{2}, 3 \mathrm{CaO} \cdot \mathrm{Al}_{2} \mathrm{O}_{3}\right.$, $\left.2 \mathrm{CaO} . \mathrm{SiO}_{2}\right)$ na escória, prejudicam a dessulfuração. De acordo com esses estudos, uma camada desses compostos se forma ao redor das partículas de $\mathrm{CaO}$, prejudicando a difusão do enxofre e aumentando a temperatura de fusão da partícula.

A Figura 61 apresenta as fases presentes nas misturas iniciais geradas a partir do Thermo-Calc. 

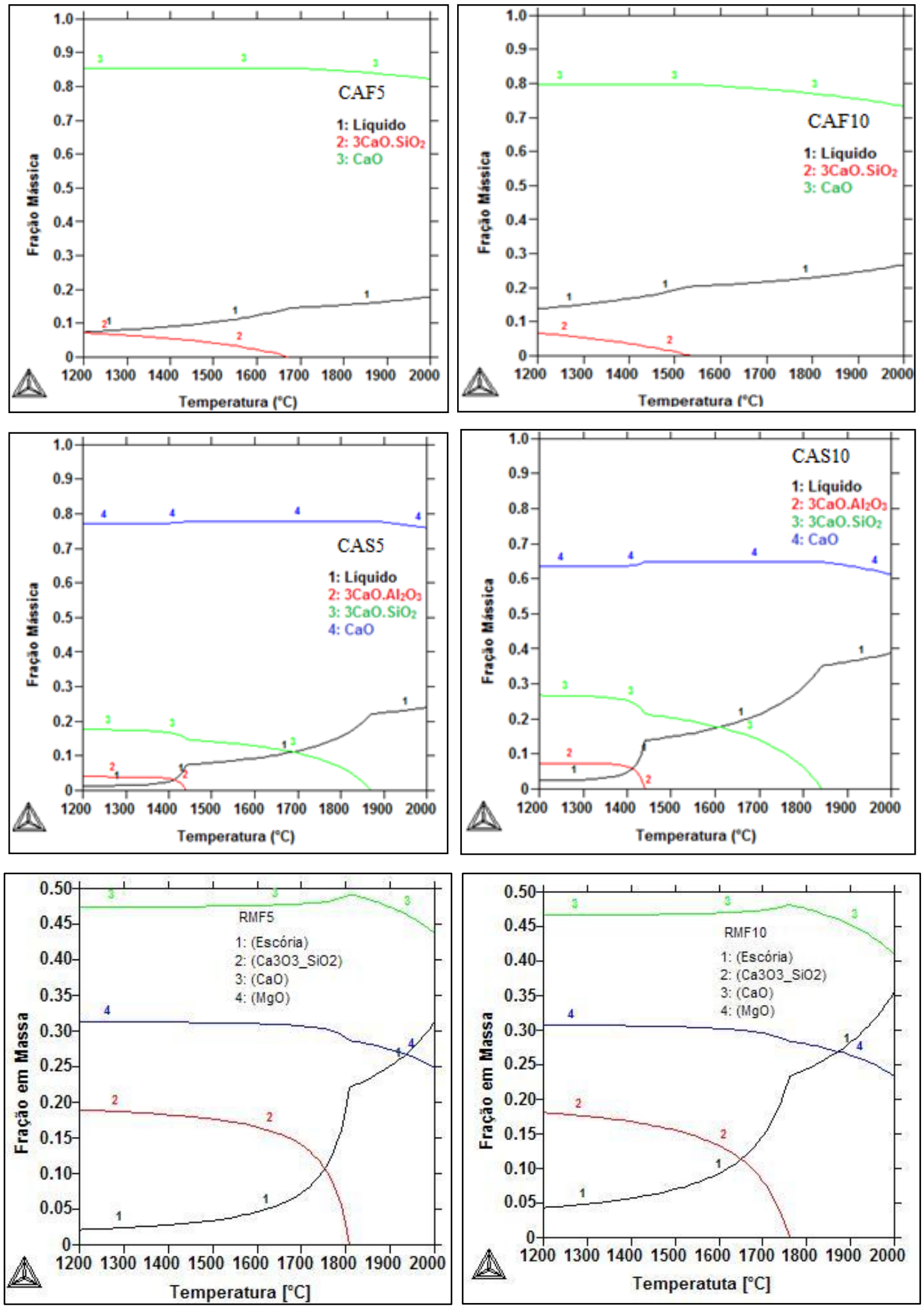

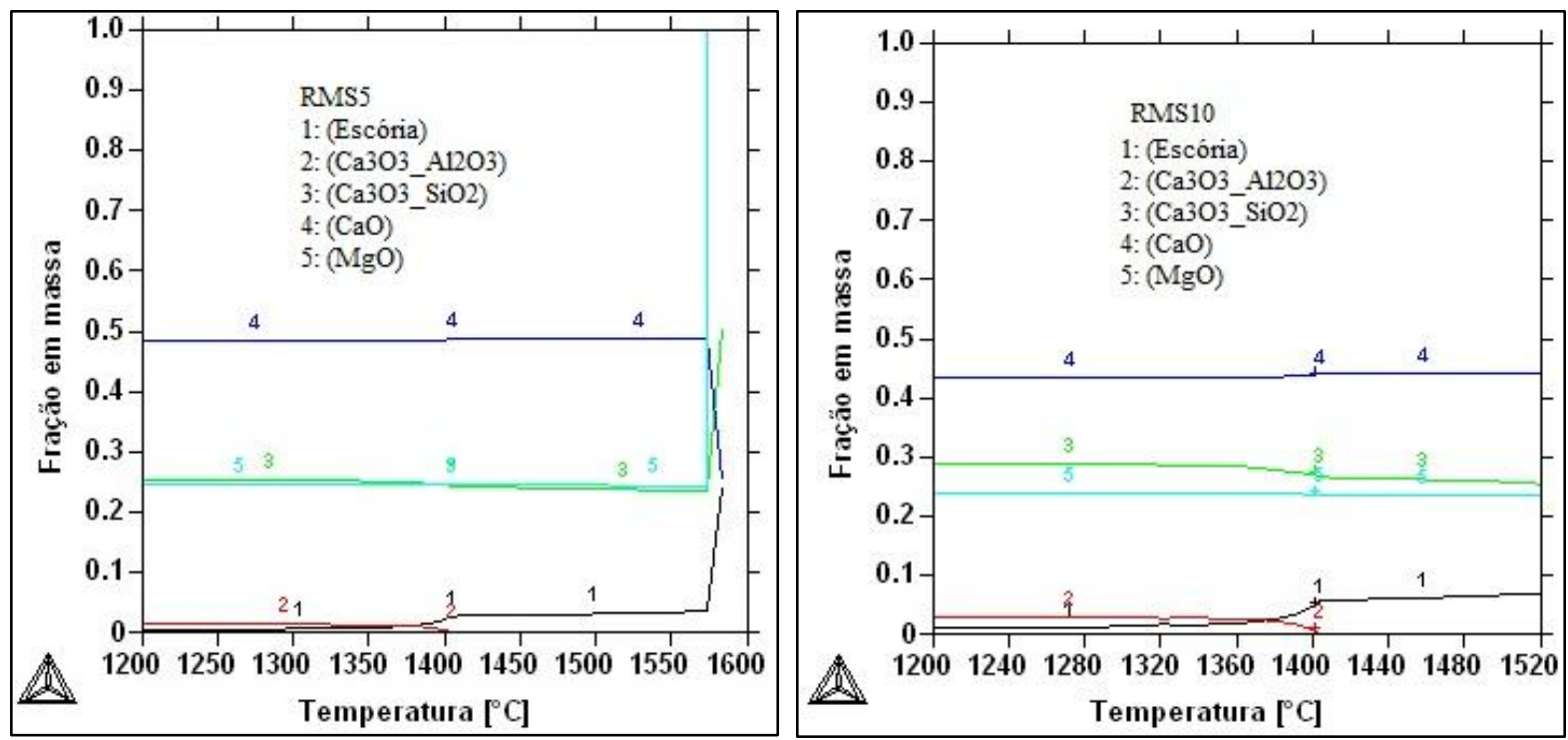

Figura 61. Fases presentes nas misturas iniciais de ferro-gusa com o aumento da temperatura.

Observa-se, através da Figura 61, que todas as misturas dessulfurantes possuem fração de sólidos maior do que a fração de líquido na temperatura em que foram realizados os experimentos $\left(1400^{\circ} \mathrm{C}\right)$.

Além disso, nota-se que as misturas formuladas com fluorita (CAF5, CAF10) apresentaram maior quantidade de fase líquida (9,0\% e 16,8\%). As misturas CS5, CS10, RMS5 e RMS10 possuem um aumento da fração de líquido em temperaturas superiores a $1400^{\circ} \mathrm{C}$. Estas misturas foram produzidas com o uso da sodalita em substituição a fluorita. Tal resultado evidencia que a utilização destas misturas, na faixa de temperatura entre $1450^{\circ} \mathrm{C}$ a $1550^{\circ} \mathrm{C}$ pode contribuir para que se obtenha melhor eficiência dessulfurante.

5.2.1.4 Efeito dos compostos sólidos $3 \mathrm{CaO} . \mathrm{SiO}_{2}$ e $3 \mathrm{CaO} . \mathrm{Al}_{2} \mathrm{O}_{3}$ na taxa de dessulfuração

O comportamento da dessulfuração com a presença dos compostos $3 \mathrm{CaO} . \mathrm{SiO}_{2}$ e do $3 \mathrm{CaO} \cdot \mathrm{Al}_{2} \mathrm{O}_{3}$ é apresentado na Figura 62. 


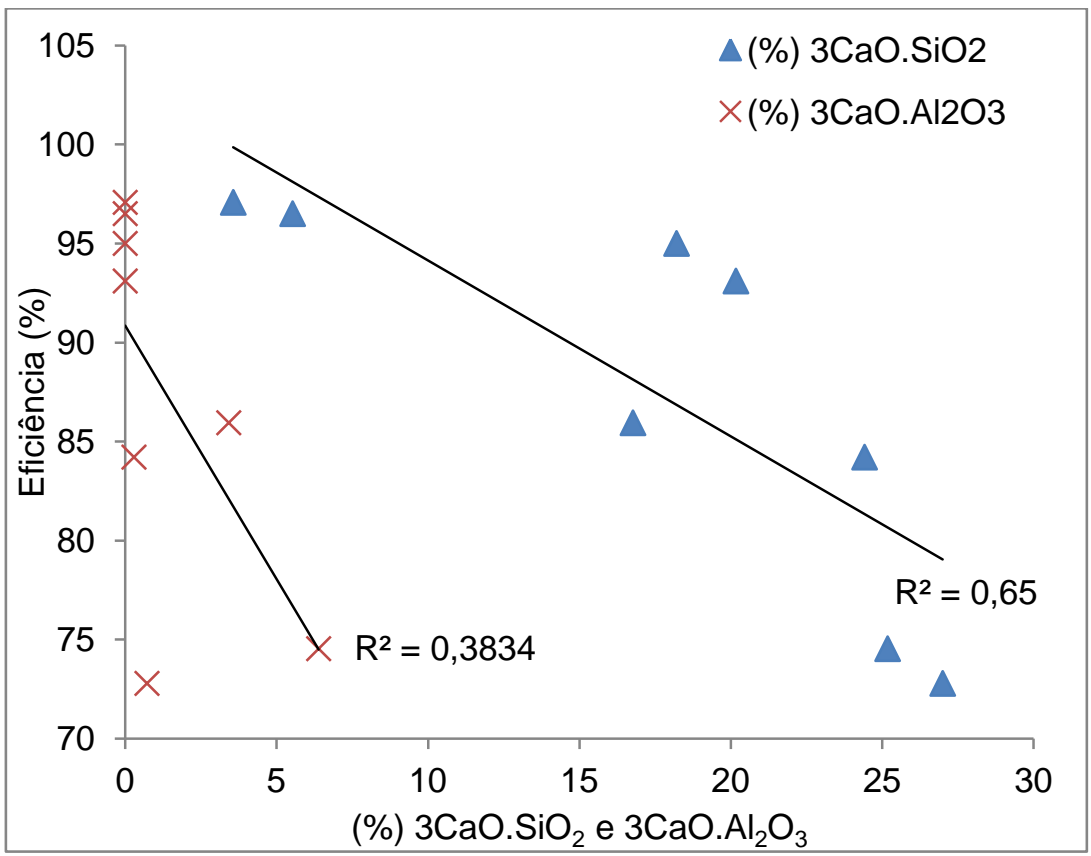

Figura 62. Influência dos compostos $3 \mathrm{CaO} . \mathrm{SiO}_{2}$ e $3 \mathrm{CaO} \cdot \mathrm{Al}_{2} \mathrm{O}_{3}$ na eficiênciada dessulfuração das misturas dessulfurantes de ferro-gusa.

Os resultados mostraram que o aumento da concentração de $3 \mathrm{CaO} \mathrm{SiO}_{2}$ e $3 \mathrm{CaO} . \mathrm{Al}_{2} \mathrm{O}_{3}$, prejudicou o rendimento dessulfurante. Para as escórias fabricadas com o resíduo de mármore e sodalita, a presença desses compostos é mais acentuada, uma vez que possuem a presença de $\mathrm{SiO}_{2}$ e $\mathrm{Al}_{2} \mathrm{O}_{3}$ em sua composição química, o que favoreceu a formação desse composto. De acordo com a literatura $(53,55,108)$, esses compostos prejudicam a dessulfuração, pois formam uma camada de fase sólida ao redor da partícula de $\mathrm{CaO}$, limitando o transporte de massa do enxofre. Essa limitação da dessulfuração pela formação dos compostos na fase sólida já foi discutida na revisão bibliográfica, conforme exposto no capítulo 2.5.2.

\subsubsection{Efeito da viscosidade das misturas iniciais}

A Figura 63 apresenta o efeito da viscosidade da fase líquida das misturas em função da eficiência dessulfurante. 


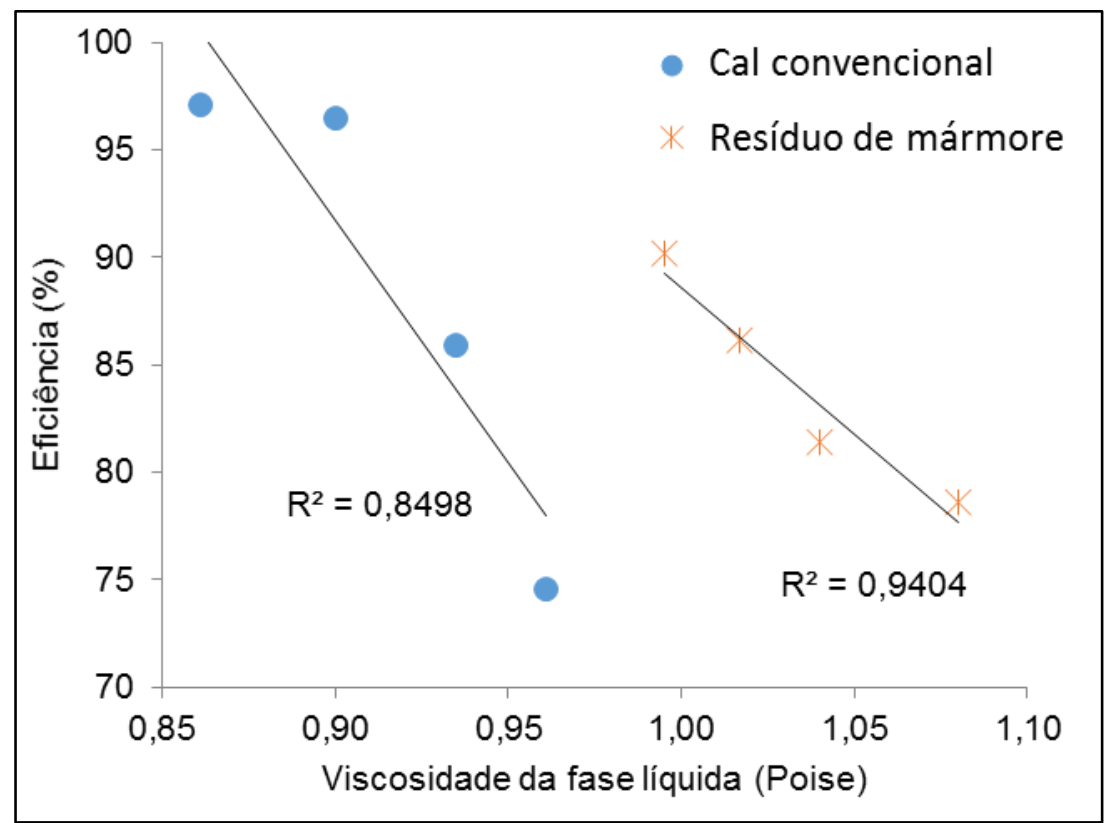

Figura 63. Efeito da viscosidade das misturas iniciais no comportamento da dessulfuração do ferro-gusa na temperatura de $1400^{\circ} \mathrm{C}$.

Ao analisar a Figura 63, verifica-se que o aumento da viscosidade prejudica o rendimento da dessulfuração. Nota-se também, que as escórias produzidas com o resíduo de mármore apresentaram maior viscosidade. De acordo com Seak ${ }^{(108)}$, a diminuição da viscosidade favorece a difusão do enxofre na escória, melhorando a cinética do processo. Com isso, ocorre um aumento da remoção do enxofre do ferro-gusa.

5.2.1.6 Efeito da fração de fase líquida e sólida em escórias dessulfurantes de ferro-gusa

Visando conhecer qual fase (líquida ou sólida) é mais efetiva na dessulfuração do ferro-gusa, realizou-se o cálculo de equilíbrio entre metal e escória com a composição e quantidade em massa da fase líquida inicial (fase em equilíbrio com os silicatos e aluminatos) da escória. A Tabela 26 apresenta os resultados da composição de equilíbrio da fase líquida encontrada e a massa utilizada para o cálculo de equilíbrio, obtidos através do Thermo-Calc. 
Tabela 26. Composição da fase líquida das misturas iniciais geradas pelo Thermo-Calc.

\begin{tabular}{ccccccccc}
\hline \multirow{2}{*}{ Experimentos } & \multicolumn{6}{c}{ Composição dos elementos em (\%) } & \multicolumn{1}{c}{$\begin{array}{c}\text { Massa de } \\
\text { escória líquida } \\
\text { (gramas) }\end{array}$} & $\eta(\%)$ \\
\hline $\mathrm{Al}_{2} \mathrm{O}_{3}$ & $\mathrm{CaO}$ & $\mathrm{MgO}$ & $\mathrm{SiO}_{2}$ & $\mathrm{CaF}_{2}$ & $\mathrm{Na}_{2} \mathrm{O}$ & \\
\hline CAF10 & 3,57 & 33,63 & 0,00 & 11,06 & 51,74 & 0,00 & 1,6815 & 97,1 \\
CAF5 & 5,53 & 35,36 & 0,00 & 10,46 & 48,65 & 0,00 & 0,9044 & 96,5 \\
RMF10 & 0,00 & 31,11 & 1,50 & 12,90 & 54,48 & 0,00 & 1,0084 & 90,2 \\
RMF5 & 0,00 & 31,11 & 1,50 & 12,90 & 54,48 & 0,00 & 0,4939 & 86,1 \\
CAS5 & 8,14 & 37,78 & 0,00 & 26,77 & 0,00 & 27,32 & 0,2562 & 85,9 \\
RMS5 & 17,31 & 48,57 & 2,83 & 18,73 & 0,00 & 12,56 & 0,3187 & 81,4 \\
RMS10 & 17,31 & 48,57 & 2,83 & 18,46 & 0,00 & 12,56 & 0,6498 & 78,5 \\
CAS10 & 8,14 & 37,78 & 0,00 & 26,77 & 0,00 & 27,32 & 0,4759 & 74,5 \\
\hline
\end{tabular}

Com a composição das escórias apresentadas na Tabela 26 e a composição inicial do ferro-gusa, foram gerados os dados de equilíbrio somente com a utilização da fração líquida da escória formada. Os resultados podem ser visualizados na Tabela 27.

Tabela 27. Teor de enxofre inicial, com 10 minutos de experimento e a composição de equilíbrio após o cálculo no Thermo-Calc.

\begin{tabular}{cccccccc}
\hline Escória & {$\left[\% \mathrm{~S}_{\text {inicial }}\right]$} & {$\left[\mathrm{S}_{\text {eq }}\right]$} & {$\left[\mathrm{S}_{10 \mathrm{~min}}\right]$} & {$\left[\mathrm{C}_{\text {eq }}\right]$} & {$\left[\mathrm{Si}_{\mathrm{eq}}\right]$} & {$\left[\mathrm{Mn}_{\mathrm{eq}}\right]$} & $\eta(\%)$ \\
\hline CAF10 & 0,031 & 0,025 & 0,0132 & 4,46 & 0,47 & 0,18 & 97,1 \\
CAF5 & 0,028 & 0,024 & 0,0122 & 4,5 & 0,49 & 0,20 & 96,5 \\
RMF10 & 0,030 & 0,026 & 0,0177 & 4,46 & 0,48 & 0,18 & 90,2 \\
RMF5 & 0,029 & 0,026 & 0,0203 & 4,49 & 0,53 & 0,20 & 86,1 \\
CAS5 & 0,036 & 0,030 & 0,0198 & 4,42 & 0,47 & 0,18 & 85,9 \\
RMS5 & 0,0285 & 0,022 & 0,0189 & 4,45 & 0,52 & 0,22 & 81,4 \\
RMS10 & 0,0305 & 0,021 & 0,0217 & 4,41 & 4,75 & 0,19 & 78,5 \\
CAS10 & 0,028 & 0,020 & 0,0207 & 4,50 & 0,50 & 0,18 & 74,5 \\
\hline
\end{tabular}

Observa-se que os valores de enxofre de equilíbrio encontrados e mostrados na Tabela 27 são maiores que os valores encontrados em dez minutos de experimento. A relação entre a fase líquida e a eficiência dessulfurante pode ser visualizada na Figura 64. 


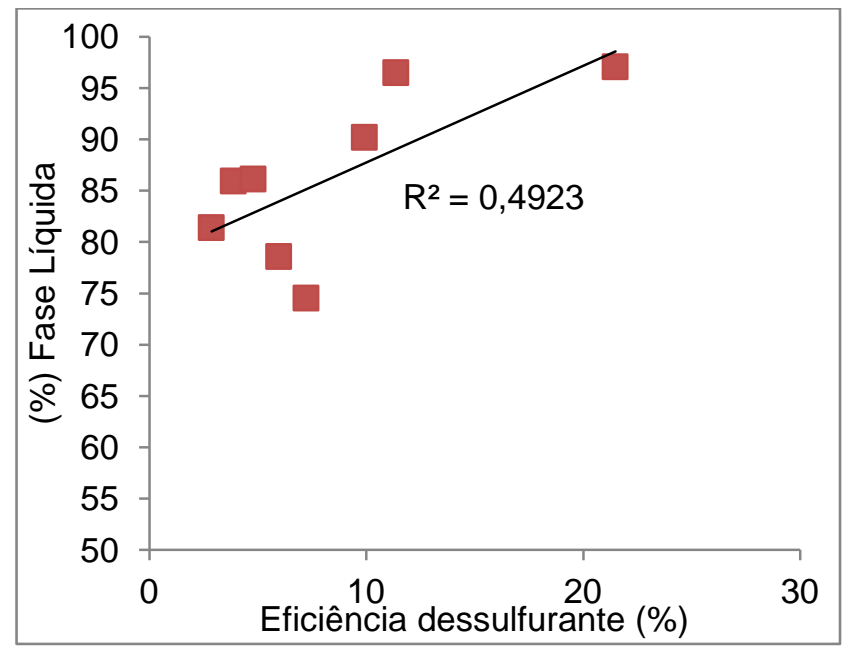

Figura 64. Relação entre a eficiência dessulfurante em função da porcentagem de fase líquida para as misturas dessulfurantes de ferro-gusa.

Verifica-se que a fase líquida tem papel secundário na dessulfuração do ferro-gusa. Visto que, a fração de fase líquida é menor em relação a fase sólida. Neste caso, a remoção do enxofre no metal é realizada pela partícula sólida do $\mathrm{CaO}$, que através da agitação é levada até o seio do metal, reagindo com o enxofre e formando CaS.

A fase líquida tem o papel de dissolver o CaS e o silicato tricálcio formado, evitando que estas fases se formem em torno da partícula de $\mathrm{CaO}$ e prejudiquem o transporte de massa do enxofre até a partícula de $\mathrm{CaO}$.

Este comportamento da fase líquida fica evidente quando é realizado um balanço de massa para conhecer a composição das escórias finais e, posteriormente, o cálculo das fases presentes nas escórias na temperatura de $1400^{\circ} \mathrm{C}$. As fases formadas nas escórias finais constam na Tabela 28.

Tabela 28. Composição das fases formadas nas escórias finais dos experimentos de ferro-gusa.

\begin{tabular}{|c|c|c|c|c|c|c|c|c|}
\hline \multirow[b]{2}{*}{ Misturas } & \multirow[b]{2}{*}{$\begin{array}{l}\text { Líquido } \\
\text { (\%) }\end{array}$} & \multirow[b]{2}{*}{$\begin{array}{c}\text { Sólido } \\
(\%)\end{array}$} & \multicolumn{5}{|c|}{ Fases formadas na fase sólida (\%) } & \multirow[b]{2}{*}{$\eta(\%)$} \\
\hline & & & $\begin{array}{l}\text { CaO } \\
\text { Livre }\end{array}$ & $3 \mathrm{CaO} .\left(\mathrm{SiO}_{2}\right)$ & $3 \mathrm{CaO} \cdot\left(\mathrm{Al}_{2} \mathrm{O}_{3}\right)$ & $\mathrm{MgO}$ & CaS & \\
\hline CAF10 & 21,48 & 78,51 & 72,18 & 6,33 & - & 0,0 & - & 97,0 \\
\hline CAF5 & 11,37 & 88,62 & 75,68 & 12,29 & - & 0,0 & 0,64 & 96,5 \\
\hline RMF10 & 9,92 & 90,07 & 43,91 & 22,26 & - & 23,5 & 0,38 & 90,2 \\
\hline RMF5 & 4,79 & 95,20 & 45,57 & 24,90 & - & 24,1 & 0,56 & 86,1 \\
\hline CAS5 & 3,88 & 96,11 & 66,18 & 26,06 & - & 0,0 & 1,24 & 85,9 \\
\hline RMS5 & 2,86 & 97,13 & 42,51 & 29,72 & - & 24,2 & 0,66 & 81,4 \\
\hline RMS10 & 5,97 & 94,02 & 37,68 & 32,22 & - & 23,5 & 0,58 & 78,5 \\
\hline CAS10 & 7,23 & 92,76 & 56,38 & 30,73 & 4,93 & - & 0,71 & 74,5 \\
\hline
\end{tabular}


Os resultados mostraram que a porcentagem de fase líquida das escórias finais foi maior do que as iniciais. Com os dados da Tabela 28 foram construídas linhas de tendência que apresentam a relação entre o CaS e silicato tricálcio $\left(3 \mathrm{CaO} . \mathrm{SiO}_{2}\right)$ presente nas escórias finais em função da fração de fase líquida. Estas linhas de tedência podem ser observadas na Figura 65 e na Figura 66.

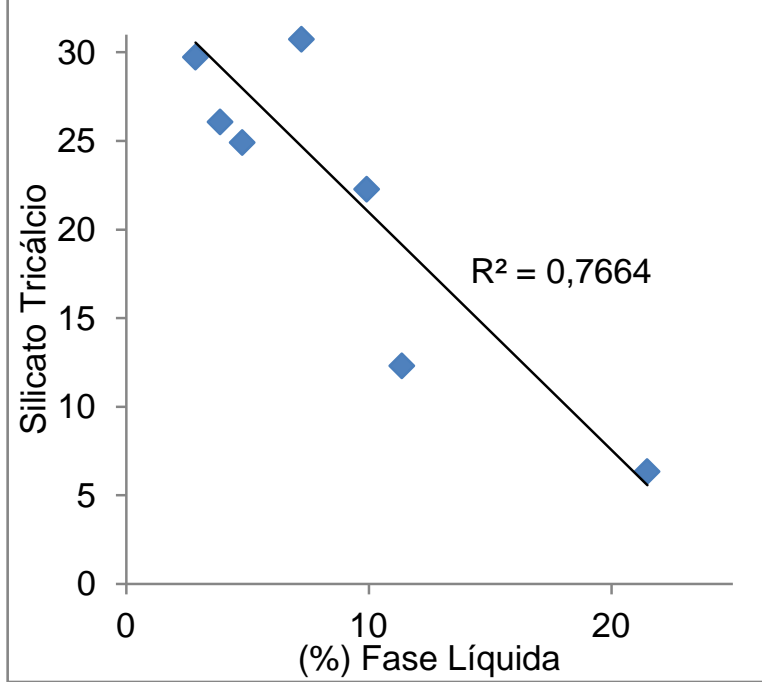

Figura 65. Relação entre o silicato tricálcio e fase líquida das escórias finais dos experimentos de dessulfuração de ferro-gusa.

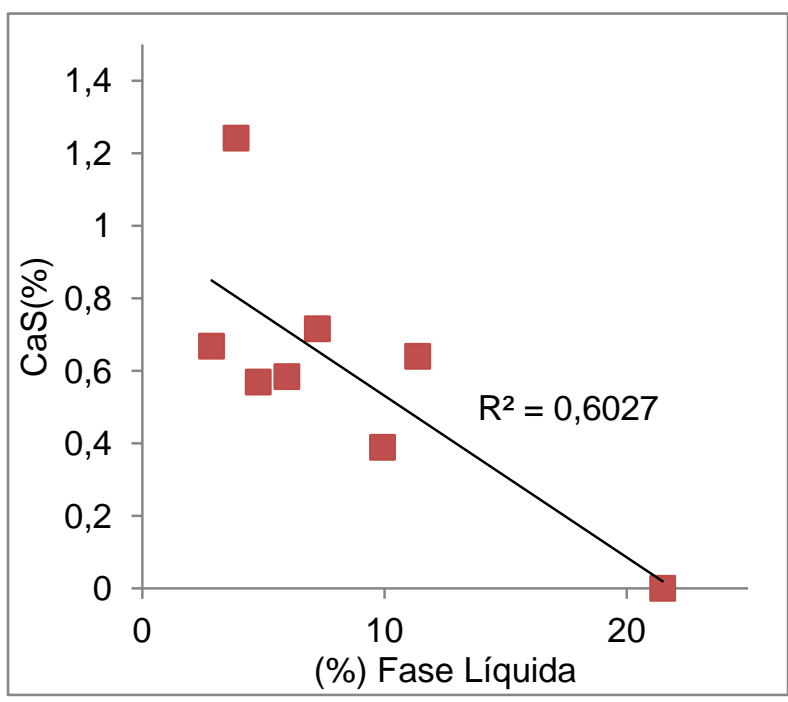

Figura 66. Relação entre o CaS e fase líquida das escórias finais dos experimentos de dessulfuração de ferro-gusa.

Percebe-se que, com o aumento da fase líquida da escória, o teor de CaS e silicato tricálcio formado diminui, o que permite concluir que a fase líquida dissolve essas fases, evitando que as mesmas se formem em torno da partícula de $\mathrm{CaO}$ e prejudiquem a dessulfuração.

Desta forma, é possível afirmar que as melhores misturas, serão aquelas que, na temperatura de trabalho, tiverem maior porcentagem de $\mathrm{CaO}$ sólido e menor porcentagem das fases $\left(3 \mathrm{CaO} . \mathrm{SiO}_{2}\right)$ e $\left(3 \mathrm{CaO} \cdot \mathrm{Al}_{2} \mathrm{O}_{3}\right)$.

Considerando o exposto, pode-se estabelecer uma metodologia de análise para um criar um parâmetro que possa prever a eficiência das misturas dessulfurantes. 
5.2.1.7 Metodologia de análise para prever a eficiência das misturas dessulfurantes de ferro-gusa

A idéia principal foi construir uma metodologia, baseada nos resultados obtidos experimentalmente, visando encontrar um parâmetro que possa prever a eficiência de remoção do enxofre das escórias dessulfurantes de ferro-gusa.

Alguns resultados, alcançados neste trabalho e demonstrados nos itens anteriores, foram considerados para o desenvolvimento deste modelo, a saber:

1. Conforme observado, o aumento da quantidade das fases $3 \mathrm{CaO}^{-\mathrm{SiO}_{2}} \mathrm{e}$ $3 \mathrm{CaO} \cdot \mathrm{Al}_{2} \mathrm{O}_{3}$, prejudica a dessulfuração, uma vez que, estas fases se formam em torno das partículas de $\mathrm{CaO}$, impedindo o transporte de massa do enxofre.

2. Também foi verificado que a fase líquida não possui participação efetiva na dessulfuração. Este é um indicativo de que no processo de dessulfuração no ferro-gusa, a fase líquida formada não tem influência direta na reação de dessulfuração, agindo somente na dissolução de parte da fase sólida formada.

3. Outro ponto observado, foi que o a partícula de $\mathrm{CaO}_{(\mathrm{S})}$ é o principal agente dessulfurante.

Para a elaboração do parâmetro, foi considerado que o $\mathrm{CaO}$ total $\left(\mathrm{CaO}_{\mathrm{T}}\right)$ para reagir, corresponde à soma da porcentagem de $\mathrm{CaO}$ sólido e líquido presente nas escórias iniciais a $1400^{\circ} \mathrm{C}$. A Equação 36 mostra esta dedução.

$\left(\% \mathrm{CaO}_{T}\right)=\left(\% \mathrm{CaO}_{s}\right)+\left(\% \mathrm{CaO}{ }_{L}\right)$

(Equação 36)

Como a dessulfuração ocorre pela reação direta entre as partículas de $\mathrm{CaO}$ e o enxofre no metal líquido, é preciso levar em consideração as partículas de CaO que estão efetivamente disponíveis para reagir. $\mathrm{E}$ como as fases $3 \mathrm{CaO} . \mathrm{SiO}_{2}$ e $3 \mathrm{CaO} \cdot \mathrm{Al}_{2} \mathrm{O}_{3}$ se formam em torno das partículas de $\mathrm{CaO}$, a quantidade destas fases deve ser considerada nestes cálculos. Portanto, um novo parâmetro é inserido e denominado de $\mathrm{CaO}$ disponível $\left(\mathrm{CaO}_{\mathrm{D}}\right)$, que corresponde à quantidade de $\mathrm{CaO}$ disponível para reagir com o enxofre. Portanto, dois conceitos de $\mathrm{CaO}_{\mathrm{D}}$ foram introduzidos:

1- Concentração de $\mathrm{CaO}$ sólido disponível (\%) $\mathrm{CaO}_{\mathrm{SD}}$ : que leva em consideração somente a porcentagem de $\mathrm{CaO}$ na fase sólida; 
2- Concentração de $\mathrm{CaO}$ total disponível (\%)CaOTD: que leva em conta a porcentagem de $\mathrm{CaO}$ na fase sólida e na fase líquida.

Após a definição desses dois parâmetros, surgem duas novas equações (Equação 37 e Equação 38), a saber:

$$
\begin{aligned}
& \left(\% \mathrm{CaO}_{S D}\right)=\left(\% \mathrm{CaO}_{s}\right)-\left(\% 3 \mathrm{CaO} \cdot \mathrm{SiO}_{2}+\% \mathrm{CaO} \cdot \mathrm{Al}_{2} \mathrm{O}_{3}\right) \\
& \left(\% \mathrm{CaO}_{T D}\right)=\left(\% \mathrm{CaO}_{T}\right)-\left(\% 3 \mathrm{CaO} \cdot \mathrm{SiO}_{2}+\% \mathrm{CaO} \cdot \mathrm{Al}_{2} \mathrm{O}_{3}\right)
\end{aligned}
$$

Com as equações descritas anteriormente e com os dados das escórias iniciais obtidas pelo Termo-Calc, foram calculados os valores de $\mathrm{CaO}_{\mathrm{SD}}$ e $\mathrm{CaO}_{\mathrm{TD}}$, os mesmos podem ser visualizados na Tabela 29.

Tabela 29. Resultados dos cálculos do $\mathrm{CaO}_{\mathrm{SD}}$ e $\mathrm{CaO}_{\mathrm{TD}}$ para as escórias dessulfurantes.

\begin{tabular}{cccc}
\hline Experimentos & $\eta(\%)$ & $\% \mathrm{CaO}_{\mathrm{SD}}$ & $\% \mathrm{CaO}_{\text {TD }}$ \\
\hline CAF10 & 97,0 & 76,0 & 76,6 \\
CAF5 & 96,4 & 79,9 & 80,2 \\
RMF10 & 90,3 & 32,4 & 32,6 \\
RMF5 & 86,2 & 31,7 & 31,8 \\
CAS5 & 85,9 & 57,0 & 57,1 \\
RMS5 & 81,4 & 23,8 & 23,9 \\
RMS10 & 78,6 & 17,1 & 17,2 \\
CAS10 & 74,4 & 32,1 & 32,3 \\
\hline
\end{tabular}

As misturas com maiores concentrações de \%CaO $\mathrm{CD}_{\mathrm{SD}}$ e \% CaO $\mathrm{CD}_{\mathrm{TD}}$ disponível apresentaram melhores resultados de eficiência de dessulfuração. A relação entre o $\mathrm{CaO}_{\mathrm{SD}}$ e $\circ \mathrm{CaO}_{\mathrm{TD}}$ em função da eficiência dessulfurante pode ser visualizada na Figura 67. 

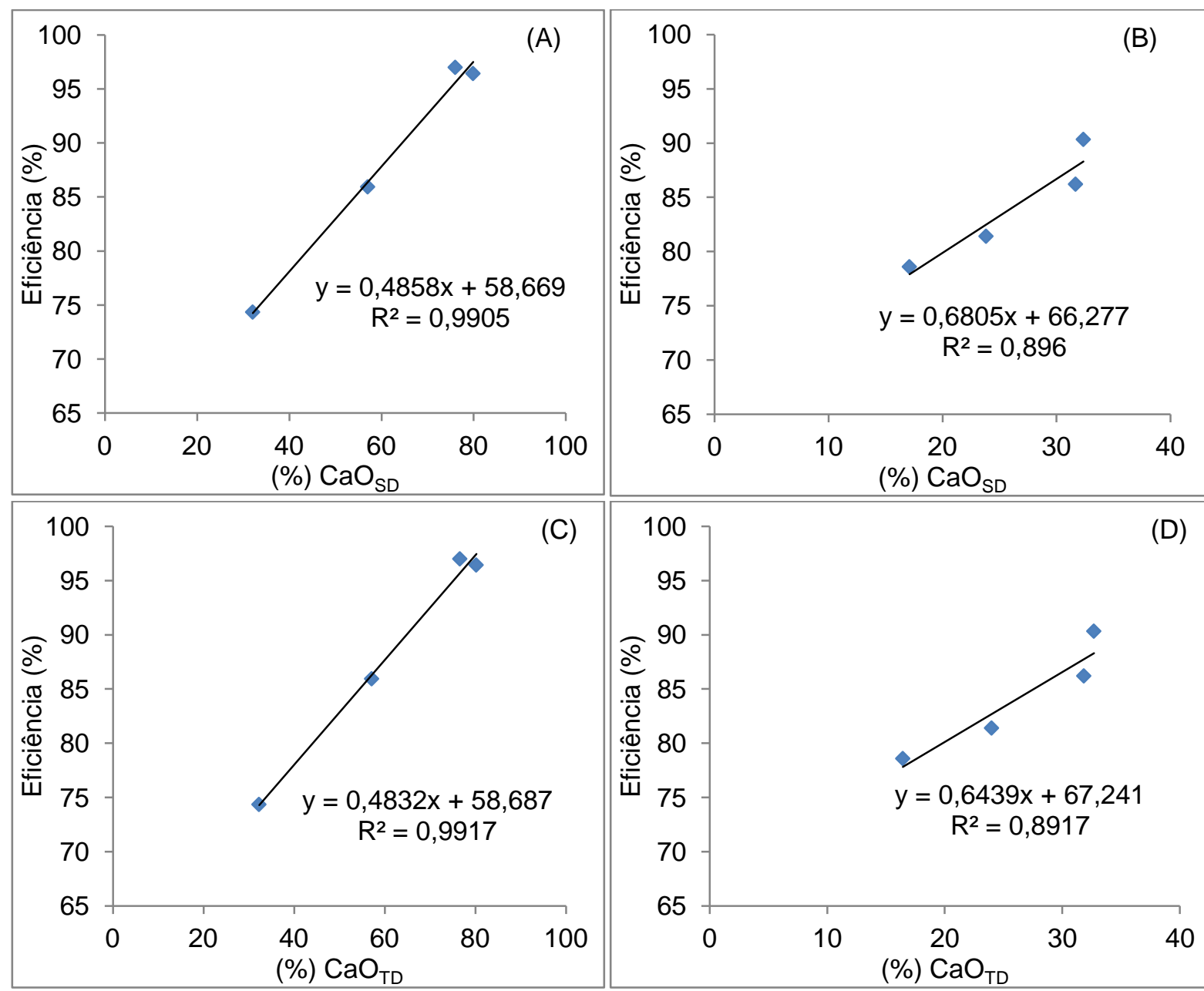

Figura 67. Influência dos parâmetros (\%) $\mathrm{CaO}_{\mathrm{SD}}$ e (\%) $\mathrm{CaO}_{\text {TD }}$ em função da eficiência dessulfurante, (A) e (C) escórias com a cal convencional e (B) e (D) escórias com o resíduo de mármore.

Verifica-se que quanto maior a concentração de $(\%) \mathrm{CaO}_{S D}$ ou $(\%) \mathrm{CaO}_{\text {TD }}$ nas escórias dessulfurantes, maior o rendimento obtido nos testes experimentais. Em uma análise comparativa entre os parâmetros, observa-se que a concentração do $\mathrm{CaO}$ líquido presente no parâmetro (\%)CaO $\mathrm{TD}_{\mathrm{TD}}$, pouco interfere na correlação. Este comportamento confirma a condição de que, nos processos abordados neste estudo, a fase líquida formada não possui influência direta na reação de dessulfuração, agindo somente na dissolução de parte da fase sólida formada.

As concentrações de $\mathrm{CaO}_{S D}$ e $\mathrm{CaO}_{\text {TD }}$ para as misturas com o resíduo de mármore foram menores, e mesmo assim, em alguns casos, as misturas com resíduo de mármore obtiveram melhores índices de eficiência dessulfurante. Esta diferença é provavelmente oriunda da agitação proporcionada pela decomposição dos carbonatos presentes no resíduo de mármore, que neste caso, aumentou a cinética do processo. 
Aguiar $^{(109)}$ realizou experimentos com o resíduo de mármore calcinado e com o resíduo de mármore in natura. Segundo o autor, a decomposição dos carbonatos pode aumentar a eficiência dessulfurante em até $11 \%$.

Por fim, os parâmetros de cal disponível $\left(\mathrm{CaO}_{\mathrm{TD}}\right.$ e $\left.\mathrm{CaO}_{\mathrm{SD}}\right)$ para calcular a eficiência das escórias dessulfurantes de ferro-gusa à base de cal convencional, podem ser descritos de acordo com as Equações 39 e 40.

$$
\begin{aligned}
& \eta(\%)=0,4832\left[\left(\% \mathrm{CaO}_{\mathrm{T}}\right)-\left(\% 3 \mathrm{CaO} \cdot \mathrm{SiO}_{2}+\% \mathrm{CaO} \cdot \mathrm{Al}_{2} \mathrm{O}_{3}\right)\right]+58,68 \quad \text { (Equação 39) } \\
& \eta(\%)=0,4957\left[\left(\% \mathrm{CaO}_{s}\right)-\left(\% 3 \mathrm{CaO} \cdot \mathrm{SiO}_{2}+\% \mathrm{CaO} \cdot \mathrm{Al}_{2} \mathrm{O}_{3}\right)\right]+57,91 \quad \text { (Equação 40) }
\end{aligned}
$$

Para escórias com resíduo de mármore são válidas as Equações 41 e 42:

$$
\begin{aligned}
& \eta(\%)=0,6439\left[\left(\% \mathrm{CaO}_{s}+\% \mathrm{CaO}_{L}\right)-\left(\% 3 \mathrm{CaO}_{\mathrm{SiO}}+\% \mathrm{CaO}_{2} \mathrm{Al}_{2} \mathrm{O}_{3}\right)\right]+67,24 \quad \text { (Equação 41) } \\
& \eta(\%)=0,6805\left[\left(\% \mathrm{CaO}_{s}\right)-\left(\% 3 \mathrm{CaO} \cdot \mathrm{SiO}_{2}+\% \mathrm{CaO} \cdot \mathrm{Al}_{2} \mathrm{O}_{3}\right)\right]+66,27 \quad \text { (Equação 42) }
\end{aligned}
$$

As Equações podem ser reescritas em função do teor de enxofre final, conforme reação global descrita na Equação 43.

$$
S_{F}=S_{I}-\left(S_{I} * n(\%) / 100\right)
$$

Onde:

$\mathrm{S}_{\mathrm{F}}$ é o enxofre final;

$S_{i}$ é o enxofre inicial; e

$\eta(\%)$ é a eficiência dessulfurante.

Com estes parâmetros, é possível estimar a porcentagem de dessulfuração para qualquer escória dessulfurante de ferro-gusa, com o uso do resíduo de mármore ou com a cal convencional. Para tanto, é necessário que sejam mantidos os mesmos parâmetros (temperatura, faixa de composição química, agitação e massa de escória) utilizadas neste trabalho. 
5.2.1.8 Cálculo da constante de velocidade $(\mathrm{k})$.

O cálculo da constante de velocidade foi realizado utilizando a Equação 24, abordada no capítulo 4.5.5. A Tabela 30 presenta os resultados do coeficiente de transferência de enxofre.

Tabela 30. Constante de velocidade em função do tempo de cada experimento com escórias de ferro-gusa.

\begin{tabular}{cllllll}
\hline Experimentos & $\mathrm{k}_{(10 \mathrm{~min})}$ & $\mathrm{k}_{(15 \mathrm{~min})}$ & $\mathrm{k}_{(20 \mathrm{~min})}$ & $\mathrm{k}_{(30 \mathrm{~min})}$ & $\mathrm{k}_{(\text {médio) }}$ & $\eta(\%)$ \\
\hline CAF10 & $1,47 \mathrm{E}-03$ & $1,36 \mathrm{E}-03$ & $1,94 \mathrm{E}-03$ & $1,97 \mathrm{E}-03$ & $1,684 \mathrm{E}-03$ & 97,0 \\
CAF5 & $1,42 \mathrm{E}-03$ & $1,26 \mathrm{E}-03$ & $1,54 \mathrm{E}-03$ & $1,87 \mathrm{E}-03$ & $1,524 \mathrm{E}-03$ & 96,4 \\
RMF10 & $8,97 \mathrm{E}-04$ & $1,07 \mathrm{E}-03$ & $1,26 \mathrm{E}-03$ & $1,30 \mathrm{E}-03$ & $1,131 \mathrm{E}-03$ & 90,3 \\
RMF5 & $6,01 \mathrm{E}-04$ & $7,98 \mathrm{E}-04$ & $9,61 \mathrm{E}-04$ & $1,10 \mathrm{E}-03$ & $8,651 \mathrm{E}-04$ & 86,2 \\
CAS5 & $9,97 \mathrm{E}-04$ & $1,37 \mathrm{E}-03$ & $1,39 \mathrm{E}-03$ & $1,09 \mathrm{E}-03$ & $1,212 \mathrm{E}-03$ & 85,9 \\
RMS5 & $6,97 \mathrm{E}-04$ & $1,14 \mathrm{E}-03$ & $1,10 \mathrm{E}-03$ & $9,40 \mathrm{E}-04$ & $9,684 \mathrm{E}-04$ & 81,4 \\
RMS10 & $5,68 \mathrm{E}-04$ & $7,31 \mathrm{E}-04$ & $8,43 \mathrm{E}-04$ & $8,58 \mathrm{E}-04$ & $7,501 \mathrm{E}-04$ & 78,6 \\
CAS10 & $7,25 \mathrm{E}-05$ & $6,51 \mathrm{E}-04$ & $7,78 \mathrm{E}-04$ & $7,61 \mathrm{E}-04$ & $5,656 \mathrm{E}-04$ & 74,4 \\
\hline
\end{tabular}

Analisando a Tabela 30 é possível observar que a cinética da dessulfuração com o uso da fluorita e cal convencional é maior, comparando com a utilização da sodalita e resíduo de mármore. Visto que, escórias produzidas com fluorita e cal convencional apresentaram maiores valores da constante de velocidade $\left(k_{\text {médio }}\right)$. Os valores da constante de velocidade encontrados nesta pesquisa estão coerentes com os encontrados em outros estudos ${ }^{(11,93,109)}$.

Além disso, quando são comparados os valores do ( $k_{\text {médio }}$ ) com a porcentagem de fase líquida, é possível observar que o aumento da fase líquida favoreceu o aumento da constante de velocidade.

A Figura 68 apresenta a relação entre a influência da fase silicato tricálcio na constante de velocidade $(\mathrm{k})$. 


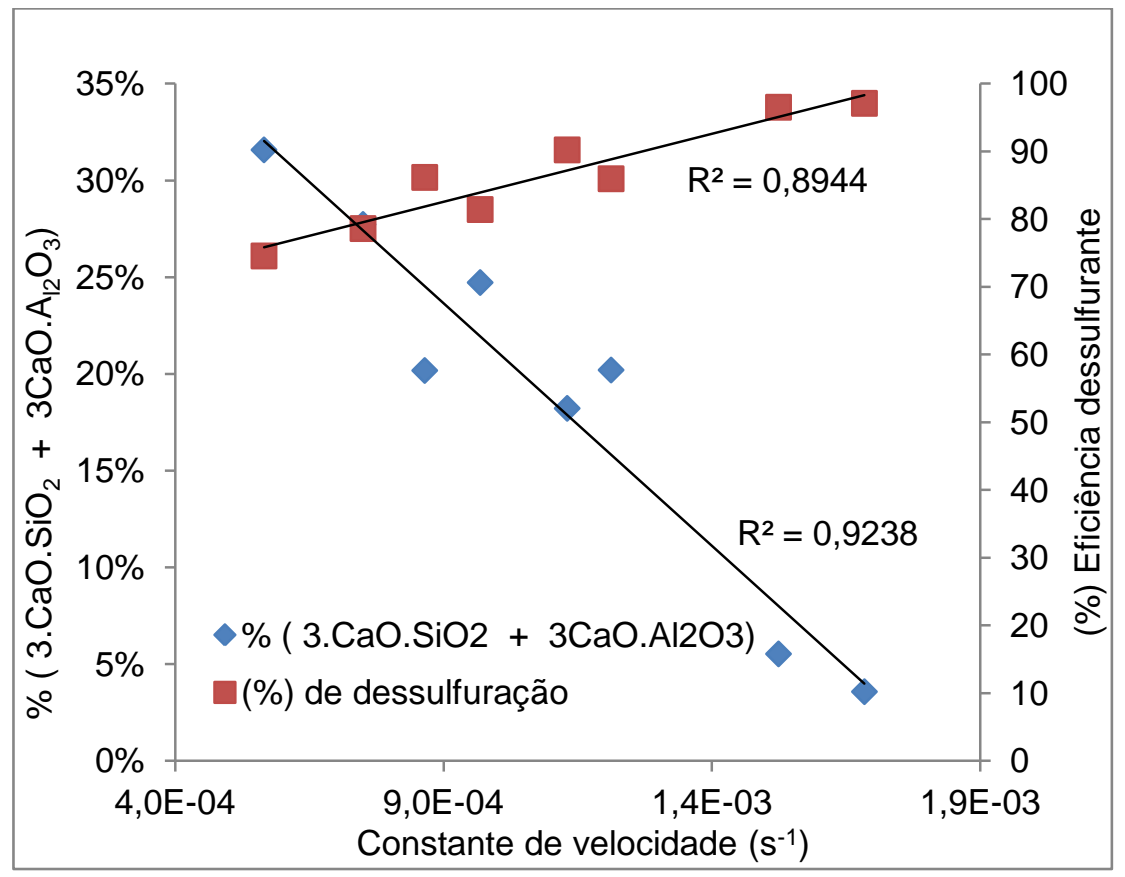

Figura 68. Relação entre a constante de velocidade em função do trisilicato dicálcio, aluminato tricálcio e da eficiência dessulfurante para escórias dessulfurantes de ferro-gusa.

Observa-se na Figura 68, que o aumento da fase sólida de silicato tricálcio e aluminato de cálcio afeta negativamente a constante de velocidade, e como consequência, diminui a remoção do enxofre no metal. Neste caso, a literatura(46) cita que o silicato tricálcio forma-se ao redor da partícula de cal, o que prejudica a difusão na interface e retardando a dessulfuração. A relação entre a concentração de $\mathrm{CaO}$ sólido sobre a constante de velocidade (k) pode ser visualizada na Figura 69. 


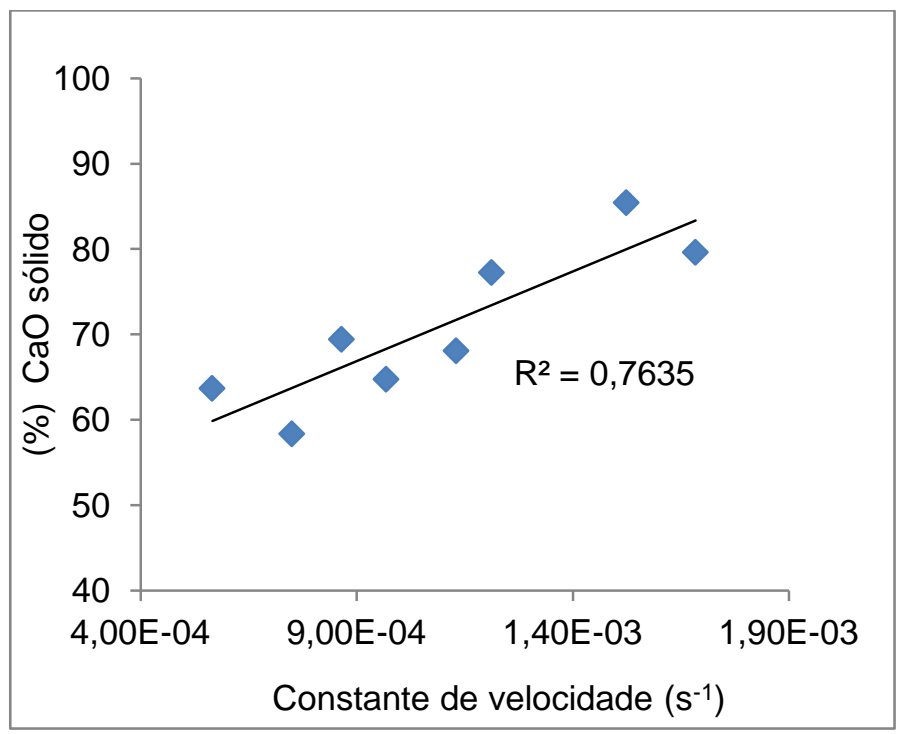

Figura 69. Relação entre a constante de velocidade e $\mathrm{CaO}$ sólido para escórias dessulfurantes de ferro-gusa.

Os resultados demonstraram que a constante de velocidade $(\mathrm{k})$ aumenta com o aumento da porcentagem de $\mathrm{CaO}$ sólido. Este resultado confirma que o $\mathrm{CaO}$ sólido é a fase dessulfurante no ferro-gusa.

\subsubsection{Avaliação dos resultados encontrados para as escórias dessulfurantes no ferro fundido}

5.2.2.1 Análise dos resultados experimentais com o uso das misturas dessulfurantes de ferro fundido

A Tabela 31 apresenta os teores de enxofre em diferentes tempos de retirada de amostras de metal nos experimentos de dessulfuração de ferro fundido. 
Tabela 31. Teor de enxofre das amostras de ferro fundido em função do tempo.

\begin{tabular}{|c|c|c|c|c|c|c|c|c|c|c|c|}
\hline \multirow[b]{2}{*}{ Ensaios } & \multicolumn{10}{|c|}{ Tempo (min) } & \multirow{3}{*}{$\eta(\%)$} \\
\hline & Inicial & 5 & 10 & 15 & 20 & 25 & 30 & 35 & 40 & 45 & \\
\hline & \multicolumn{10}{|c|}{ Enxofre (\%) } & \\
\hline CICAF11 & 0,101 & 0,074 & 0,047 & 0,035 & 0,023 & 0,015 & 0,010 & 0,009 & 0,009 & 0,010 & 90,10 \\
\hline CICA3 & 0,103 & 0,062 & 0,056 & 0,054 & 0,041 & 0,030 & 0,029 & 0,016 & 0,012 & 0,013 & 89,81 \\
\hline CIRMF12 & 0,091 & 0,069 & 0,056 & 0,051 & 0,031 & 0,023 & 0,020 & 0,014 & 0,010 & 0,011 & 87,25 \\
\hline CIRM8 & 0,091 & 0,066 & 0,061 & 0,054 & 0,045 & 0,031 & 0,025 & 0,015 & 0,018 & 0,018 & 87,03 \\
\hline CICA4 & 0,096 & 0,087 & 0,072 & 0,064 & 0,063 & 0,043 & 0,040 & 0,029 & 0,024 & 0,019 & 86,56 \\
\hline CIRM7 & 0,087 & 0,063 & 0,054 & 0,051 & 0,038 & 0,027 & 0,023 & 0,019 & 0,015 & 0,012 & 85,63 \\
\hline CIRM9 & 0,090 & 0,059 & 0,052 & 0,052 & 0,038 & 0,028 & 0,026 & 0,015 & 0,009 & 0,009 & 85,33 \\
\hline CICA2 & 0,084 & 0,058 & 0,056 & 0,056 & 0,041 & 0,034 & 0,027 & 0,023 & 0,015 & 0,014 & 84,64 \\
\hline CIRM6 & 0,084 & 0,063 & 0,052 & 0,045 & 0,033 & 0,024 & 0,022 & 0,016 & 0,014 & 0,010 & 83,93 \\
\hline CICA1 & 0,103 & 0,077 & 0,072 & 0,074 & 0,058 & 0,047 & 0,041 & 0,036 & 0,025 & 0,016 & 82,52 \\
\hline CICA5 & 0,084 & 0,061 & 0,046 & 0,040 & 0,028 & 0,023 & 0,016 & 0,012 & 0,010 & 0,014 & 79,76 \\
\hline CIRM10 & 0,082 & 0,057 & 0,050 & 0,050 & 0,033 & 0,029 & 0,025 & 0,020 & 0,015 & 0,013 & 79,63 \\
\hline
\end{tabular}

Com os dados constantes na Tabela 31 foram construídas curvas de variação do enxofre com o tempo para as escórias produzidas com o resíduo de mármore e cal convencional. Os resultados podem ser visualizados na Figura 70 e na Figura 71.

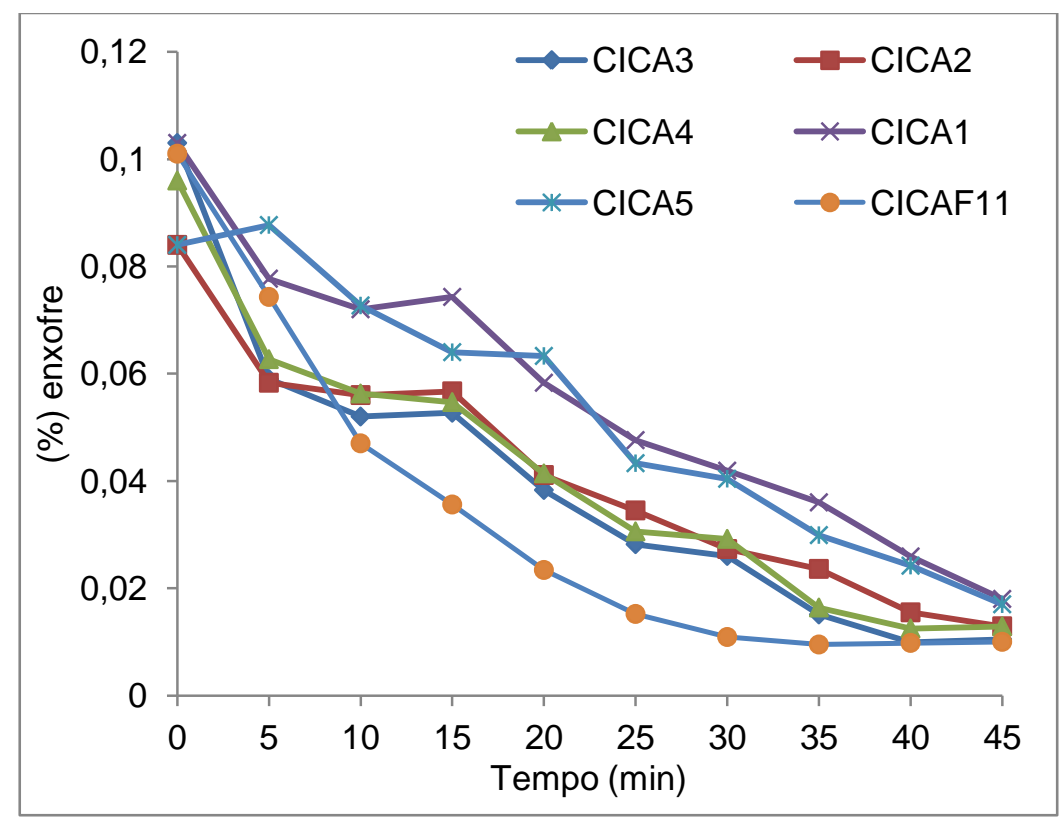

Figura 70. Teor de enxofre no ferro fundido em função do tempo de experimento para as escórias com a cal convencional. 


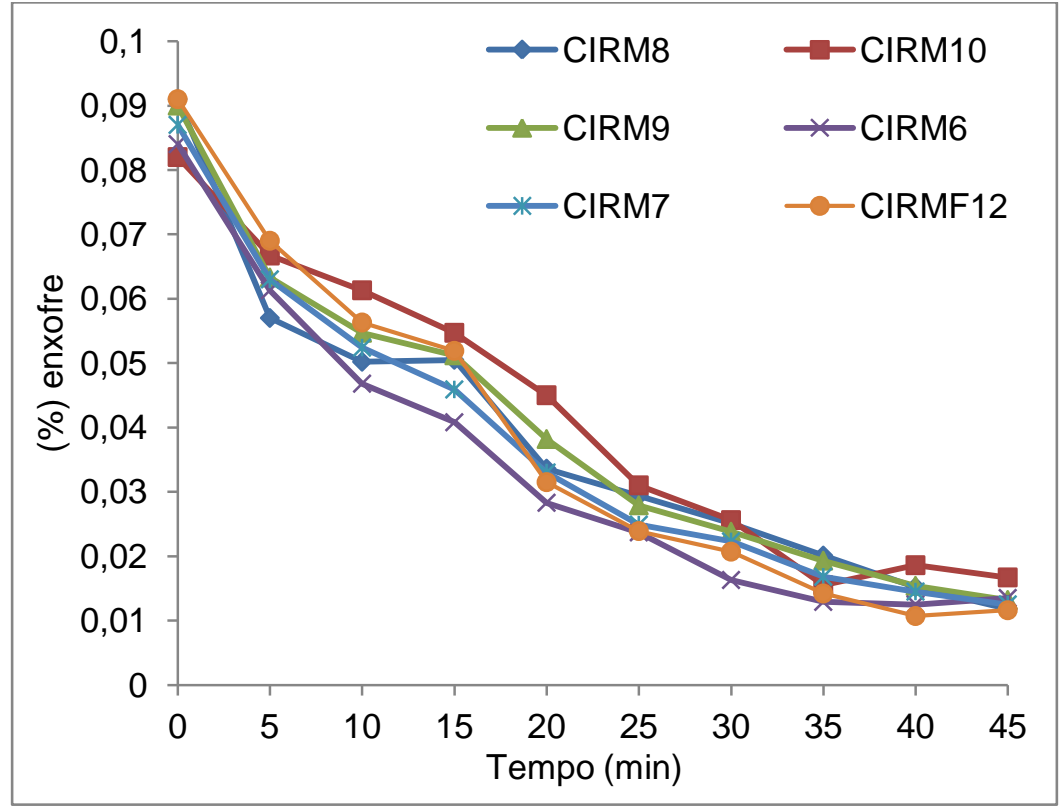

Figura 71. Teor de enxofre no ferro fundido em função do tempo de experimento para as escórias com resíduo de mármore.

Nota-se que, para os experimentos CIRM6 e CIRM7, o resíduo de mármore foi melhor dessulfurante $(83,93 \%$ e $85,63 \%)$ quando comparado com os experimentos de cal convencional CICA1 e CICA2, que obtiveram eficência dessulfurante de $82,52 \%$ e $84,64 \%$, respectivamente.

Nos demais experimentos (CICA3, CICA4 e CICA5), a cal convencional apresentou um resultado melhor do que seus respectivos ensaios com resíduo de mármore (CIRM8, CIRM9, CIRM10).

Dessa forma, é difícil afirmar qual é o melhor agente dessulfurante. Então, foi necessária uma análise termodinâmica da composição das misturas e dos resultados obtidos tanto experimentalmente como pelo Thermo-Calc. Esta análise será abordada no item 5.2.2.4.

5.2.2.2 Resultados dos cálculos de $C_{s}, L_{s}$ e $\wedge$ para as misturas dessulfurantes de ferro fundido

Os resultados dos cálculos de $C_{s}, L_{s}$ e $\wedge$ para as misturas dessulfurantes de ferro fundido podem ser visualizados na Tabela 32. 
Tabela 32. Valores da basicidade ótica $(\Lambda)$, capacidade de sulfeto $\left(C_{s}\right)$ e partição de enxofre $\left(L_{s}\right)$ das misturas dessulfurantes de ferro fundido a $1550^{\circ} \mathrm{C}$.

\begin{tabular}{|c|c|c|c|c|c|c|c|}
\hline \multirow[b]{2}{*}{ Misturas } & \multirow[b]{2}{*}{$\Lambda$} & \multicolumn{2}{|c|}{ Capacidade de Sulfeto (Cs) } & \multicolumn{3}{|c|}{ Partição de enxofre (Ls) } & \multirow[b]{2}{*}{$\eta(\%)$} \\
\hline & & $\begin{array}{c}\text { Sosinsky e } \\
\text { Sommerville }{ }^{(32)} \\
{[- \text { Log Cs] }}\end{array}$ & $\begin{array}{c}\text { Shankar }^{(34)} \\
{[\text { Cs] }}\end{array}$ & $\begin{array}{l}\text { Inoue e } \\
\text { Suito }{ }^{(49)} \\
\text { [Log Ls] }\end{array}$ & $\begin{array}{c}\text { Shankar }^{(34)} \\
\text { [Log Ls] }\end{array}$ & $\begin{array}{c}\text { Matsutaka } \\
\quad[\text { Log Ls] }\end{array}$ & \\
\hline CICAF11 & 0,82 & 3,72 & 0,0008 & 1,87 & 2,28 & 1,37 & 90,10 \\
\hline СICA3 & 0,87 & 3,31 & 0,0014 & 2,27 & 2,49 & 1,58 & 89,81 \\
\hline CIRMF12 & 0,79 & 3,96 & 0,0005 & 1,62 & 2,03 & 1,16 & 87,25 \\
\hline CIRM8 & 0,83 & 3,62 & 0,0009 & 1,96 & 2,31 & 1,44 & 87,03 \\
\hline CICA4 & 0,91 & 3,00 & 0,0017 & 2,59 & 2,59 & 1,70 & 86,56 \\
\hline CIRM7 & 0,84 & 3,51 & 0,0010 & 2,07 & 2,36 & 1,51 & 85,63 \\
\hline CIRM9 & 0,86 & 3,38 & 0,0012 & 2,20 & 2,42 & 1,58 & 85,33 \\
\hline CICA2 & 0,89 & 3,12 & 0,0016 & 2,46 & 2,55 & 1,66 & 84,64 \\
\hline CIRM6 & 0,87 & 3,27 & 0,0013 & 2,32 & 2,46 & 1,65 & 83,93 \\
\hline CICA1 & 0,93 & 2,80 & 0,0019 & 2,79 & 2,64 & 1,79 & 82,52 \\
\hline CICA5 & 0,94 & 2,71 & 0,0020 & 2,88 & 2,65 & 1,84 & 79,76 \\
\hline CIRM10 & 0,87 & 3,28 & 0,0012 & 2,31 & 2,44 & 1,67 & 79,63 \\
\hline
\end{tabular}

A relação entre a eficiência dessulfurante em função da basicidade ótica, partição de enxofre e capacidade é apresentada na Figura 72. 

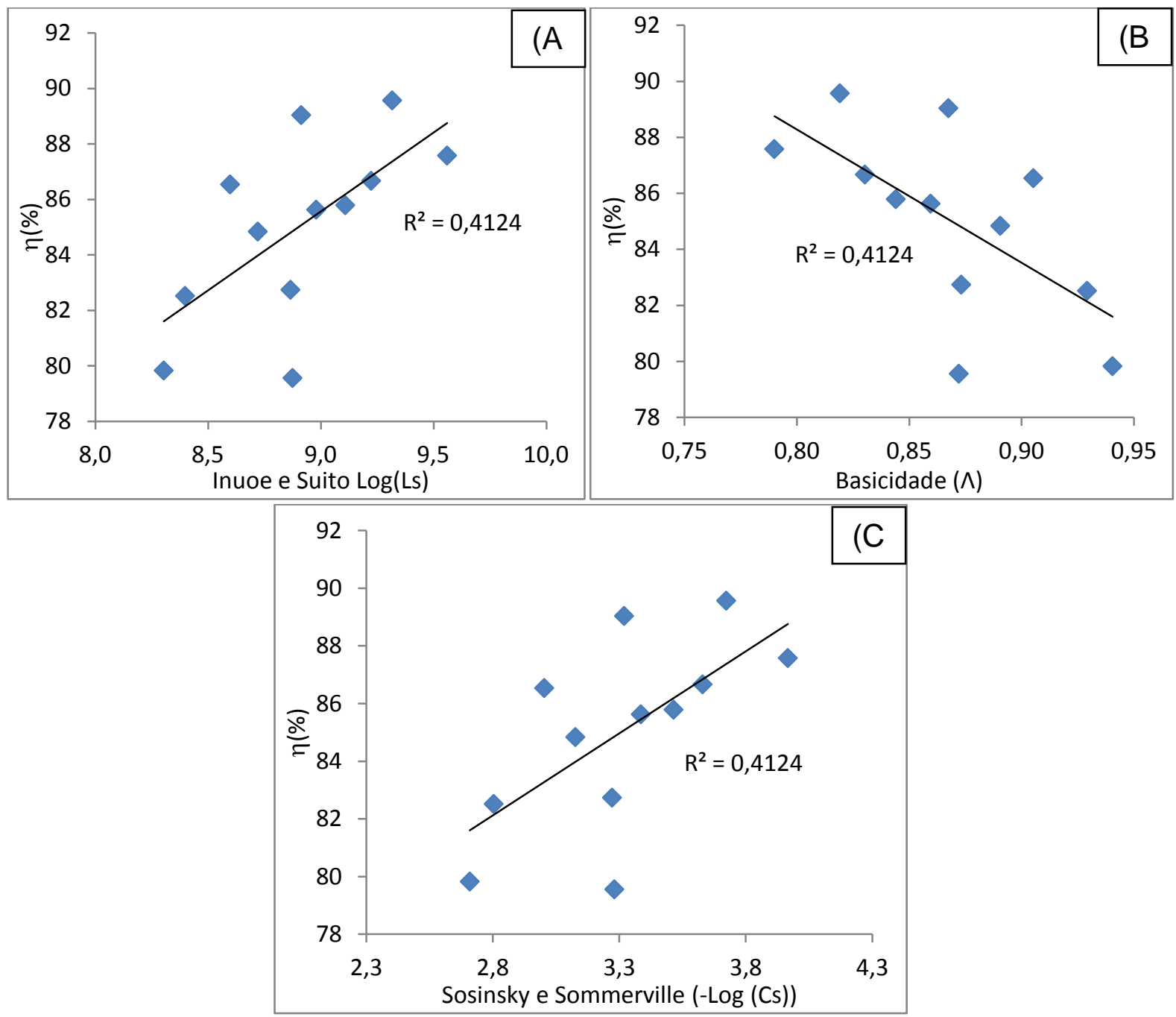

Figura 72. Relação entre a partição de enxofre (A), basicidade ótica (B), capacidade de sulfeto $(C)$, e função d eficiência ( $\eta$ \%) obtida nos testes de dessulfuração.

Os resultados mostram que os valores de Cs, Ls e $\wedge$ não se interrelacionam com a eficiência. O dados obtidos a partir dos modelos termodinâmicos, são explicados por Nzotta et $a^{(110)}$, que aplicou um modelo de capacidade de sulfeto para escórias com multicomponentes. $O$ autor ressalta que apenas previsões aproximadas podem ser feitas a partir dos dados de capacidade sulfeto e partição de enxofre. Em uma situação de produção, a escória não chega a atingir o equilíbrio propriamente dito, o qual é considerado para os cálculos da capacidade. Ainda de acordo com o autor, para os dados apurados, os valores previstos e os experimentalmente calculados de capacidade sulfeto, estão dentro da mesma ordem de grandeza. 
5.2.2.3 Utilização da termodinâmica computacional na análise dos resultados da dessulfuração de ferro fundido

$\mathrm{Na}$ Tabela 33 consta a concentração de equilíbrio dos elementos presentes no ferro fundido. Esses resultados foram gerados pelo Thermo-Calc.

Tabela 33. Teores de equilíbrio dos elementos presentes na composição química do ferro fundido.

\begin{tabular}{llcccc}
\hline Mistura & {$\left[\% \mathrm{~S}_{\text {eq. }}\right]$} & {$\left[\% \mathrm{Si}_{\text {eq. }}\right]$} & {$\left[\% \mathrm{C}_{\text {eq. }}\right]$} & {$[\% \mathrm{Mn}]$} & $\eta(\%)$ \\
\hline CICAF11 & $5,17 \mathrm{E}-05$ & 1,61 & 3,19 & 0,53 & 90,10 \\
CICA3 & $2,21 \mathrm{E}-04$ & 1,59 & 3,18 & 0,53 & 89,81 \\
CIRMF12 & $5,75 \mathrm{E}-05$ & 1,62 & 3,19 & 0,55 & 87,25 \\
CIRM8 & $3,95 \mathrm{E}-04$ & 1,56 & 3,18 & 0,53 & 87,03 \\
CICA4 & $1,74 \mathrm{E}-04$ & 1,53 & 3,18 & 0,53 & 86,56 \\
CIRM7 & $1,36 \mathrm{E}-04$ & 1,56 & 3,19 & 0,53 & 85,63 \\
CIRM9 & $3,46 \mathrm{E}-04$ & 1,54 & 3,18 & 0,54 & 85,33 \\
CICA2 & $6,30 \mathrm{E}-05$ & 1,54 & 3,19 & 0,53 & 84,64 \\
CIRM6 & $1,49 \mathrm{E}-04$ & 1,53 & 3,19 & 0,53 & 83,93 \\
CICA1 & $6,41 \mathrm{E}-05$ & 1,51 & 3,19 & 0,53 & 82,52 \\
CICA5 & $6,30 \mathrm{E}-05$ & 1,54 & 3,19 & 0,53 & 79,76 \\
CIRM10 & $6,26 \mathrm{E}-05$ & 1,53 & 3,20 & 0,54 & 79,63 \\
\hline
\end{tabular}

Observa-se que as misturas com os menores valores de enxofre de equilíbrio foram formuladas com o uso de $\mathrm{CaF}_{2}$ (CICAF11 e CIRMF12). Na sequência, com a mesma ordem de grandeza, aparecem as misturas que utilizaram concentração (\%) de $\mathrm{CaO}$ em excesso (CICA5 e CIRM10). Este resultado indica que essas misturas possuem potencial termodinâmico maior em relação as demais. No entanto, fatores cinéticos podem ter interferido para que as misturas com o maior potencial termodinâmico não obtivessem o maior rendimento dessulfurante.

Dessa forma, foram calculadas as fases presentes nas misturas iniciais com o Thermo-Calc, visando correlacionar às fases presentes com a eficiência obtida pelos experimentos. Os resultados podem ser visualizados na Figura 73. 

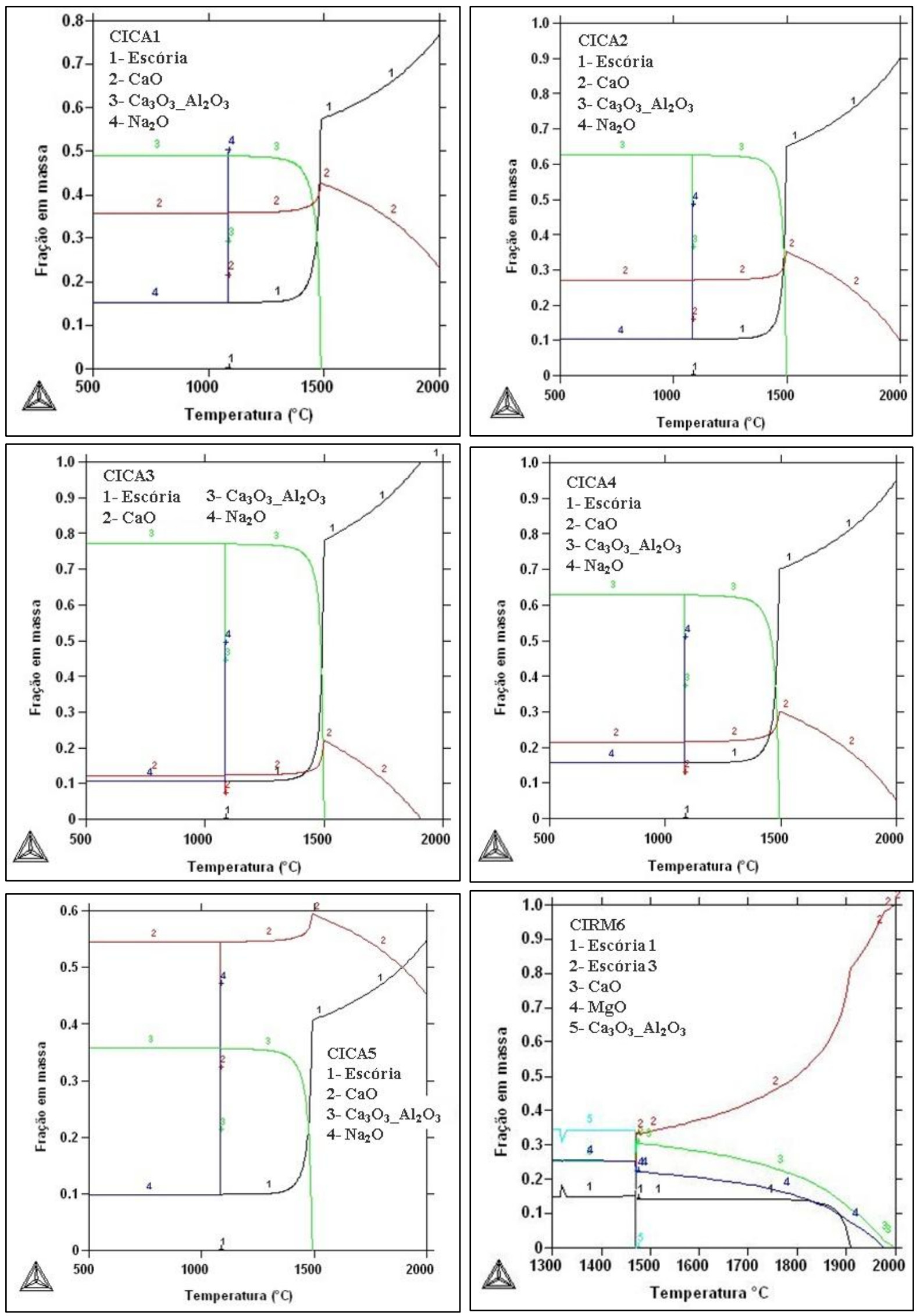

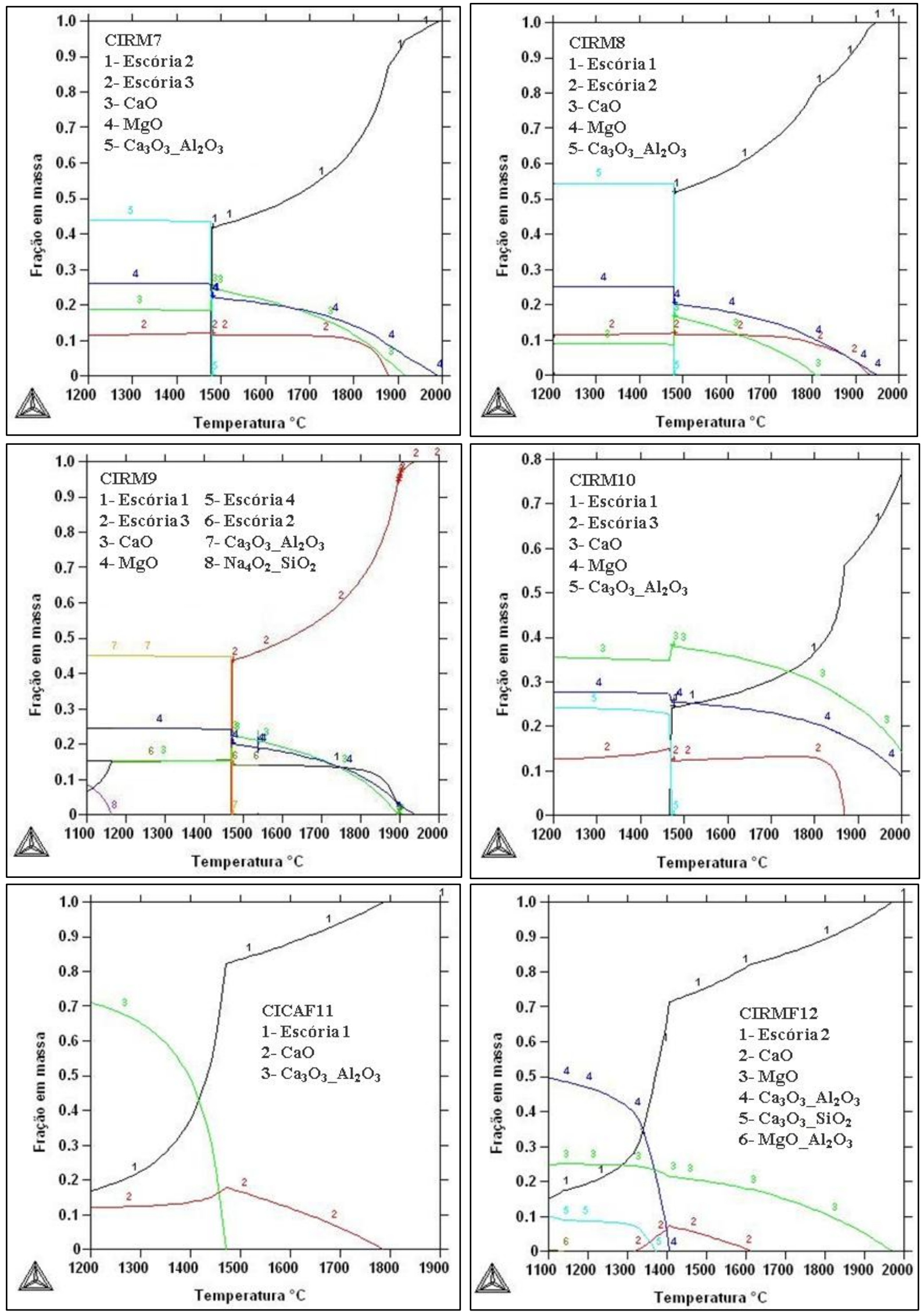

Figura 73. Fases presentes nas misturas iniciais dessulfurantes utilizadas na dessulfuração de ferro fundido. 
A partir da Figura 73 é possível obter informações sobre as fases presentes. Além disso, pode-se também conhecer a proporção entre estas fases. Observa-se que, diferente do ferro-gusa, o aluminato de cálcio $\left(\mathrm{Ca}_{3} \mathrm{O}_{3} \mathrm{Al}_{2} \mathrm{O}_{3}\right)$ já não está mais sólido na temperatura dos ensaios $\left(1550^{\circ} \mathrm{C}\right)$.

Analisando as curvas da Figura 73, nas misturas formuladas com cal convencional: CICA1, CICA2, CICA3, CICA4, CICA5 e CICA11, observa-se que as frações de fase líquida foram respectivamente de $62,97 \%, 70,45 \%, 82,74 \%, 75,18 \%$, $46,05 \%$ e $88,02 \%$ na temperatura dos ensaios $\left(1550^{\circ} \mathrm{C}\right)$, além disso, apresentaram $\mathrm{CaO}$ sólido. Para as misturas formuladas com resíduo de mármore: CIRM6, CIRM7, CIRM8, CIRM9, CIRM10 e CIRM12, as frações de fase líquida foram respectivamente de $56,17 \%, 63,00 \%, 73,26 \%, 67,14 \%, 43,39 \%$ e $82,39 \%$. Além do $\mathrm{CaO}$ as misturas com resíduo também apresentam o $\mathrm{MgO}$ como fase sólida. As concentrações das demais fases formadas na temperatura de $1550^{\circ} \mathrm{C}$, obtidas através das curvas de equilíbrio mostradas na Figura 73, foram inseridas na Tabela 34 e serão abordadas no próximo item.

5.2.2.4 Efeito da fase líquida e da fase sólida na dessulfuração de ferro fundido

Análogo ao procedimento realizado para as escórias de ferro-gusa, e com o objetivo de conhecer a influência da fase líquida na dessulfuração do ferro fundido por escória de topo, a fase líquida foi colocada em equilíbrio com o ferro fundido. A Tabela 34 apresenta a porcentagem da fase líquida e sólida das misturas iniciais, além da massa $(\mathrm{g})$ da fase líquida inicial. 
Tabela 34. Resultados dos cálculos de equilíbrio das misturas iniciais dessulfurantes de ferro fundido, utilizando o software Thermo-Calc.

\begin{tabular}{ccccccc}
\hline Misturas & $\begin{array}{c}\text { Fase } \\
\text { líquida }(\%)\end{array}$ & $\begin{array}{c}\text { Massa da fase } \\
\text { líquida }(\mathrm{g})\end{array}$ & $\begin{array}{c}\text { Fase } \\
\text { Sólida }(\%)\end{array}$ & \multicolumn{2}{c}{$\begin{array}{c}\text { Fases formadas na } \\
\text { fase sólida }\end{array}$} & (\%) CaO \\
$(\%) \mathrm{MgO}$ & $\eta(\%)$ \\
\hline CICAF11 & 88,02 & 36,97 & 11,98 & 11,97 & 0 & 90,10 \\
CICA3 & 82,74 & 34,75 & 17,26 & 17,26 & 0 & 89,81 \\
CIRMF12 & 82,39 & 29,99 & 17,61 & 4,14 & 13,47 & 87,25 \\
CIRM8 & 73,26 & 26,67 & 26,74 & 13,7 & 13,04 & 87,03 \\
CICA4 & 75,18 & 31,58 & 24,82 & 24,82 & 0 & 86,56 \\
CIRM7 & 63,00 & 24,89 & 37,00 & 22,15 & 14,84 & 85,63 \\
CIRM9 & 67,14 & 24,44 & 32,86 & 19,84 & 13,01 & 85,33 \\
CICA2 & 70,45 & 29,59 & 29,55 & 29,55 & 0 & 84,64 \\
CIRM6 & 56,17 & 22,19 & 43,83 & 28,78 & 15,04 & 83,93 \\
CICA1 & 62,97 & 26,45 & 37,03 & 37,03 & 0 & 82,52 \\
CICA5 & 46,05 & 19,34 & 53,95 & 53,95 & 0 & 79,76 \\
CIRM10 & 43,39 & 19,74 & 56,61 & 38,36 & 18,25 & 79,63 \\
\hline
\end{tabular}

Em seguida, foi calculado o teor de enxofre de equilíbrio quando se considera apenas a fase líquida na dessulfuração. Os resultados obtidos podem ser visualizados na Tabela 35.

Tabela 35. Teor de enxofre inicial e final dos experimentos e composição de equilíbrio após o cálculo no Thermo-Calc.

\begin{tabular}{cccccccc}
\hline Escória & {$\left[\% \mathrm{~S}_{\text {iniciala }}\right]$} & {$\left[\% \mathrm{~S}_{\text {final }}\right]$} & {$\left[\mathrm{S}_{\text {eq }}\right]$} & {$\left[\mathrm{C}_{\text {eq }}\right]$} & {$\left[\mathrm{Si}_{\text {eq }}\right]$} & {$\left[\mathrm{Mn}_{\text {eq }}\right]$} & $\eta(\%)$ \\
\hline CICAF11 & 0,101 & 0,010 & 0,00057 & 3,19 & 1,60 & 0,53 & 90,10 \\
CICA3 & 0,090 & 0,013 & 0,00149 & 3,18 & 1,59 & 0,53 & 89,81 \\
CIRMF12 & 0,091 & 0,011 & 0,00102 & 3,20 & 1,63 & 0,53 & 87,25 \\
CIRM8 & 0,082 & 0,018 & 0,00354 & 3,16 & 1,64 & 0,53 & 87,03 \\
CICA4 & 0,103 & 0,019 & 0,00065 & 3,17 & 1,60 & 0,53 & 86,56 \\
CIRM7 & 0,084 & 0,012 & 0,00433 & 3,14 & 1,65 & 0,53 & 85,63 \\
CIRM9 & 0,087 & 0,009 & 0,00484 & 3,12 & 1,65 & 0,53 & 85,33 \\
CICA2 & 0,084 & 0,014 & 0,00175 & 3,17 & 1,62 & 0,53 & 84,64 \\
CIRM6 & 0,084 & 0,010 & 0,00554 & 3,11 & 1,67 & 0,53 & 83,93 \\
CICA1 & 0,103 & 0,016 & 0,00344 & 3,12 & 1,62 & 0,53 & 82,52 \\
CICA5 & 0,096 & 0,014 & 0,00465 & 3,12 & 1,64 & 0,53 & 79,76 \\
CIRM10 & 0,091 & 0,013 & 0,00751 & 3,10 & 1,69 & 0,53 & 79,63 \\
\hline
\end{tabular}

Os resultados indicaram que os teores de enxofre de equilíbrio estão abaixo dos valores finais obtidos após o término dos ensaios experimentais. A eficiência de dessulfuração em função da fase líquida pode ser visualizada Figura 74. 

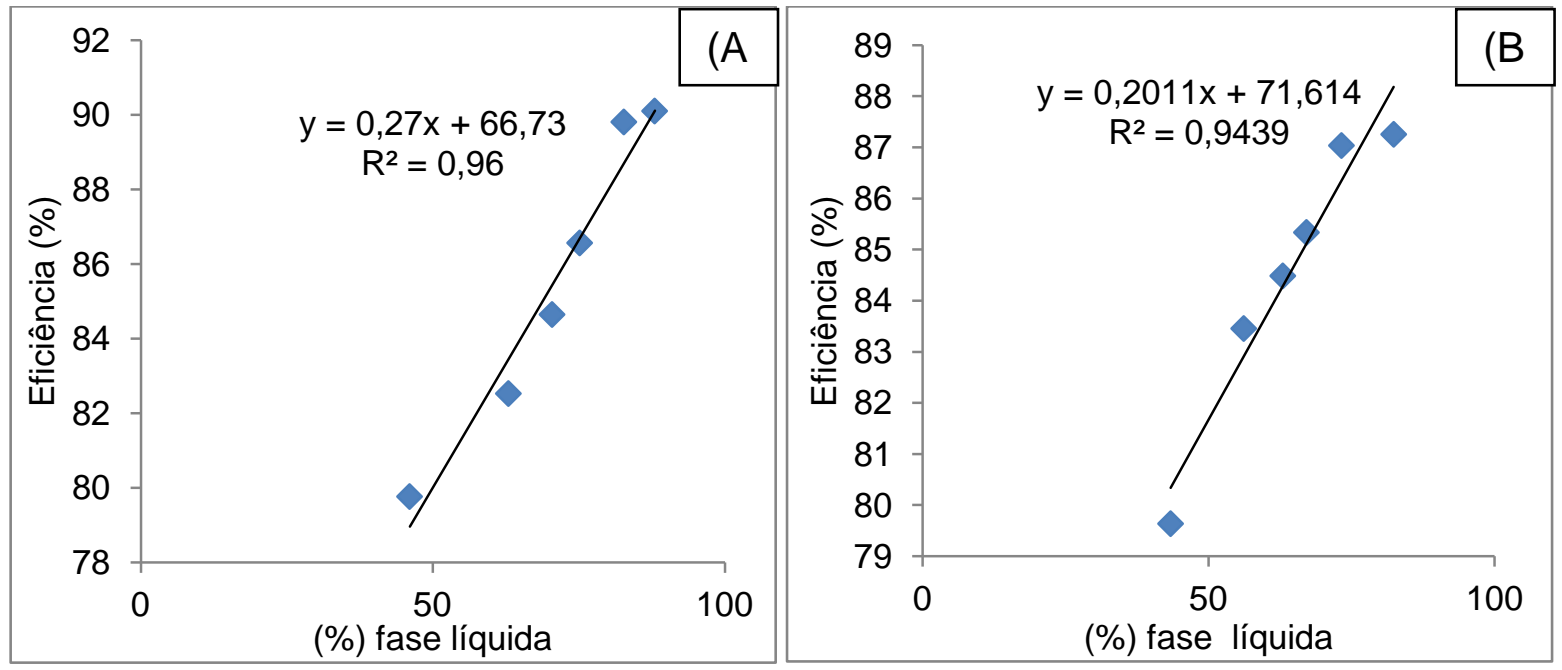

Figura 74. Relação entre a eficiência e a quantidade de fase líquida para escórias dessulfurantes à base de cal $(A)$ e resíduo de mármore (B).

Nota-se que fase líquida se interrelacionam com a eficiência dessulfurante, visto que, o coeficiente de correlação linear $\left(R^{2}\right)$ é de 0,96 e 0,94 para as misturas com cal convencional e com resíduo de mármore, respectivamente. Dessa forma, a equação da linha de tendência pode ser utilizada como parâmetro para descrever o comportamento de escórias à base de $\mathrm{CaO}-\mathrm{Al}_{2} \mathrm{O}_{3}$ e resíduo de mármore na dessulfuração do ferro fundido por escória de topo. Este comportamento observado para as escórias de topo é bastante difundido na literatura e encontrado em outros trabalhos $(26,42,52)$. Neste caso, com o aumento da fase líquida, o transporte de massa do enxofre na escória e na interface metal/escória é mais eficaz, favorecendo a remoção do enxofre.

Com o aumento da fase líquida, ocorre concomitantemente o aumento da quantidade de $\mathrm{CaO}$ disponível para reagir nas escórias. Dessa forma, o aumento da eficiência pode ser analisado considerando $\mathrm{o} \mathrm{CaO}$ na fase líquida, conforme pode ser visualizado na Figura 75 . 

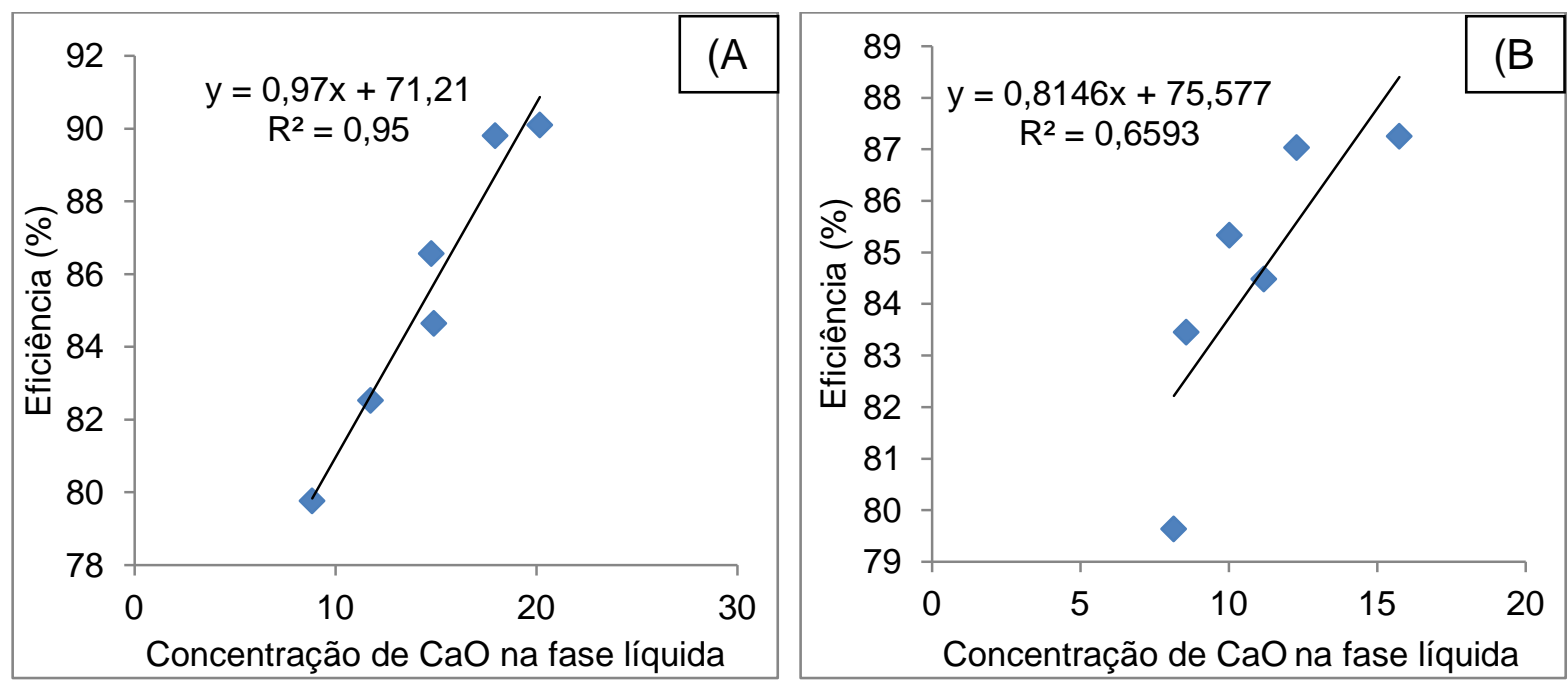

Figura 75. Relação entre a concentração de $\mathrm{CaO}$ na fase líquida em função da eficiência dessulfurante para escórias dessulfurantes à base de cal $(A)$ e resíduo de mármore (B).

Para as misturas produzidas com cal convencional, os resultados mostraram que a concentração de $\mathrm{CaO}$ na fase líquida possui correlação com a eficência $\left(R^{2}=0,95\right)$. Por outro lado, para as escórias com resíduo de mármore, não foi observado o mesmo comportamento linear encontrado para as escórias formuladas com cal convencional. Com isso, a concentração de $\mathrm{MgO}$ sólido presente no resíduo de mármore pode ter interferido negativamente na dessulfuração, conforme pode ser visualizado na Figura 76.
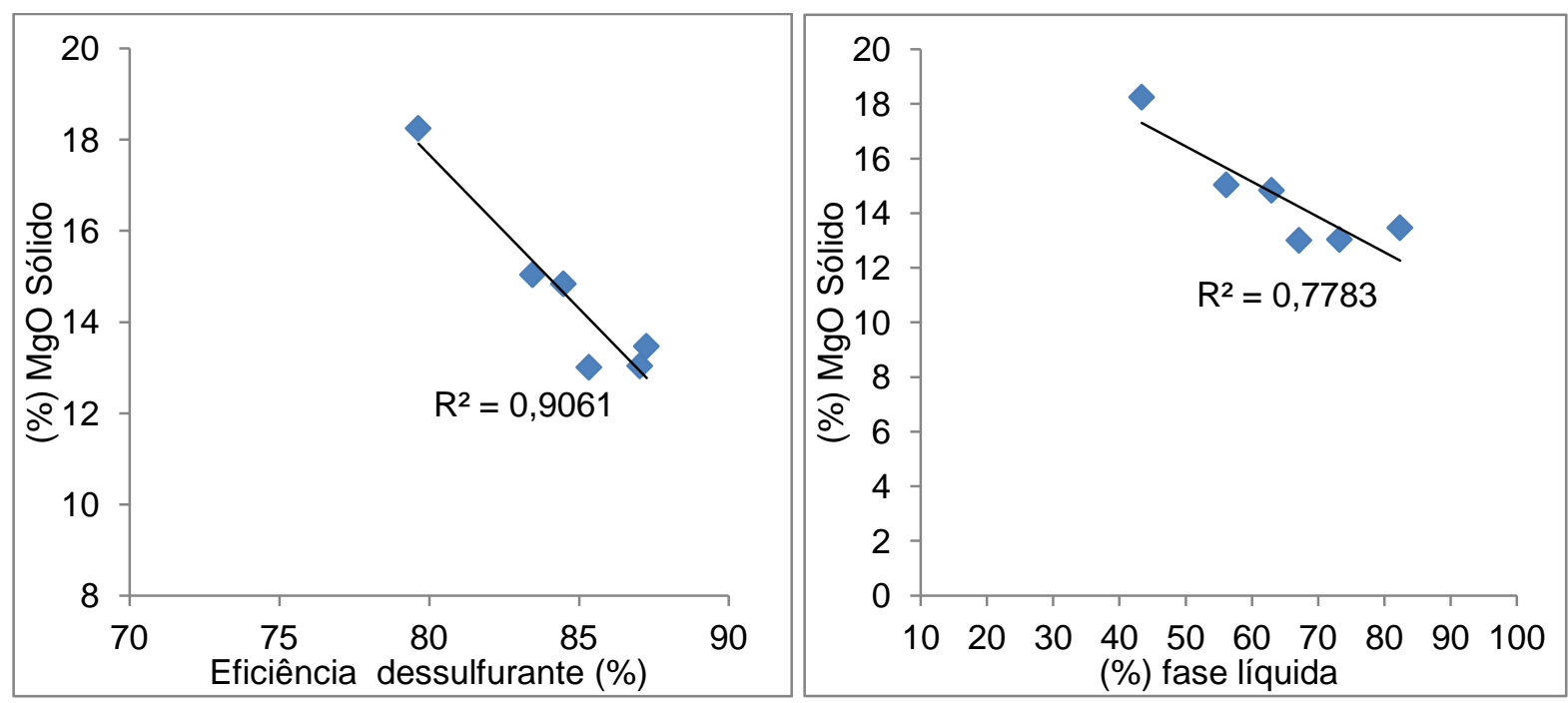

Figura 76. Relação entre a concentração de $\mathrm{MgO}$ em função da fase líquida e eficiência dessulfurante para as escórias formuladas com resíduo de mármore. 
Observa-se que aumento da concentração de $\mathrm{MgO}$ interfere negativamente na eficiência dessulfurante e na quantidade de fase líquida. Dessa forma, o aumento da concentração de $\mathrm{MgO}$ pode ter sido um dos fatores limitantes no refino com o uso de misturas formuladas com resíduo de mármore.

Mesmo que a decomposição dos carbonatos tenha favorecido a dessulfuração, atuando no mecanismo de transferência de enxofre até interface metal escória, a presença do MgO sólido agiu no sentido de retardar o processo.

Com base nesses resultados, a utilização do resíduo de mármore intercalado com a cal convencional ou em substituição a cal dolomítica, pode ser uma alternativa para diminuiur o efeito negativo do $\mathrm{MgO}$ na dessulfuração.

A partir desses resultados e visando verificar se ao final do processo a melhor escória dessulfurante permanece com a escória saturada em $\mathrm{CaO}$, foi realizado um balanço de massa para determinar a composição final das escórias geradas nos experimentos. O cálculo da composição da escória final por balanço de massa foi realizado considerando a análise química da amostra final do ferro fundido. Com base na massa do ferro fundido adicionado e na análise inicial e final da composição química do mesmo, sabe-se a quantidade de enxofre presente antes e depois do experimento de dessulfuração. A partir disso, pode-se considerar que o enxofre removido do metal reagiu com o $\mathrm{CaO}$ formando $\mathrm{CaS}$ e o oxigênio resultante na reação reagiu com o Si do ferro fundido. De acordo com a reação global, mostrada na Equação 6.

$$
(\mathrm{CaO})_{(S)}+[\mathrm{S}]+1 / 2[\mathrm{Si}]=(\mathrm{CaS})_{(S)}+1 / 2\left(\mathrm{SiO}_{2}\right)_{(S)}
$$

Após o balanço, foram determinadas novamente as fases presentes nas escórias pelo Thermo-Calc e os resultados podem ser visualizados na Tabela 36. 
Tabela 36. Fases formadas nas escórias finais após o balanço de massa e cálculo no Thermo-Calc.

\begin{tabular}{|c|c|c|c|c|c|c|}
\hline \multirow{2}{*}{$\begin{array}{l}\text { Identificação } \\
\text { das escórias }\end{array}$} & \multirow{2}{*}{$\begin{array}{c}\text { Fase } \\
\text { líquida } \\
(\%)\end{array}$} & \multirow{2}{*}{$\begin{array}{c}\text { Fase } \\
\text { Sólida } \\
(\%)\end{array}$} & \multicolumn{2}{|c|}{$\begin{array}{l}\text { Fases formadas na fase } \\
\text { sólida }\end{array}$} & \multirow{2}{*}{$\begin{array}{l}\text { Atividade do } \\
\text { CaO }\end{array}$} & \multirow[b]{2}{*}{$\eta(\%)$} \\
\hline & & & $\begin{array}{l}\text { (\%) } \mathrm{CaO} \\
\text { Livre }\end{array}$ & $(\%) \mathrm{MgO}$ & & \\
\hline CICAF11 & 97 & 3,04 & 3,04 & 0 & 1 & 90,10 \\
\hline CICA3 & 87,24 & 12,76 & 12,76 & - & 1 & 89,81 \\
\hline CIRMF12 & 87,81 & 12,19 & 0 & 12,19 & 0,91 & 87,25 \\
\hline CIRM8 & 79,43 & 20,57 & 7,77 & 12,80 & 1 & 87,03 \\
\hline CICA4 & 79,13 & 20,87 & 20,87 & - & 1 & 86,56 \\
\hline CIRM7 & 69,08 & 30,92 & 16,36 & 14,56 & 1 & 85,63 \\
\hline CIRM9 & 70,05 & 29,95 & 16,61 & 13,34 & 1 & 85,33 \\
\hline CICA2 & 74,57 & 25,53 & 25,53 & - & 1 & 84,64 \\
\hline CIRM6 & 61,92 & 38,08 & 25,79 & 12,29 & 1 & 83,93 \\
\hline CICA1 & 67,1 & 32,9 & 32,9 & - & 1 & 82,52 \\
\hline CICA5 & 49,45 & 50,55 & 49,45 & - & 1 & 79,76 \\
\hline CIRM10 & 49,12 & 50,88 & 32,94 & 17,94 & 1 & 79,63 \\
\hline
\end{tabular}

$\mathrm{Na}$ Tabela 36, nota-se que a escória (CICAF11) foi a que apresentou maior quantidade de fase líquida, menor quantidade de fase sólida e a atividade do $\mathrm{CaO}$ igual a 1(um) no final do processo. Com isso, pode-se inferir que para o processo de escória de topo, como no processo de dessulfuração de ferro fundido deste trabalho, a concentração de $\mathrm{CaO}$ sólido na mistura inicial deve ser o suficiente para que no final da etapa de refino, mantenha a atividade do $\mathrm{CaO}$ igual a 1 e evite prejuízos cinéticos ao refino.

5.2.2.5 Análise comparativa da substituição da cal convencional por resíduo de mármore

A Figura 77 mostra uma comparação entre escórias com uso de resíduo de mármore e cal convencional. 


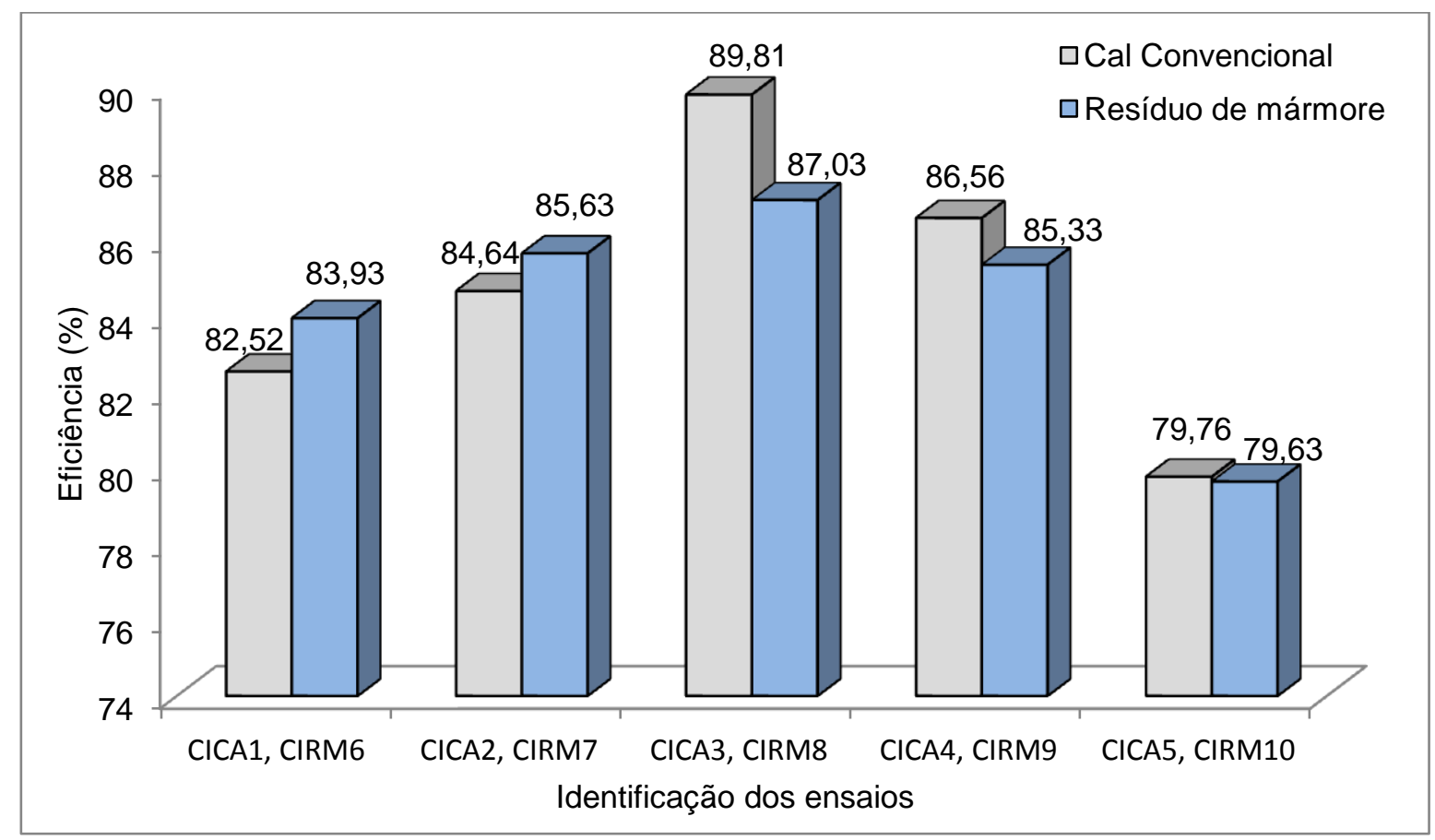

Figura 77. Porcentagem de dessulfuração dos experimentos de ferro fundido.

As misturas produzidas com resíduo de mármore, identificadas por CIRM6 e CIRM7, apresentaram maior eficiência dessulfurante (83,4\% e 84,4\%) quando comparadas com as escórias produzidas com cal convencional (CICA1 e CICA2) que obtiveram $82,5 \%$ e $85,6 \%$, respectivamente. Estes resultados podem ser um indicativo que a decomposição dos carbonatos presentes nas escórias com resíduo de mármore favoreceu a dessulfuração. Com isso, a agitação aumentou a área de interface metal/escória e melhorou a dessulfuração. Para a faixa de composição dessas misturas, o resíduo de mármore pode ser uma alternativa em substituição a cal convencional.

Verifica-se que o comportamento inverte nas próximas misturas (CICA3, CICA4, CIRM8 e CIRM9), ou seja, as escórias formuladas com cal convencional passaram a obter maior eficiência dessulfurante $(89,8 \%$ e $86,5 \%)$ em comparação com as escórias com resíduo de mármore (87,0\% e 85,3\%). Este comportamento pode ser causado devido a influência da fase líquida, que neste caso, foi preponderante nas escórias de cal convencional em relação à decomposição dos carbonatos nas escórias com resíduo de mármore. Nota-se que quando a porcentagem de fase líquida foi superior a $75 \%$, as escórias com formuladas com cal convencional passam ter melhor eficiência dessulfurante. 
As escórias CICA5 e CIRM10 apresentaram valores similares de dessulfuração. Nestas misturas foi utilizada a massa de $\mathrm{CaO}$ superior às demais escórias. Neste caso, o aumento da massa de $\mathrm{CaO}$ diminuiu a fração de fase líquida, prejudicando a cinética em ambas as escórias.

Por fim, o resíduo de mármore pode ser uma alternativa em substituição a cal convencional na dessulfuração do ferro fundido. Mesmo apresentando desvantagens em algumas situações, os resultados obtidos estiveram próximos aos alcançados nas escórias produzidas com cal convencional.

5.2.2.6 Análise comparativa da substituição da fluorita por $\mathrm{Al}_{2} \mathrm{O}_{3}$

A análise comparativa de substituição da fluorita por $\mathrm{Al}_{2} \mathrm{O}_{3}$ foi realizada considerando escórias com uso do resíduo de mármore e cal convencional, mantendo a mesma massa de $\mathrm{CaO}$ para todos os ensaios. As escórias que foram utilizadas são identificadas por CICAF3, CIRM8, CICAF11 e CIRMF12. A Figura 78 apresenta a uma comparação entre os resultados com o uso da fluortia e $\mathrm{Al}_{2} \mathrm{O}_{3}$.

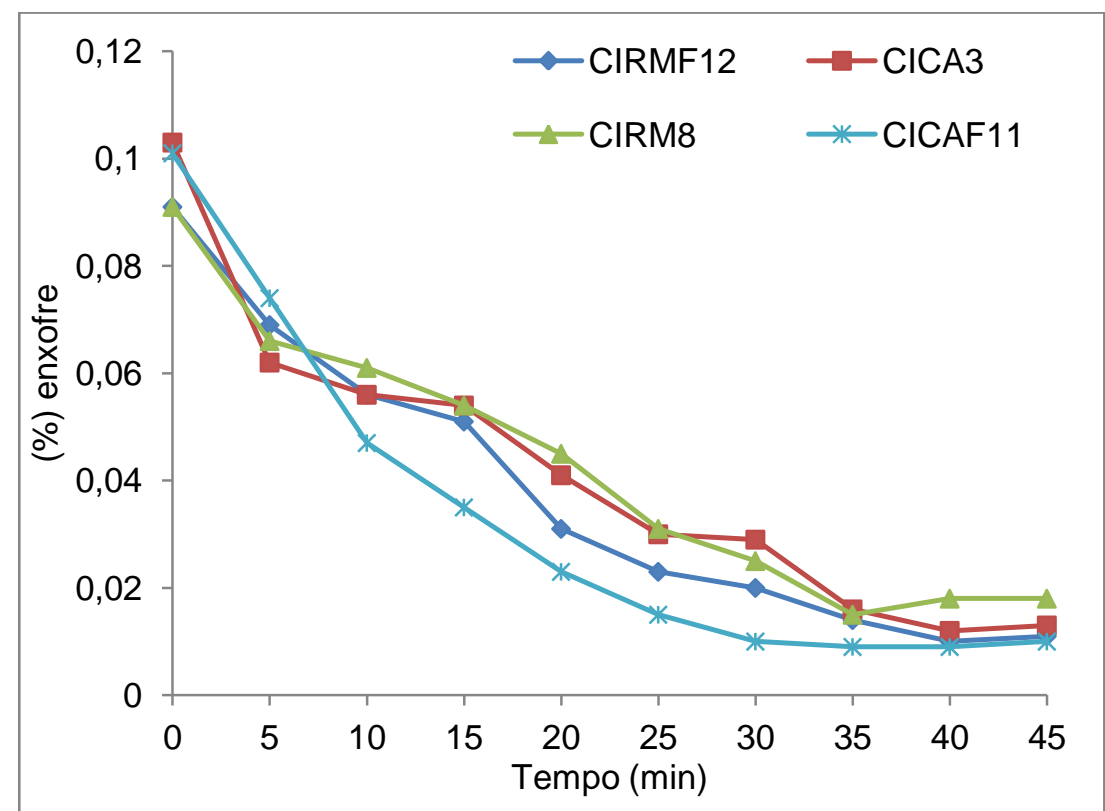

Figura 78. Remoção do enxofre em função do tempo, utilizando as escórias CICAF11, CIRM8, CIRMF12 e CICA3.

Os resultados mostraram que nos primeiros 10 minutos de experimentos, a ordem descrescente das escórias na remoção do enxofre foi 
CICAF11>ClRM8>CICA3>CIRMF12. Após 15 minutos de ensaio, segundo e terceiro carregamento de escória, observa-se que a ordem de remoção do enxofre foi alterada para: $\mathrm{CICAF} 11>\mathrm{CIRMF} 12>\mathrm{CIRM} 8>\mathrm{CICA} 3$.

Este comportamento pode ser analisado utilizando a fração de fase líquida das misturas iniciais, conforme mostrado na Figura 79.

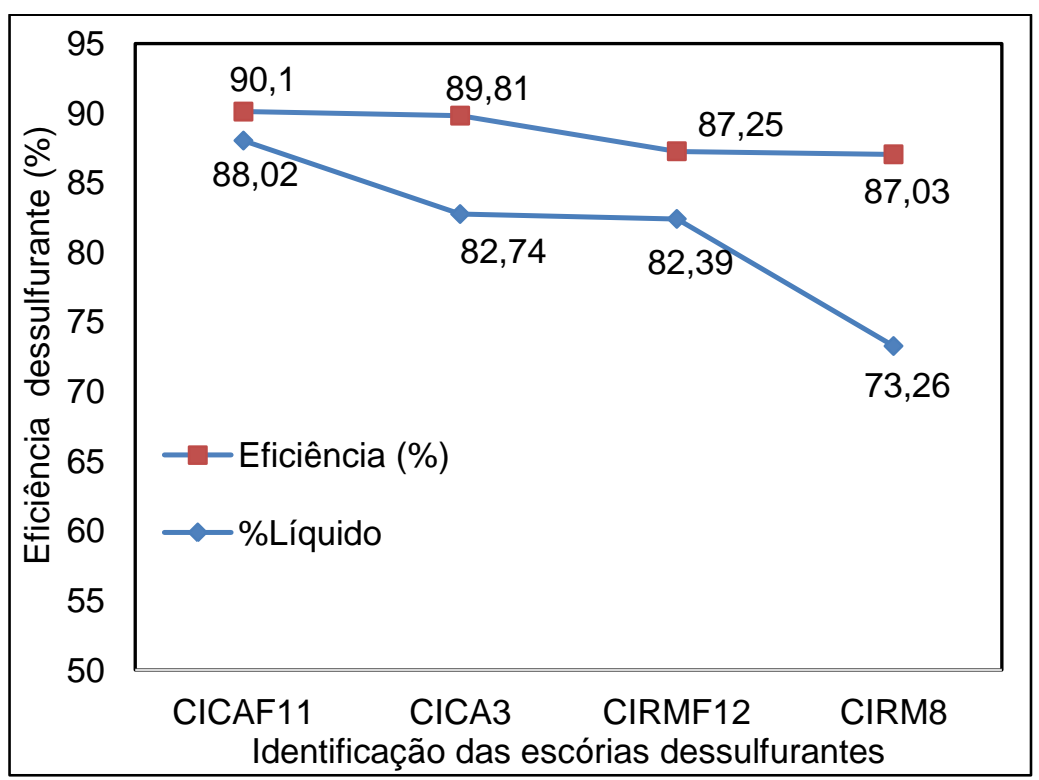

Figura 79. Comparação entre a fração de fase líquida das misturas e a eficiência de dessulfuração dessulfurante para as misturas utilizadas no ferro fundido.

Nota-se que o aumento da fase líquida favoreceu a remoção do enxofre no ferro fundido. Além disso, escórias produzidas com cal convencional apresentaram os maiores valores de eficiência dessulfurante. Quando se compara o rendimento obtido pelas duas escórias produzidas com cal convencional (CICAF11 e CICA3), é possível observar que os valores alcançados estão próximos (89,5\% e 89,0\%). Este resultado indica que a substituição da fluorita por $\mathrm{Al}_{2} \mathrm{O}_{3}$ pode ser uma alternativa viável.

A escória com resíduo de mármore e fluorita (CIRMF12), apresentou rendimento dessulfurante de aproximadamente $88,0 \%$. Este resultado coloca o resíduo de mármore como substituito alternativo da cal convencional, uma vez que o rendimento obtido está próximo ao encontrado nas escórias produzidas com cal convencional $(89,57 \%)$.

Verifica-se ainda, que a fluorita reduz o ponto de fusão das misturas, fazendo com que haja maior quantidade de fase líquida e, consequentemente, facilitando o 
transporte de massa e melhorando a dessulfuração. Além de reduzir o ponto de fusão da mistura, segundo Nita et $a{ }^{(18)}$, a fluorita também reduz a viscosidade da escória formada.

\subsubsection{Efeito da viscosidade na dessulfuração de ferro fundido}

O efeito da viscosidade na remoção do enxofre no ferro fundido pode ser visualizado na Figura 80.

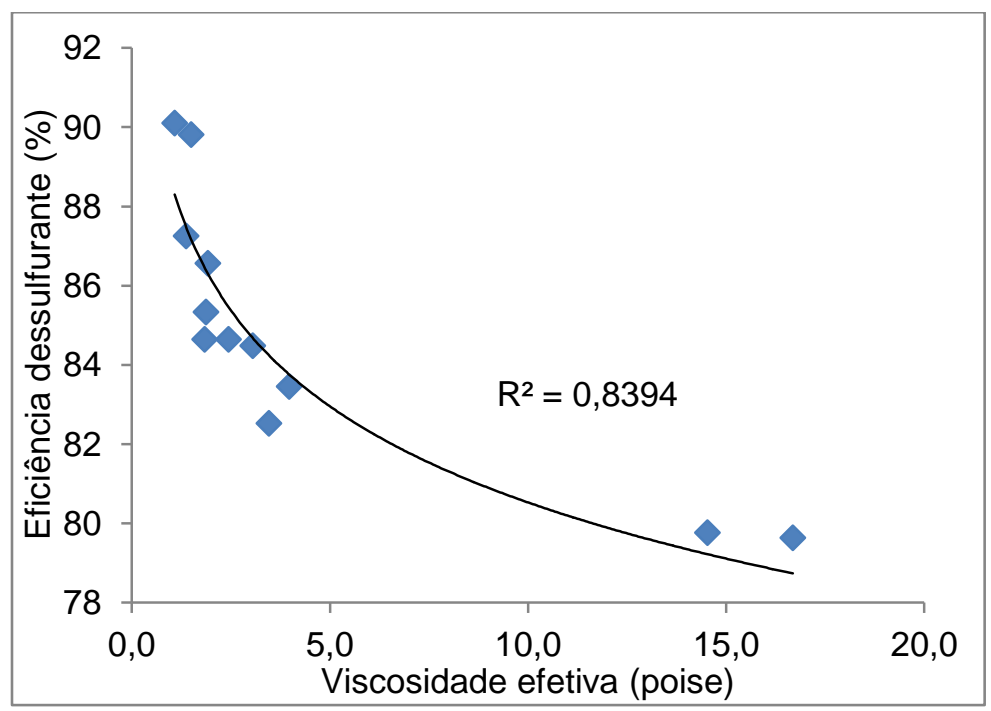

Figura 80. Relação entre a viscosidade em função da eficiência (\%) para escórias dessulfurantes de ferro fundido.

Verifica-se que a eficiência dessulfurante das escórias tende a aumentar com a diminuição da viscosidade. De acordo com a literatura ${ }^{(12,14,47)}$, a diminuição da viscosidade, causa uma redução no tamanho da camada limite na interface metal/escória, melhorando a eficiência dessulfurante, conforme verificado nos experimentos. 
5.2.2.8 Influência da granulometria no processo de dessulfuração no ferro fundido

A granulometria das misturas pode interferir na eficiência dessulfurante das mesmas. Dessa forma, foi avaliado o efeito da granulometria do $\mathrm{CaO}$ na remoção do enxofre no metal, conforme pode se visualizada na Figura 81.

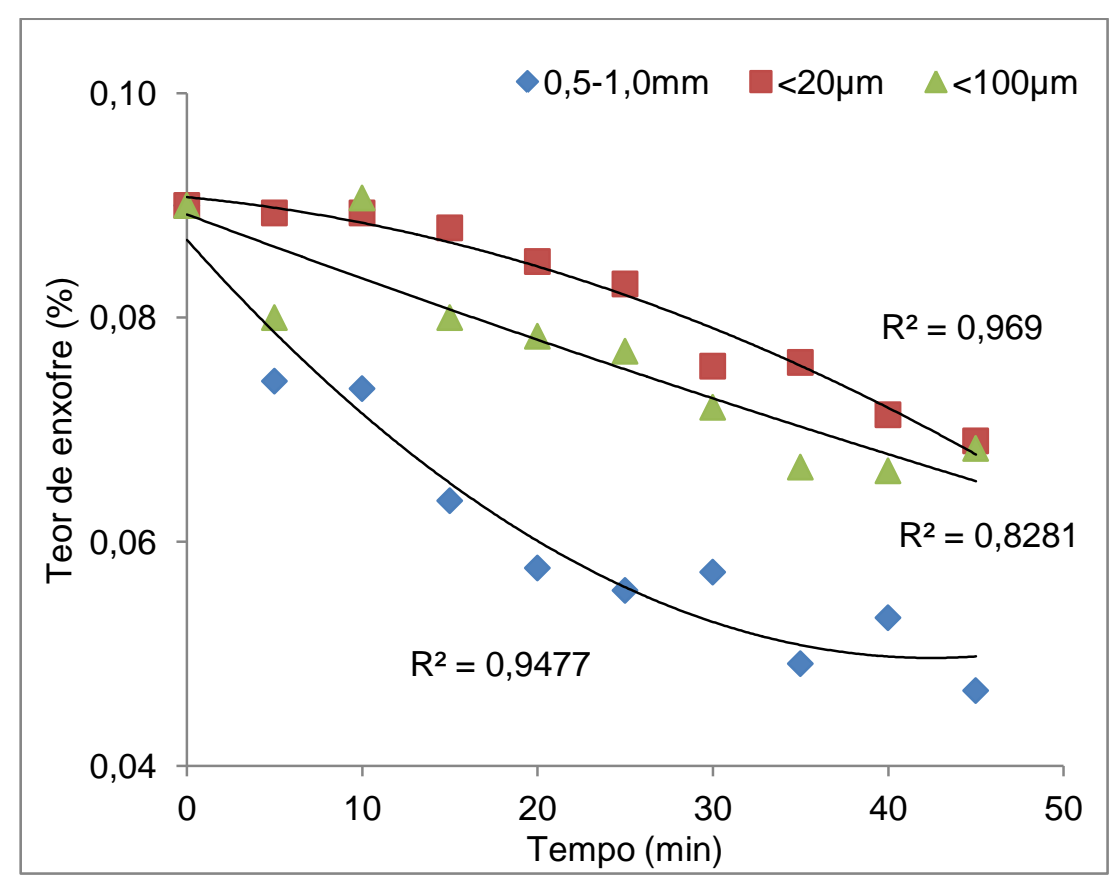

Figura 81. Análise da influência da granulometria do $\mathrm{CaO}$ em função do teor de enxofre no metal.

Observa-se que o aumento da granulometria favorece o processo de dessulfuração. Este comportamento revela-se contraditório, uma vez que, a diminuição da granulometria aumentaria a área superficial. Entretanto, foi observado durante os experimentos, que as escórias com granulometria de $20 \mu \mathrm{m}$ e $100 \mu \mathrm{m}$ aglomeravam (sinterizavam) após a adição no metal. A Figura 82 e a Figura 83, apresentam exatamente o que foi descrito neste parágrafo. 


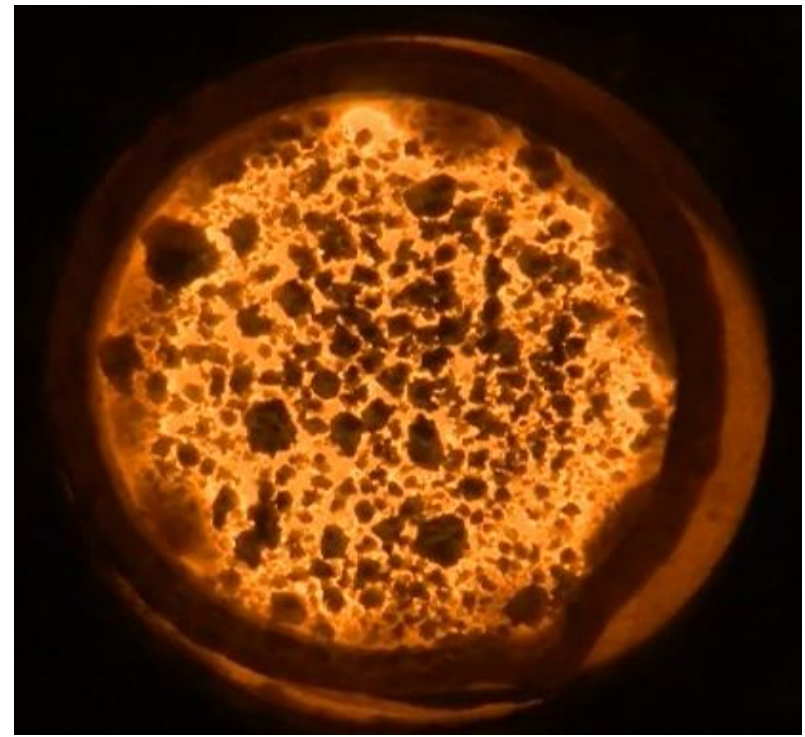

Figura 82. Foto tirada aos 5 minutos de experimento com a Cal $<100 \mu \mathrm{m}$, apresentado a aglomeração das partículas.

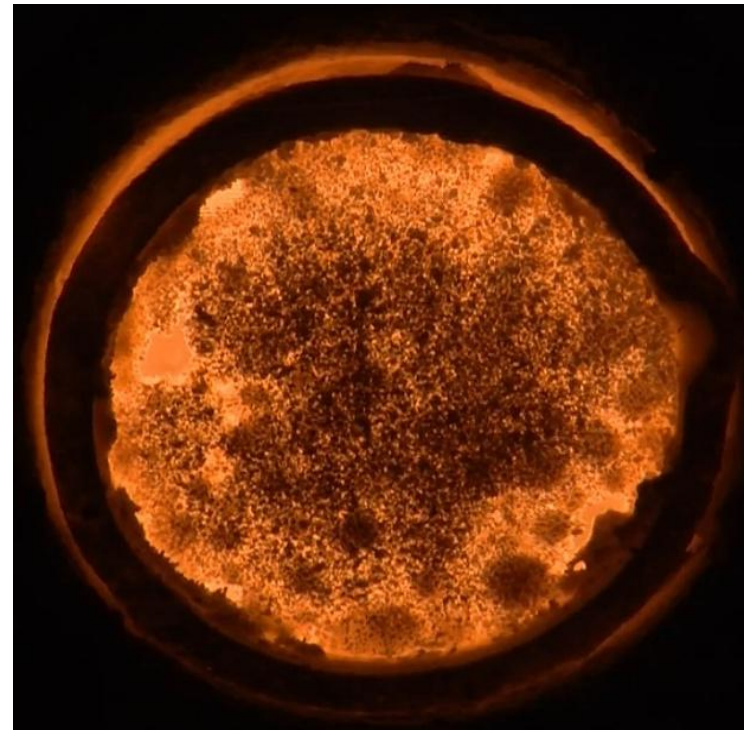

Figura 83. Foto tirada aos 5 minutos de experimento com a Cal 0,5-1,0 mm, mostrando que não ocorreu o processo de aglomeração das partículas.

Fruehan et $a{ }^{(111)}$ também estudou o efeito das partículas de $\mathrm{CaO}$ em escórias $\mathrm{CaO}-\mathrm{CaF}_{2}$ na remoção do enxofre. Segundo o autor, quando o $\mathrm{CaO}$ é utilizado com granulometria menor que $1,5 \mathrm{~mm}$, a fase líquida faz com que as partículas de CaO se aglomerem, enquanto que, quando a granulometria do $\mathrm{CaO}$ é utilizada entre (20 a $30 \mathrm{~mm}$ ), a aglomeração encontrada foi menor. Por fim, conclui-se que existe um tamanho ideal de partícula, entre 2,0-2,5 mm. A Figura 84 apresenta a influência dos tamanhos das partículas de cal na remoção de enxofre, descrito por Fruehan ${ }^{(111)}$.

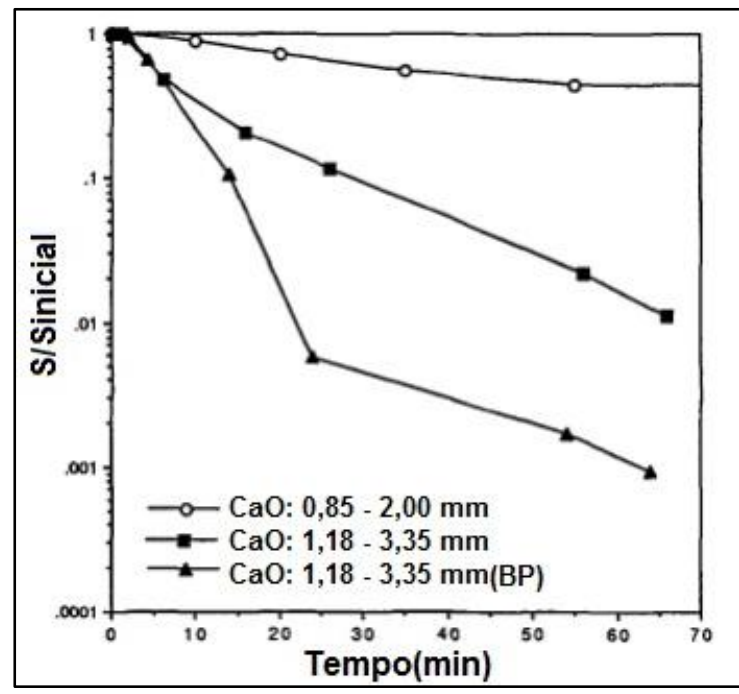

Figura 84. Efeito do tamanho de partícula na remoção do enxofre. 
Analisando a Figura 84, observa-se que o aumento da granulometria favoreceu a dessulfuração. Além disso, o $\mathrm{CaO}$ com menor porosidade identificado por: $\mathrm{CaO}: 1,18-3,35 \mathrm{~mm}(\mathrm{BP})$, apresentou melhor dessulfuração.

5.2.2.9 Cálculo da constante de velocidade (k) para escórias de ferro fundido.

A Tabela 37 apresenta os valores da constante de velocidade dos ensaios de ferro fundido. A equação utilizada e o método adotado foram apresentados no item 4.5.5.

Tabela 37. Cálculo da constante de velocidade ( $\mathrm{k}$ ) em diferentes tempos de retirada de amostras para cada experimento.

\begin{tabular}{|c|c|c|c|c|c|c|c|c|c|c|}
\hline \multirow{3}{*}{ Ensaios } & \multicolumn{9}{|c|}{ Constante de velocidade $\left(10^{-4}\right)$} & \multirow{3}{*}{$\mathrm{K}$ (médio) } \\
\hline & \multicolumn{9}{|c|}{ Tempo (min) } & \\
\hline & 5 & 10 & 15 & 20 & 25 & 30 & 35 & 40 & 45 & \\
\hline $\mathrm{Cl} 1$ & 9,50 & 6,02 & 3,66 & 4,77 & 5,16 & 5,01 & 5,02 & 5,76 & 6,75 & 5,74 \\
\hline $\mathrm{Cl} 2$ & 12,44 & 6,89 & 4,45 & 6,02 & 5,98 & 6,28 & 6,08 & 7,07 & 6,46 & 6,85 \\
\hline C3 & 14,20 & 9,20 & 5,98 & 7,15 & 7,76 & 6,92 & 8,51 & 9,21 & 8,19 & 8,57 \\
\hline $\mathrm{Cl} 4$ & 16,65 & 10,12 & 7,06 & 7,62 & 8,11 & 7,02 & 8,76 & 8,80 & 7,53 & 9,07 \\
\hline $\mathrm{Cl} 5$ & 3,24 & 4,74 & 4,58 & 3,52 & 5,35 & 4,84 & 5,58 & 5,77 & 5,92 & 4,84 \\
\hline CIRM6 & 10,50 & 9,74 & 8,02 & 9,06 & 8,43 & 9,11 & 8,92 & 8,66 & 6,50 & 8,77 \\
\hline CIRM7 & 9,72 & 7,93 & 6,76 & 7,81 & 8,13 & 7,39 & 7,68 & 7,33 & 7,78 & 7,84 \\
\hline CIRM8 & 12,39 & 8,31 & 5,47 & 7,50 & 6,89 & 6,62 & 6,73 & 7,05 & 6,71 & 7,52 \\
\hline CIRM9 & 10,60 & 7,73 & 5,89 & 6,85 & 7,58 & 7,20 & 7,17 & 7,21 & 7,18 & 7,49 \\
\hline CIRM10 & 10,36 & 6,58 & 5,65 & 5,86 & 7,17 & 7,04 & 8,43 & 6,61 & 5,88 & 7,06 \\
\hline $\mathrm{Cl} 11$ & 10,45 & 12,86 & 11,66 & 12,24 & 12,67 & 12,41 & 11,29 & 9,74 & 8,37 & 11,30 \\
\hline CIRM12 & 9,22 & 8,00 & 6,23 & 8,84 & 8,91 & 8,22 & 8,84 & 8,91 & 7,72 & 8,32 \\
\hline
\end{tabular}

Na Figura 85 pode ser visualizada a relação entre a fração de fase líquida e os valores da constante de velocidade ( $k_{\text {médio }}$ ) presentes na Tabela 37. 


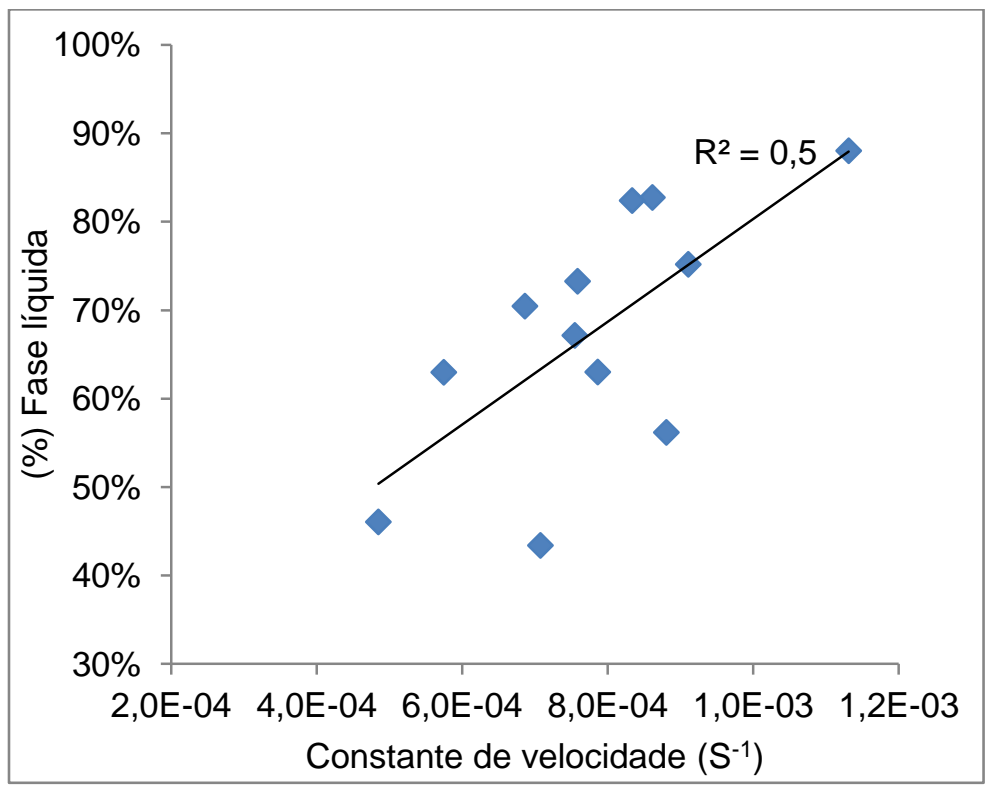

Figura 85. Relação entre constante de velocidade em função da (\%) de fase líquida.

A Figura 85 mostra que a constante de velocidade $(k)$ aumenta com o aumento da quantidade de fase líquida das escórias. Segundo Kirmse ${ }^{(13)}$, a constante de velocidade interfere na eficiência dessulfurantes dos processos químicos. Maiores níveis de agitação e fase líquida resultam em maiores valores da constante de velocidade (k), exatamente como observado na Figura 85.

Além disso, as escórias com fluorita (CIRMF12 e CICAF11) apresentaram maiores valores da constante de velocidade. Chushao e $\mathrm{Xin}^{\left({ }^{(8)}\right)}$ evidenciam que a constante de velocidade $(\mathrm{k})$ também aumenta com o aumento de $\mathrm{CaF}_{2}$ em mistura com o $\mathrm{CaO}$ na faixa de $0 \%$ a $10 \%$. Contudo, em escórias com a concentração acima de $10 \%$ de $\mathrm{CaF}_{2}$, a constante de velocidade pouco altera.

\subsubsection{Avaliação dos resultados encontrados para escórias dessulfurantes de aço}

5.2.3.1 Análise dos resultados experimentais para as misturas dessulfurantes de aço

$\mathrm{Na}$ Tabela 38 pode ser visualizada a variação do enxofre no tempo, bem como, a eficiência dessulfurante das misturas. 
Tabela 38. Variação do enxofre no tempo de experimento e rendimento em ordem descrescente dos experimentos de dessulfuração do aço.

\begin{tabular}{|c|c|c|c|c|c|c|c|}
\hline \multirow{2}{*}{ Misturas } & \multicolumn{6}{|c|}{ Variação do enxofre (\% em massa) } & \multirow{2}{*}{$\eta(\%)$} \\
\hline & Inicial & 5 & 10 & 15 & 20 & 30 & \\
\hline ACAD4 & 0,0080 & 0,0034 & 0,0018 & 0,0019 & 0,0018 & 0,0017 & 78,7 \\
\hline ACAF12 & 0,0080 & 0,0029 & 0,0021 & 0,0018 & 0,0019 & 0,0018 & 77,5 \\
\hline ACAD3 & 0,0080 & 0,0030 & 0,0020 & 0,0019 & 0,0020 & 0,0020 & 75,0 \\
\hline ARMD8 & 0,0080 & 0,0036 & 0,0025 & 0,0026 & 0,0025 & 0,0024 & 70,0 \\
\hline ACAD2 & 0,0080 & 0,0032 & 0,0025 & 0,0026 & 0,0024 & 0,0025 & 68,7 \\
\hline ARMCF14 & 0,0080 & 0,0026 & 0,0027 & 0,0026 & 0,0022 & 0,0025 & 68,7 \\
\hline ACAD5 & 0,0080 & 0,0047 & 0,0030 & 0,0026 & 0,0027 & 0,0026 & 67,5 \\
\hline ARMD9 & 0,0080 & 0,0028 & 0,0032 & 0,0030 & 0,0030 & 0,0027 & 66,2 \\
\hline ARMCD13 & 0,0080 & 0,0057 & 0,0030 & 0,0028 & 0,0030 & 0,0028 & 65,0 \\
\hline ARMD10 & 0,0080 & 0,0032 & 0,0031 & 0,0033 & 0,0031 & 0,0030 & 62,5 \\
\hline ARMD7 & 0,0080 & 0,0050 & 0,0040 & 0,0033 & 0,0031 & 0,0031 & 61,2 \\
\hline ARMF11 & 0,0080 & 0,0032 & 0,0031 & 0,0033 & 0,0032 & 0,0032 & 60,0 \\
\hline ACAD6 & 0,0080 & 0,0049 & 0,0032 & 0,0031 & 0,0032 & 0,0033 & 58,7 \\
\hline ACAD1 & 0,0080 & 0,0034 & 0,0035 & 0,0036 & 0,0036 & 0,0034 & 57,5 \\
\hline
\end{tabular}

Para melhor compreensão dos resultados constantes na Tabela 38 , as escórias foram agrupadas. A Tabela 39 mostra os resultados da variação do enxofre no metal para as misturas à base de cal convencional (ACAD1-ACAD6) e para as misturas com o resíduo de mármore (ARMD7-ARMD10).

Tabela 39. Variação do enxofre para as misturas à base de cal convencional e resíduo de mármore com o uso do $\mathrm{Al}_{2} \mathrm{O}_{3}$.

\begin{tabular}{cccccccccc}
\hline \multirow{2}{*}{ Misturas } & \multicolumn{4}{c}{ Variação do enxofre (\% em massa) } & \multicolumn{2}{c}{ Massa $(\mathrm{g})$} & \multirow{2}{*}{$(\%)$} \\
\cline { 2 - 7 } & Inicial & 5 & 10 & 15 & 20 & 30 & $\mathrm{CaO}$ & $\mathrm{Al}_{2} \mathrm{O}_{3}$ & $\eta$ \\
\hline ACAD4 & 0,0080 & 0,0034 & 0,0018 & 0,0019 & 0,0018 & 0,0017 & 6,8 & 3,2 & 78,7 \\
ACAD3 & 0,0080 & 0,0030 & 0,0020 & 0,0019 & 0,0020 & 0,0020 & 7,2 & 2,93 & 75,0 \\
ARMD8 & 0,0080 & 0,0036 & 0,0025 & 0,0026 & 0,0025 & 0,0024 & 6,8 & 3,20 & 70,0 \\
ACAD2 & 0,0080 & 0,0032 & 0,0025 & 0,0026 & 0,0024 & 0,0025 & 7,5 & 2,54 & 68,7 \\
ACAD5 & 0,0080 & 0,0047 & 0,0030 & 0,0026 & 0,0027 & 0,0026 & 6,5 & 3,63 & 67,5 \\
ARMD9 & 0,0080 & 0,0028 & 0,0032 & 0,0030 & 0,0030 & 0,0027 & 6,5 & 3,6 & 66,2 \\
ARMD10 & 0,0080 & 0,0032 & 0,0031 & 0,0033 & 0,0031 & 0,0030 & 6,1 & 4,0 & 62,5 \\
ARMD7 & 0,0080 & 0,0050 & 0,0040 & 0,0033 & 0,0031 & 0,0031 & 7,2 & 2,9 & 61,2 \\
ACAD6 & 0,0080 & 0,0049 & 0,0032 & 0,0031 & 0,0032 & 0,0033 & 6,1 & 4,0 & 58,7 \\
ACAD1 & 0,0080 & 0,0044 & 0,0038 & 0,0036 & 0,0036 & 0,0034 & 7,9 & 2,14 & 57,5 \\
\hline
\end{tabular}

As curvas de variação do enxofre em função do tempo, para as escórias formuladas com resíduo de mármore e cal convencional, podem ser visualizadas na Figura 86. 


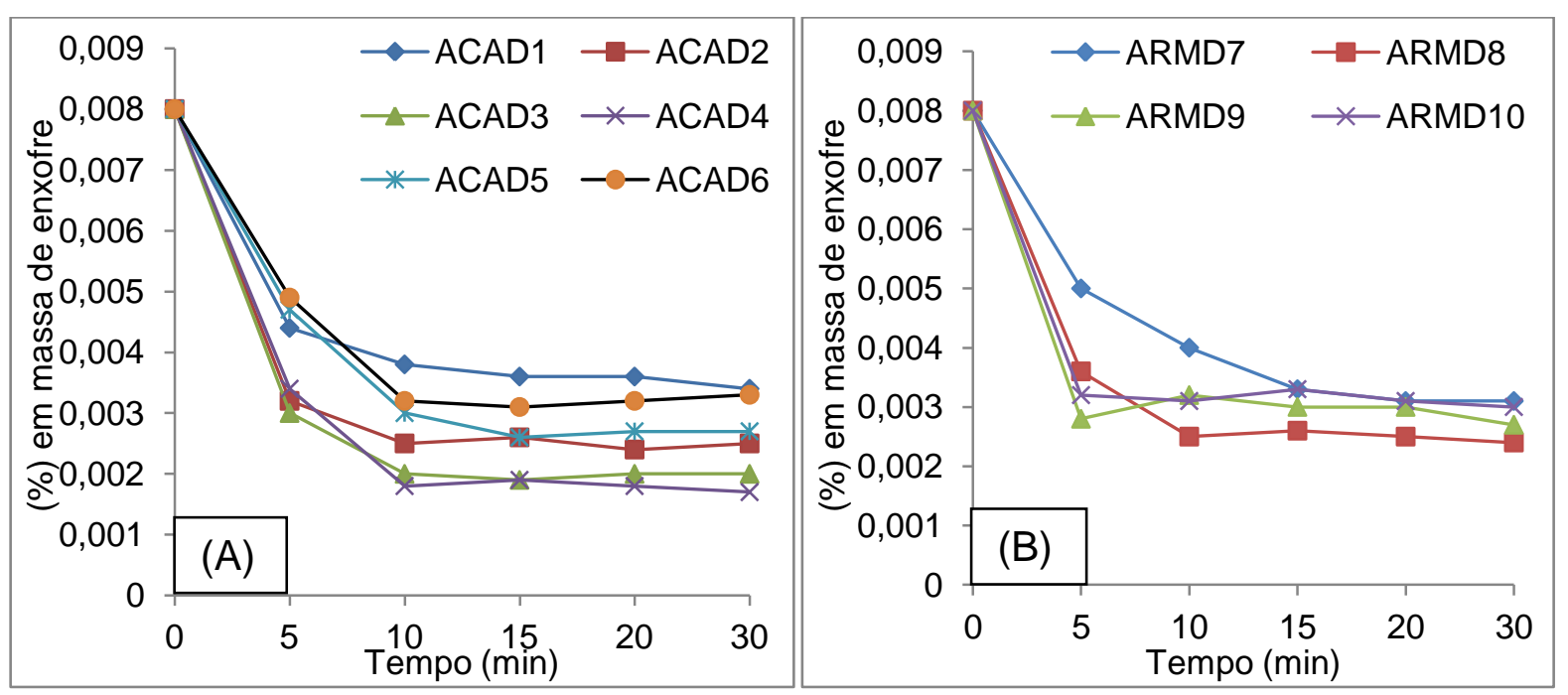

Figura 86. Variação do enxofre e relação ao tempo de experimento para as misturas dessulfurantes com o uso de Cal e alumina (A) e resíduo de alumina (B).

Nota-se que praticamente toda a dessulfuração ocorre nos primeiros 10 minutos de experimento e, após este período, o enxofre permanece constante no metal. Para as siderúrgicas que não possuem forno panela e aproveitam para remover o enxofre durante o vazamento do conversor LD para a panela de transferência, essas misturas podem ser utilizadas para remover o enxofre. Visto que, o tempo de vazamento é de aproximadamente 10 minutos.

O menor teor de enxofre $(0,0017 \%)$ foi obtido pela a mistura identificada por ACAD4. Já para as misturas com resíduo de mármore, a melhor mistura obteve teor de enxofre de 0,0024\% (ARMD8).

As misturas à base de cal convencional obtiveram melhores resultados dessulfurantes em relação às misturas com resíduo de mármore. Neste caso, mesmo que a decomposição dos carbonatos favoreça a agitação e melhore a cinética do refino, a diminuição da temperatura proporcionada pelas reações endotérmicas e a presença de $\mathrm{MgO}$ sólido nas escórias com resíduo, foi preponderante para diminuir a eficiência. 
5.2.3.2 Influência da decomposição dos carbonatos na dessulfuração de aço

$\mathrm{Na}$ Tabela 40, pode ser visualizada a variação do enxofre no tempo de experimento e o rendimento dessulfurante das misturas à base de resíduo de mármore calcinado e resíduo in natura.

Tabela 40. Variação do enxofre no tempo de experimento para misturas à base de resíduo de mármore e resíduo de mármore calcinado.

\begin{tabular}{|c|c|c|c|c|c|c|c|c|c|}
\hline \multirow{2}{*}{$\begin{array}{l}\text { Identificação } \\
\text { das escórias }\end{array}$} & \multicolumn{6}{|c|}{ Enxofre no aço (\% em massa) } & \multicolumn{2}{|c|}{ Massa $(\mathrm{g})$} & \multirow[b]{2}{*}{$\eta(\%)$} \\
\hline & Inicial & 5 & 10 & 15 & 20 & 30 & $\mathrm{CaO}$ & $\mathrm{Al}_{2} \mathrm{O}_{3}$ & \\
\hline ARMCF14 & 0,0080 & 0,0026 & 0,0027 & 0,0026 & 0,0022 & 0,0025 & 7,2 & 2,9 & 68,7 \\
\hline ARMCD13 & 0,0080 & 0,0057 & 0,0030 & 0,0028 & 0,0030 & 0,0028 & 7,2 & 2,9 & 65,0 \\
\hline ARMD7 & 0,0080 & 0,0050 & 0,0040 & 0,0033 & 0,0031 & 0,0031 & 7,2 & 2,9 & 61,2 \\
\hline ARMF11 & 0,0080 & 0,0032 & 0,0031 & 0,0033 & 0,0032 & 0,0032 & 7,2 & 2,9 & 60,0 \\
\hline
\end{tabular}

Uma análise do efeito da calcinação do resíduo de mármore pode ser visualizada na Figura 87.

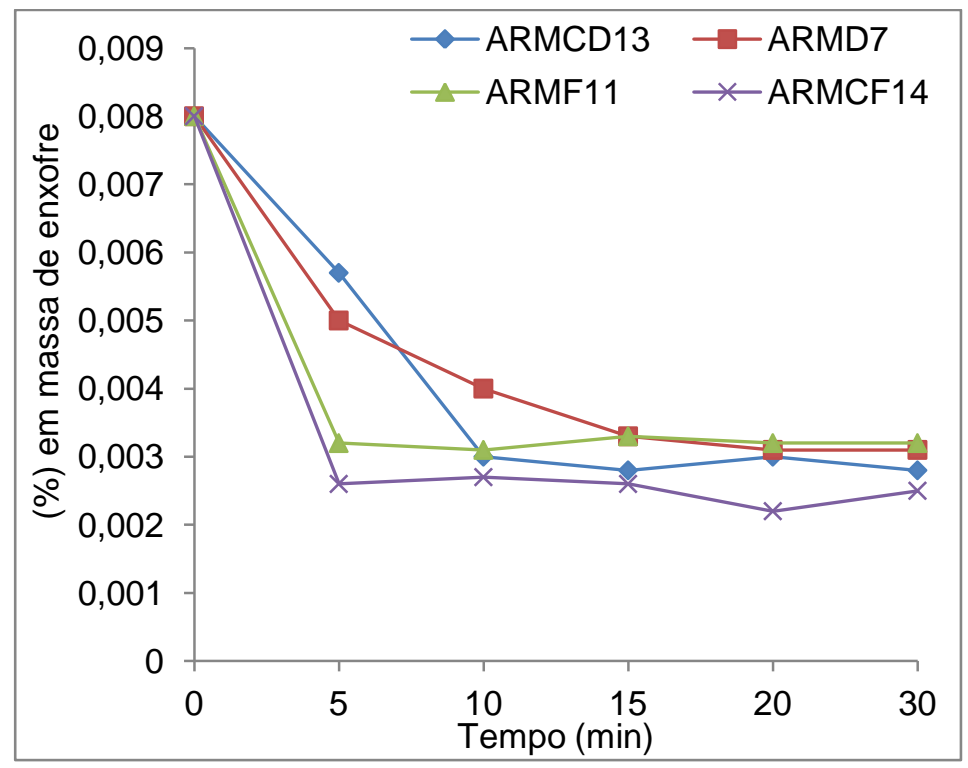

Figura 87. Variação do enxofre em função do tempo de experimento das misturas dessulfurantes de aço com o uso de resíduo calcinado e não calcinado.

Os resultados mostraram que as misturas ARMCF14 e ARMCD13, com resíduo de mármore calcinado e com a adição de fluorita e $\mathrm{Al}_{2} \mathrm{O}_{3}$, respectivamente, apresentaram os maiores valores de remoção do enxofre $(68,7 \%$ e $65 \%)$, quando comparadas com as escórias de resíduo de mármore in natura (ARMD7 e ARMF11). Este resultado é um indicativo de que a decomposição dos carbonatos afeta negativamente a dessulfuração de aço. Neste caso, a diminuição da temperatura 
proporcionada pelas reações endotérmicas, inteferiu para diminuir a eficiência das misturas. Além disso, a massa de mistura e a concentração de MgO podem ter contribuído para remoção de menores teores de enxofre.

\subsubsection{Análise comparativa da substituição de resíduo de mármore por cal convencional e fluorita por $\mathrm{Al}_{2} \mathrm{O}_{3}$}

$\mathrm{Na}$ Tabela 41 pode ser visualizada a variação do enxofre para misturas com resíduo de mármore e cal convencional.

Tabela 41. Variação do enxofre no tempo de experimento para misturas com cal convencional e resíduo de mármore.

\begin{tabular}{cccccccccc}
\hline Identificação & \multicolumn{4}{c}{ Enxofre no aço (\% em massa) } & \multicolumn{3}{c}{ Massa (g) } & \multirow{2}{*}{ das escórias } \\
\cline { 2 - 7 } & Inicial & 5 & 10 & 15 & 20 & 30 & $\mathrm{CaO}^{\prime}$ & $\mathrm{Al}_{2} \mathrm{O}_{3}$ & $\eta(\%)$ \\
\hline ACAF12 & 0,0080 & 0,0029 & 0,0021 & 0,0018 & 0,0019 & 0,0018 & 7,2 & 2,2 & 77,5 \\
ACAD3 & 0,0080 & 0,0030 & 0,0020 & 0,0019 & 0,0020 & 0,0020 & 7,2 & 2,9 & 75,0 \\
ARMD7 & 0,0080 & 0,0050 & 0,0040 & 0,0033 & 0,0031 & 0,0031 & 7,2 & 2,9 & 61,2 \\
ARMF11 & 0,0080 & 0,0032 & 0,0031 & 0,0033 & 0,0032 & 0,0032 & 7,2 & 2,9 & 60,0 \\
\hline
\end{tabular}

A Figura 88 apresenta uma análise comparativa entre o uso de resíduo de mármore e cal convencional com a adição de fluorita e $\mathrm{Al}_{2} \mathrm{O}_{3}$.

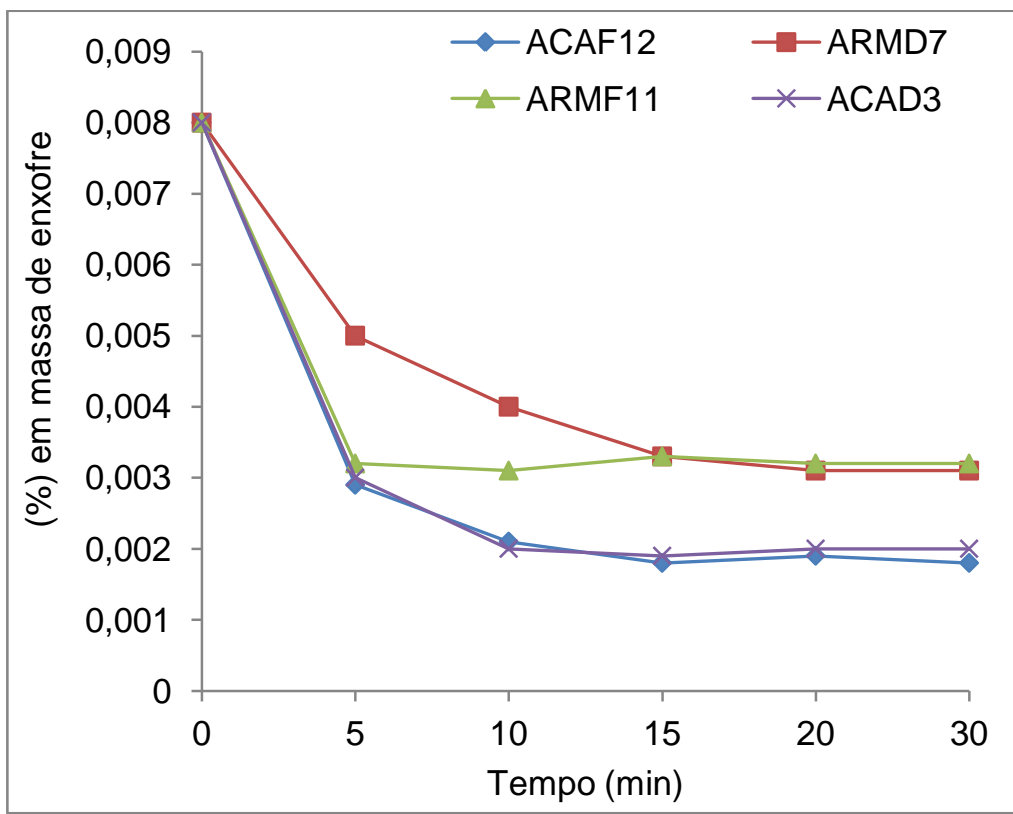

Figura 88. Análise comparativa entre o uso do resíduo de mármore e cal convencional com o uso de fluorita e $\mathrm{Al}_{2} \mathrm{O}_{3}$. 
Verifica-se que a melhor escória foi a ACAF12, em que houve a adição de $\mathrm{CaO}$ e fluorita. Por outro lado, a escória $\mathrm{ACAD} 3$, em que foi adicionado $\mathrm{Al}_{2} \mathrm{O}_{3}$ em substituição à fluorita, mostrou dessulfuração próximo ao encontrado pela mistura com fluorita (ACAF12). Sendo assim, um primeiro indicativo de uma possível substituição da fluorita por $\mathrm{Al}_{2} \mathrm{O}_{3}$ pode se considerado. Se o objetivo da dessulfuração for atingir teor de enxofre em torno de 0,0030\%, as misturas com resíduo de mármore podem ser uma alternativa para a substituição da cal convencional.

5.2.3.4 Análise dos parâmetros termodinâmicos de basicidade ótica, capacidade de sulfeto e partição de enxofre

A Tabela 42 apresenta os valores da basicidade ótica, capacidade de sulfeto e partição de enxofre das misturas dessulfurantes de aço. 
Tabela 42. Resultados dos cálculos termodinâmicos de basicidade ótica $(\Lambda)$, capacidade de sulfeto (Cs) e coeficiente de partição para misturas dessulfurantes de aço.

\begin{tabular}{|c|c|c|c|c|c|c|c|c|}
\hline \multirow[b]{2}{*}{ Escórias } & \multirow[b]{2}{*}{$(\Lambda)$} & \multicolumn{3}{|c|}{ Capacidade de Sulfeto (Cs) } & \multicolumn{3}{|c|}{ Coeficiente de Partição (Ls) } & \multirow[b]{2}{*}{$\eta(\%)$} \\
\hline & & $\begin{array}{c}\text { Shankar }^{(34)} \\
{[\mathrm{Cs}]}\end{array}$ & $\begin{array}{c}\text { Young }^{(112)} \\
{[\log \mathrm{Cs}]}\end{array}$ & $\begin{array}{c}\text { Taniguchi }^{(35)} \\
{[-\log \text { Cs }]}\end{array}$ & $\begin{array}{l}\text { Inuoe e } \\
\text { Suito }{ }^{(49)} \\
\text { Log [Ls] }\end{array}$ & $\begin{array}{c}\text { Shankar }^{(34)} \\
\text { Log }[\mathrm{Ls}]\end{array}$ & $\begin{array}{c}\text { Mitsutaka }^{(44)} \\
\text { Log }[\mathrm{Ls}]\end{array}$ & \\
\hline ACAD4 & 0,82 & 0,00112 & 1,0827 & 2,199 & 2,071 & 5,864 & 2,160 & 78,7 \\
\hline ACAD3 & 0,83 & 0,00122 & 1,0874 & 1,959 & 2,179 & 6,354 & 2,209 & 75,0 \\
\hline ARMD8 & 0,79 & 0,00086 & 0,0047 & 1,532 & 1,873 & 4,445 & 2,068 & 70,0 \\
\hline ACAD2 & 0,84 & 0,00136 & 1,0952 & 1,606 & 2,337 & 7,087 & 2,278 & 68,7 \\
\hline ACAD5 & 0,80 & 0,00100 & 0,0059 & 2,522 & 1,924 & 5,200 & 2,091 & 67,5 \\
\hline ARMD9 & 0,78 & 0,00078 & 0,0042 & 1,835 & 1,774 & 4,034 & 2,008 & 66,2 \\
\hline ARMD10 & 0,78 & 0,00075 & 0,0040 & 1,952 & 1,735 & 3,875 & 1,984 & 62,5 \\
\hline ARMD7 & 0,80 & 0,00092 & 1,0784 & 1,267 & 1,958 & 4,806 & 2,118 & 61,2 \\
\hline ACAD6 & 0,79 & 0,00089 & 0,0050 & 2,813 & 1,789 & 4,603 & 2,023 & 58,7 \\
\hline ACAD1 & 0,86 & 0,00149 & 1,1034 & 1,278 & 2,482 & 7,763 & 2,339 & 57,5 \\
\hline ACAF12 & 0,85 & 0,00289 & 0,0872 & 0,953 & 4,681 & 18,328 & 2,573 & 77,5 \\
\hline ARMCF14 & 0,80 & 0,00239 & 0,0674 & 1,337 & 3,983 & 15,134 & 2,542 & 68,2 \\
\hline ARMCD13 & 0,80 & 0,00241 & 0,0674 & 0,907 & 3,984 & 15,234 & 2,534 & 65,0 \\
\hline ARMF11 & 0,80 & 0,00239 & 0,0674 & 1,337 & 3,983 & 15,134 & 2,542 & 60,0 \\
\hline
\end{tabular}


A Figura 89 apresenta a relação entre a eficiência dessulfurante em função da capacidade de sulfeto, basicidade e partição de enxofre das misturas dessulfurantes de aço.
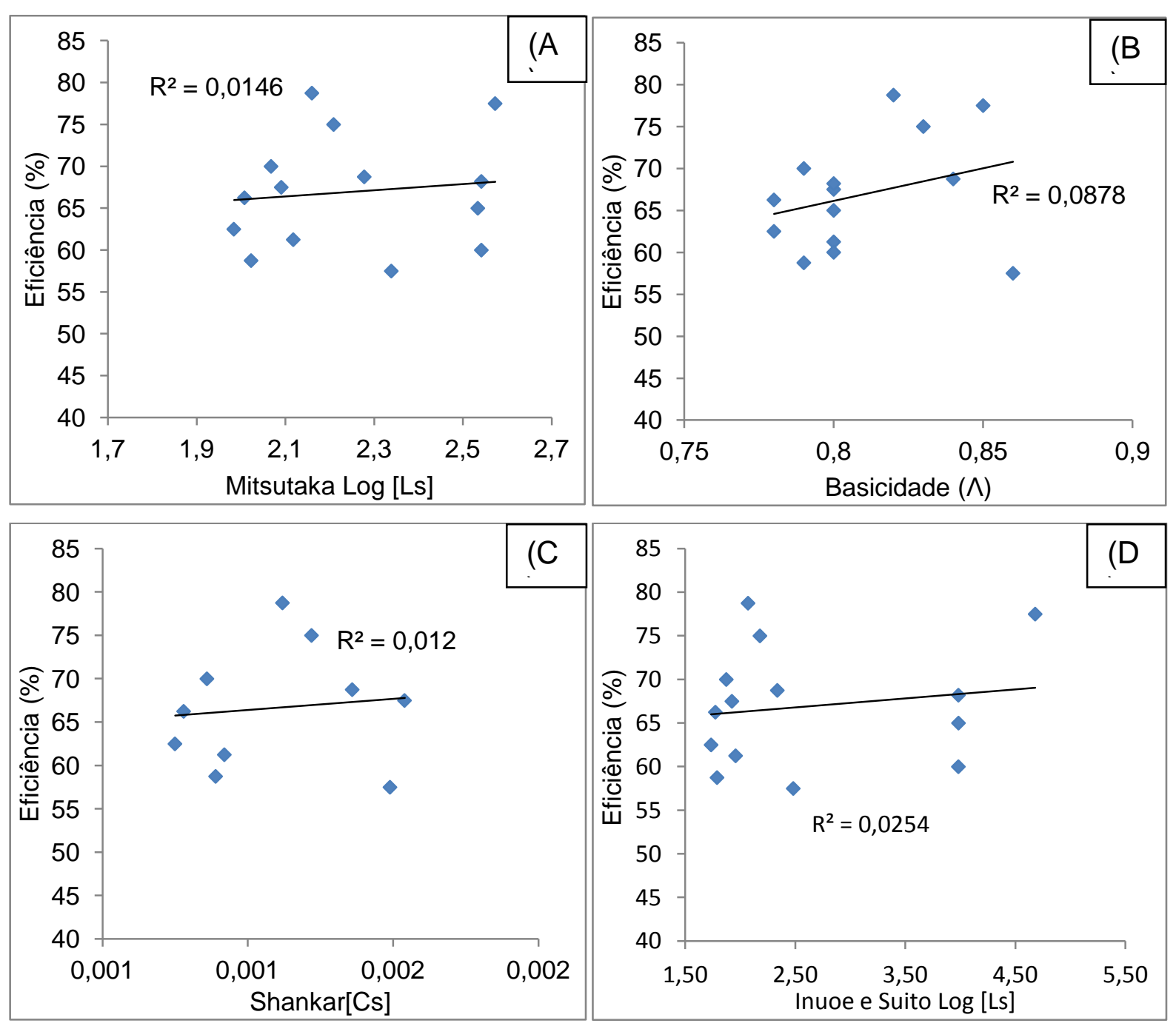

Figura 89. Relação entre a capacidade de sulfeto, partição e basicidade ótica em função do rendimento de misturas dessulfurantes de aço.

Da mesma forma que as misturas de ferro fundido, os parâmetros de Cs, Ls e $\wedge$ não apresentaram correlação. Os valores de capacidade de sulfeto (Cs) e partição de enxofre (Ls) influenciam o termo termodinâmico $\left(\underline{S}-\underline{S}_{\text {eq }}\right)$, conforme a mostra a Equação 25. 
$\frac{d \underline{S}}{d t}=K\left(\underline{S}-\underline{S}_{e q}\right)$

(Equação 25)

Onde:

$\frac{d(\%) \underline{S}}{d t}=$ taxa de dessulfuração das escórias (\%S.min $\left.{ }^{-1}\right)$;

$\mathrm{k}=$ constante de velocidade $\left(\mathrm{min}^{-1}\right) ; \mathrm{e}$

$\left(\mathrm{S}-\mathrm{S}_{\mathrm{eq}}\right)=$ Termo termodinâmico.

Diante do exposto, quanto maior o valor de Ls e Cs, menor o $S_{\text {eq, o que }}$ aumenta o termo termodinâmico ( $\underline{\mathrm{S}}_{\text {inicial }}$ - $\left.\underline{\mathrm{S}}_{\text {eq }}\right)$ da equação. Em geral, quanto maiores os valores dos parâmetros termodinâmicos (Cs e Ls), menor o valor do $S_{\text {eq. }}$

5.2.3.5 Utilização da termodinâmica computacional na análise dos resultados da dessulfuração do aço

Com base na composição química das misturas e aço, foram feitas simulações utilizando o software Thermo-Calc para determinar o teor de enxofre de equilíbrio, fases presentes nas misturas iniciais e atividade dos componentes das misturas. Com estes resultados, foi analisada a influência destes parâmetros na eficiência dessulfurante.

Os teores de equilíbrio dos elementos presentes no aço constam na Tabela 43. 
Tabela 43. Concentração de equilíbrio dos elementos presentes aço na temperatura de $1600^{\circ} \mathrm{C}$.

\begin{tabular}{cccccccc}
\hline Mistura & {$\left[\% \mathrm{~S}_{\text {eq. }}\right]$} & {$\left[\% \mathrm{O}_{\text {eq. }}\right]$} & {$\left[\% \mathrm{Si}_{\text {eq. }}\right]$} & {$\left[\% \mathrm{C}_{\text {eq }}\right]$} & {$[\% \mathrm{Mn}]$} & {$[\% \mathrm{Al}]$} & $\eta(\%)$ \\
\hline ACAD4 & $1,29 \mathrm{E}-04$ & $5,56 \mathrm{E}-05$ & $2,47 \mathrm{E}-01$ & $2,13 \mathrm{E}-01$ & $7,70 \mathrm{E}-01$ & $9,25 \mathrm{E}-02$ & 78,7 \\
ACAD3 & $1,40 \mathrm{E}-04$ & $5,51 \mathrm{E}-05$ & $2,47 \mathrm{E}-01$ & $2,13 \mathrm{E}-01$ & $7,70 \mathrm{E}-01$ & $9,13 \mathrm{E}-02$ & 75,0 \\
ARMD8 & $1,53 \mathrm{E}-04$ & $5,43 \mathrm{E}-05$ & $2,61 \mathrm{E}-01$ & $2,13 \mathrm{E}-01$ & $7,70 \mathrm{E}-01$ & $7,49 \mathrm{E}-02$ & 70,0 \\
ACAD2 & $1,58 \mathrm{E}-04$ & $5,48 \mathrm{E}-05$ & $2,48 \mathrm{E}-01$ & $2,13 \mathrm{E}-01$ & $7,70 \mathrm{E}-01$ & $9,05 \mathrm{E}-02$ & 68,7 \\
ACAD5 & $1,18 \mathrm{E}-04$ & $5,56 \mathrm{E}-05$ & $2,47 \mathrm{E}-01$ & $2,13 \mathrm{E}-01$ & $7,70 \mathrm{E}-01$ & $9,25 \mathrm{E}-02$ & 67,5 \\
ARMD9 & $1,75 \mathrm{E}-04$ & $5,91 \mathrm{E}-05$ & $8,25 \mathrm{E}-01$ & $2,13 \mathrm{E}-01$ & $7,70 \mathrm{E}-01$ & $7,64 \mathrm{E}-02$ & 66,2 \\
ARMD10 & $2,18 \mathrm{E}-04$ & $6,48 \mathrm{E}-05$ & $2,60 \mathrm{E}-01$ & $2,13 \mathrm{E}-01$ & $7,69 \mathrm{E}-01$ & $7,68 \mathrm{E}-02$ & 62,5 \\
ARMD7 & $1,67 \mathrm{E}-04$ & $5,42 \mathrm{E}-05$ & $2,63 \mathrm{E}-01$ & $2,13 \mathrm{E}-01$ & $7,70 \mathrm{E}-01$ & $7,36 \mathrm{E}-02$ & 61,2 \\
ACAD6 & $1,84 \mathrm{E}-04$ & $6,94 \mathrm{E}-05$ & $2,45 \mathrm{E}-01$ & $2,13 \mathrm{E}-01$ & $7,70 \mathrm{E}-01$ & $9,49 \mathrm{E}-02$ & 58,7 \\
ACAD1 & $1,79 \mathrm{E}-04$ & $5,45 \mathrm{E}-05$ & $2,49 \mathrm{E}-01$ & $2,13 \mathrm{E}-01$ & $7,70 \mathrm{E}-01$ & $8,95 \mathrm{E}-02$ & 57,5 \\
ACAF12 & $1,07 \mathrm{E}-04$ & $5,14 \mathrm{E}-05$ & $2,55 \mathrm{E}-01$ & $2,13 \mathrm{E}-01$ & $7,70 \mathrm{E}-01$ & $8,39 \mathrm{E}-02$ & 77,5 \\
ARMCF14 & $1,07 \mathrm{E}-04$ & $5,14 \mathrm{E}-05$ & $2,55 \mathrm{E}-01$ & $2,13 \mathrm{E}-01$ & $7,70 \mathrm{E}-01$ & $8,39 \mathrm{E}-02$ & 68,2 \\
ARMCD13 & $1,30 \mathrm{E}-04$ & $4,86 \mathrm{E}-05$ & $2,61 \mathrm{E}-01$ & $2,13 \mathrm{E}-01$ & $7,70 \mathrm{E}-01$ & $7,49 \mathrm{E}-02$ & 65,0 \\
ARMF11 & $1,30 \mathrm{E}-04$ & $4,86 \mathrm{E}-05$ & $2,61 \mathrm{E}-01$ & $2,13 \mathrm{E}-01$ & $7,70 \mathrm{E}-01$ & $7,49 \mathrm{E}-02$ & 60,0 \\
\hline
\end{tabular}

Observa-se que tanto para as misturas produzidas com cal convencional quanto para as misturas produzidas com resíduo de mármore, os teores de enxofre estão dentro da mesma ordem de grandeza. Diante disso, as misturas com cal convencional e com resíduo de mármore possuem o mesmo potencial termodinâmico para remover o enxofre.

Sendo assim, foi realizado o cálculo das fases para as misturas iniciais visando encontrar os parâmetros termodinâmicos $(\mathrm{aCaO})$ e cinéticos (viscosidade, (\%) de líquido e de sólido). Os resultados podem ser visualizados na Figura 90. 

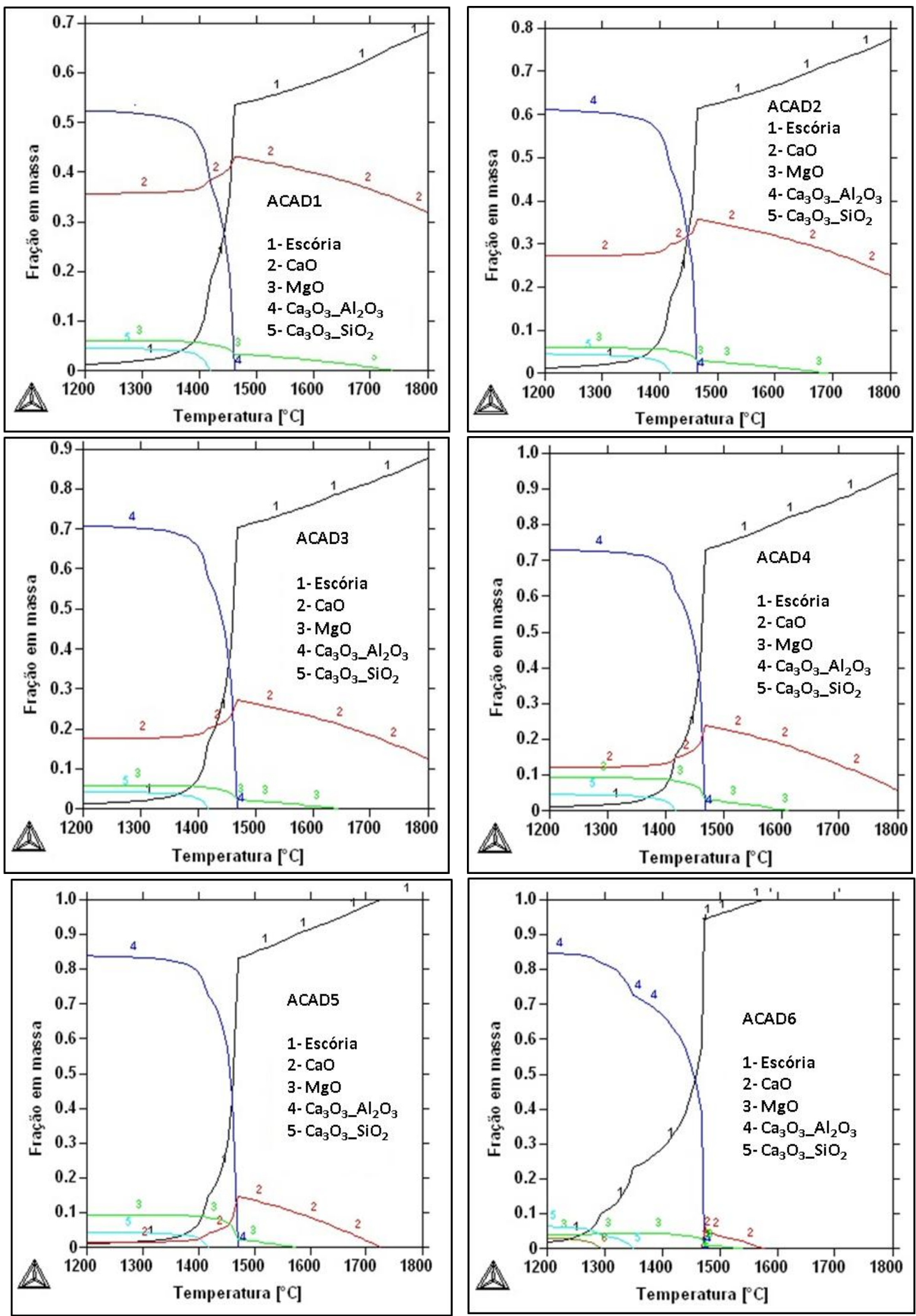

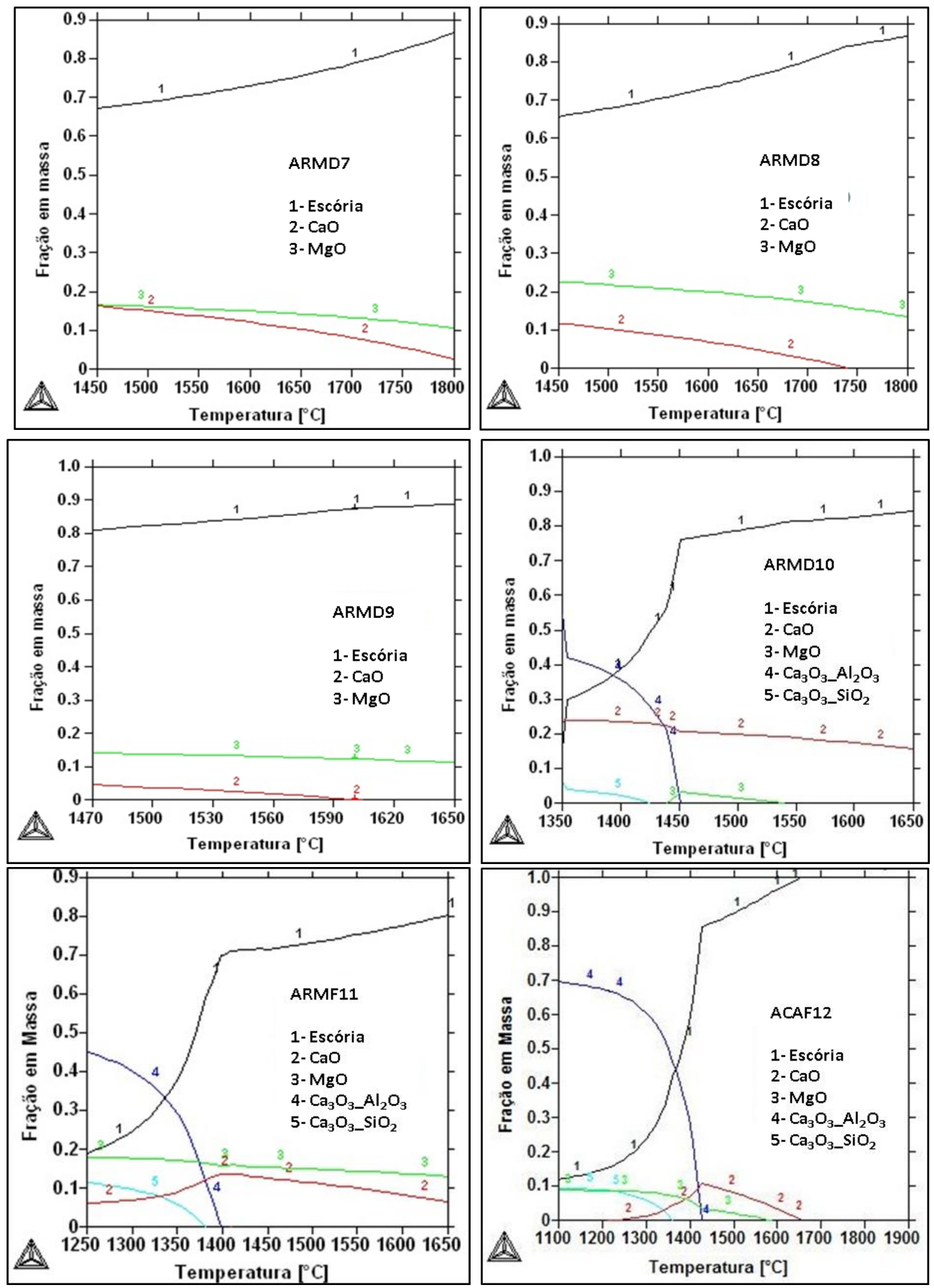

Figura 90. Curvas de equilíbrio das misturas iniciais a diferentes temperaturas para as escórias dessulfurantes de aço. 
Verifica-se que com o aumento da temperatura, as fases sólidas presentes nas misturas passam para a fase líquida, aumentando sua fração (curva 1: escória líquida). A porcentagem de fase líquida das misturas com cal convencional está compreendida entre 60 e $100 \%$ na temperatura de $1600^{\circ} \mathrm{C}$. Observa-se que a fase formada de aluminato de cálcio $\left(\mathrm{Ca}_{3} \mathrm{O}_{3} \mathrm{Al}_{2} \mathrm{O}_{3}\right)$ possui ponto de fusão de aproximadamente $1450^{\circ} \mathrm{C}$.

Observa-se também, que as misturas ARMD e ARMF, que contém resíduo de mármore na composição, mantiveram $\mathrm{MgO}$ sólido, o que auxilia na proteção do refratário do reator. Ressalta-se ainda, que a mistura ACAD6 teve $100 \%$ de fase líquida à $1600^{\circ} \mathrm{C}$ devido ao maior teor de $\mathrm{Al}_{2} \mathrm{O}_{3}$ em sua composição (36,99\%). As concentrações das demais fases formadas, obtidas através das curvas de equilíbrio mostradas na Figura 90, foram inseridas na Tabela 44 e serão abordadas no próximo item.

\subsubsection{Efeito da fração da fase líquida e sólida na dessulfuração}

As misturas dessulfurantes de aço foram submetidas ao processo de cálculo de fases em equilíbrio na temperatura de $1600^{\circ} \mathrm{C}$. Com isso, foi possível conhecer a fração de fase líquida e sólida das misturas. Os resultados para as diferentes escórias estão apresentados na Tabela 44.

Tabela 44. Cálculos das fases presentes nas misturas dessulfurantes de aço.

\begin{tabular}{|c|c|c|c|c|c|}
\hline \multirow{2}{*}{ Misturas } & \multirow{2}{*}{$\begin{array}{c}\text { Fase } \\
\text { líquida (\%) }\end{array}$} & \multirow{2}{*}{$\begin{array}{c}\text { Fase } \\
\text { Sólida (\%) }\end{array}$} & \multicolumn{2}{|c|}{$\begin{array}{l}\text { Fases formadas na fase } \\
\text { sólida }\end{array}$} & \multirow{2}{*}{$\eta(\%)$} \\
\hline & & & $\% \mathrm{CaO}$ & $\% \mathrm{MgO}$ & \\
\hline ACAD4 & 83,22 & 16,78 & 16,55 & 0,23 & 78,7 \\
\hline ACAD3 & 76,28 & 23,72 & 22,97 & 0,75 & 75,0 \\
\hline ARMD8 & 79,53 & 20,48 & 6,69 & 13,79 & 70,0 \\
\hline ACAD2 & 66,63 & 33,37 & 31,90 & 1,47 & 68,7 \\
\hline ACAD5 & 92,52 & 7,48 & 7,48 & 0,00 & 67,5 \\
\hline ARMD9 & 87,37 & 12,63 & 0,21 & 12,42 & 66,2 \\
\hline ARMD10 & 88,29 & 11,72 & 0,00 & 11,72 & 62,5 \\
\hline ARMD7 & 72,94 & 27,06 & 12,1 & 14,95 & 61,2 \\
\hline ACAD6 & 100,00 & 0,00 & 0,00 & 0,00 & 58,7 \\
\hline ACAD1 & 58,03 & 41,97 & 39,84 & 2,12 & 57,5 \\
\hline ACAF12 & 96,99 & 3,01 & 3,01 & 0,00 & 77,5 \\
\hline ARMCF14 & 77,73 & 22,27 & 8,40 & 22,27 & 68,2 \\
\hline ARMCD13 & 72,94 & 27,06 & 12,1 & 14,95 & 65,0 \\
\hline ARMF11 & 77,73 & 22,27 & 8,40 & 22,27 & 60,0 \\
\hline
\end{tabular}


As misturas produzidas com resíduo de mármore mantiveram concentração de fase líquida similar, quando comparadas com as misturas produzidas com cal convencional. Este comportamento pode ser observado na Figura 91.

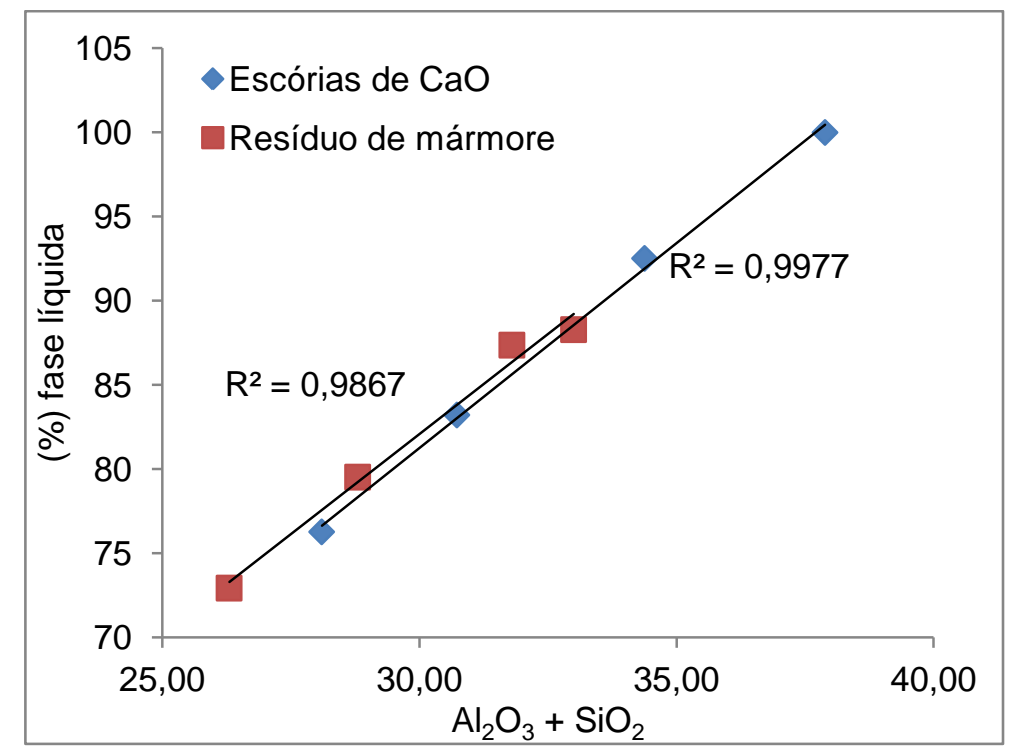

Figura 91. Influência da porcentagem $\mathrm{Al}_{2} \mathrm{O}_{3}$ e $\mathrm{SiO}_{2}$ na fração de fase líquida das escórias com resíduo e cal convencional.

Observa-se que as escórias produzidas com resíduo de mármore possuem maior fração de fase líquida do que as produzidas com a cal convencional. Isto se deve à presença de $\mathrm{SiO}_{2}$ no resíduo de mármore, que favoreceu a formação de compostos líquidos na temperatura de $1600^{\circ} \mathrm{C}$. A adição de sílica e alumina com a consequente redução do $\mathrm{CaO}$, faz com que, a composição da mistura se afaste do campo do $\mathrm{CaO}$ no Ternário, ou seja, diminua a temperatura de fusão da mistura e consequentemente aumente a quantidade de líquido.

O efeito da fase líquida na dessulfuração das misturas pode ser visualizado na Figura 92. 

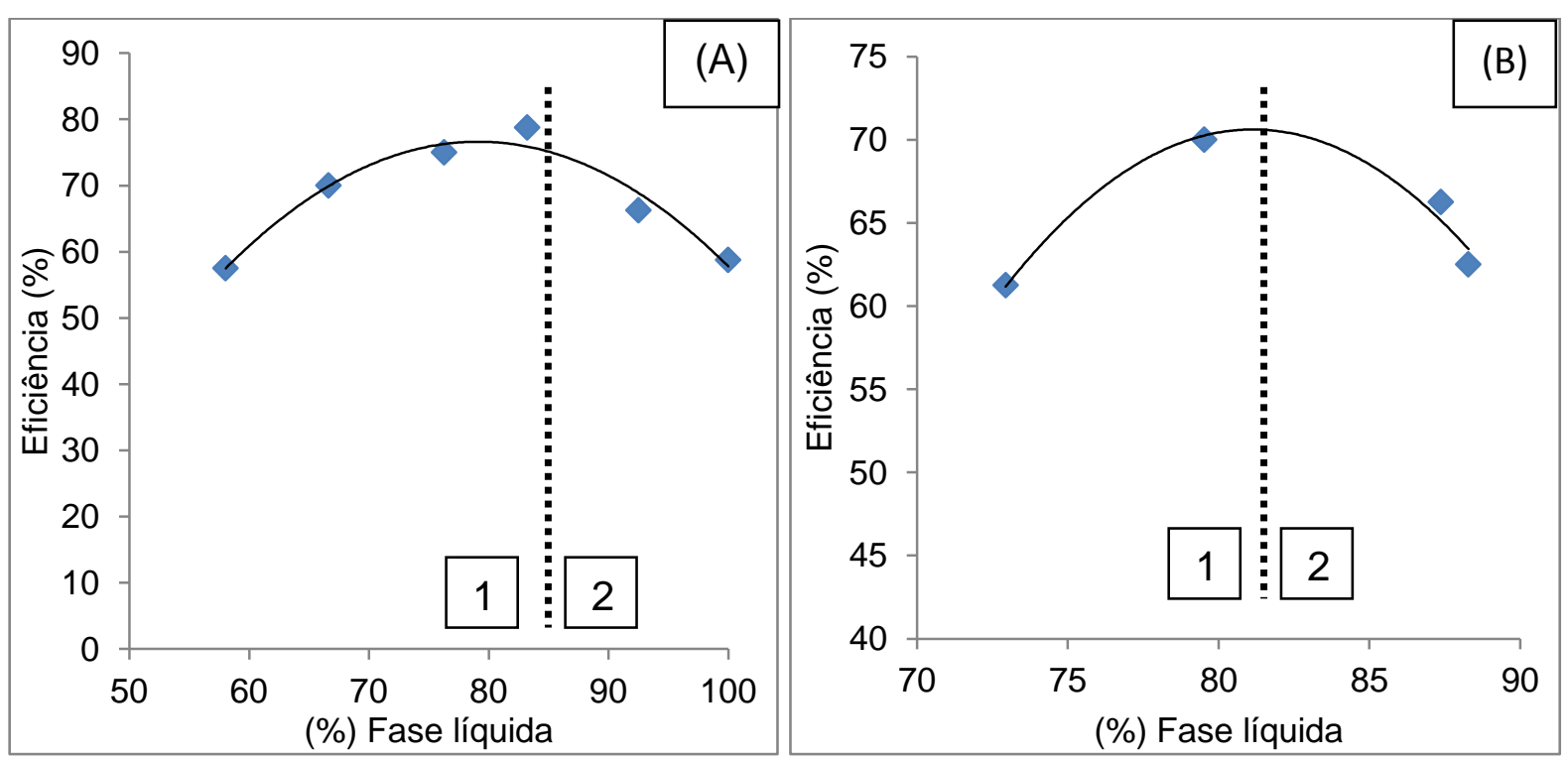

Figura 92. Relação entre a fração de fase líquida em função da eficiência dessulfurante das misturas formuladas com cal convencional (A) e com resíduo de mármore (B).

$\mathrm{Na}$ região identificada por 1 , em ambos os casos, pode-se observar que o aumento da porcentagem de fase líquida, contribuiu para aumentar da eficiência dessulfurante. Por outro lado, na região 2, a porcentagem de fase líquida ainda permanece crescente, no entanto, é observada a diminuição da eficiência dessulfurante.

Misturas com teor de fase líquida superior a $85 \%$ com a cal convencional e superior a $82 \%$ com o resíduo de mármore, não se mostraram eficazes na remoção do enxofre do aço.

A Figura 93 apresenta a relação entre a porcentagem de $\mathrm{CaO}$ na composição inicial das escórias e a (\%) de $\mathrm{CaO}$ sólido obtida pelo Thermo-Calc. 

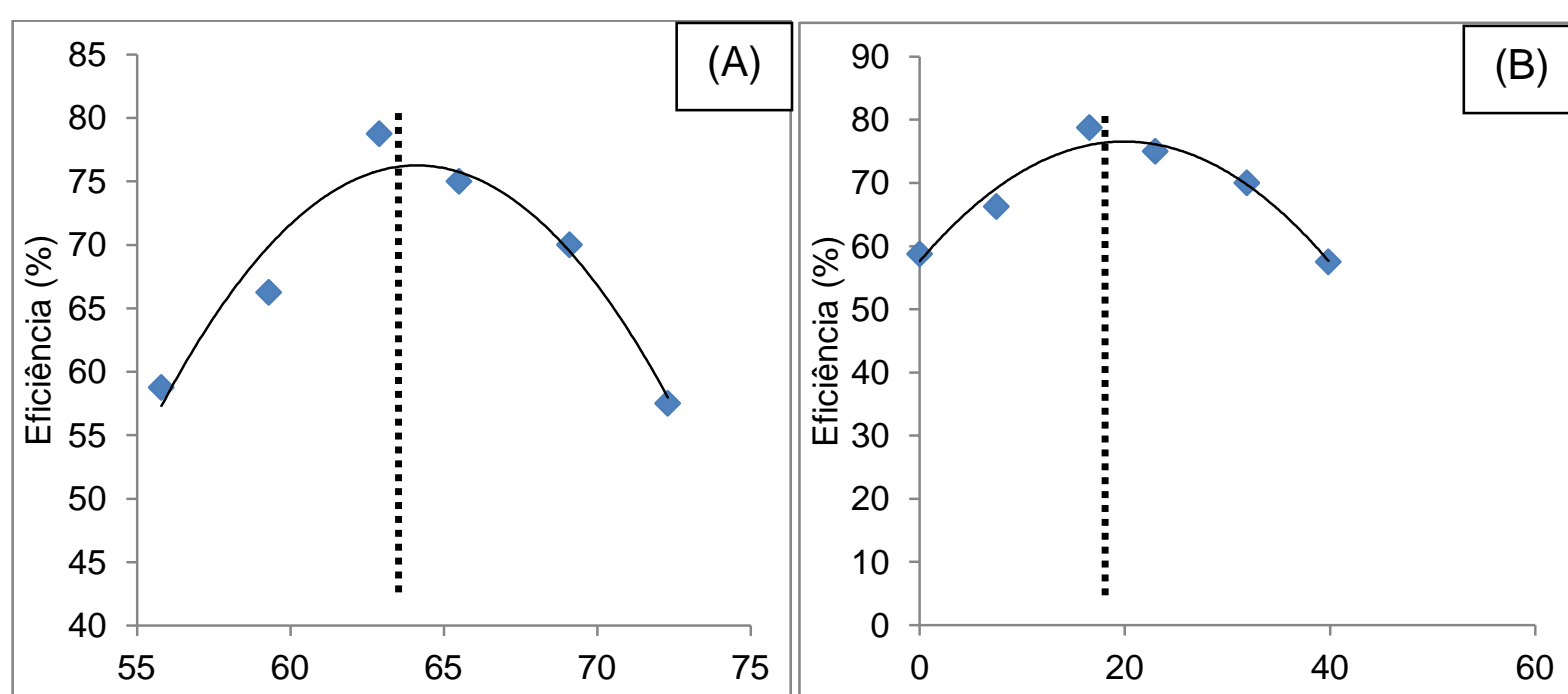

(\%) de $\mathrm{CaO}$

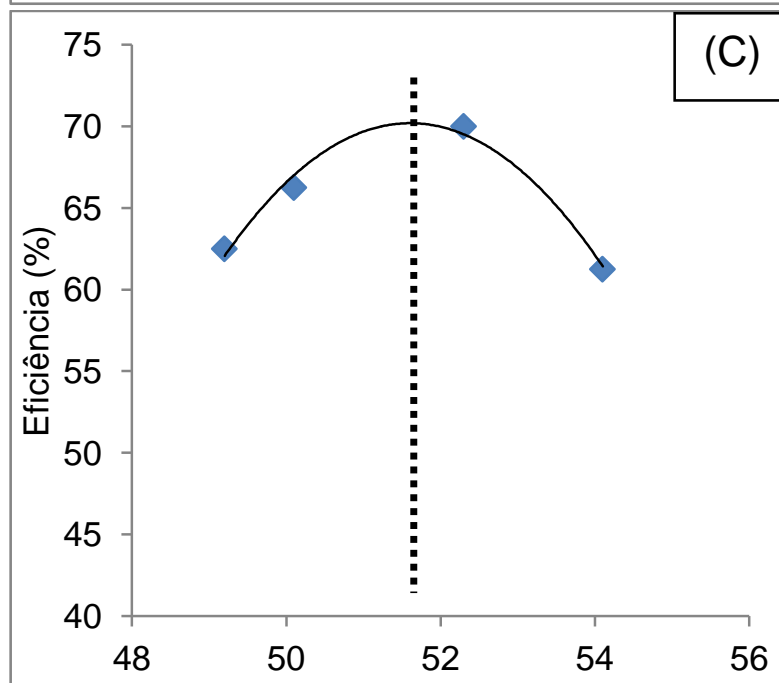

(\%) de $\mathrm{CaO}$

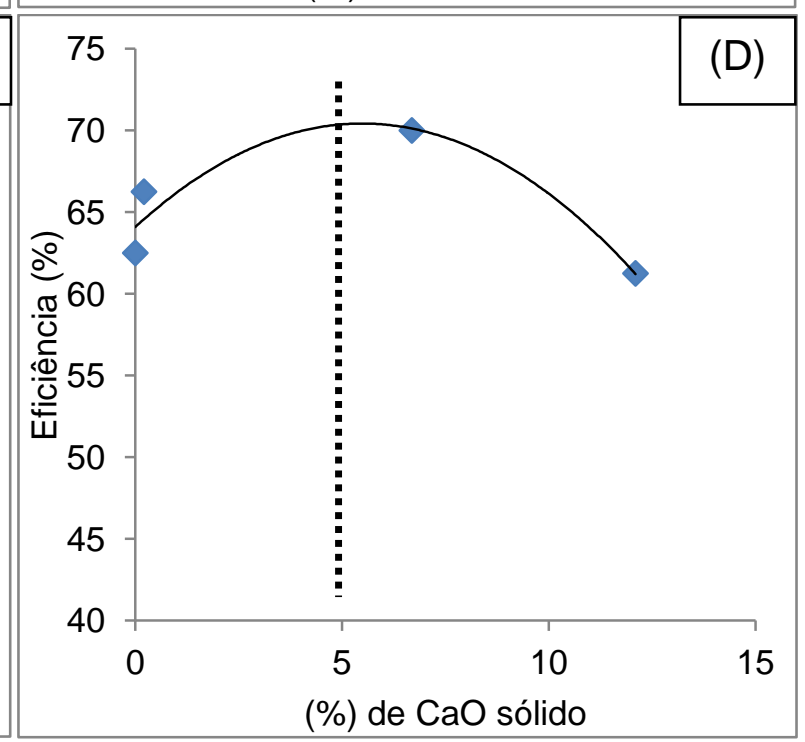

Figura 93. Relação entre a (\%) de $\mathrm{CaO}$ na composição inicial e (\%) de $\mathrm{CaO}$ sólido calculado pelo Thermo-Calc em função da eficiência dessulfurante das escórias $(A)$ e $(B)$ cal convencional e (C) e (D) resíduo de mármore.

Os resultados mostraram que para as misturas produzidas com cal convencional, o aumento da concentração de $\mathrm{CaO}$ na composição inicial é eficaz até teores próximos de $64 \%$. Quando considerada a fase sólida de $\mathrm{CaO}$, o valor encontrado foi de $17 \%$ de $\mathrm{CaO}_{(\mathrm{s})}$. Para maiores concentrações de $\mathrm{CaO}_{(\mathrm{s})}$, ocorreu o decréscimo da dessulfuração. Considerando a mesma análise para as escórias com resíduo de mármore, a porcentagem de $\mathrm{CaO}$ está em torno de $51 \%$ e $\mathrm{CaO}_{(\mathrm{s})}$ próximo de $5 \%$. 
Neste caso, mesmo que fração de $\mathrm{CaO}$ sólido prejudique a cinética do processo, pode-se inferir que o processo de dessulfuração no aço foi por escória mista (escória de topo e fase sólida). Como o processo de agitação foi por um rotor, tudo indica que a dessulfuração ocorreu pela fase líquida e pelo $\mathrm{CaO}_{(\mathrm{s})}$ das misturas.

Com o intuíto de comprovar se a atividade do $\mathrm{CaO}$ no final do processo permanece igual a 1 , realizou-se um balanço de massa para obter a composição das escórias finais. Em seguida, com a composição encontrada no balanço de massa, foi calculada as fases presentes nas escórias finais pelo Thermo-Calc. Na Tabela 45 constam os resultados.

Tabela 45. Concentração de fase líquida e sólida das escórias finais e atividade final e inicial do CaO.

\begin{tabular}{|c|c|c|c|c|c|c|}
\hline \multirow{2}{*}{$\begin{array}{l}\text { Identificação das } \\
\text { escórias }\end{array}$} & \multirow{2}{*}{$\begin{array}{l}\text { (\%) fase } \\
\text { líquida }\end{array}$} & \multicolumn{2}{|c|}{ Fase sólida(\%) } & \multirow{2}{*}{$\begin{array}{c}\text { Atividade } \\
\text { Final do } \\
\mathrm{CaO}\end{array}$} & \multirow{2}{*}{$\begin{array}{c}\text { Atividade } \\
\text { inicial de } \\
\mathrm{CaO}\end{array}$} & \multirow{2}{*}{$\eta(\%)$} \\
\hline & & $\mathrm{CaO}$ & $\mathrm{MgO}$ & & & \\
\hline ACAD4 & 84,71 & 15,08 & 0,21 & 1,0 & 1,0 & 78,75 \\
\hline ACAD3 & 77,33 & 21,93 & 0,74 & 1,0 & 1,0 & 75,00 \\
\hline ARMD8 & 80,62 & 5,65 & 13,73 & 1,0 & 1,0 & 70,00 \\
\hline ACAD2 & 67,96 & 30,6 & 1,44 & 1,0 & 1,0 & 68,75 \\
\hline ACAD5 & 90,64 & 9,36 & 0 & 1,0 & 1,0 & 67,50 \\
\hline ARMD9 & 87,68 & 0 & 12,32 & 0,96 & 1,0 & 66,25 \\
\hline ARMD10 & 88,42 & 0 & 11,58 & 0,85 & 0,89 & 62,50 \\
\hline ARMD7 & 73,78 & 11,31 & 14,91 & 1,0 & 1,0 & 61,25 \\
\hline ACAD6 & 100 & 0 & 0 & 0,91 & 0,93 & 58,75 \\
\hline ACAD1 & 59,05 & 38,84 & 2,11 & 1,0 & 1,0 & 57,50 \\
\hline ACAF12 & 86,82 & 4,98 & 8,20 & 1,0 & 1,0 & 77,5 \\
\hline ARMCF14 & 78,85 & 7,36 & 13,79 & 1,0 & 1,0 & 68,2 \\
\hline ARMCD13 & 74,18 & 10,93 & 14,89 & 1,0 & 1,0 & 65,0 \\
\hline ARMF11 & 78,91 & 7,3 & 13,79 & 1,0 & 1,0 & 60,0 \\
\hline
\end{tabular}

Com os dados gerados na Tabela 45, foram construídas as curvas de concentração de $\mathrm{CaO}$ sólido final em função do rendimento e atividade do $\mathrm{CaO}$. Foram utilizadas as atividade finais de $\mathrm{CaO}$, visto que, pode ter variado com 0 decorrer dos experimentos. Os resultados podem ser vistos na Figura 94 e na Figura 95. 


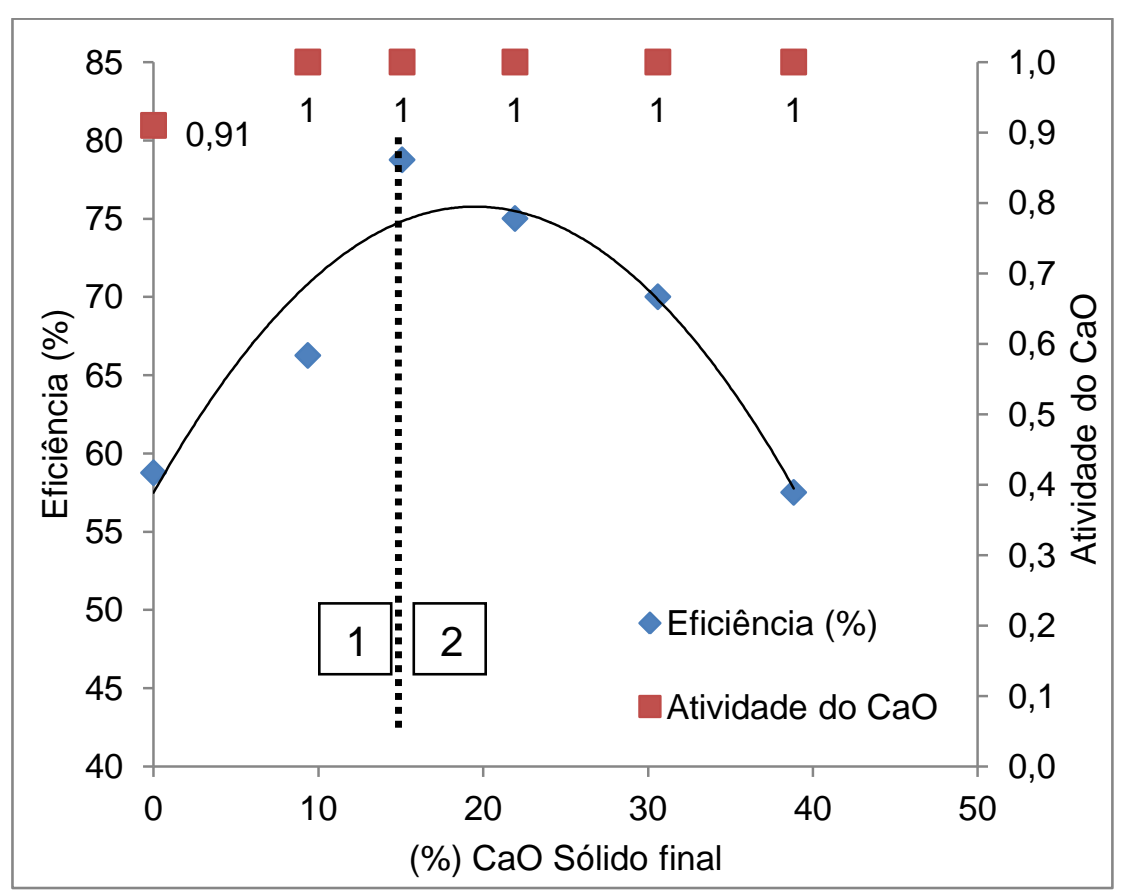

Figura 94. Relação entre a concentração de $\mathrm{CaO}$ sólido em função da eficiência dessulfurante e da atividade do $\mathrm{CaO}$ nas escórias finais produzidas com cal convencional (ACAD1 - ACAD6).

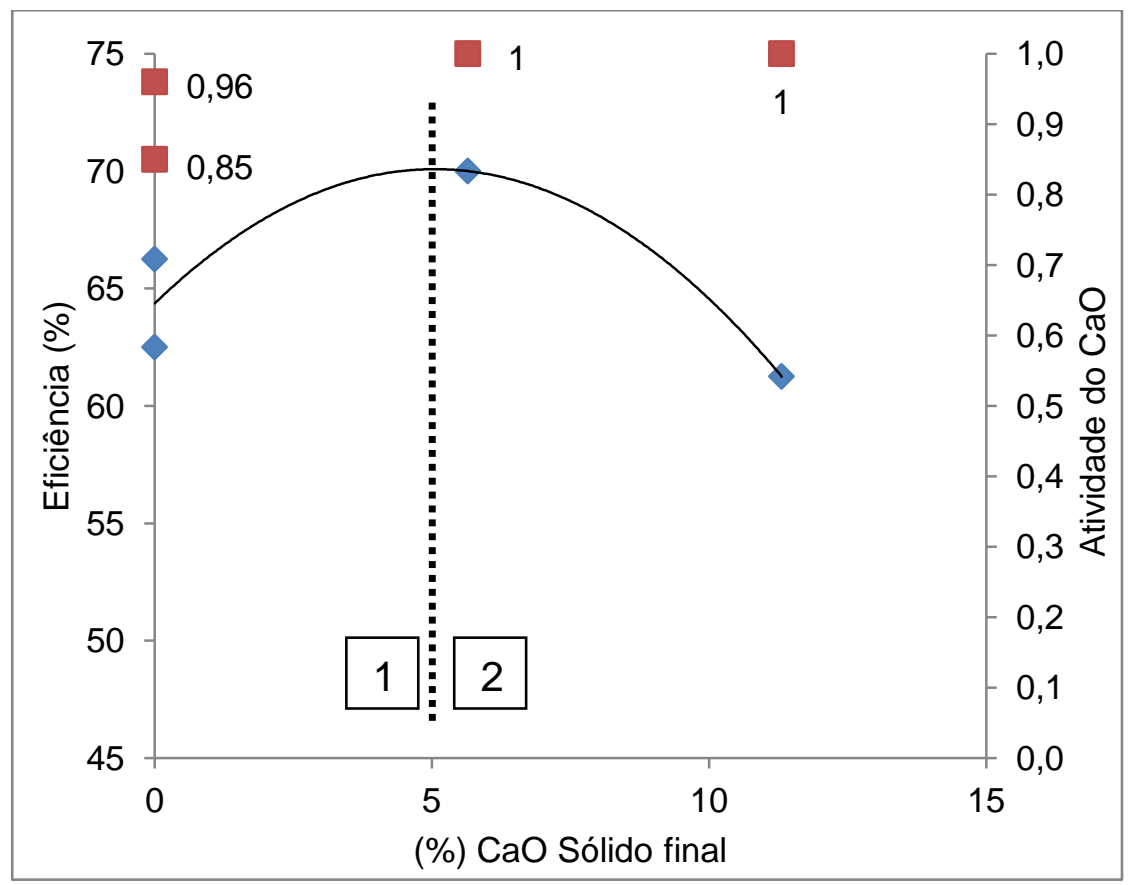

Figura 95. Relação entre a concentração de $\mathrm{CaO}$ sólido em função da eficiência dessulfurante e da atividade do $\mathrm{CaO}$ nas escórias finais produzidas com resíduo de mármore (ARMD7 - ARMD10). 
A região 1 , corresponde a região de escórias que possuem atividade de $\mathrm{CaO}$ menor ou igual a 1, mas não possuem quantidade de $\mathrm{CaO}$ sólido suficiente para manter a fase líquida sempre saturada em $\mathrm{CaO}$ durante os experimentos.

A região 2, representa as escórias que possuem atividade do $\mathrm{CaO}$ igual a $1 \mathrm{e}$ fase sólida de $\mathrm{CaO}$ em excesso. Os resultados mostraram que, a medida que o valor de $\mathrm{CaO}$ sólido aumenta, a remoção do enxofre diminui, visto que, o transporte do enxofre na escória começa a ser prejudicado com o aumento da fase sólida de $\mathrm{CaO}$.

Estes resultados mostraram a necessidade de se manter uma fase sólida de $\mathrm{CaO}$ e atividade de $\mathrm{CaO}$ igual a 1 . No processo de dessulfuração por escória de topo, quanto maior a fração de líquidos, maior a eficiência dessulfurante ${ }^{(51)}$, o mesmo foi observado para os ensaios com ferro fundido. Os resultados de dessulfuração de aço mostraram que tanto a fase líquida, quanto o $\mathrm{CaO}$ sólido influenciam positivamente até o limite de saturação de sólido, valor este próximo a $17 \%$, sugerindo um controle misto.

\subsubsection{Efeito da viscosidade na dessulfuração de aço}

A Figura 96 apresenta os resultados da basicidade quartenária das misturas em função da viscosidade efetiva e da porcentagem de fase líquida das escórias produzidas com resíduo de mármore e cal convencional. 


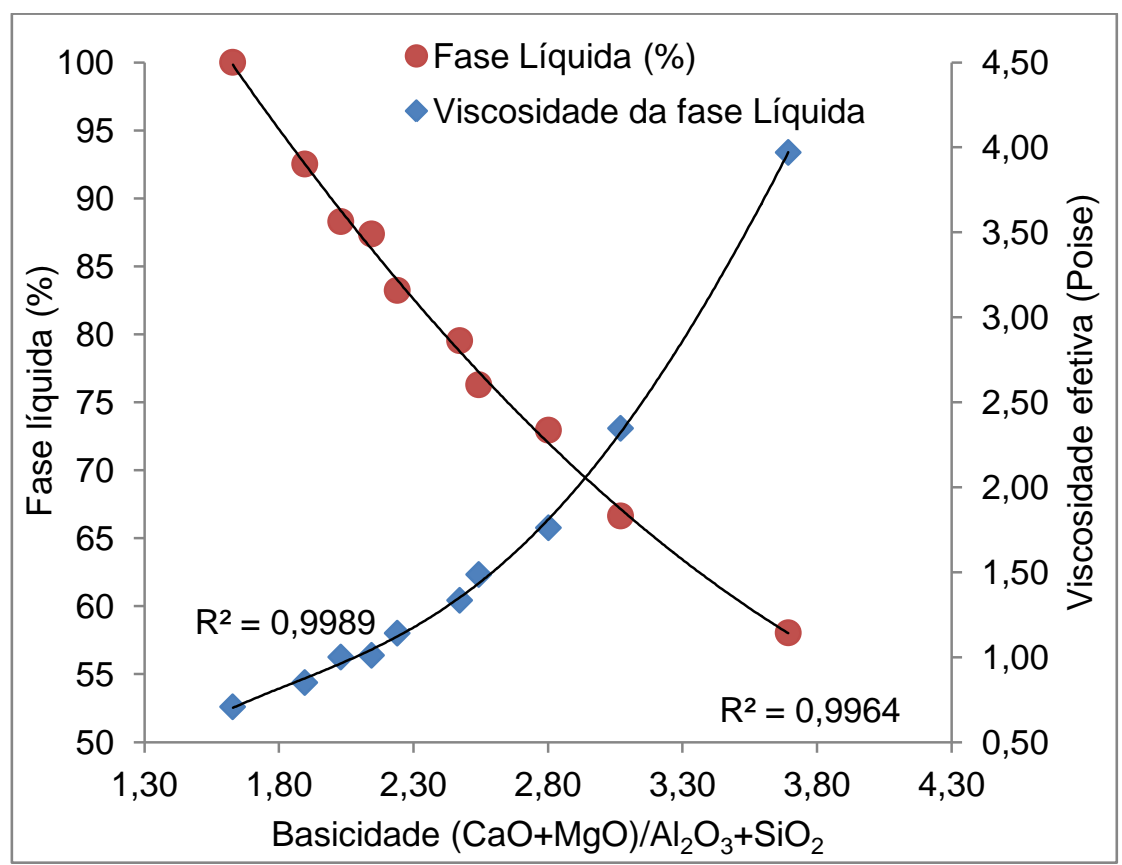

Figura 96. Influência da basicidade sobre a fase líquida e viscosidade efetiva das misturas produzidas com resíduo de mármore (ARMD7 - ARMD10) e cal convencional (ACAF1 - ACAF6).

Os resultados mostram que aumento do $\mathrm{Al}_{2} \mathrm{O}_{3}$ e $\mathrm{SiO}_{2}$ na composição das escórias, ou seja, a diminuição da basicidade, acarreta no aumento da fração de fase líquida. Concomitante ao aumento da fase líquida, ocorre a diminuição da viscosidade efetiva das escórias. Com isso, o uso do $\mathrm{Al}_{2} \mathrm{O}_{3}$ e do $\mathrm{SiO}_{2}$ pode melhorar as condições cinéticas ${ }^{(113)}$.

A Figura 97 apresenta o comportamento entre a variação do $\mathrm{CaO}$ sólido inicial das misturas em função da eficiência e da viscosidade. 


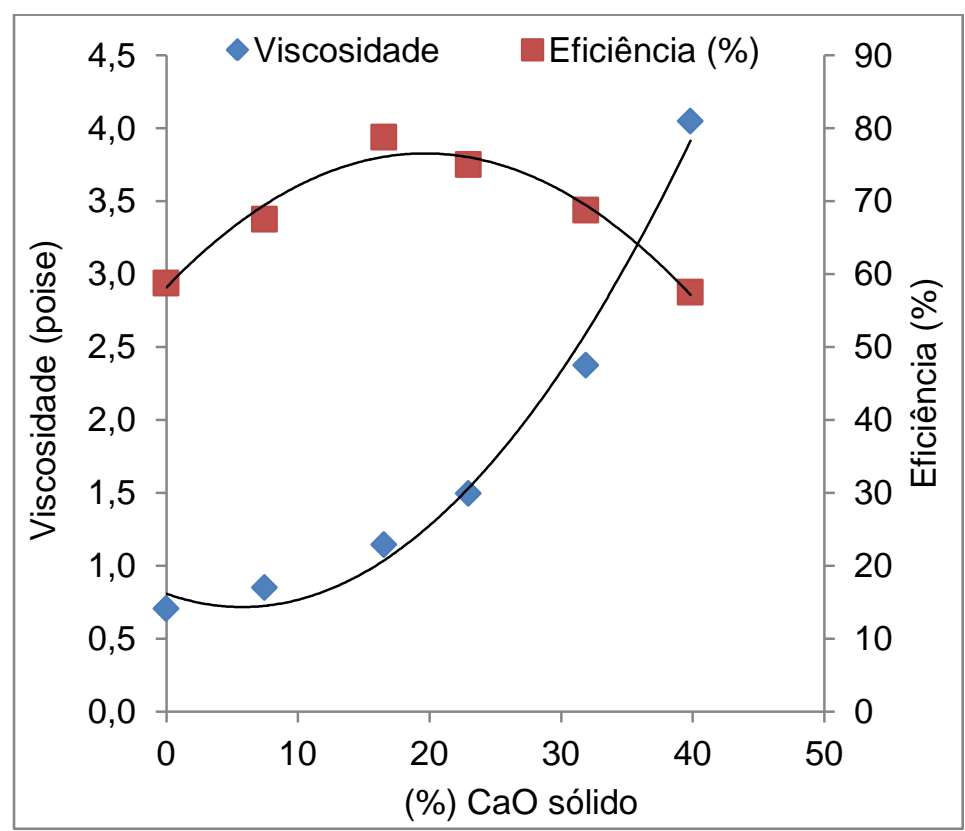

Figura 97. Viscosidade e eficiência das escórias com cal convencional em função da fase sólida de $\mathrm{CaO}$ presente.

Nota-se que a variação da fase sólida de $\mathrm{CaO}$ até cerca de $17 \%$, promoveu um aumento da viscosidade de 0,7 até 1,5 (poise). Acima disto, a fase sólida de $\mathrm{CaO}$ tem uma influência muito mais acentuada, elevando a viscosidade para aproximadamente 4 poise com $40 \%$ de $\mathrm{CaO}$ sólido. Este aumento da viscosidade prejudica a dessulfuraçao. Putan et al ${ }^{(114)}$ afirmaram que em escórias a base de $\mathrm{CaO}-\mathrm{Al}_{2} \mathrm{O}_{3}$, o aumento da viscosidade de 1,5 para 4,5 (poise), conduz para uma redução de 30\% na interação do aço com a escória. A Figura 98 apresenta comportamento entre a variação do $\mathrm{CaO}$ sólido inicial das misturas com resíduo de mármore em função da viscosidade e eficiência. 


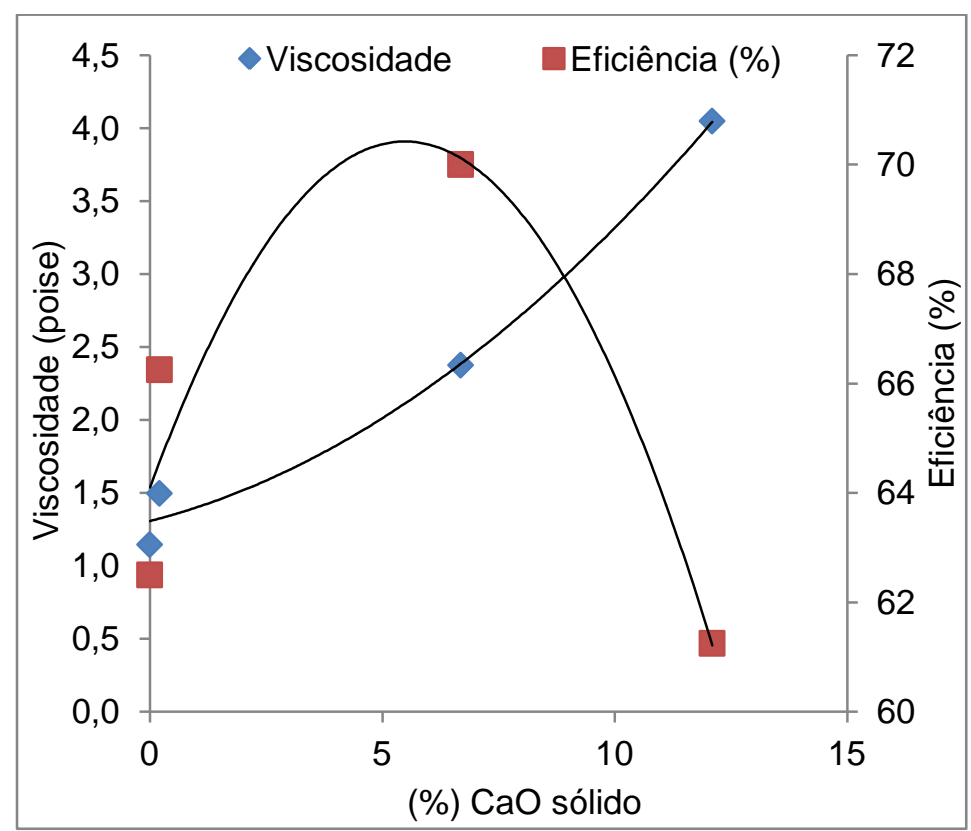

Figura 98. Viscosidade e eficiência das escórias com resíduo de mármore em função da fase sólida de $\mathrm{CaO}$ presente.

Verifica-se que nas misturas com resíduo de mármore, a viscosidade foi superior a encontrada nas misturas com o uso de cal convencional. Isto se deve a presença de $\mathrm{MgO}_{(\mathrm{s})}$ na composição do resíduo, o que contribui para o aumento da viscosidade.

5.2.3.8 Cálculo da constante de velocidade (k) para escórias dessulfurantes de aço.

$\mathrm{Na}$ Tabela 46 constam os valores calculados das constantes de velocidade ( $\mathrm{k}$ ) das escórias de aço. 
Tabela 46. Valores da constante de velocidade para as escórias de dessulfurantes de aço.

\begin{tabular}{ccccccc}
\hline Misturas & $\mathrm{k}(5 \mathrm{~min})$ & $\mathrm{k}(10 \mathrm{~min})$ & $\mathrm{k}(15 \mathrm{~min})$ & $\mathrm{k}(20 \mathrm{~min})$ & $\mathrm{k}(30 \mathrm{~min})$ & $\mathrm{k}$ (médio) \\
\hline ACAD4 & $2,93 \mathrm{E}-03$ & $2,58 \mathrm{E}-03$ & $1,66 \mathrm{E}-03$ & $1,29 \mathrm{E}-03$ & $8,95 \mathrm{E}-04$ & $1,871 \mathrm{E}-03$ \\
ACAD3 & $3,37 \mathrm{E}-03$ & $2,40 \mathrm{E}-03$ & $1,66 \mathrm{E}-03$ & $1,20 \mathrm{E}-03$ & $8,01 \mathrm{E}-04$ & $1,887 \mathrm{E}-03$ \\
ARMD8 & $2,74 \mathrm{E}-03$ & $2,01 \mathrm{E}-03$ & $1,29 \mathrm{E}-03$ & $1,01 \mathrm{E}-03$ & $6,95 \mathrm{E}-04$ & $1,550 \mathrm{E}-03$ \\
ACAD2 & $3,16 \mathrm{E}-03$ & $2,01 \mathrm{E}-03$ & $1,30 \mathrm{E}-03$ & $1,04 \mathrm{E}-03$ & $6,71 \mathrm{E}-04$ & $1,636 \mathrm{E}-03$ \\
ACAD5 & $1,81 \mathrm{E}-03$ & $1,68 \mathrm{E}-03$ & $1,28 \mathrm{E}-03$ & $9,30 \mathrm{E}-04$ & $6,42 \mathrm{E}-04$ & $1,268 \mathrm{E}-03$ \\
ARMD9 & $3,64 \mathrm{E}-03$ & $1,58 \mathrm{E}-03$ & $1,13 \mathrm{E}-03$ & $8,49 \mathrm{E}-04$ & $6,28 \mathrm{E}-04$ & $1,567 \mathrm{E}-03$ \\
ARMD10 & $3,20 \mathrm{E}-03$ & $1,66 \mathrm{E}-03$ & $1,03 \mathrm{E}-03$ & $8,28 \mathrm{E}-04$ & $5,71 \mathrm{E}-04$ & $1,456 \mathrm{E}-03$ \\
ARMD7 & $1,61 \mathrm{E}-03$ & $1,19 \mathrm{E}-03$ & $1,02 \mathrm{E}-03$ & $8,19 \mathrm{E}-04$ & $5,46 \mathrm{E}-04$ & $1,037 \mathrm{E}-03$ \\
ACAD6 & $1,68 \mathrm{E}-03$ & $1,59 \mathrm{E}-03$ & $1,10 \mathrm{E}-03$ & $7,94 \mathrm{E}-04$ & $5,11 \mathrm{E}-04$ & $1,134 \mathrm{E}-03$ \\
ACAD1 & $2,96 \mathrm{E}-03$ & $1,43 \mathrm{E}-03$ & $9,19 \mathrm{E}-04$ & $6,89 \mathrm{E}-04$ & $4,93 \mathrm{E}-04$ & $1,297 \mathrm{E}-03$ \\
ACAF12 & $3,46 \mathrm{E}-03$ & $2,29 \mathrm{E}-03$ & $1,71 \mathrm{E}-03$ & $1,24 \mathrm{E}-03$ & $8,55 \mathrm{E}-04$ & $1,912 \mathrm{E}-03$ \\
ARMCF14 & $3,84 \mathrm{E}-03$ & $1,86 \mathrm{E}-03$ & $1,28 \mathrm{E}-03$ & $1,11 \mathrm{E}-03$ & $6,63 \mathrm{E}-04$ & $1,749 \mathrm{E}-03$ \\
ARMCD13 & $1,15 \mathrm{E}-03$ & $1,68 \mathrm{E}-03$ & $1,20 \mathrm{E}-03$ & $8,41 \mathrm{E}-04$ & $6,01 \mathrm{E}-04$ & $1,095 \mathrm{E}-03$ \\
ARMF11 & $3,14 \mathrm{E}-03$ & $1,62 \mathrm{E}-03$ & $1,01 \mathrm{E}-03$ & $7,84 \mathrm{E}-04$ & $5,23 \mathrm{E}-04$ & $1,416 \mathrm{E}-03$ \\
\hline
\end{tabular}

A relação entre a constante de velocidade $(k)$ em função da eficiência da dessulfuração, obtida através dos dados constantes na Tabela 46, pode ser visualizada na Figura 99.

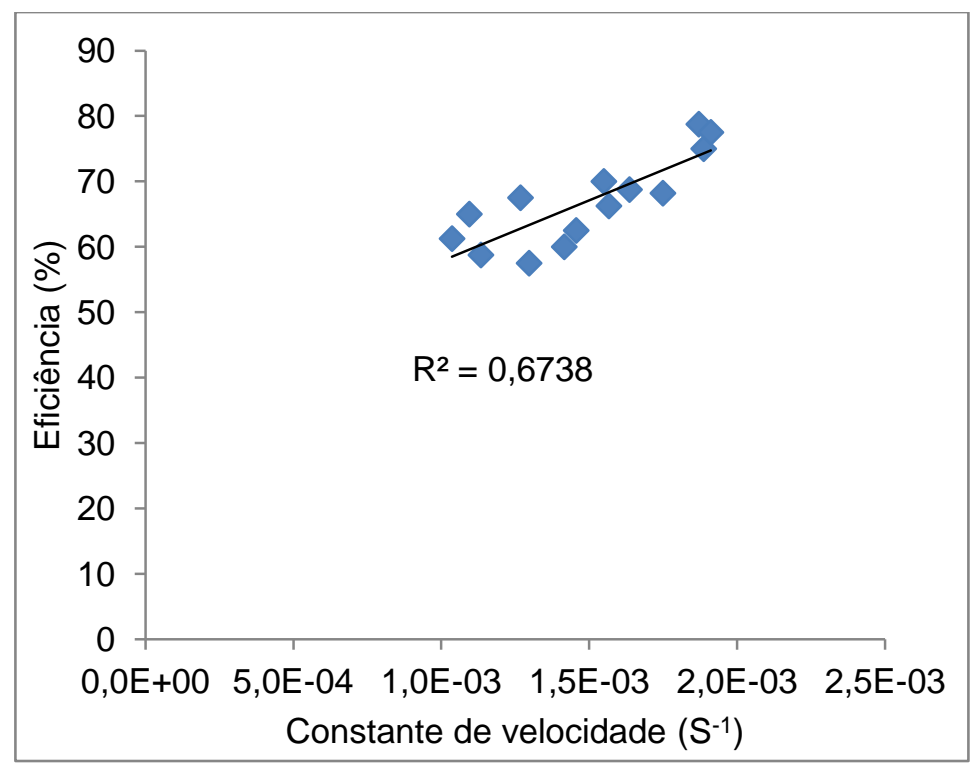

Figura 99. Relação entre a constante de velocidade em função da eficiência das escórias dessulfurantes de aço.

Verifica-se que com o aumento da constante de velocidade, há também um aumento na eficiência de dessulfuração. Além disso, nas escórias contendo resíduo de mármore, os valores da constante de velocidade $(\mathrm{k})$ foram menores, comparadas com as escórias contendo a cal convencional. Os menores valores da constante de 
velocidade $(k)$ nas escórias com o resíduo se deve decomposição dos carbonatos $\left(\mathrm{CaCO}_{3}\right.$ e $\left.\mathrm{MgCO}_{3}\right)$ e a presença de $\mathrm{MgO}$ sólido. 


\section{CONCLUSÕES}

As conclusões foram agrupadas para melhor assimilação dos resultados e são apresentadas nos itens a seguir:

Sobre a caracterização dos materiais, pode-se concluir que:

1- O resíduo de mármore é composto principalmente por carbonato de cálcio e carbonato de magnésio. $\mathrm{Na}$ análise termogravimétrica, verificou-se que a perda de massa com a decomposição dos carbonatos foi de aproximadamente $43,81 \%$. Sobre a análise granulométrica, constatou-se que o resíduo apresentou $90 \%$ das partículas com diâmetro abaixo de $100 \mu \mathrm{m}$ e área superficial de $0,24 \mathrm{~m}^{2} / \mathrm{g}$. Por fim, na análise de microscópica eletrônica de varredura, foi observada uma morfologia predominantemente rugosa com linhas de clivagem.

2- A cal convencional apresentou em sua composição $92,9 \%$ de $\mathrm{CaO}$. Sobre a análise granulométrica, verificou-se que aproximadamente 100\% das partículas do $\mathrm{CaO}$ possuem diâmetro menor que $100 \mu \mathrm{m}$ e área superficial e $1,52 \mathrm{~m}^{2} / \mathrm{g}$.

3- A sodalita apresentou a sílica (51,7\%) como principal óxido na sua composição química. Em seguida, o $\mathrm{Al}_{2} \mathrm{O}_{3} \operatorname{com} 21,87 \%$ e o $\mathrm{Na}_{2} \mathrm{O}$ com $12,6 \%$. A análise de microscopia eletrônica de varredura mostrou que 0 material possui partículas angulosas e irregulares.

Para a dessulfuração de ferro-gusa, pode-se concluir que:

4- $\quad$ As misturas com adição de fluorita (CAF5 e CAF10) obtiveram melhores resultados de dessulfuração, quando comparadas com as misturas com adição de sodalita (CAS5 e CAS10). Para as misturas formuladas com resíduo de mármore, também foi observado este comportamento. 
5- $\quad$ As misturas com a adição de sodalita, quando comparadas com as misturas com adição de fluorita, apresentaram maiores teores dos compostos sólidos $\left(3 \mathrm{CaO} . \mathrm{SiO}_{2}\right.$ e $\left.3 \mathrm{CaO} . \mathrm{Al}_{2} \mathrm{O}_{3}\right)$, que prejudicaram o processo de dessulfuração do ferro-gusa. Neste caso, a presença dos compostos foi mais acentuada, uma vez que, a sodalita possui $\mathrm{SiO}_{2}$ e $\mathrm{Al}_{2} \mathrm{O}_{3}$ em sua composição.

6- $\quad$ Verificou-se que a fase sólida de $\mathrm{CaO}$ é responsável por promover a remoção do enxofre do ferro-gusa. A fase líquida possui papel secundário na dessulfuração do ferro-gusa, tendo a função de dissolver os compostos sólidos $\left(3 \mathrm{CaO} . \mathrm{SiO}_{2}\right.$, $3 \mathrm{CaO} . \mathrm{Al}_{2} \mathrm{O}_{3}$ e $\mathrm{CaS}$ ).

7- $\quad$ A metodologia de análise para prever o teor de enxofre mostrou que a melhor mistura dessulfurante será a que apresentar menor concentração dos compostos sólidos $\left(3 \mathrm{CaO} . \mathrm{SiO}_{2}, 3 \mathrm{CaO} . \mathrm{Al}_{2} \mathrm{O}_{3}\right)$ e os maiores teores de $\mathrm{CaO}_{\mathrm{SD}}$ ou $\mathrm{CaO}$ TD.

Para a dessulfuração do ferro fundido, pode-se concluir que:

8. As misturas com resíduo de mármore que obtiveram a melhor eficiência dessulfurante foram; CIRMF12 e CIRM8 $(87,25 \%$ e $87,03 \%)$. Para a cal convencional as melhores misturas dessulfurantes foram; CICAF11 e CICA3 $(90,10 \%$ e $89,81 \%)$. A análise termodinâmica computacional efetuada com o auxílio do Thermo-Calc mostrou menores teores de enxofre de equilíbrio para as misturas; CICAF11, CIRM12, CICA5 e CIRM10.

9. A concentração de $\mathrm{MgO}$ nas escórias com resíduo de mármore, interferiu negativamente na eficiência dessulfurante, diminuindo a fração de fase líquida e a eficiência.

10. O aumento da fase líquida favoreceu o transporte de massa do enxofre na escória e na interface metal/escória, aumentando a eficiência dessulfurante das misturas. Além disso, o aumento da fase líquida aumentou a constante de velocidade $(k)$. 
11. O aumento do diâmetro de partículas do $\mathrm{CaO}$ favoreceu o processo de dessulfuração. Foi observado que o diâmetro das partículas de $\mathrm{CaO}$ entre 20 e $100 \mu \mathrm{m}$, aglomeravam (sinterizavam) após a adição das misturas no metal, prejudicando a dessulfuração.

Para a dessulfuração do aço, pode-se concluir que:

12. As misturas à base de cal convencional obtiveram melhores resultados dessulfurantes em relação às misturas com resíduo de mármore. O menor teor de enxofre $(0,0017 \%)$ foi obtido pela a mistura identificada por ACAD4. Já para as misturas com resíduo de mármore, a melhor mistura obteve teor de enxofre de 0,0024\% (ARMD8).

13. Observou-se que praticamente toda a dessulfuração ocorre nos primeiros 10 minutos de experimento, que é condizente ao tempo de tratamento em reatores industriais.

14. Verificou-se que a diminuição da temperatura proporcionada pelas reações endotérmicas durante a decomposição dos carbonatos interferiu negativamente na eficiência das misturas dessulfurantes com resíduo de mármore.

15. O aumento da concentração de $\mathrm{CaO}$ na composição inicial, das misturas com cal convencional, é eficaz até teores próximos de $64 \%$. Considerando a fase sólida de $\mathrm{CaO}$, o valor encontrado foi de $17 \%$ de $\mathrm{CaO}$ sólido. Considerando a mesma análise para as escórias com resíduo de mármore, a porcentagem de $\mathrm{CaO}$ foi de aproximadamente $51 \%$ e $\mathrm{CaO}$ sólido próximo de $5 \%$.

16. A variação da fase sólida de $\mathrm{CaO}$ até cerca de $17 \%$ promoveu um aumento da viscosidade de 0,7 até 1,5 (poise). Acima disto, a fase sólida de $\mathrm{CaO}$ tem uma influência muito mais acentuada, elevando a viscosidade para aproximadamente 4 (poise) com $40 \%$ de $\mathrm{CaO}$ sólido. 


\section{REFERÊNCIAS BIBLIOGRÁFICAS}

1 INSTITUTO AÇO BRASIL (2012). Dados de mercado 2012. Disponível em: http://www.acobrasil.org.br/site/portugues/numeros/numeros--mercado.asp, acesso em: 29 de janeiro de 2014.

2 SUSAKI, K. Estudo Prospectivo do Setor Siderúrgico brasileiro, Disponível em: http://www.abmbrasil.com.br/epss/arquivos/documentos/ 2 SUSAKI, K. Estudo Prospectivo do Setor Siderúrgico brasileiro, Disponível em: http://www.abmbrasil.com.br/epss/arquivos/documentos/ acesso em: 20/07/2013.

3 WORLD STEEL ASSOCIATION (2014). Steel Statistical Yearbook 2014. Bruxelas: WORLD STEEL ASSOCIATION. Disponível em: http://www.worldsteel.org/mediacentre/press-releases/2015/January-2015-crude-steel-production-for-the-65countries-reporting-to-worldsteel.html, acesso em: 20 de janeiro de 2015.

4 HOLAPPA, L.E.K. Ladle injection metallurgy, International Metals Reviews, v. 27, n. 2, p. 53-76. 1982.

5 OETERS, F. Metallurgy of steelmaking. $2^{\circ}$ ed. Berlin: Editora Druckzentrum Sutter + Partner, Essen. 1994. 512 p.

6 YUGOV, P.I.; ROMBERG, A. L.; YANG, D.H. Improving the quality of pig iron and steel. Metallurgist, v. 42, p. 81-89, 1998.

7 ROSKILL, Various, "Magnesium Metal: Global Industry Markets \& Outlook," London, 2013.

8 LINDSTROM, D.; NORTIER, P.; SICHEN, D. Functions of Mg and Mg-CaO mixtures in hot metal desulfurization. Steel Research International, v. 85, p. 76-88, 2013.

9 SHIMIZU, K.; SUZUKI, T.; JIMBO, I.; CRAMB, A.W. An Investigation on the Vaporization of Fluorides from Slag Melts. Ironmaking Conference Proceedings, v. 55, p. 727-733, 1996. 
10 MINERAL COMMODITY SUMMARIES 2009. Fluorspar, U.S. Geological Survey, Washington, p.58- 59, january 2009.

$11 \mathrm{GHOSH}, \mathrm{A}$. Secondary Steelmaking: Principles and Applications. Boca Raton: CRC Press LLC, 2001. 307p.

12 TURKDOGAN, E. Fundamentals of steelmaking. London: The Institute of Materials, 1996. Cap 9, p. 275-285. 331p.

$13 \mathrm{KIRMSE}, \mathrm{O}$. J. Estudo do comportamento metalúrgico do "reator kambara" através de modelagem física. 2006. 119p. Dissertação (Mestrado) -REDEMATUniversidade Federal de Ouro Preto, 2006, p. 34, 56, 78, 85.

14 LEMOS, L. R.; SILVA, C. A.; SILVA, I. A.; MANSUR, F. V., KIRMSE, O. J. Aumento da eficiência de dessulfuração do gusa líquido em um reator kanbara.

Tecnologia Metalurgia Materiais e Mineração, n. 1, v. 8, p. 31-36, 2011.

15 FINCHAM, C. J. B.; RICHARDSON, F. D. The behaviour of sulphur in silicate and aluminate melts. Proceedings of the Royal Society A, London, v. 223, p. 40-62, 1954.

16 VISSER, H.; BOOM, R. Advanced process modelling of hot metal desulphurisation by injection of $\mathrm{Mg}$ and $\mathrm{CaO}$. ISIJ International, n. 12, v. 46, p. 1771-1777, 2006.

17 BRAHMA DEO, ROB BOOM. Fundamentos os steelmaking metallurgy. cap. 6. 189-205 p. Hertfordshire (UK): Prentice Hall International, 1993.

18 NITA, P. S.; BUTNARIU, I.; CONSTANTIN, N. The efficiency at industrial scale of a thermodynamic model for desulphurization of aluminium killed steels using slags in the system CaO-MgO- $-\mathrm{Al}_{2} \mathrm{O}_{3}-\mathrm{SiO}_{2}$. Revista de Metalurgia, v. 46, n. 1, p. 5-14, 2010.

19 VIANA, J. F.;COSTA, S. L. S; PRENAZZI, A.; LEE, D.; Hot metal desulfurization by $\mathrm{CaO}-\mathrm{Mg}$ Co-Injection in usiminas steel shop 02. In: STEELMAKING 
CONFERENCE IRON AND STEEL SOCIETY, 1999, Chicago, Proceedings, v. 82, p. 21-24.

20 SHEVCHENKO, A. F.; VERGUN, A. S.; BULAKHTIN, A. S.; SHEVCHENKO, S. A.; KISLYAKOV, V. G. Improving the ladle desulfurization of hot metal in low sulfur steel production. Journal: Steel in Translation, n. 12, v. 41, 2011.

21 DYUDKIN, D. A.; GRINBERG, S. E.; MARINTSEV, S. N. Mechanism of the desulfurization of pig iron by granulated magnesium. Metallurgist, v. 45, n.3, p. 150 155, 2001.

22 KUMAR, R. V.; LIU, J. Research for using iron \& steelmaking zinc laden dust to desulphurize hot metal. Steel Research International, n. 10, v. 81, p. 847-851, 2010.

23 LINDSTRÖM, D.; NORTIER, P.; GLASER, B.; SICHEN, D. Study on the possibility of using $\mathrm{ZnO}$ for hot metal desulfurization. Steel research international, 2013, v. 84, n. 5, p. 419-425, 2012.

24 LINDSTRÖM, D.; SICHEN, D. Study on desulfurization abilities of some commonly used desulfurization agents. Steel research international, v.86, p.73-83, 2015.

25 SILVA, Y, I A. Estudo Físico-Químico da Dessulfuração do Gusa. Dissertação (Mestrado). 1976, 116p. Universidade Federal de Minas Gerais, 1976, p.27-38.

26 TAKANO, C. Termodinâmica de cinética no processo de dessulfuração de ferro e Aço. In: CONFERÊNCIA INTERNACIONAL SOBRE DESSULFURAÇÃO E CONTROLE DE INCLUSÕES DA ABM. 1997, Volta Redonda, Anais... ABM, p. 1-18.

27 DUFFY, J. A.; INGRAM, M. D. An interpretation of glass chemistry in terms of the optical basicity concept. Journal of Non-Crystalline Solids, v. 21, p. 373-373, 1976.

28 DUFFY, J. A. A review of optical basicity and its applications to oxidic systems. Geochimica et Cosmochimica Acta, n. 16, v. 57, p. 3961-3970, 1993. 
29 DUFFY, J. A. Optical basicity of sulfide systems. Journal of the Chemical Society, Faraday Transactions, n. 16, v. 88, p. 2397-3970, 1992. 30 MARTINS, J. A. Fabricação de Escória Sintética em Fornos de Indução para uso em Aciarias. 2003, 109p. Dissertação (Mestrado) - REDEMAT- Universidade Federal de Ouro Preto, 2003, p. 34, 39, 75.

$31 \mathrm{GHOSH}$, D.; KRISHNAMURTHY, V. A.; SANKARANARAYANAN, S. R. Application of Optical Basicity to Viscosity of High Alumina Blast Furnace Slags, Journal of Mining and Metallurgy, n. 1, v. 46, p. 41-49, 2010.

32 SOSINSKY, D. J.; SOMMERVILLE, I. D. The Composition and temperature dependence of the sulfide capacity of metallurgical slags. Metallurgical Transactions B, v. 17B, p. 331-337, 1986.

33 YOUNG, R. W.; DUFFY, J. A.; HASSALL, G. J.; XU, Z. Use of optical basicity concept for determining phosphorus and sulfur Slag-Metal partitions. Ironmaking Steelmaking, n. 3, v. 19, p. 201-207, 1992.

34 SHANKAR, A. Sulphur partition between hot metal and high alumina blast furnace slag. Ironmaking and Steelmaking, n. 5, v. 33, p. 413-418, 2006.

35 TANIGUSHI, Y.; SANO, N.; SEETHARAMAN, S. Sulphide capacities of CaO$\mathrm{Al}_{2} \mathrm{O}_{3}-\mathrm{SIO}_{2}-\mathrm{MgO}-\mathrm{MnO}$ slags in the temperature range $1673-1773 \mathrm{~K}$. ISIJ International, n. 2, v. 49, p. 156-163, 2009.

36 NZOTTA M. M.; SICHEN, D.; SEETHARAMAN, S. Sulfide capacities in some multi component slag systems. ISIJ international, n. 38, v. 11, p. 1170-1179, 1998.

37 NZOTTA, M. M.; DU, S. C.; SEETHARAMAN, S. Sulphide capacities of "FeO"$\mathrm{SiO}_{2}, \mathrm{CaO}-\mathrm{FeO}$ ", and "FeO"-MnO slags. ISIJ International, n.7, v. 39, p. 657-661, 1999.

38 SOSINSKY, D. J.; SOMMERVILLE, I. D. The composition and temperature dependence of the sulfide capacity of metallurgical slags. Metallurgical Transactions B, v. 17B, p. 331-337, 1986. 
39 WANG, L.; HAYASHI, M.; CHOU, K.; SEETHARAMAN, S. An Insight into Slag Structure from Sulphide Capacities. Metallurgical and Materials Transactions B, v. 43B, p. 23-34, 2012.

40 NITA, P. S. Analisys and Definition of Sulphide Capacity. Metalurgia, v. 43, p. 1621, 1991.

41 SHI, C.; YANG, X.; JIAO, J.; LI, C.; GUO, H. A Sulphide Capacity Prediction Model of $\mathrm{CaO}-\mathrm{SiO}_{2}-\mathrm{MgO}-\mathrm{Al}_{2} \mathrm{O}_{3}$ Ironmaking slags based on the ion and molecule coexistence theory. ISIJ International, n. 10, v. 50, p. 1362-1372, 2010.

42 ANDERSOON T, JONSSON G, HALBERG M. Optimization of ladle slag composition by application of sulphide capacity model. Ironmaking and Steelmaking, n. 4, v. 27, p. 286-293, 2000.

43 INOUE, R.; SUITO, H. Sulfur partitions between carbon-saturated melt and $\mathrm{Na}_{2} \mathrm{O}-$ $\mathrm{SiO}_{2}$ Slags. Transactions of the Iron and Steel Institute of Japan, v. 22, p. 514523, 1982.

44 MITSUTAKA, H.; KITAGAWA, S.; BAN-YA, S. Sulphide Capacities Slags of CaO$\mathrm{Al}_{2} \mathrm{O}_{3}-\mathrm{MgO}$ and $\mathrm{CaO}-\mathrm{Al}_{2} \mathrm{O}_{3}-\mathrm{SiO}_{2}$. ISIJ International, n.1, v. 33, p. 36-42, 1993.

45 MAGALHÃES, H. L. G. Melhoria da limpidez do aço SAE 1045 desoxidado ao alumínio com aplicação na indústria automobilística, utilizando termodinâmica computacional. 2010. 117p. Dissertação (Mestrado) - REDEMAT- Universidade Federal de Ouro Preto, 2010, p. 35-40.

46 TURKDOGAN, E.T. Physical chemistry of high temperature technology: Physical Chemistry of Ironmaking and Steelmaking, cap. 9. 342-394p. New York: Editora Academic Press. 1980.

47 KOR, G. J. W.; GLAWS, P. C. In. Making Shaping and Treating of Steel: Ladle refining and vacuum degassing, cap. 11, p. 661-713. Pittsburg, PA. The AISE steel foundation, 1998. 
48 FRUEHAN, R. J. Desulfurization of liquid steel containing aluminum or silicon with lime. Metalurgical transactions B, v. 9, p. 287-292, 1978.

49 SUITO, H.; INOUE, H. INOUE, R. Aluminium-oxygen equilibrium liquid iron between $\mathrm{CaO}-\mathrm{Al}_{2} \mathrm{O}_{3}$ melts and liquid iron. ISIJ International. v. 31, n. 12, p. 13811388, 1991.

50 FRUEHAN, R. J. Activities in Liquid Fe-Al-O and Fe-Ti-O Alloys. Metallurgical Transactions, n. 12, v. 1, p. 3403-3410, 1970.

51 PRETORIUS, E. Slags and the relationship with the refractory life and steel production. Santos: LWB Refractories, 2002. 121p.

52 RIBEIRO, D. B.; THEODORO, J. C. A influência da escória de topo na dessulfuração do gusa líquido. In: XXVII SEMINÁRIO SOBRE FUSÃO, REFINO E SOLIDIFICAÇÃO DOS AÇOS, 1996, Belo Horizonate, Anais... ABM, p. 299-310.

53 NIEDRINGHAUS, J. C.; FRUEHAN, R. J. Reaction mechanism for the CaO-Al and $\mathrm{CaO}-\mathrm{CaF}_{2}$ desulfurization of carbon-saturated iron. Metallurgical Transactions B. v. 19B, p. 261-268, 1988.

54 MITSUO, T.; SHOJI, T.; HATTA, Y.; ONO, H.; MORI, H.; KAI, T. Improvement of desulfurization by addition of aluminum to hot metal in the lime injection process.

Transactions of the Japan Institute of Metals. n. 12, v. 23, p. 768-779, 1982.

55 LINDSTROM, D.; SICHEN, DU. Kinetic Study on Desulfurization of Hot Metal Using $\mathrm{CaO}$ and $\mathrm{CaC}_{2}$, Metallurgical and Materials Transactions B, v.46, p. 83-92, 2014.

56 KAWAI, Y.; MORI, K.; SANNOMIYA, Y.; Rate of desulfurization of pig iron by solid lime. Tetsu-to-Hagane, n. 1, v. 61, p. 29-35, 1975.

57 TANAKA, T.; OGISO, Y.; UEDA, M.; LEE, J. Trial on the application of capillary phenomenon of solid $\mathrm{CaO}$ to desulfurization of liquid Fe. ISIJ International, n. 8, v. 50, p 1071-1077, 2010. 
58 TAKAHASHI, K.; UTAGAWA, K.; SHIBATA, H.; KITAMURA, S.; KIKUCHI, N.; KISHIMOTO, Y. Influence of solid $\mathrm{CaO}$ and liquid slag on hot metal desulfurization. ISIJ International, n. 1, v. 52, p. 10-17, 2012.

59 CAMPOS, V.F. Tecnologia de Fabricação do Aço Líquido. Belo Horizonte: UFMG, 1985.

60 ROSENQVIST, T. Principles of extractive metallurgy. $2^{\circ}$ ed. Singapura: McGraw-Hill, 1983. Cap 13, p. 345-374.

61 SHAHBAZIAN, F.; SICHEN, D.; SEETHARAMAN, S. The effect of addition of $\mathrm{Al}_{2} \mathrm{O}_{3}$ on the viscosity of $\mathrm{CaO}-" \mathrm{FeO}^{-}-\mathrm{SiO}_{2}-\mathrm{CaF}_{2}$ slags. ISIJ International, n. 2, v. 42, p. 155-162, 2002.

$62 \mathrm{MACHIN}$, J. S.; YEE, T. B. Viscosity studies of system $\mathrm{CaO}-\mathrm{MgO}-\mathrm{Al}_{2} \mathrm{O}_{3}-\mathrm{SiO}_{2}$ : II, $\mathrm{CaO}-\mathrm{Al}_{2} \mathrm{O}_{3}-\mathrm{SiO}_{2}$. Journal of the American Ceramic Society, v. 31, p. 200-204, 1948.

63 MACHIN, J. S.; YEE, T. B.; HANNA, D. L. Viscosity studies of system CaO-MgO$\mathrm{Al}_{2} \mathrm{O}_{3}-\mathrm{SiO}_{2}: \mathrm{III}, 35,45$, and $50 \% \mathrm{SiO}_{2}$. Journal of the American Ceramic Society, v. 35, p. 322-325, 1952.

$64 \mathrm{MACHIN}$, J. S.; YEE, T. B. Viscosity studies of system $\mathrm{CaO}-\mathrm{MgO}-\mathrm{Al}_{2} \mathrm{O}_{3}-\mathrm{SiO}_{2}$ : IV, 60 and $65 \% \mathrm{SiO}_{2}$. Journal of the American Ceramic Society, v. 37, p. 177-186, 1954.

65 ROMASHIN, V. M. Y.; AMFITEATROV, V. A. Viscosity of $\mathrm{CaO}$ based slags with variable $\mathrm{Al}_{2} \mathrm{O}_{3}, \mathrm{SiO}_{2}$, and $\mathrm{MgO}$ contents. Steel in USSR, v. 7, p. 617-618, 1977.

66 MILLS, K. C.; SRIDHAR, S. Viscosities of ironmaking and steelmaking slags. Ironmaking and Steelmaking, v. 26, n. 4, p. 262-268, 1999.

67 SHANKAR, A.; GÖRNERUP, M.; Experimental investigation of the viscosities in $\mathrm{CaO}-\mathrm{SiO}_{2}-\mathrm{MgO}-\mathrm{Al}_{2} \mathrm{O}_{3}$ and $\mathrm{CaO}-\mathrm{SiO}_{2}-\mathrm{MgO}^{-} \mathrm{Al}_{2} \mathrm{O}_{3}-\mathrm{TiO}_{2}$ slags. Metallurgical and Materials Transactions B, v. 38, n. 6, p. 911-915, 2007. 
68 SONG, M.; SHU Q.; SICHEN, D. Viscosities of the quaternary $\mathrm{Al}_{2} \mathrm{O}_{3}-\mathrm{CaO}-\mathrm{MgO}-$ $\mathrm{SiO}_{2}$ slags. Steel Research International, v. 82, n. 3, p. 260-268, 2011.

69 GAYE, H.; LEHMANN, J.; Modelling and prediction of reactions involving metals, slags and fluxes, In: VII INTERNATIONAL CONFERENCE ON MOLTEN SLAGS FLUXES AND SALTS. 2004, South African Institute of Mining and Mettalurgy, Proceedings, 2004, p. 619-623.

70 ANDERSSON, M.; HALLBERG, M.; JONSSON, L.; JONSSON, P. Slag-metal reactions during ladle treatment with focus on desulphurization. Ironmaking and Steelmaking, n. 3, v. 29, p 224-232, 2002.

71 HAYAKAWA, H.; HASEGAWA, M.; OHNUKI, K. SAWAI, T.; IWASE, M. Sulphide capacities of $\mathrm{CaO}-\mathrm{SiO}_{2}-\mathrm{Al}_{2} \mathrm{O}_{3}-\mathrm{MgO}$ slags. Steel Research International, n. 1, v. 77, p. 14-20, 2006.

72 TURKDOGAN E. T. Physicochemical properties of molten slags and glasses, Metals Society London. 1983.

73 CARLSSON, G.; BRAMMING, M.; WHEELER, C. Top slag and gas purging - A low-budget method for desulfurizing steel in the ladle. In: ISS STEELMAKING CONFERENCE, 1986, Washington, Proceedings, 1986, p. 456-461.

74 MATSUZAWA, A.; HARADA, H. Effect of Flux Composition on Desulfurization Reaction Rate of Molten Steel. In: AISTech Conference, 2013, Pittsburgh, Proceedings, 2013, p. 333-340.

75 ENDO, K.; KANEKO, T.; HARADA, S.; SUZUKI, H. Examination of optimum flux composition on desulfurization of molten steel, Tetsu-to-Hagane, v.71, n. 4, p.S284, 1985.

76 TAKEUCHI, E.; KISHIMOTO, M.; MORI K.; KAWAI, Y. Rate of Desulfurization of Liquid Iron by $\mathrm{CaO}-\mathrm{SiO}_{2}-\mathrm{Al}_{2} \mathrm{O}_{3}$ Slag and Interfacial Phenomena", Tetsu-to-Hagane, n. 12, v. 64, p.1704-1713, 1978. 
77 TRIBE, T. S.; KINGSTON, P. W.; MACDONALD, J. B.; CALEY, W. F. Reduction of fluorspar consumption in secondary steelmaking. Ironmaking and Steelmaking, n. 2, v. 21, p. 145-149, 1994.

78 MACLEAN, J. R.; KINGSTON, P. K.; MACDONALD, J. B.; CALEY, W. F. Potential role of feldspar/feldspathoid minerals in secondary steelmaking. Ironmaking and Steelmaking, n. 5, v. 24, p. 406-411, 1997.

79 VOLKMANN, A. Utilização da sodalita-nefelínica em substituição a fluorita na aciaria da Usiminas. IN: 33ํㅡㄴ SEMINÁRIO DE FUSÃO, REFINO E SOLIDIFICAÇÃO DOS METAIS, 2002, Santos, Anais... São Paulo, ABM, p. 187-195.

80 SILVA, M. A. Avaliação da utilização de agentes dessulfurantes a base de carbureto de cálcio contendo sodalita em substituição à fluorita em carro torpedo. 2012. 98p. Dissertação (Mestrado) - Universidade Federal de Minas Gerais, 2012, p. 39-38.

81 SINGH, B. N.; RAVAT, Y. F.; CHATTERJEE, A.; CHAKRAVARTY, P. K. Use of Ilmenite sand as a substitute for fluorspar in Open-Hearth steelmaking. Ironmaking Steelmaking, n. 3, v. 4, p. 170-175, 1977.

82 POGGI, D.; LEE, H.Y. Massive Ilmenite as a slag thinner in steelmaking.

Canadian Metallurgical Quarterly, n. 3, v. 13, p. 529-533, 1974.

83 AMINI, S. H.; OSTROVSKI, O.; BRUNGS, M. P. A study of dissolution of dense lime in molten slags under static conditions. In: VII INTERNATIONAL CONFERENCE ON MOLTEN SLAGS FLUXES AND SALTS, 2004, Johannesburg, Proceedings, Africa do Sul, 2004, p.595-600.

84 DONG, K.; WU, L.; LIU, W.; ZHU, R. Desulfurization of $\mathrm{CaO}-\mathrm{Al}_{2} \mathrm{O}_{3}-\mathrm{SiO}_{2}-\mathrm{TiO}_{2}$ slag system. ISIJ International, n. 10, v. 54, p. 2248-2254, 2014.

85 SOMMERVILLE, I. D.; BELL, H. B. The behaviour of titania in metallurgical slags. Canadian Metallurgical Quarterly, n. 2, v. 21, p. 145-155, 1982. 
86 SANO, N. LU, W. RIBOUD, P. V. MAEDA, M. "Advanced Physical Chemistry for Process Metallurgy", Academic Press, London, p. 5 - 117, 1997.

87 LANGE, K. W. Thermodynamic and kinetic aspects of secondary steelmaking processes. International Materials Reviews, n. 1, v. 33, p. 53-89, 1988.

$88 \mathrm{CHOI}$, J.; KIM, D.; LEE, H. Reaction kinetics of desulfurization of molten pig iron using $\mathrm{CaO}-\mathrm{SiO}_{2}-\mathrm{Al}_{2} \mathrm{O}_{3}-\mathrm{Na}_{2} \mathrm{O}$ slag systems. ISIJ International, n. 3, v. 41, p. $216-$ 224, 2001.

89 SESHADRI, V.; DA SILVA, C. A.; DA SILVA, I. A.; KRUGER, P. A Kinetic model applied to the molten pig iron desulfurization by injection of lime-based power. ISIJ International, n. 1, v. 37, p. 21-30, 1997.

90 MUHMOOD, L.; VISWANATHAN, N.; SEETHARAMAN, S. Evaluating the chemical diffusion coefficient of sulfur in slag by metal analysis: Model concept and experiments. Metallurgical Materials Transactions B, v. 42, p. 274-279, 2011.

91 YAN, P.; GUO, X.; HUANG, S.; DYCK, J. V.; GUO, M.; BLANPAIN, B. Desulphurisation of stainless steel by using $\mathrm{CaO}-\mathrm{Al}_{2} \mathrm{O}_{3}$ based slags during secondary metallurgy. ISIJ International, n. 3, v. 53, p. 459-467, 2013.

$92 \mathrm{CHUSHAO}, \mathrm{X} . ; \mathrm{XIN}, \mathrm{T}$. The kinetics of desulfurization of hot metal by $\mathrm{CaO}-\mathrm{CaF}_{2}$ based fluxes. ISIJ International, n. 10, v. 32, p. 1081-1083, 1992.

93 AGUIAR, F. N. Utilização de resíduo de mármore como dessulfurante de ferro-gusa. 2011. 104 p. Dissertação (Mestrado) - Instituto Federal do Espírito Santo. Vitória, 2011, p. 19, 33, 44.

94 BIELEFELD, W. V. Tratamento de inclusões não-metálicas com cálcio nos aços SAE 1141 e SAE 8620, 2009. 168 p. Tese (doutorado) - Universidade Federal do Rio Grande do Sul, 2009, p. 55.

95 OERTEL, L. C.; SILVA, A. C.; Application of Thermodynamic Modeling to SlagMetal Equilibria in Steelmaking. Calphad, v. 23, p. 379 - 391, 1999. 
96 MORAES, C. A. M.; BORDIN, F.; ZETTERMANN, L. F.; BIELEFELDT, W. V.; VILELA, A. C. F. Análise termodinâmica das interfaces metal-escória e metalInclusões na produção de aço - Utilização de modelo termodinâmico computacional e sua combinação com modelos de escoamento. IN: $57^{\circ}$ Congresso Anual da ABM, 2002. Anais... São Paulo, ABM, 2002, p. 348-358.

97 GRILLO, F. F.; SAMPAIO, R. A.; VIANA, J. F.; OLIVEIRA, J. R. Use of computational thermodynamic software in study of desulfurizing mixtures of hot metal. In: AISTech, 2014, Indianápolis, Proceedings. p. 1207-1212.

98 GRILLO, F. F.; SAMPAIO, R. A.; VIANA, J. F.; ESPINOSA, D. C. R.; OLIVEIRA, $\mathrm{J}$. R. Analysis of pig iron desulfurization with mixtures from the CaO-Fluorspar and $\mathrm{CaO}$-Sodalite system with the use of computational thermodynamics. Revista Escola de Minas, v. 66, p. 461-465, 2013.

99 SAMPAIO, R. A. Utilização dos softwares de termodinâmica computacional no estudo das etapas de pré-tratamento do ferro-gusa. 2014, 151p. Dissertação (Mestrado) - Instituto Federal do Espírito Santo, Vitória, 2014, p. 78-85.

100 DOUGLAS A. S.; HOLLER, F. J.; NIEMAN, T. A. Principles instrumental Analysis. $5^{\circ}$ edition. Cap. 12, cap. 288.

101 BIELEFELDT, W. V.; VILELA, A. C. F.; CEZAR, N. Evaluation of the Slag System $\mathrm{CaO}-\mathrm{MgO}_{-} \mathrm{Al}_{2} \mathrm{O}_{3}-\mathrm{SiO}_{2}$. In: 44 $\mathrm{STEELMAKING} \mathrm{SEMINAR,} \mathrm{2013,} \mathrm{Araxá.}$ Anais... Minas Gerais, ABM, 2013, p 163-172.

102 PRETORIUS, E. B.; CARLISLE, R. C. Foamy slag fundamentals and their practical application to electric furnace steelmaking. In: ELECTRIC FURNACE CONFERENCE, 1998, New Orleans, Proceedings, p. 275-292.

$103 \mathrm{COCCHI}$, M.C. Análise da Incorporação de Lama de Manufatura do Mármore em Cerâmica Estrutural. In: CONGRESSO BRASILEIRO DE ENGENHARIA E CIÊNCIA DOS MATERIAIS, 2006. Anais... Paraná, Foz do Iguaçu, 2006, p. 245-251. 
104 ALYAMAÇ, K. E.; INCE, R. A preliminary concrete mix design for SCC with marble powders. Construction and Building Materials. v. 23, n. 3, p. 1201-1210, 2009.

105 MANSUR, A.; MANSUR, H. Caracterização de matérias-primas utilizadas na produção de concreto celular. In: CONGRESSO BRASILEIRO DE ENGENHARIA E CIÊNCIA DOS MATERIAIS, 2006. Anais... Foz do Iguaçu: CBECiMat, 2006, p. 192-199.

106 BAN-YA, S.; HOBO, M.; KAJI, T.; ITOH, T.; HINO, M. Sulphide capacity and sulphur solubility in $\mathrm{CaO}-\mathrm{Al}_{2} \mathrm{O}_{3}$ and $\mathrm{CaO}-\mathrm{Al}_{2} \mathrm{O}_{3}-\mathrm{CaF}_{2}$ slags. ISIJ International. n. 11, v. 44, p.1810-1816, 2004.

107 OHYA, T.; KODAMA, F.; MATSUNAGA, H.; MOTOYOSHI, M.; HIGASHIGUCHI, M. Desulfurization of hot metal with burnt lime. Steelmaking Proceedings, v.60, p.345-55, 1977.

108 SEOK, S.; JUNG, S.; LEE, Y.; MIN, D. Viscosity of highly basic slags. ISIJ International. n. 8, v. 47, p. 1090-1096, 2007.

109 AGUIAR, F. N.; GRILLO, F. F.; TENÓRIO, J. A. S.; OLIVEIRA, J. R. Hot metal desulfurization by marble waste and fluorspar. Revista Escola de Minas, n. 2, v. 65, p. 233-240, 2012.

110 NZOTTA, M. M.; ANDREASSON, M.; JÖNSSON, P.; SEETHARAMAN, S. A study on the sulfide capaciteis of steelmaking slags. Scandinavian journal of metallurgy, v. 29, p. 177-184, 2000.

111 McFEATERS, L. B.; FRUEHAN, R.J. Desulfurization of Bath Smelter Metal. Metallurgical Transactions B, v. 24B, p. 441-447, 1993.

112 YOUNG, R. W. U. Use of the optical basicity concept for determining phosphorus and sulphur slag/metal partitions. Technical Steel Research, v. 9, p. 78-84, 1991. 
113 SHANKAR, A.; GORNERUP, M.; LAHIRI, A. K.; SEETHARAMAN, S. Experimental investigation of the viscosities in $\mathrm{CaO}-\mathrm{SiO}_{2}-\mathrm{MgO}-\mathrm{Al}_{2} \mathrm{O}_{3}$ and $\mathrm{CaO}-\mathrm{SiO}_{2}-\mathrm{MgO}-\mathrm{Al}_{2} \mathrm{O}_{3}-\mathrm{TiO}_{2}$ slags. Metallurgical and Materials Transactions $\mathrm{B}$, v. 38, p. 911-915, 2007.

114 PUTAN, A.; PUTAN, V.; HEPUT, T.; SOCALICI, A. Steel treatment with calcium-aluminate synthetic slag and addition of titanium oxide. Revista de Metalurgia, v. 49, p. 31 - 43, 2013. 